\title{
Clinical evaluation of the surgical and endoscopic treatment of morbid obesity
}

Citation for published version (APA):

Schouten, R. (2011). Clinical evaluation of the surgical and endoscopic treatment of morbid obesity. [Doctoral Thesis, Maastricht University]. Universiteit Maastricht. https://doi.org/10.26481/dis.20110211rs

Document status and date:

Published: 01/01/2011

DOI:

10.26481/dis.20110211rs

Document Version:

Publisher's PDF, also known as Version of record

\section{Please check the document version of this publication:}

- A submitted manuscript is the version of the article upon submission and before peer-review. There can be important differences between the submitted version and the official published version of record.

People interested in the research are advised to contact the author for the final version of the publication, or visit the DOI to the publisher's website.

- The final author version and the galley proof are versions of the publication after peer review.

- The final published version features the final layout of the paper including the volume, issue and page numbers.

Link to publication

\footnotetext{
General rights rights.

- You may freely distribute the URL identifying the publication in the public portal. please follow below link for the End User Agreement:

www.umlib.nl/taverne-license

Take down policy

If you believe that this document breaches copyright please contact us at:

repository@maastrichtuniversity.nl

providing details and we will investigate your claim.
}

Copyright and moral rights for the publications made accessible in the public portal are retained by the authors and/or other copyright owners and it is a condition of accessing publications that users recognise and abide by the legal requirements associated with these

- Users may download and print one copy of any publication from the public portal for the purpose of private study or research.

- You may not further distribute the material or use it for any profit-making activity or commercial gain

If the publication is distributed under the terms of Article $25 \mathrm{fa}$ of the Dutch Copyright Act, indicated by the "Taverne" license above, 
Clinical evaluation of the surgical and endoscopic treatment of morbid obesity

Ruben Schouten 
ISBN 978-90-8891-208-5

Layout: Jelte van Abbema

Printed by: Proefschriftmaken.nl || Printyourthesis.com

Published by: Uitgeverij BOXPress, Oisterwijk

The publication of this thesis was financially supported by:

Allergan, Boston Scientific Nederland, GI Dynamics, Atrium Medisch Centrum Parkstad, Dutch Society for Metabolic and Bariatric Surgery, Belgian Section of Obesity and Metabolic Surgery, Mölnlycke Health Care, Will Pharma, Novartis, AstraZeneca, Ethicon Endo-Surgery, Sanofi Aventis, Olympus Nederland BV, ABN AMRO, Abbott, Baxter B.V., Boehringer Ingelheim, Covidien, Fresenius Kabi, Eusapharma, Laprolan, Braun Medical BV and Norgine

All rights reserved. No part of this publication may be reproduced, stored in a retrieval system, or transmitted in any form or by any means, electronic, mechanical, photocopying, recording or otherwise, without prior written permission of the author. 


\section{Clinical evaluation of the surgical and endoscopic treatment of morbid obesity}

Ter verkrijging van de graad van doctor aan de Universiteit Maastricht, op gezag van de Rector Magnificus, Prof. mr. G.P.M.F. Mols volgens het besluit van het College van Decanen,

in het openbaar te verdedigen

op vrijdag 11 februari 2011 om 14:00 uur

door

Ruben Schouten 


\section{Promotor:}

Prof. dr. J.W.M. Greve

\section{Copromotor:}

Dr. W.G. van Gemert

\section{Beoordelingscommissie:}

Prof. dr. A.A.M. Masclee (voorzitter)

Prof. dr. L. Angrisani (University of Naples, Italy)

Prof. dr. M.J.H.M. Jacobs

Dr. B. van Ramshorst (Sint Antonius ziekenhuis, Nieuwegein)

Prof. dr. N. C. Schaper 
"I break the storm through the clouds" Anneke van Giersbergen, the Gathering. From: New Moon, Different Day (Nighttime Birds, 1997) 


\section{Contents}

Chapter 1 Introduction and outline of the thesis

Chapter $2 \quad$ Long term results of restrictive procedures

2.1 Long term results of bariatric restrictive procedures:

a prospective study

Obesity Surgery 2010; June, 19 (epub ahead of print)

2.2 Quality of life assessment in morbidly obese patients:

46 preoperative, short and long term results after restrictive procedures

Submitted

Chapter 3 Re-operations after restrictive procedures

3.1 Conversion of vertical banded gastroplasty to Roux-en-Y gastric bypass results in restoration of the positive effect on weight loss and comorbidities: evaluation of 101 patients Obesity Surgery 2007; May, 17(5): 622-30

3.2 Re-operation after laparoscopic adjustable gastric banding leads to a further decrease in BMI and obesity-related co-morbidities: results in 33 patients Obesity Surgery 2006; July, 16: 821-28

3.3 A systematic literature review of re-operations after gastric banding. Is a stepwise approach justified? Surgery for Obesity and Related Diseases (accepted) 
Chapter 4 The endoscopic treatment of morbid obesity

4.1 Endoscopic duodenal - jenunal bypass sleeve in the treatment of morbid obesity

Handbook of Obesity Surgery 2010. Editor: M. Deitel, FDcommunications Inc., Toronto, Canada ISBN 978-0-9684426-5-4

4.2 A multi-center, randomized efficacy study of the EndoBarrier Gastrointestinal Liner for pre-surgical weight loss prior to bariatric surgery Annals of Surgery 2010 Feb, 251(2): 236-43.

Chapter 5 General discussion and summary

Samenvatting

Dankwoord

Curriculum vitae 

CHAPTER 1

Introduction and outline of the thesis

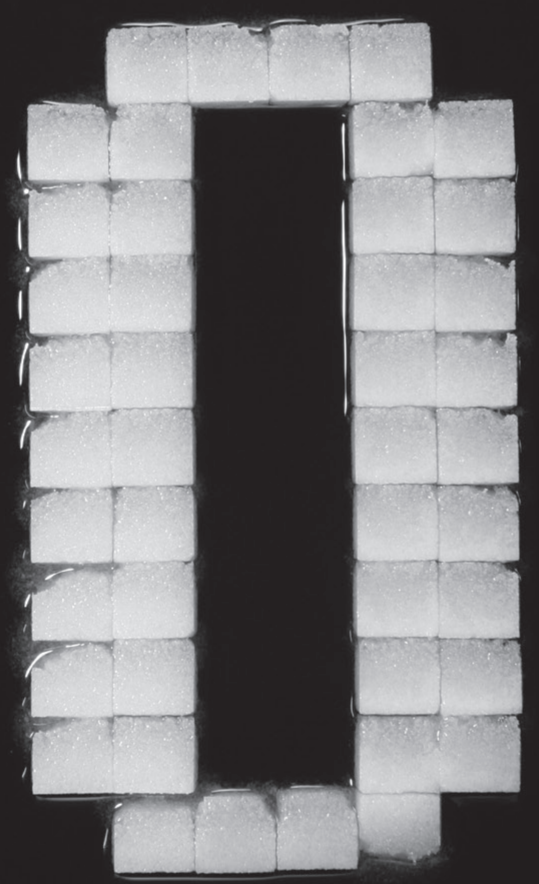





\section{Morbid obesity}

Obesity is defined as an abnormal state of health in which there is an excess of body fat ultimately detrimental to health. The Metropolitan Life Insurance Tables are used to classify obesity by means of the body mass index (BMl; weight/(height $\left.{ }^{2}\right)$ ). Grade 0 is defined as normal weight (BMI 20-24.9 kg/m²), grade 1 as overweight (BMI 25-29.9 kg/ $\mathrm{m}^{2}$ ), grade 2 as obesity (BMI $30-40 \mathrm{~kg} / \mathrm{m}^{2}$ ) and grade 3 as morbid obesity (BMI > 40 $\mathrm{kg} / \mathrm{m}^{2}$ ). Grade 2 and especially grade 3 pose a threat to the patients' health. Therefore, in the year 2000 obesity was officially declared a chronic disease by the World Health Organization [1]. In 2006, 35.1\% of the adult population in the United States suffered from obesity with a BMI of $>30 \mathrm{~kg} / \mathrm{m}^{2}$. In the same year the prevalence of morbid obesity with a BMI of $>40 \mathrm{~kg} / \mathrm{m}^{2}$ had risen to a dramatic $6.2 \%$ [2]. Percentages in the Netherlands are less well described but in 2010 the percentage of overweight (BMI of $>25 \mathrm{~kg} / \mathrm{m}^{2}$ ) was $47.2 \%$ [3]. The prevalence of obesity is estimated at $10-12 \%$ and of morbid obesity at $1.5-2.0 \%$. Especially the percentages of morbid obesity of $6.2 \%$ and $1.5 \%$ in the USA and the Netherlands are of major concern [1-4].

Morbid obesity is a lifelong, progressive disease of fat storage manifested by medical, physical, psychological, social and economic comorbidities and increases the risk of developing life threatening diseases [5]. As a result of the extreme overweight morbidly obese patients develop a range of medical conditions related to the overweight. This phenomenon is known as obesity-related comorbidity. Well established comorbidities are type 2 diabetes mellitus (T2DM), hypertension, cardiovascular disease, obstructive sleep apnea syndrome, pulmonary insufficiency, thromboembolism, osteoarthritis and infertility [5-7]. Furthermore, obesity is a risk factor for developing breast, endometrium, ovarian and kidney cancer [8, 9]. In a recently published review the relationship between obesity and certain types of gastrointestinal cancer (oesophageal, hepatic, gallbladder and colorectal cancer) has also been described [10]. As a result of these serious comorbid conditions the life expectancy of morbidly obese patients is far lower than that of the general population. In the studies by Drenick and Borelli et al. the mortality rate of morbidly obese subjects was 7 to 12 times higher than could be expected [11, 12]. Apart from the increased mortality and physical morbidity associated with morbid obesity it also influences the general and mental well-being of the patient in a negative manner. Morbidly obese patients have an impaired quality of life indicated by lower values on nearly all quality of life tests compared to control groups from a normal weight population. The average mental well-being of morbidly obese patients in the study by Sullivan et al. was worse compared to chronically ill patients or cancer survivors 
[13]. The significant discrimination and prejudice in the society against obesity is one of the main factors responsible for this low quality of life and leads to social isolation, unsatisfactory relationships and job problems [14, 15]. In conclusion, morbid obesity is a serious chronic medical condition leading to a variety of physical, psychosocial and economical problems.

\section{Bariatric surgery: a historical note}

Traditionally, obese patients are treated by means of dieting, exercise and behavior modification. However, in the case of morbid obesity all these non-surgical approaches are proven to be unsuccessful in the long term with respect to maintaining weight loss and decreasing obesity-related comorbidities. Surgical therapy is the only treatment option that results in sufficient and long term weight loss [16-18]. Bariatric surgery is defined as the surgical treatment of morbid obesity. Historically, bariatric procedures have been divided into restrictive and malabsorptive procedures or a combination of both. The first surgical procedures with the intention to treat morbid obesity were performed in the 1950s. The jejuno-colic bypass was the first procedure but quickly abandoned because of severe fluid and electrolyte imbalances and liver failure [19]. The jejunal-ileal bypass became a very popular bariatric procedure in the 1970s. Although the side effects were less severe than with the jejuno-colic bypass many patients still suffered from electrolyte imbalances, diarrhoea, urinary stones, bacterial overgrowth in the long blind loop and hepatic failure [20, 21]. Despite many modifications the jejunal-ileal bypass is not performed nowadays because of these side effects. In order to overcome the problem of the long blind loop in the jejunal-ileal bypass procedure, Scopinaro developed the biliopancreatic diversion (BPD) in the mid-1970s. It involves the creation of a 200-500 $\mathrm{ml}$ proximal gastric pouch, a gastro-ileostomy and an ileo-ileostomy resulting in an alimentary limb of $200 \mathrm{~cm}$ and a common limb of $50 \mathrm{~cm}$ where the alimentary and biliopancreatic limb are joined for digestion and absorption [22]. A modification of the technique was described by Marceau and Hess in the 1990s. The duodenal switch (DS) with biliopancreatic diversion consists of a gastric sleeve resection, a duodeno-ileostomy and ileo-ileostomy resulting in an alimentary limb of 150-175 cm and a common limb of $75-100 \mathrm{~cm}$ [23]. Both procedures involve the risk of protein malnutrition, vitamin and mineral deficiencies and electrolyte imbalances. Therefore, a life long medical follow up, dietary adjustments and vitamin supplementation is mandatory after these malabsorptive procedures. In order to decrease the disadvantages of malabsorption 
newer techniques have been developed with less malabsorption and more restriction. In the 1960s, Mason already reported on the loop gastric bypass which combined a gastric restriction with a slight malabsorption [24]. This procedure was safer but anastomotic leaks led to a high mortality while severe bile reflux led to a high morbidity. Griffen added the Roux limb to the gastric bypass resulting in the Roux-en-Y gastric bypass (RYGB) [25]. Because both major disadvantages of the loop gastric bypass were overcome with this procedure it is nowadays still one of the most performed bariatric procedures. However, the risk of anastomotic leakage is always present with bypass procedures. With this in mind and the idea that restriction alone might be enough to lose weight, Pace described the first purely restrictive procedure in 1979 [26]. However, the horizontal banded gastroplasty led to problematic pouch and outlet dilatation. It was again Mason who developed an important modification of the technique in 1982 resulting in the vertical banded gastroplasty (VBG). This procedure consists of creating a vertical gastric pouch along the lesser curvature while controlling the outlet with a nondilatable band [27]. Although this procedure has been very popular in the 1980s and 1990s it turned out to be too complicated in the long term with many patients suffering from weight gain and serious side effects because of stapler line dehiscence, stoma stenosis and severe pouch dilatation. A potential solution for these problems was the development of a gastric band. In the beginning of the 1980s Molina et al. already developed a gastric band that could be placed around the upper part of the stomach creating a small pouch [28]. In 1990, Kuzmak changed the technique into an adjustable gastric band by connecting this to a subcutaneous port. With this technique the band could be inflated and deflated according to the weight loss and complaints of the patient [29]. This procedure became increasingly popular because soon after its introduction it was performed completely by laparoscopy (laparoscopic adjustable gastric banding, LAGB) [30]. It is nowadays the most performed bariatric procedure together with the Roux-en-Y gastric bypass.

\section{Results of bariatric surgery}

Results of bariatric surgery have been described extensively in the literature. Published reports focus on postoperative weight loss and the decrease in obesity-related comorbidities but lately there has been increased interest in the postoperative quality of life as well as the cost effectiveness of bariatric surgery. It is important to state that morbid obesity interferes unfavorably with the general and mental well-being of the 
patient. Results of quality of life assessments of morbidly obese patients show that quality of life is significantly improved after surgically induced weight loss and seems not to be related to the type of surgical procedure [31,32]. There is also growing evidence that bariatric surgery is cost effective compared to conventional treatment especially in the case of morbidly obese patients suffering from type 2 diabetes mellitus [33-35]. However, most studies focus on weight loss and comorbidities. Apart from numerous reports from single centres and a relatively small amount of comparative randomized trials, meta-analyses concerning weight loss and decrease in comorbidities after bariatric surgery have been published. The most frequently cited data in this matter is the work by Buchwald et al. Their systematic review and meta-analysis from 2004 described the overall results of the different bariatric procedures. Mean excess weight loss (\%EWL; amount of kilograms lost since baseline $\times 100 /$ excess weight) was 47.5\% after LAGB, 68.2\% after VBG, 61.6\% after RYGB and $70.1 \%$ after BPD and DS. Decrease in obesity-related comorbidities tends to be in proportion with weight loss. For example, resolution of hypertension was $43.2 \%$ after LAGB, $69.0 \%$ after VBG, $67.5 \%$ after RYGB and $83.4 \%$ after BPD and DS. The postoperative decrease in hyperlipidemia and sleep apnea syndrome is comparable. The resolution of T2DM is not solely dependent on weight loss but also on the duodenal bypass effect of the RYGB and BPD / DS which explains the even higher resolution after these procedures $(47.9 \%$ after LAGB, $71.6 \%$ after VBG, $83.7 \%$ after RYGB and $98.9 \%$ after BPD and DS) [36]. As a general rule it can be stated that the lesser invasive restrictive procedures result in the least weight loss and the more invasive malabsorptive procedures in the most weight loss. Based on the meta-analysis of Buchwald et al. this appears to be true. However, the follow up period after the different types of procedures is unclear. Regarding the results of bariatric surgery this is an important determinant because weight loss tends to be more slowly and gradually after LAGB compared to the malabsorptive procedures and it also lasts for a more prolonged period. Weight loss more than 5 years after LAGB varies in literature from $56 \%$ to $62 \%$ EWL [37-39] while after VBG it varies from $30 \%$ to $59 \%$ EWL $[37,38,40]$. The systematic review by O'Brien et al. showed that LAGB is still successful after 10 years and after this period weight loss is comparable with RYGB (EWL of 59\% and 52\%, respectively) [41]. Even better and durable results can be achieved with the more malabsorptive procedures. Weight loss more than 10 years after BPD is $>70 \%$ EWL while after DS this is even $75 \%[42,43]$. However, because of the more invasive and malabsorptive character of these procedures they are also more prone to complications. Therefore, weight loss and decrease in comorbidities are not the only factors of importance when discussing the results of bariatric surgery. 


\section{Long term complications and re-operations}

As outlined in the historical overview bariatric surgery is a relatively new field in surgery with an experience of less than 50 years. Procedures like the jejuno-ileal bypass have been abandoned because of severe complications. However, long term results of the presently popular procedures are only now starting to become available and are quite variable. After LAGB, a variety of band-related problems can occur, e.g. band slippage, band erosion, pouch dilatation and band leakage as well as port-related problems like dislocation and infection. Especially the band-related complications occur after a prolonged period with a mean of 28 months [44]. This phenomenon partially explains why the rate of re-operations differs tremendously in literature from $2 \%$ to $80 \%$ [44-48]. Apart from the differences in follow up period results vary according to the used surgical technique, either perigastric or pars flaccida, the latter having better results especially due to a decrease in band slippages $[49,50]$. In case of band failure due to technical complications it is usually possible to refixate or replace the band by laparoscopy with satisfying results afterwards $[44,51,52]$. However, in case of severe pouch dilatation, band erosion or non-compliance a conversion to another bariatric procedure might be a better solution [44,53]. Revisional surgery is often necessary after VBG because of stoma stenosis, pouch enlargement or stapler line dehiscence. Percentages in the literature range from $10 \%$ to $50 \%$ and are again strongly associated with the completeness and duration of follow up because complications necessitating a re-operation occur after a mean period of 2 years [54-58]. In the case of failure after VBG it has been indisputably proven that re-doing the procedure (re-VBG) leads to poor results and a re-operation rate of up to $68 \%[55,59-63]$. Therefore, a conversion to another bariatric procedure like laparoscopic RYGB is always necessary in the case of VBG failure. This explains why VBG is nowadays an infrequently performed procedure. Long term complications after laparoscopic RYGB consist mostly of anastomotic stenosis and occur in $4 \%$ to $38 \%$ according to the literature $[40,55,57,59,64-66]$. This problem can usually be treated by endoscopic dilatation and the prevalence has decreased since the introduction of a larger anastomosis with a silastic ring around the pouch (Fobi-Pouch) [67, 68]. Less frequent complications after (laparoscopic) RYGB are marginal ulcers $(0.6 \%$ to $16 \%)$ and internal herniations (1.2\% to 5\%) [69-73]. Re-operations after RYGB are infrequent and mainly necessary in case of renewed weight gain which can be treated by adding a silicone band to the pouch or lengthening of the alimentary limb. Also, patients suffering from internal herniations usually have to undergo a re-operation in order to solve the problem. The exact percentage of re-operations is however not known. Another specific 
long term complication after RYGB is vitamin deficiency as a result of the bypassing of the stomach and proximal intestine. In contrast, this problem is infrequently encountered after purely restrictive procedures. In case of RYGB especially iron and vitamin B12 levels can become deficient in up to $49 \%$ and $70 \%$, respectively [74, 75]. A lifelong follow up with regular vitamin and mineral measurements is therefore mandatory. This accounts even more for the purely malabsorptive procedures. Although re-operations are seldom necessary after BPD, protein malnutrition, vitamin and mineral deficiencies are serious and even life-threatening complications and occur often postoperatively, for example calcium (48\%), vitamin A $(69 \%)$, vitamin $\mathrm{K}(68 \%)$ and vitamin D $(63 \%)$ deficiency $[76,77]$. In case of severe or repeated protein malnutrition a re-operation with elongation of the common limb is necessary although this occurs in less than $1 \%$ of cases [43].

\section{Bariatric surgery: the future}

Because of the frequent long term complications of bariatric procedures the search for safer, less invasive but still effective procedures goes on. Gastric sleeve resection is not the only recent development in bariatric surgery that tries to achieve weight loss by less invasive and less complicated means. Especially the endoscopic methods to treat morbid obesity have recently gained attention. Apart from the "older" technique of temporarily placing an intragastric balloon [78], more recent developments include endoscopic transoral gastroplasty [79], endoscopic gastric botulinum toxin injection [80, 81] and implantable gastric stimulation (gastric pacing) [82-84]. The latest development in the minimally invasive devices in order to treat morbid obesity is The EndoBarrier Gastrointestinal Liner, a single use endoscopic implant mimicking a duodenal-jejunal bypass [85]. It is designed to achieve pre-surgical weight loss in morbidly obese patients and has an impressive effect on type 2 diabetes mellitus as a result of the duodenal bypass effect [86]. The latter makes this device especially interesting because of the potential use in moderately obese patients with severe type 2 diabetes mellitus. However, as accounts for the above mentioned minimally invasive devices, long term results of the EndoBarrier Gastrointestinal Liner are not yet available and future studies will have to focus on long term efficacy and effectiveness on type 2 diabetes mellitus. In conclusion, the future of bariatric surgery will be a refining of the present procedures in order to reduce the number of complications and re-operations and the development 
of less invasive techniques with possibly comparable or even better results on weight loss and comorbidities.

\section{Outline of the thesis}

The main purpose of this thesis was to describe the clinical results of bariatric surgery with a special focus on long term results, complications and re-operations. In order to completely investigate these issues we also paid attention to the results after reoperations. Because quality of life is an important aspect in present health care this topic was included in the thesis. Finally, because of the frequent complications and reoperations occurring after bariatric surgery we also investigated a new minimally invasive endoscopic device for the treatment of morbid obesity and its related comorbidities.

In chapter 2, the clinical long term results of bariatric restrictive procedures are described. Chapter 2.1 focuses on weight loss, decrease in comorbidities, long term complications, re-operations as well as vitamin and mineral status after LAGB and VBG. Chapter 2.2 describes the preoperative, short and long term results on health-related quality of life after restrictive procedures. In both studies we also investigated the influence of long term complications and especially re-operations on the clinical outcome parameters and quality of life.

Chapter 3 continues on the subject of re-operations after restrictive bariatric procedures. In chapter 3.1, the conversion from failed VBG to RYGB is described. Special attention is given to the operative technique, complications and clinical results. In chapter 3.2 the results of re-operations after failed LAGB are discussed and in this chapter we specifically focus on the possibility of refixating the band. Finally, in chapter $3.3 \mathrm{a}$ literature review is presented which systematically describes the results of the various revisional possibilities in case of LAGB failure.

In chapter 4, we focus on future improvements in the treatment of morbid obesity including endoscopic techniques. Chapter 4.1 presents the concept of preoperative weight loss and provides an overview of the working mechanism of the endoscopically placed duodenal-jejunal bypass sleeve. Chapter 4.2 describes the first European experience with the EndoBarrier Gastrointestinal Liner for the treatment of morbid obesity and type 2 diabetes mellitus. 


\section{References}

1. Obesity: preventing and managing the global epidemic. Report of a WHO consultation. World Health Organ Tech Rep Ser, 2000. 894: p. i-xii, 1-253.

2. Anonymous, World Health Organisation: obesity prevalence 2006, https://apps.who.int/infobase/report.aspx.

3. Anonymous, Centraal Bureau Statistiek (CBS): gezondheidscijfers Nederland. 2010, http:// statline.cbs.nl/StatWeb/publication/

4. Kemper, H.C., M. Stasse-Wolthuis, and W. Bosman, The prevention and treatment of overweight and obesity. Summary of the advisory report by the Health Council of The Netherlands. Neth J Med, 2004. 62(1): p. 10-7.

5. Cowan, G.S., Jr., et al., Obesity Stereotypes Among Physicians, Medical and College Students, Bariatric Surgery Patients and Families. Obes Surg, 1991. 1(2): p. 171-176.

6. Sjostrom, L.V., Morbidity of severely obese subjects. Am J Clin Nutr, 1992. 55(2 Suppl): p. 508S-515S.

7. Van Gaal, L.F., I.L. Mertens, and C.E. De Block, Mechanisms linking obesity with cardiovascular disease. Nature, 2006. 444(7121): p. 875-80.

8. Pischon, T., U. Nothlings, and H. Boeing, Obesity and cancer. Proc Nutr Soc, 2008. 67(2): p. $128-45$.

9. Percik, R. and M. Stumvoll, Obesity and cancer. Exp Clin Endocrinol Diabetes, 2009. 117(10): p. 563-6.

10. Donohoe, C.L., et al., Obesity and gastrointestinal cancer. Br J Surg. 97(5): p. 628-42.

11. Borrelli, R., et al., Mortality rate, causes and predictive factors of death in severely obese patients. Int J Vitam Nutr Res, 1988. 58(3): p. 343-50.

12. Drenick, E.J., et al., Excessive mortality and causes of death in morbidly obese men. Jama, 1980. 243(5): p. 443-5.

13. Sullivan, M., et al., Swedish obese subjects (SOS)--an intervention study of obesity. Baseline evaluation of health and psychosocial functioning in the first 1743 subjects examined. Int J Obes Relat Metab Disord, 1993. 17(9): p. 503-12.

14. Sarlio-Lahteenkorva, S., A. Stunkard, and A. Rissanen, Psychosocial factors and quality of life in obesity. Int J Obes Relat Metab Disord, 1995. 19 Suppl 6: p. S1-5.

15. Stunkard, A.J., W.R. LaFleur, and T.A. Wadden, Stigmatization of obesity in medieval times: Asia and Europe. Int J Obes Relat Metab Disord, 1998. 22(12): p. 1141-4.

16. Fisher, B.L. and P. Schauer, Medical and surgical options in the treatment of severe obesity. Am J Surg, 2002. 184(6B): p. 9S-16S.

17. Bjorntorp, P., Results of conservative therapy of obesity: correlation with adipose tissue morphology. Am J Clin Nutr, 1980. 33(2 Suppl): p. 370-5.

18. O'Brien, P.E., et al., Treatment of mild to moderate obesity with laparoscopic adjustable gastric banding or an intensive medical program: a randomized trial. Ann Intern Med, 2006. 144(9): p. 625-33.

19. Deitel, M., A synopsis of the development of bariatric operations. Obes Surg, 2007. 17(6): p. 707-10.

20. Deitel, M., et al., Long-term Outcome in a Series of Jejunoileal Bypass Patients. Obes Surg, 1993. 3(3): p. 247-252.

21. Kremen, A.J., J.H. Linner, and C.H. Nelson, An experimental evaluation of the nutritional importance of proximal and distal small intestine. Ann Surg, 1954. 140(3): p. 439-48.

22. Scopinaro, N., et al., Biliopancreatic diversion. World J Surg, 1998. 22(9): p. 936-46.

23. Hess, D.S. and D.W. Hess, Biliopancreatic diversion with a duodenal switch. Obes Surg, 1998. 8(3): p. 267-82. 
24. Mason, E.E. and C. Ito, Gastric bypass in obesity. Surg Clin North Am, 1967. 47(6): p. 134551.

25. Griffen, W.O., Jr., V.L. Young, and C.C. Stevenson, A prospective comparison of gastric and jejunoileal bypass procedures for morbid obesity. Ann Surg, 1977. 186(4): p. 500-9.

26. Pace, W.G., et al., Gastric partitioning for morbid obesity. Ann Surg, 1979. 190(3): p. 392400.

27. Mason, E.E., Vertical banded gastroplasty for obesity. Arch Surg, 1982. 117(5): p. 701-6.

28. Buchwald, H., Overview of bariatric surgery. J Am Coll Surg, 2002. 194(3): p. 367-75.

29. Kuzmak, L.I., et al., Surgery for morbid obesity. Using an inflatable gastric band. Aorn J, 1990. 51(5): p. 1307-24.

30. Catona, A., et al., Laparoscopic Gastric Banding: preliminary series. Obes Surg, 1993. 3(2): p. 207-209.

31. van Gemert, W.G., et al., Quality of life assessment of morbidly obese patients: effect of weight-reducing surgery. Am J Clin Nutr, 1998. 67(2): p. 197-201.

32. Steffen, R., et al., Successful multi-intervention treatment of severe obesity: a 7-year prospective study with $96 \%$ follow-up. Obes Surg, 2009. 19(1): p. 3-12.

33. van Gemert, W.G., et al., A prospective cost-effectiveness analysis of vertical banded gastroplasty for the treatment of morbid obesity. Obes Surg, 1999. 9(5): p. 484-91.

34. Keating, C.L., et al., Cost-effectiveness of surgically induced weight loss for the management of type 2 diabetes: modeled lifetime analysis. Diabetes Care, 2009. 32(4): p. 567-74.

35. Picot, J., et al., The clinical effectiveness and cost-effectiveness of bariatric (weight loss) surgery for obesity: a systematic review and economic evaluation. Health Technol Assess, 2009. 13(41): p. 1-190, 215-357, iii-iv.

36. Buchwald, H., et al., Bariatric surgery: a systematic review and meta-analysis. Jama, 2004. 292(14): p. 1724-37.

37. Miller, K., A. Pump, and E. Hell, Vertical banded gastroplasty versus adjustable gastric banding: prospective long-term follow-up study. Surg Obes Relat Dis, 2007. 3(1): p. 84-90.

38. Nilsell, K., et al., Prospective randomised comparison of adjustable gastric banding and vertical banded gastroplasty for morbid obesity. Eur J Surg, 2001. 167(7): p. 504-9.

39. O'Brien, P.E. and J.B. Dixon, Lap-band: outcomes and results. J Laparoendosc Adv Surg Tech A, 2003. 13(4): p. 265-70.

40. Balsiger, B.M., et al., Ten and more years after vertical banded gastroplasty as primary operation for morbid obesity. J Gastrointest Surg, 2000. 4(6): p. 598-605.

41. O'Brien, P.E., et al., Systematic review of medium-term weight loss after bariatric operations. Obes Surg, 2006. 16(8): p. 1032-40.

42. Hess, D.S., D.W. Hess, and R.S. Oakley, The biliopancreatic diversion with the duodenal switch: results beyond 10 years. Obes Surg, 2005. 15(3): p. 408-16.

43. Scopinaro, N., Biliopancreatic diversion: mechanisms of action and long-term results. Obes Surg, 2006. 16(6): p. 683-9.

44. Schouten, R., F.M. van Dielen, and J.W. Greve, Re-operation after laparoscopic adjustable gastric banding leads to a further decrease in BMI and obesity-related co-morbidities: results in 33 patients. Obes Surg, 2006. 16(7): p. 821-8.

45. Belachew, M., P.H. Belva, and C. Desaive, Long-term results of laparoscopic adjustable gastric banding for the treatment of morbid obesity. Obes Surg, 2002. 12(4): p. 564-8.

46. Westling, A., et al., Silicone-adjustable gastric banding: disappointing results. Obes Surg, 1998. 8(4): p. 467-74.

47. Doherty, C., J.W. Maher, and D.S. Heitshusen, Prospective investigation of complications, reoperations, and sustained weight loss with an adjustable gastric banding device for treatment of morbid obesity. J Gastrointest Surg, 1998. 2(1): p. 102-8. 
48. Martikainen, T., et al., Long-term results, late complications and quality of life in a series of adjustable gastric banding. Obes Surg, 2004. 14(5): p. 648-54.

49. Weiner, R., et al., A prospective randomized trial of different laparoscopic gastric banding techniques for morbid obesity. Surg Endosc, 2001. 15(1): p. 63-8.

50. O'Brien, P.E., et al., A prospective randomized trial of placement of the laparoscopic adjustable gastric band: comparison of the perigastric and pars flaccida pathways. Obes Surg, 2005. 15(6): p. 820-6.

51. Niville, E., et al., Results of lap rebanding procedures after Lap-Band removal for band erosion -- a mid-term evaluation. Obes Surg, 2005. 15(5): p. 630-3.

52. Niville, E. and A. Dams, Late pouch dilation after laparoscopic adjustable gastric and esophagogastric banding: incidence, treatment, and outcome. Obes Surg, 1999. 9(4): p. 381-4.

53. Suter, M., et al., Band erosion after laparoscopic gastric banding: occurrence and results after conversion to Roux-en-Y gastric bypass. Obes Surg, 2004. 14(3): p. 381-6.

54. Hall, J.C., et al., Gastric surgery for morbid obesity. The Adelaide Study. Ann Surg, 1990. 211(4): p. 419-27.

55. van Gemert, W.G., et al., Revisional surgery after failed vertical banded gastroplasty: restoration of vertical banded gastroplasty or conversion to gastric bypass. Obes Surg, 1998. 8(1): p. 21-8.

56. Nightengale, M.L., et al., Prospective evaluation of vertical banded gastroplasty as the primary operation for morbid obesity. Mayo Clin Proc, 1991. 66(8): p. 773-82.

57. MacLean, L.D., B.M. Rhode, and R.A. Forse, Late results of vertical banded gastroplasty for morbid and super obesity. Surgery, 1990. 107(1): p. 20-7.

58. Naslund, E., et al., Seven year results of vertical banded gastroplasty for morbid obesity. Eur J Surg, 1997. 163(4): p. 281-6.

59. Sugerman, H.J., et al., Conversion of failed or complicated vertical banded gastroplasty to gastric bypass in morbid obesity. Am J Surg, 1996. 171(2): p. 263-9.

60. Sugerman, H.J. and J.L. Wolper, Failed gastroplasty for morbid obesity. Revised gastroplasty versus Roux-Y gastric bypass. Am J Surg, 1984. 148(3): p. 331-6.

61. Kfoury, E. and A. Vanguri, Distal Roux-en-Y Gastric Bypass Conversion Operation for Failed Vertical Banded Gastroplasty. Obes Surg, 1993. 3(1): p. 41-43.

62. Behrns, K.E., et al., Reoperative bariatric surgery. Lessons learned to improve patient selection and results. Ann Surg, 1993. 218(5): p. 646-53.

63. Linner, J.H. and R.L. Drew, Reoperative surgery--indications, efficacy, and long-term followup. Am J Clin Nutr, 1992. 55(2 Suppl): p. 606S-610S.

64. Cordera, F., et al., Unsatisfactory weight loss after vertical banded gastroplasty: is conversion to Roux-en-Y gastric bypass successful? Surgery, 2004. 136(4): p. 731-7.

65. Gonzalez, R., et al., Operative technique for converting a failed vertical banded gastroplasty to Roux-en-Y gastric bypass. J Am Coll Surg, 2005. 201(3): p. 366-74.

66. Schouten, R., et al., Conversion of vertical banded gastroplasty to Roux-en-Y gastric bypass results in restoration of the positive effect on weight loss and co-morbidities: evaluation of 101 patients. Obes Surg, 2007. 17(5): p. 622-30.

67. Fobi, M.A., Placement of the GaBP ring system in the banded gastric bypass operation. Obes Surg, 2005. 15(8): p. 1196-201.

68. Fobi, M.A. and H. Lee, The surgical technique of the Fobi-Pouch operation for obesity (the transected silastic vertical gastric bypass). Obes Surg, 1998. 8(3): p. 283-8.

69. Champion, J.K. and M. Williams, Small bowel obstruction and internal hernias after laparoscopic Roux-en-Y gastric bypass. Obes Surg, 2003. 13(4): p. 596-600.

70. Felsher, J., J. Brodsky, and F. Brody, Small bowel obstruction after laparoscopic Roux-en-Y gastric bypass. Surgery, 2003. 134(3): p. 501-5. 
71. Higa, K.D., T. Ho, and K.B. Boone, Internal hernias after laparoscopic Roux-en-Y gastric bypass: incidence, treatment and prevention. Obes Surg, 2003. 13(3): p. 350-4.

72. Rogula, T., P.R. Yenumula, and P.R. Schauer, A complication of Roux-en-Y gastric bypass: intestinal obstruction. Surg Endosc, 2007. 21(11): p. 1914-8.

73. Sapala, J.A., et al., Marginal ulcer after gastric bypass: a prospective 3-year study of 173 patients. Obes Surg, 1998. 8(5): p. 505-16.

74. Amaral, J.F., et al., Prospective hematologic evaluation of gastric exclusion surgery for morbid obesity. Ann Surg, 1985. 201(2): p. 186-93.

75. Brolin, R.E., Gastric bypass. Surg Clin North Am, 2001. 81(5): p. 1077-95.

76. Slater, G.H., et al., Serum fat-soluble vitamin deficiency and abnormal calcium metabolism after malabsorptive bariatric surgery. J Gastrointest Surg, 2004. 8(1): p. 48-55; discussion 54-5.

77. Malinowski, S.S., Nutritional and metabolic complications of bariatric surgery. Am J Med Sci, 2006. 331(4): p. 219-25.

78. Mathus-Vliegen, E.M., Intragastric balloon treatment for obesity: what does it really offer? Dig Dis, 2008. 26(1): p. 40-4.

79. Deviere, J., et al., Safety, feasibility and weight loss after transoral gastroplasty: First human multicenter study. Surg Endosc, 2008. 22(3): p. 589-98.

80. Foschi, D., et al., Effects of intramural administration of Botulinum Toxin A on gastric emptying and eating capacity in obese patients. Dig Liver Dis, 2008. 40(8): p. 667-72.

81. Foschi, D., et al., Treatment of morbid obesity by intraparietogastric administration of botulinum toxin: a randomized, double-blind, controlled study. Int J Obes (Lond), 2007. 31(4): p. 707-12.

82. Favretti, F., et al., Treatment of morbid obesity with the Transcend Implantable Gastric Stimulator (IGS): a prospective survey. Obes Surg, 2004. 14(5): p. 666-70.

83. Miller, K., E. Hoeller, and F. Aigner, The Implantable Gastric Stimulator for Obesity : An Update of the European Experience in the LOSS (Laparoscopic Obesity Stimulation Survey) Study. Treat Endocrinol, 2006. 5(1): p. 53-8.

84. Bohdjalian, A., et al., One-year experience with Tantalus: a new surgical approach to treat morbid obesity. Obes Surg, 2006. 16(5): p. 627-34.

85. Gersin, K.S., et al., Duodenal- jejunal bypass sleeve: a totally endoscopic device for the treatment of morbid obesity. Surg Innov, 2007. 14(4): p. 275-8.

86. Rodriguez-Grunert, L., et al., First human experience with endoscopically delivered and retrieved duodenal-jejunal bypass sleeve. Surg Obes Relat Dis, 2008. 4(1): p. 55-9. 

Long term results of restrictive procedures

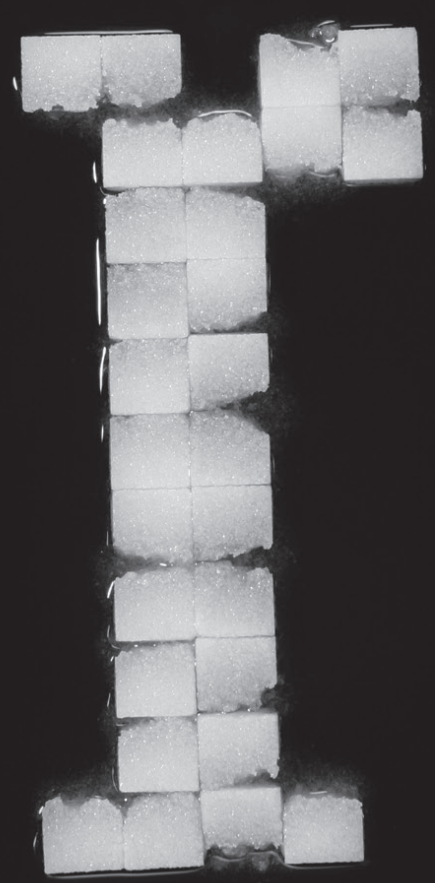


Long term results of bariatric restrictive procedures: a prospective study

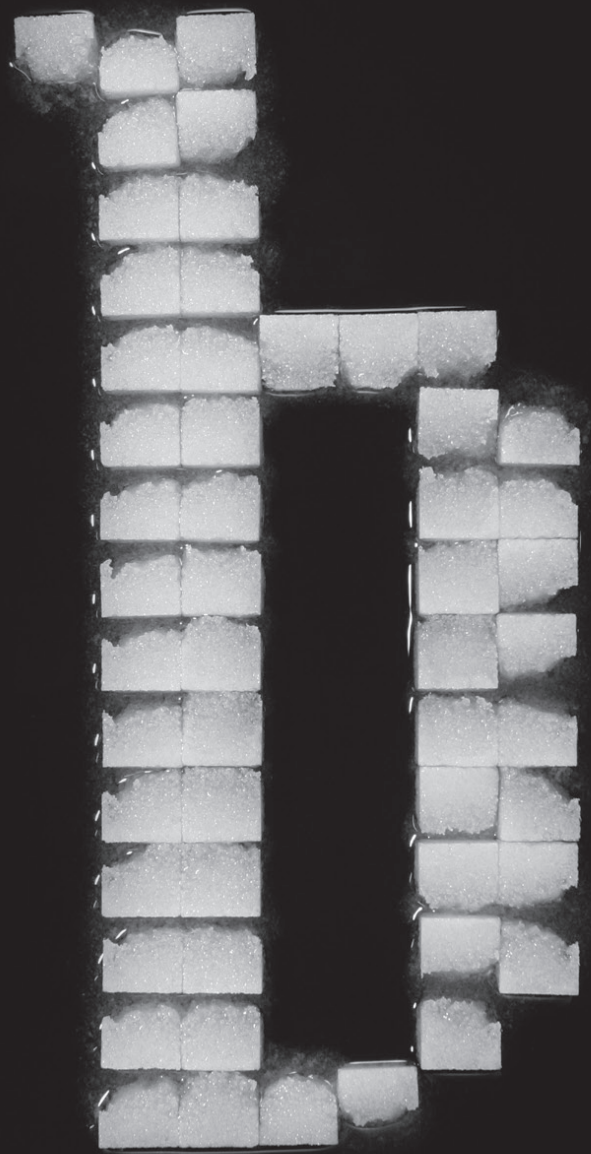

Ruben Schouten

Dorothee C.M.S. Wiryasaputra

Francois M.H. van Dielen

Wim G. van Gemert

Jan Willem M. Greve

Obesity Surgery 2010; June, 19 (epub ahead of print) 


\begin{abstract}
Background: laparoscopic adjustable gastric banding (LAGB) and vertical banded gastroplasty (VBG) are surgical treatment modalities for morbid obesity. This prospective study describes the long term results of LAGB and VBG.
\end{abstract}

Methods: 100 patients were included in the study. Fifty patients underwent LAGB and 50 patients open VBG. Study parameters were weight loss, changes in obesity-related comorbidities, long term complications, re-operations including conversions to other bariatric procedures and laboratory parameters including vitamin status.

Results: from 91 patients $(91 \%)$ data was obtained with a mean follow up duration of 84 months (7 years). Weight loss (\% excess weight loss; EWL) was significantly more after VBG compared to LAGB; $66 \%$ versus $54 \%$, respectively. All comorbidities significantly decreased in both groups. Long term complications after VBG were mainly staple line disruption (54\%) and incisional hernia (27\%). After LAGB, the most frequent complications were pouch dilatation $(21 \%)$ and anterior slippage (17\%). Major reoperations after VBG were performed in $60 \%$ of patients. All re-operations following VBG were conversions to roux-en-y gastric bypass (RYGB). In the LAGB group 33\% of patients had a refixation or replacement of the band and $11 \%$ underwent conversion to another bariatric procedure. There were no significant differences in weight loss between patients with or without re-interventions. No vitamin deficiencies were present after 7 years although supplement usage was inconsistent.

Conclusion: this long term follow up study confirms the high occurrence of late complications after restrictive bariatric surgery. The failure rate of $65 \%$ after VBG is too high and this procedure is not performed anymore in our institution. The re-operation rate after $L A G B$ is decreasing as a result of new techniques and materials. Results of the re-operations are good with sustained weight loss and reduction in comorbidities. However, in order to achieve these results a durable and complete follow up after restrictive procedures is imperative. 


\section{Introduction}

Morbid obesity, defined as a body mass index (BMI) of $>40 \mathrm{~kg} / \mathrm{m}^{2}$ or $>35 \mathrm{~kg} / \mathrm{m}^{2}$ with obesity-related comorbidities, is a rapidly growing problem in western society. In the United States, about 6 million people currently have a BMI of $>40 \mathrm{~kg} / \mathrm{m}^{2}$ and another 10 million people have a BMI of $>35 \mathrm{~kg} / \mathrm{m}^{2}$ with comorbidities. Worldwide, the incidence of morbid obesity has doubled and about 300 million people are now obese [1, 2]. In the Netherlands the prevalence is less disturbing but the incidence of morbid obesity is rising progressively to $1.5 \%$ of the total population [3]. At this moment surgical therapy is the only treatment option for these patients that results in sufficient long term weight loss. Non-surgical approaches, like low energy diets and behavior modification, are not successful in the long term with respect to maintaining weight loss and decreasing obesity-related comorbidities $[4,5]$.

Gastric restrictive surgery was introduced in the mid-1970s with transverse gastroplasty and has been developed and improved since. This procedure evolved to vertical banded gastroplasty (VBG) as described by Mason and others and has been performed on many patients worldwide [6, 7]. In 1993, a new type of gastric restrictive surgery was introduced in the form of laparoscopic adjustable gastric banding (LAGB) with the advantages of a minimal invasive technique and adjustability and as a result more gradual weight loss [8]. In 1998, no randomized trials were published that compared these two operative techniques. A randomized controlled clinical trial was conducted in our institution by van Dielen et al. The 2-year results of this study demonstrated a significantly shorter hospital stay after LAGB (3.5 versus 6.8 days), a significantly greater weight loss after VBG (\% excess weight loss (EWL) of $72.7 \%$ versus $53.3 \%$ ), significant decrease of all comorbidities in both groups and a higher percentage of major re-operations after VBG (36\% versus $28 \%$ ) and incisional hernias (16\% versus $0 \%$ ) [9]. Prospective trials comparing operative techniques are few in bariatric surgery and only short- or mid-term results are reported [10-12]. Few studies have published long-term results [13, 14]. All patients participating in the aforementioned study are more than 5 years after initial surgery. The present study describes the long term results of this prospectively followed group of patients after restrictive bariatric procedures. 


\section{Patients and methods}

Patients

Patients were considered eligible for the study if their BMI was $>40 \mathrm{~kg} / \mathrm{m} 2$ or $>35$ $\mathrm{kg} / \mathrm{m} 2$ with obesity-related comorbidities. One hundred patients were included. In the initial study, patients were randomly assigned to LAGB (50) or open VBG (50) using a computer generated randomisation list. The initial study and long term follow up study were approved by the medical ethical committee of the Maastricht University Medical Centre, the Netherlands.

\section{Methods}

During the initial study demographic data, BMI, medication, medical history and comorbidities were recorded as well as intra -and postoperative complications and length of hospital stay. After discharge, all patients were evaluated in the outpatient clinic after 1 and 6 weeks and after 3, 6 and 12 months. After this period patients were evaluated once a year. The following data was obtained: body weight, blood pressure, pulse, comorbidities, medication, symptoms and complaints, present dietary habits, complications, re-operations, conversions and laboratory measurements (hemoglobin, urea, creatinin, ASAT, ALAT, albumin, total protein, cholesterol, triglycerides, HDL and LDL). Furthermore, in order to investigate vitamin status and possible deficiencies after restrictive surgery patients were asked about the use of vitamin supplements and a set of parameters (iron, zinc, vitamin B1, B6, B12 and folic acid) was measured during the last follow up visit.

\section{Surgical technique}

All patients received general anaesthesia, a single dose of preoperative antibiotics and a double daily dose of low-molecular-weight heparin. The surgical techniques of LAGB and open VBG are described in detail elsewhere [9] as well as the technique of converting VBG to RYGB [15]. In summary, in case of VBG a small pouch of the stomach was created with a 4-row linear stapler (TA-90B, United States Surgical Corp., Norwalk, CT) and a Dacron band of $5.0 \mathrm{~cm}$ in circumference was placed through the window formed by a circular stapler (Premium Plus CEEA $31 \mathrm{~mm}$, United States Surgical Corp., Norwalk, CT). Laparoscopic gastric banding was in all cases performed by placing a $9.75 \mathrm{~cm}$ lap-band (Allergan, Santa Barbara, CA). During the study period, the LAGB was insufflated when weight loss was insufficient (less than approximately 1 kilogram 
per week) with the first insufflation at least 6 weeks postoperatively. After the first 32 patients the surgical technique of placing the laparoscopic band was changed from "perigastric" to "pars flaccida" because of several international reports suggesting the latter to be a superior technique with fewer complications [16-18].

\section{Statistical analysis}

Statistical analyses were performed using the SPSS 15.0.0 statistical package (SPSS Inc., Chicago, IL, USA). The Student's t-test was used to calculate differences between the groups. In case of a skewed distribution the Mann Whitney $U$ test was used for comparison between the groups and the Wilcoxon signed-rank test for comparison in one group throughout time. Analysis of the differences in postoperative complications and re-operations between the perigastric and pars flaccida technique in the LAGB group was performed with the Chi-square test. Data are given as mean and standard deviation. A p-value of $p<0.05$ was denoted as statistically significant.

\section{Results}

\section{Preoperative data}

Preoperative patient characteristics are summarized in table 1. Both groups consisted of 50 patients with a male to female ratio of 1 to 4 . Mean age, weight, BMI and total number of obesity-related comorbidities did not differ significantly between the groups.

\begin{tabular}{lccc}
\hline & LAGB & VBG & P-value* $^{*}$ \\
\hline Patients $(\mathrm{n})$ & 50 & 50 & - \\
M : $\mathrm{F}(\mathrm{n})$ & $10: 40$ & $10: 40$ & - \\
Age $($ years $)$ & $39 \pm 8$ & $37 \pm 9$ & 0.32 \\
Weight $(\mathrm{kg})$ & $133 \pm 21$ & $131 \pm 24$ & 0.87 \\
BMI $\left(\mathrm{kg} / \mathrm{m}^{2}\right)$ & $47 \pm 6$ & $47 \pm 6$ & 0.97 \\
Total comorbidities $(\mathrm{n})$ & $1.3 \pm 1.0$ & $1.3 \pm 1.1$ & 0.97 \\
\hline
\end{tabular}

Table 1: Preoperative patient characteristics

*T-test 


\section{Patients}

Follow up in the total group was $91 \%$ with a mean period in both groups of 84 months (7 years), ranging from a minimum of 67 months (5.6 years) to a maximum of 101 months (8.4 years). In the direct postoperative period 2 patients died in the VBG group, one patient due to sepsis as a result of leakage and one patient due to respiratory complications of a pre-existing pneumonia. Five patients were lost to follow up. As a result, 43 patients were included in the final analysis in the VBG group. In the LAGB group, 2 patients died during follow up as a result of gynecological malignancies. Data from these 2 deceased patients are included in the analysis until the moment of death. Two patients were lost to follow up. As a result, 48 patients from the LAGB group were analyzed.

\section{Long term complications}

Complications were classified as "major" or "minor" depending on the need for a surgical re-intervention. All complications that required a re-operation or conversion to another bariatric procedure were classified as "major". All complications that were managed with conservative measures, medication or were treated under local anesthesia were considered "minor". Major and minor complications are summarized in table 2.

In both groups many long term complications occurred requiring either a re-operation or conversion to another bariatric procedure. A flow chart describing the follow up data including re-operations and conversions is provided in figure 1.

\begin{tabular}{lrcc}
\hline LAGB & $\begin{array}{c}\text { VBG } \\
\text { "non-converted" } \\
(\mathrm{n}=17)\end{array}$ & $\begin{array}{c}\text { RYGB } \\
\text { "converted VBG" } \\
(\mathrm{n}=26)\end{array}$ \\
\hline Reflux & $(\mathrm{n}=48)$ & $1(6 \%)$ & $0(0 \%)$ \\
Vomiting & $3(6 \%)$ & $7(41 \%)$ & $0(0 \%)$ \\
Dysphagia & $20(42 \%)$ & $1(6 \%)$ & $1(4 \%)$ \\
Port-related problems & $1(2 \%)$ & - & - \\
Re-operations & $5(10 \%)$ & $11(26 \%)$ & $2(8 \%)$ \\
Conversions & $16(33 \%)$ & $26(65 \%)$ & - \\
2nd re-operation & $5(10 \%)$ & $2(8 \%)$ & - \\
\hline
\end{tabular}

Table 2: long term complications 


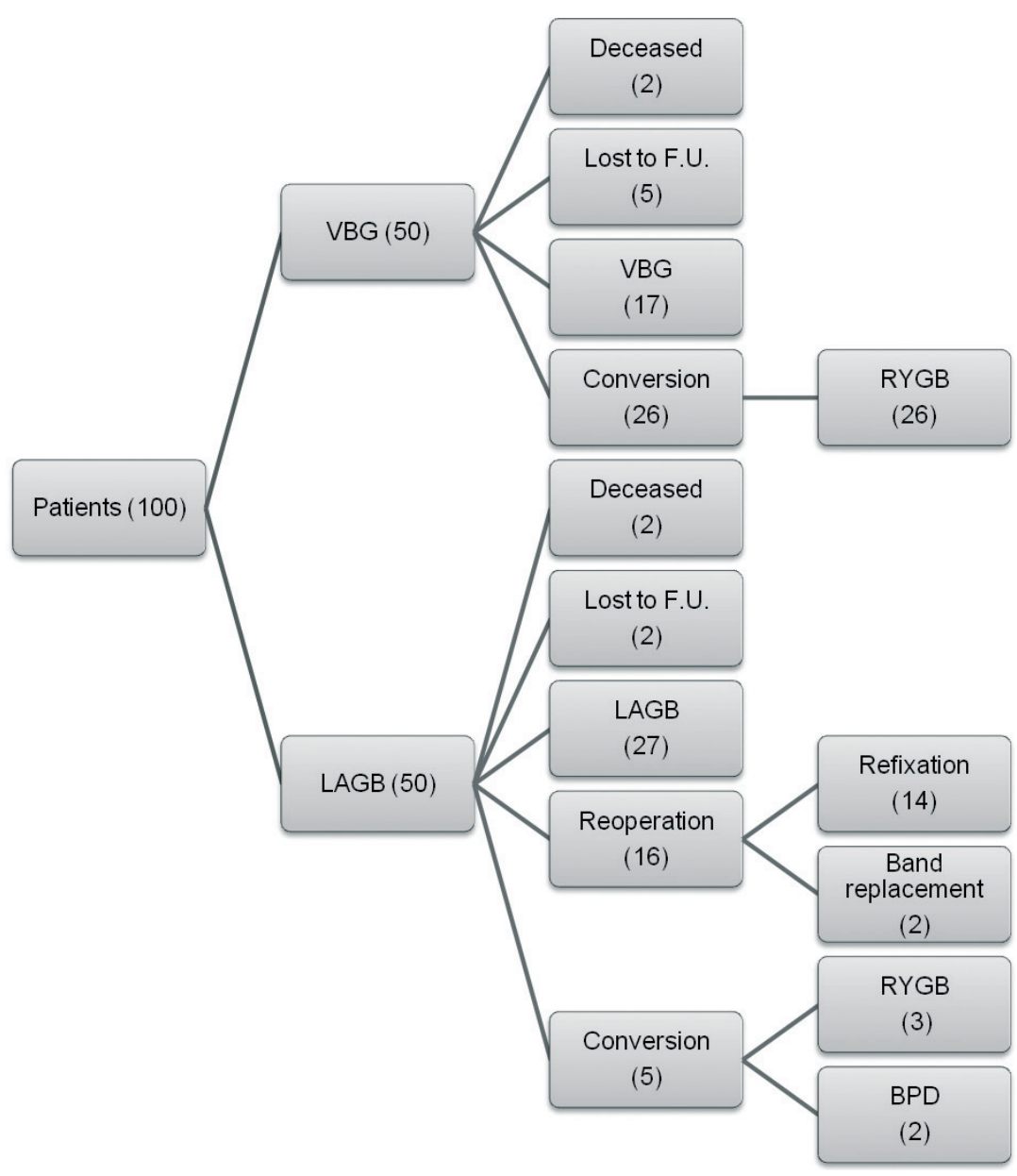

Figure 1: flow chart of re-operations and conversions

\section{Major complications}

Mean time between the first operation and the re-operation or conversion was 2 years. However, this ranged from a minimum of 6 months to a maximum of 7 years.

Procedure-specific major complications occurred in $60 \%$ of patients after VBG $(26 / 43$ patients) and included staple line dehiscence $(n=22)$ and recurrent outlet stenosis $(n=4)$. In all cases, an open conversion to RYGB was performed. Ten patients (23\%), including 4 patients who already underwent conversion to RYGB, developed a symptomatic incisional hernia and underwent open repair with mesh. Two patients had complications 
after the conversion to RYGB necessitating another re-operation (8\%). This included one patient with serious weight regain 2 years after conversion. A distal gastric bypass was performed. Another patient developed a recurrent stenosis of the anastomosis and a new gastrojejunostomy was created. Complications necessitating a re-operation after LAGB were also frequent. In total, 44\% (21/48 patients) underwent either re-operation or conversion to another bariatric procedure during follow up. Main causes were pouch dilatation $(n=10)$, anterior slippage $(n=8)$, band erosion $(n=2)$ and band leakage $(n=1)$. The re-operation rate in perigastric $(n=32)$ and pars flaccida $(n=18)$ operated patients was $41 \%$ and $33 \%$, respectively. Performed laparoscopic re-operations were band refixation (14 patients) and band replacement (2 patients). In 5 patients refixation or replacement of the band was not possible because of band erosion (2 patients) and severe pouch dilatation (3 patients). These patients were converted to open biliopancreatic diversion (BPD) in case of band erosion and to open RYGB in case of pouch dilatation.

After re-operation one patient $(1 / 21 ; 5 \%)$ developed a complication which necessitated a second re-operation. This patient had a re-slippage and underwent another laparoscopic refixation.

\section{Minor complications}

After VBG, minor problems which were still present after 7 years were vomiting (more than once a week) (41\%), reflux $(6 \%)$ and dysphagia (6\%). All patients with vomiting more than once a week were patients still having the VBG configuration after 7 years while no patients converted to RYGB complained of vomiting. Reflux and dysphagia occurred in the converted patients in $0 \%$ and $4 \%$, respectively. After LAGB, patients reported the same minor problems: vomiting $(42 \%)$, reflux $(6 \%)$ and dysphagia $(2 \%)$ without significant differences between uncomplicated and re-operated LAGB patients. Furthermore, $10 \%$ of patients had port-related problems (dislocation in all cases) and were successfully treated under local anesthesia. No port infections occurred.

\section{Weight loss - $L A G B$ versus VBG}

$\%$ Excess weight loss (\%EWL) 2 and 7 years after surgery are presented in table 3 . In both groups, weight significantly decreased in the first 2 postoperative years. Weight loss was significantly better after VBG compared to LAGB (EWL of $73 \%$ versus $55 \%$, respectively). In the non-converted VBG group a slight but not significant weight gain occurred after 7 years (73\% after 2 years and $69 \%$ after 7 years). In the LAGB group, after excluding the 5 patients that underwent conversion to another bariatric procedure, 
weight loss remained successful and unchanged after 7 years (55\% after 2 years and $54 \%$ after 7 years). Furthermore, there was no difference in weight loss between patients with or without re-operation (both EWL of 54\%). However, weight loss remained significantly greater after VBG compared to LAGB.

\begin{tabular}{lccc}
\hline & LAGB & $\begin{array}{c}\text { VBG } \\
\text { "non-converted" } \\
(n=17)\end{array}$ & $\begin{array}{c}\text { RYGB } \\
\text { "converted VBG" } \\
(n=26)\end{array}$ \\
\hline BMI (pre-operative) & $47 \pm 6(n=50)$ & $43 \pm 7(n=17)$ & $48 \pm 6(n=26)$ \\
BMl (2 years) & $34 \pm 6(n=50)$ & $30 \pm 5(n=36)$ & $33 \pm 7(n=11)$ \\
EWL (2 years) & $55 \% \pm 22(n=49)$ & $73 \% \pm 23(n=36)$ & $66 \% \pm 27(n=11)$ \\
BMl (7 years) & $35 \pm 7(n=43)^{\#}$ & $31 \pm 6(n=17)$ & $31 \pm 5(n=26)$ \\
EWL (7 years) & $54 \% \pm 25(n=43)^{\#}$ & $69 \% \pm 22(n=17)$ & $69 \% \pm 24(n=26)$ \\
\hline
\end{tabular}

Table 3: weight loss after 2 and 7 years

\# Converted LAGB patients $(n=5)$ were excluded

Weight loss - VBG versus RYGB

When interpreting long term weight loss results it is important to realize that $60 \%$ of VBG patients were converted to RYGB. Preoperative BMI of patients eventually converted to RYGB was significantly higher compared to non-converted VBG patients (BMI of 48 versus 43 , respectively). Two years after the initial operation 11 patients were already converted to RYGB. At this point, EWL was not significantly different between converted and non-converted patients ( $66 \%$ and $73 \%$, respectively) while after 7 years weight loss was the same in non-converted VBG patients and converted RYGB patients (both EWL of $69 \%)$.

\section{Comorbidities}

In both groups, the most prevalent obesity-related comorbidities were type 2 diabetes mellitus (T2DM), hypertension and joint problems (5, 7 and 28 patients in the LAGB group and 7, 10 and 29 patients in the VBG group). All obesity-related comorbidities significantly decreased in both groups 2 years after surgery (table 4).However, an increase in certain comorbidities was observed after 7 years. For example, 5 patients 
had T2DM compared to one patient after 2 years. In the VBG group, 6 patients had hypertension although only one patient had this after 2 years. Joint problems were again reported by 17 patients in both groups compared to 11 and 12 patients after 2 years in the LAGB and VBG group, respectively. However, the joints involved changed from mainly ankle and knee problems before operation to back problems afterwards. In the long term the total number of comorbidities per patient decreased after both procedures from 1.3 to $0.6(p=0.01)$. Apart from the increase in T2DM in the LAGB group there were no significant differences between the 2 groups. Also, as presented in table 5, there were no significant differences in the decrease of comorbidities between VBG patients with or without conversion to RYGB ( $p=0.8)$.

\begin{tabular}{lcccccc}
\hline & \multicolumn{3}{c}{ LAGB } & \multicolumn{3}{c}{ VBG } \\
\hline & $\begin{array}{c}\text { preop } \\
(n=50)\end{array}$ & $\begin{array}{c}2 \text { years } \\
(n=50)\end{array}$ & $\begin{array}{c}7 \text { years } \\
(n=48)\end{array}$ & $\begin{array}{c}\text { preop } \\
(n=50)\end{array}$ & $\begin{array}{c}2 \text { years } \\
(n=48)\end{array}$ & $\begin{array}{c}7 \text { years } \\
(n=43)\end{array}$ \\
\hline Diabetes & 5 & 1 & 5 & 7 & 1 & 0 \\
Hypertension & 7 & 3 & 4 & 10 & 1 & 6 \\
Joint problems & 28 & 11 & 17 & 29 & 12 & 17 \\
Hyperchol & 2 & 1 & 0 & 2 & 1 & 1 \\
OSAS & 1 & 0 & 0 & 1 & 0 & 0 \\
\hline
\end{tabular}

Table 4: obesity-related comorbidities 2 and 7 years postoperatively (LAGB and VBG patients)

\section{Laboratory parameters and vitamin status}

Laboratory parameters (hemoglobin, urea, creatinin, ASAT, ALAT, albumin, total protein, cholesterol, triglycerides, HDL and LDL) and vitamin status (iron, zinc, vitamin B1, B6, B12 and folic acid) 7 years after restrictive surgery are summarized in table 6 . There were no significant differences between patients with LAGB compared to VBG. Furthermore, all values in both groups were within the normal range except high density lipoprotein which was $2.0 \mathrm{mmol} / \mathrm{L}$ (normal range: $0.7-1.5 \mathrm{mmol} / \mathrm{L}$ ) in the VBG group. Comparing patients with or without conversion to RYGB in the VBG group did not change these results. In table 7 , the laboratory parameters of converted and non-converted VBG patients are listed. No significant differences were found and no parameters were out of the normal range except $\mathrm{HDL}(2.2$, normal range $0.7-1.5 \mathrm{mmol} / \mathrm{L})$ in the converted group. 


\begin{tabular}{lccccc}
\hline & & $\begin{array}{c}\text { VBG } \\
\text { "non-converted" } \\
(\mathrm{n}=17)\end{array}$ & \multicolumn{2}{c}{$\begin{array}{c}\text { RYGB } \\
\text { "converted VBG" } \\
(\mathrm{n}=26)\end{array}$} \\
\hline & $\begin{array}{l}\text { preop } \\
(n=50)\end{array}$ & $\begin{array}{c}2 \text { years } \\
(n=36)\end{array}$ & $\begin{array}{c}7 \text { years } \\
(n=17)\end{array}$ & $\begin{array}{c}2 \text { years } \\
(n=11)\end{array}$ & $\begin{array}{c}7 \text { years } \\
(n=26)\end{array}$ \\
\hline Diabetes & 7 & 1 & 0 & 0 & 0 \\
Hypertension & 10 & 1 & 3 & 0 & 3 \\
Joint problems & 29 & 6 & 8 & 6 & 9 \\
Hyperchol & 2 & 0 & 0 & 1 & 1 \\
OSAS & 1 & 0 & 0 & 0 & 0 \\
\hline
\end{tabular}

Table 5: obesity-related comorbidities 2 and 7 years postoperatively (VBG and converted VBG to RYGB patients)

Noteworthy is that all vitamins were within the normal range in all groups (LAGB, VBG and RYGB) and no deficiencies were present after 7 years. However, there was a difference in medication use in the form of vitamin supplements between the groups. Oral multivitamin supplements were significantly more used by LAGB patients compared to VBG and RYGB patients (55\% versus $32 \%$, respectively). A pattern in vitamin supplement usage and vitamin levels was not apparent. Patients without any supplements also had normal vitamin levels. Vitamin B12 injections (every 3 months) and iron supplements were used more frequently after VBG and RYGB than after LAGB ( $29 \%$ versus $21 \%$ and $13 \%$ versus $6 \%$ of patients, respectively). 


\begin{tabular}{lcclll}
\hline & $\begin{array}{c}\text { LAGB } \\
(\mathrm{n}-48)\end{array}$ & $\begin{array}{c}\text { VBG } \\
(\mathrm{n}=43)\end{array}$ & \multicolumn{2}{c}{ Normal range } & P-value* $^{*}$ \\
\hline Haemoglobin & 8.1 & 7.9 & $7.5-10.0$ & $(\mathrm{mmol} / \mathrm{L})$ & 0.61 \\
ASAT $^{1}$ & 17 & 20 & $<35$ & $(\mathrm{U} / \mathrm{L})$ & 0.13 \\
ALAT $^{2}$ & 21 & 23 & $<40$ & $(\mathrm{U} / \mathrm{L})$ & 0.58 \\
Albumin & 39 & 39 & $35-50$ & $(\mathrm{~g} / \mathrm{L})$ & 0.94 \\
Total protein & 69 & 67 & $60-80$ & $(\mathrm{~g} / \mathrm{L})$ & 0.49 \\
Cholesterol & 5.2 & 5.0 & $4.3-5.6$ & $(\mathrm{mmol} / \mathrm{L})$ & 0.47 \\
Triglycerides & 1.1 & 1.1 & $0.80-2.00$ & $(\mathrm{mmol} / \mathrm{L})$ & 0.94 \\
HDL $^{3}$ & 1.3 & 2.0 & $0.7-1.5$ & $(\mathrm{mmol} / \mathrm{L})$ & 0.22 \\
LDL $^{4}$ & 3.5 & 3.0 & $1.9-4.5$ & $(\mathrm{mmol} / \mathrm{L})$ & 0.05 \\
Iron & 12.5 & 12.8 & $11.0-30.0$ & $(\mu \mathrm{mol} / \mathrm{L})$ & 0.86 \\
Zinc & 12.7 & 12.4 & $10-18$ & $(\mu \mathrm{mol} / \mathrm{L})$ & 0.70 \\
Vitamin B1 & 126 & 135 & $74-222$ & $(\mathrm{nmol} / \mathrm{L})$ & 0.27 \\
Vitamin B6 & 61 & 78 & $20-122$ & $(\mathrm{nmol} / \mathrm{L})$ & 0.16 \\
Vitamin B12 & 0.23 & 0.27 & $0.15-0.67$ & $(\mathrm{nmol} / \mathrm{L})$ & 0.18 \\
Folic acid & 13.9 & 17.5 & $7.0-45.4$ & $(\mathrm{mmol} / \mathrm{L})$ & 0.24 \\
\hline
\end{tabular}

Table 6: laboratory measurements after 7 years; LAGB versus VBG / GB

* T-test

${ }^{1}$ aspartate aminotransferase, ${ }^{2}$ alanine aminotransferase, ${ }^{3}$ high density lipoprotein, ${ }^{4}$ low density lipoprotein 


\begin{tabular}{|c|c|c|c|c|}
\hline & $\begin{array}{c}\text { VBG } \\
\text { "non-converted" } \\
(\mathrm{n}=17)\end{array}$ & $\begin{array}{c}\text { RYGB } \\
\text { “converted VBG" } \\
(n=26)\end{array}$ & Normal range & P-value* \\
\hline Haemoglobin & 7.7 & 7.9 & $7.5-10.0(\mathrm{mmol} / \mathrm{L})$ & 0.79 \\
\hline ASAT $^{1}$ & 18 & 21 & $<35 \quad(U / L)$ & 0.32 \\
\hline $\mathrm{ALAT}^{2}$ & 20 & 25 & $(\mathrm{U} / \mathrm{L})$ & 0.32 \\
\hline Albumin & 41 & 38 & $35-50$ & 0.13 \\
\hline Total protein & 68 & 66 & $60-80$ & 0.58 \\
\hline Cholesterol & 4.8 & 4.9 & $4.3-5.6 \quad(\mathrm{mmol} / \mathrm{L})$ & 0.92 \\
\hline Triglycerides & 0.9 & 1.2 & $0.80-2.00(\mathrm{mmol} / \mathrm{L})$ & 0.31 \\
\hline $\mathrm{HDL}^{3}$ & 1.4 & 2.2 & $0.7-1.5 \quad(\mathrm{mmol} / \mathrm{L})$ & 0.32 \\
\hline LDL $^{4}$ & 2.9 & 3.0 & $1.9-4.5 \quad(\mathrm{mmol} / \mathrm{L})$ & 0.95 \\
\hline Iron & 15.0 & 11.6 & $11.0-30.0(\mu \mathrm{mol} / \mathrm{L})$ & 0.21 \\
\hline Zinc & 12.9 & 12.2 & $10-18 \quad(\mu \mathrm{mol} / \mathrm{L})$ & 0.53 \\
\hline Vitamin B1 & 135 & 136 & $(\mathrm{nmol} / \mathrm{L})$ & 0.93 \\
\hline Vitamin B6 & 91 & 69 & $20-122 \quad(\mathrm{nmol} / \mathrm{L})$ & 0.39 \\
\hline Vitamin B12 & 0.27 & 0.26 & $0.15-0.67(\mathrm{nmol} / \mathrm{L})$ & 0.85 \\
\hline Folic acid & 17.5 & 16.1 & $7.0-45.4(\mathrm{mmol} / \mathrm{L})$ & 0.53 \\
\hline
\end{tabular}

Table 7: laboratory measurements after 7 years; VBG versus RYGB

* T-test

${ }^{1}$ aspartate aminotransferase, ${ }^{2}$ alanine aminotransferase, ${ }^{3}$ high density lipoprotein, ${ }^{4}$ low density lipoprotein

\section{Discussion}

Morbid obesity and its related comorbidities is a worldwide epidemic. Surgery is, in contrast to conventional treatment modalities, the only treatment with a proven longlasting effect on weight and comorbidities and has a positive effect on the quality of life $[19,20]$. Weight loss more than 5 years after VBG varies in the literature from $30 \%$ to $59 \%$ EWL $[13,14,21]$ while after LAGB it varies from $56 \%$ to $62 \% \operatorname{EWL}([13,14,22]$. The long term results of O'Brien et al. show that 10 years after gastric banding it is still successful and weight loss is comparable with gastric bypass (59\% and $52 \% \mathrm{EWL}$, respectively) [23]. Most studies show a rapid weight loss after VBG with a weight regain after 2 years while patients with LAGB tend to lose weight more slowly but for a prolonged period. Our study results are consistent with the literature with $73 \%$ and $55 \%$ EWL after 2 years and $69 \%$ and $54 \%$ EWL after 7 years for VBG and LAGB, respectively. Weight loss was not significantly different between 2 and 7 years within the groups. Although 
weight loss was significantly more after VBG compared to LAGB it is important to notice that $60 \%$ of patients in the VBG group no longer had the VBG configuration but were converted to RYGB because of complications. On the other hand, weight loss was the same after 7 years for patients in the VBG group with or without conversion to RYGB (both EWL of $69 \%$ ). In terms of weight loss, successful bariatric surgery is defined as the maintenance of an EWL of at least $50 \%$. In our patient group this applies to $79 \%$ of VBG patients (converted and non-converted) and $60 \%$ of LAGB patients.

The decrease in obesity-related comorbidities after bariatric surgery is well documented and depends on the weight loss and the type of surgery [20, 24-26]. Our study confirms this once again but interestingly, an increase in T2DM was observed 7 years after LAGB while it was almost non-existent after 2 years. A clear explanation for this increase from 1 to 5 patients was not found. Weight loss in these 5 patients was EWL $44 \%$ and for the total group of LAGB patients $54 \%$ (ns). They also did not experience a rapid weight gain during the final period of follow up. Furthermore, 3 patients in this diabetic group did not have any complications while 2 patients had a band slippage and underwent refixation. There is no literature available describing a possible increase in diabetes many years after LAGB. Possibly, a combination of factors could be responsible for this phenomenon. The $10 \%$ difference in weight loss could be important because a resolution of T2DM is possible after only $10 \%$ weight loss [27, 28]. Furthermore, the ageing of the study population during follow up could be a factor in the development of T2DM.

A wide range of laboratory measurements was investigated 7 years after surgery including haemoglobin, urea, creatinin, ASAT, ALAT, albumin, total protein, cholesterol, triglycerides, HDL and LDL. There were no significant differences between the groups and except high density lipoprotein in the VBG and converted RYGB patients, all values were within normal ranges. Especially the values of minerals and vitamins (iron, zinc, vitamin B1, B6, B12 and folic acid) are of interest. In all groups, including the converted RYGB patients, all levels were within the normal range implying no deficiencies were present. In the literature, comparison between restrictive and more malabsorptive procedures shows that deficiencies are much less common after purely restrictive procedures because the gastrointestinal tract remains intact and absorption is normal $[29,30]$. This is confirmed in several reports except that low levels of folic acid are frequently observed caused by a difference in eating habits after surgery (less wholemeal bread, vegetables and fruit) $[31,32]$. This is considered the most important reason to recommend vitamin supplementation after restrictive surgery. However, in the present study the postoperative levels of folic acid were normal irrespective of vitamin supplement usage. The supplement use was low in both groups but significantly higher 
in the LAGB group (55\%) compared to the VBG / RYGB group (32\%). Continued vitamin use is probably associated with regular follow up and this tends to be higher after LAGB because of visits before and after insufflations. On the other hand, vitamin B12 injections (every 3 months) and iron supplements were used more frequently after VBG and RYGB than after LAGB (29\% versus $21 \%$ and $13 \%$ versus $6 \%$ of patients, respectively). The latter can be explained by the $60 \%$ conversion rate to RYGB in the VBG group. The deficiency of vitamin B12 and iron is well known after RYGB because of the bypassed stomach and proximal intestine [33-35] and therefore, vitamin monitoring and supplementation is mandatory after RYGB. In our study group a pattern in vitamin supplement usage and vitamin levels was not apparent. Patients without any supplements also had normal vitamin levels and this issue has been discussed in the literature [36]. It is mostly explained by medication adherence which is, in case of bariatric surgery, below $50 \%$ and deteriorates during follow up [30, 37]. No randomized trials on this subject are published to provide a definitive answer if supplements are needed after purely restrictive procedures and therefore, it is still common practice to prescribe vitamin supplements to all bariatric patients. Although our results are not consistent, based on the available literature and possible consequences of deficiencies, continuation of this policy seems justified.

Revisional surgery is often necessary after VBG because of stoma stenosis, pouch enlargement or stapler line dehiscence. Percentages in the literature range from $10 \%$ to $50 \%$ and are strongly associated with the completeness and duration of follow up [3842]. Also, developments in VBG techniques may possibly lead to better results with a lower re-operation rate, e.g. the Mason Mclean operation with partition of the stomach instead of only stapling. However, no long term results of this procedure are described in the literature so a comparison with standard VBG or LAGB is not possible. In the present study the mean time between the primary operation and the re-operation was 2 years with a range from 6 months to 7 years. Therefore, in order to present reliable reoperation rates after VBG a minimum follow up period of 3 years is necessary. Balsiger et al. described a re-operation rate of 19\% 10 years after VBG [21]. Comparable results were found by van de Weijgert et al. with a re-operation rate of $18 \%$ after a mean period of 7.2 years [43]. Studies by van Gemert et al. and MacLean et al. reported higher rates (31\% and $36 \%$, respectively) after 52 months and 2 to 5 years of follow up $[39,41]$. Finally, the prospective study by Miller et al. (follow up of 92 months) is most comparative with our results with a re-operation rate after VBG of $49.7 \%$ [14]. Purely technical failure after VBG occurred in $60 \%$ of our patients and in all cases conversion to RYGB was performed. Conversion from VBG to RYGB has been described in literature 
with positive results. Sugerman et al. reported on 53 patients where EWL increased from $36 \%$ to $67 \%$ after the conversion [44]. The patient group of Cordera et al. showed a decrease in BMI of 46 to $35 \mathrm{~kg} / \mathrm{m}^{2}$ after conversion [45]. Kfoury et al. performed a distal RYGB in 45 patients after failed VBG. Results after a follow up period of at least two years were available for 29 patients and \%EWL was $74 \%$ in this group [46]. Finally, the conversion led to a decrease in BMI from $40 \mathrm{~kg} / \mathrm{m}^{2}$ to $32 \mathrm{~kg} / \mathrm{m}^{2}$ at 16 months postoperatively in the group described by Gonzalez et al [47]. We also reported on 101 patients who were converted from failed VBG to RYGB and demonstrated good results on weight loss, comorbidities and patients' symptoms [15]. The present study confirms the positive results of this conversion with a long term EWL of $69 \%$ and a low re-intervention rate $(8 \%)$.

The rate of re-operations after LAGB differs tremendously in literature from $2 \%$ to $80 \%$ [48]. Several reasons for these differences have been proposed. First, results vary according to the used surgical technique, either perigastric or pars flaccida, the latter having better results especially due to a decrease in band slippages $[18,49]$. In two randomized studies from Weiner et al. and O'Brien et al. the pars flaccida technique was demonstrated to be a safer technique with less complications and is therefore nowadays considered best surgical practice [18, 49]. In a previously reported study from our institution, based on a study population operated more recently than the population from the present study, the re-operation rate decreased significantly from $42 \%$ to $8 \%$ after introduction of the pars flaccida technique. This was mainly due to a decrease in band slippage and pouch dilatation from $29 \%$ in the perigastric group to $4 \%$ in the pars flaccida group [48]. In the present study this difference is not confirmed; the re-operation rate after perigastric and pars flaccida operated patients was $41 \%$ and $33 \%$, respectively (n.s.). However, in this consecutive group of patients the perigastric technique was used in 30 patients and the pars flaccida technique in 18 patients, the latter representing our first experience with this technique. Therefore, our experience with the different techniques is not comparable in this group. This might explain the nonsignificant difference in re-operation rate.

The second important issue explaining differences in re-operation rate after LAGB is follow up time. In the present study, mean time between the primary operation and the re-operation because of complications after LAGB was 3 years. Most publications report on short term results after LAGB which explains re-operation rates as low as $2 \%$. However, a follow up of a reasonable patient population beyond 3 years is necessary for a reliable estimation of the re-operation rate. For example, the re-operation rate in a retrospective study by Christou et al. was $16.1 \%$ after 3 years but only one third of 
patients were available for follow up [50]. In a case-controlled study by Cottam et al. the re-operation rate was $53 \%$ in the first year decreasing to $0 \%$ in the third year. However, follow up after 3 years was only $25 \%$ [51]. The prospective long term study by Miller et al., with a follow up rate of $92 \%$, is therefore the only comparable study with a mean follow up of 92 months and a minimum of 60 months. They reported a re-operation rate of $8 \%$ which is low compared to the $44 \%$ from the present study [14]. Whether the perigastric or pars flaccida technique was used is unclear. As mentioned above, since the introduction of the pars flaccida technique our re-operation rate decreased to from $44 \%$ (follow up 84 months) to $8 \%$ (follow up of 48 months) [48].

As we previously reported re-operations after LAGB, especially refixation of the band or replacement, are highly successful [48]. Weiss et al. reported on 73 patients who underwent a surgical revision after LAGB. After a follow-up period of 42 months BMI decreased from $37.8 \mathrm{~kg} / \mathrm{m}^{2}$ to $29.5 \mathrm{~kg} / \mathrm{m}^{2}$ [52]. Peterli et al. performed 250 operations and re-operated 39 patients (16\%) because of failed LAGB. After re-operation $5.3 \%$ of patients developed a second failure of the band but re-slippages were not observed [53]. These positive results of re-operations after LAGB are confirmed in the present study as only one patient had a re-slippage after refixation of the band $(5 \%)$. Weight loss was successful after re-operation and more importantly, the same in patients with or without re-operation (both EWL of $54 \%$ ).

In conclusion, VBG results in long term weight loss and improvement of obesityrelated comorbidities. However, because of the $60 \%$ failure rate and the necessity to perform a conversion in case of failure we do not offer VBG to our patients nowadays. Although the re-operation rate after long term follow up is also high in LAGB patients, the results of these re-operations (in most cases only refixation of the band) are good. Many improvements have been made, e.g. the pars flaccida instead of the perigastric technique and low pressure - high volume bands instead of high pressure- low volume bands with a dramatic decrease in re-operation rate as a result. LAGB is the least complicated procedure in comparison with more invasive and non-reversible procedures like RYGB and BPD. Therefore, we still recommend and perform LAGB but patients need to be informed extensively before the operation and follow up needs to be durable and complete. 


\section{Conclusion}

This long term follow up study confirms the high occurrence of late complications after restrictive bariatric surgery. The failure rate of $60 \%$ after VBG is too high and this procedure is not performed anymore in our institution. The re-operation rate after LAGB is decreasing as a result of new techniques and materials. Results of the re-operations are good with sustained weight loss and reduction in comorbidities. However, in order to achieve these results durable and complete follow up after restrictive procedures is imperative. 


\section{References}

1. Mitka, M., Surgery for obesity: demand soars amid scientific, ethical questions. Jama, 2003. 289(14): p. 1761-2.

2. Tessier, D.J. and J.C. Eagon, Surgical management of morbid obesity. Curr Probl Surg, 2008. 45(2): p. 68-137.

3. Kemper, H.C., M. Stasse-Wolthuis, and W. Bosman, The prevention and treatment of overweight and obesity. Summary of the advisory report by the Health Council of The Netherlands. Neth J Med, 2004. 62(1): p. 10-7.

4. Bjorntorp, P., Results of conservative therapy of obesity: correlation with adipose tissue morphology. Am J Clin Nutr, 1980. 33(2 Suppl): p. 370-5.

5. Fisher, B.L. and P. Schauer, Medical and surgical options in the treatment of severe obesity. Am J Surg, 2002. 184(6B): p. 9S-16S.

6. Mason, E.E., et al., Vertical gastroplasty: evolution of vertical banded gastroplasty. World J Surg, 1998. 22(9): p. 919-24.

7. Eckhout, G.V., O.L. Willbanks, and J.T. Moore, Vertical ring gastroplasty for morbid obesity. Five year experience with 1,463 patients. Am J Surg, 1986. 152(6): p. 713-6.

8. Catona, A., et al., Laparoscopic Gastric Banding: preliminary series. Obes Surg, 1993. 3(2): p. 207-209.

9. van Dielen, F.M., et al., Laparoscopic adjustable gastric banding versus open vertical banded gastroplasty: a prospective randomized trial. Obes Surg, 2005. 15(9): p. 1292-8.

10. de Wit, L.T., et al., Open versus laparoscopic adjustable silicone gastric banding: a prospective randomized trial for treatment of morbid obesity. Ann Surg, 1999. 230(6): p. 800-5; discussion 805-7.

11. Olbers, T., et al., Randomized clinical trial of laparoscopic Roux-en-Y gastric bypass versus laparoscopic vertical banded gastroplasty for obesity. Br J Surg, 2005. 92(5): p. 557-62.

12. Morino, M., et al., Laparoscopic adjustable silicone gastric banding versus vertical banded gastroplasty in morbidly obese patients: a prospective randomized controlled clinical trial. Ann Surg, 2003. 238(6): p. 835-41; discussion 841-2.

13. Nilsell, K., et al., Prospective randomised comparison of adjustable gastric banding and vertical banded gastroplasty for morbid obesity. Eur J Surg, 2001. 167(7): p. 504-9.

14. Miller, K., A. Pump, and E. Hell, Vertical banded gastroplasty versus adjustable gastric banding: prospective long-term follow-up study. Surg Obes Relat Dis, 2007. 3(1): p. 84-90.

15. Schouten, R., et al., Conversion of vertical banded gastroplasty to Roux-en-Y gastric bypass results in restoration of the positive effect on weight loss and co-morbidities: evaluation of 101 patients. Obes Surg, 2007. 17(5): p. 622-30.

16. Belachew, M., et al., Laparoscopic adjustable gastric banding. World J Surg, 1998. 22(9): p. 955-63.

17. Dargent, J., Pouch dilatation and slippage after adjustable gastric banding: is it still an issue? Obes Surg, 2003. 13(1): p. 111-5.

18. Weiner, R., et al., A prospective randomized trial of different laparoscopic gastric banding techniques for morbid obesity. Surg Endosc, 2001. 15(1): p. 63-8.

19. Karlsson, J., et al., Ten-year trends in health-related quality of life after surgical and conventional treatment for severe obesity: the SOS intervention study. Int J Obes (Lond), 2007. 31(8): p. 1248-61.

20. Sjostrom, L., et al., Lifestyle, diabetes, and cardiovascular risk factors 10 years after bariatric surgery. N Engl J Med, 2004. 351(26): p. 2683-93.

21. Balsiger, B.M., et al., Ten and more years after vertical banded gastroplasty as primary operation for morbid obesity. J Gastrointest Surg, 2000. 4(6): p. 598-605. 
22. O'Brien, P.E. and J.B. Dixon, Lap-band: outcomes and results. J Laparoendosc Adv Surg Tech A, 2003. 13(4): p. 265-70.

23. O'Brien, P.E., et al., Systematic review of medium-term weight loss after bariatric operations. Obes Surg, 2006. 16(8): p. 1032-40.

24. Buchwald, H., et al., Bariatric surgery: a systematic review and meta-analysis. Jama, 2004. 292(14): p. 1724-37.

25. Chapman, A.E., et al., Laparoscopic adjustable gastric banding in the treatment of obesity: a systematic literature review. Surgery, 2004. 135(3): p. 326-51.

26. Colquitt, J., et al., Surgery for morbid obesity. Cochrane Database Syst Rev, 2005(4): p. CD003641.

27. Pi-Sunyer, X., et al., Reduction in weight and cardiovascular disease risk factors in individuals with type 2 diabetes: one-year results of the look AHEAD trial. Diabetes Care, 2007. 30(6): p. 1374-83.

28. Knowler, W.C., et al., Reduction in the incidence of type 2 diabetes with lifestyle intervention or metformin. N Engl J Med, 2002. 346(6): p. 393-403.

29. Pournaras, D.J. and C.W. le Roux, After bariatric surgery, what vitamins should be measured and what supplements should be given? Clin Endocrinol (Oxf), 2009. 71(3): p. 322-5.

30. Coupaye, M., et al., Nutritional consequences of adjustable gastric banding and gastric bypass: a 1-year prospective study. Obes Surg, 2009. 19(1): p. 56-65.

31. Gasteyger, C., et al., Changes in body composition, metabolic profile and nutritional status 24 months after gastric banding. Obes Surg, 2006. 16(3): p. 243-50.

32. Cooper, P.L., et al., Nutritional consequences of modified vertical gastroplasty in obese subjects. Int J Obes Relat Metab Disord, 1999. 23(4): p. 382-8.

33. Parkes, E., Nutritional management of patients after bariatric surgery. Am J Med Sci, 2006. 331(4): p. 207-13.

34. Malinowski, S.S., Nutritional and metabolic complications of bariatric surgery. Am J Med Sci, 2006. 331(4): p. 219-25.

35. Fujioka, K., Follow-up of nutritional and metabolic problems after bariatric surgery. Diabetes Care, 2005. 28(2): p. 481-4.

36. Ledoux, S., et al., Comparison of nutritional consequences of conventional therapy of obesity, adjustable gastric banding, and gastric bypass. Obes Surg, 2006. 16(8): p. 1041-9.

37. Trostler, N., et al., Nutrient Intake following Vertical Banded Gastroplasty or Gastric Bypass. Obes Surg, 1995. 5(4): p. 403-410.

38. Hall, J.C., et al., Gastric surgery for morbid obesity. The Adelaide Study. Ann Surg, 1990. 211(4): p. 419-27.

39. van Gemert, W.G., et al., Revisional surgery after failed vertical banded gastroplasty: restoration of vertical banded gastroplasty or conversion to gastric bypass. Obes Surg, 1998. 8(1): p. 21-8.

40. Nightengale, M.L., et al., Prospective evaluation of vertical banded gastroplasty as the primary operation for morbid obesity. Mayo Clin Proc, 1991. 66(8): p. 773-82.

41. MacLean, L.D., B.M. Rhode, and R.A. Forse, Late results of vertical banded gastroplasty for morbid and super obesity. Surgery, 1990. 107(1): p. 20-7.

42. Naslund, E., et al., Seven year results of vertical banded gastroplasty for morbid obesity. Eur J Surg, 1997. 163(4): p. 281-6.

43. van de Weijgert, E.J., C.H. Ruseler, and J.W. Elte, Long-term follow-up after gastric surgery for morbid obesity: preoperative weight loss improves the long-term control of morbid obesity after vertical banded gastroplasty. Obes Surg, 1999. 9(5): p. 426-32.

44. Sugerman, H.J., et al., Conversion of failed or complicated vertical banded gastroplasty to gastric bypass in morbid obesity. Am J Surg, 1996. 171(2): p. 263-9. 
45. Cordera, F., et al., Unsatisfactory weight loss after vertical banded gastroplasty: is conversion to Roux-en-Y gastric bypass successful? Surgery, 2004. 136(4): p. 731-7.

46. Kfoury, E. and A. Vanguri, Distal Roux-en-Y Gastric Bypass Conversion Operation for Failed Vertical Banded Gastroplasty. Obes Surg, 1993. 3(1): p. 41-43.

47. Gonzalez, R., et al., Operative technique for converting a failed vertical banded gastroplasty to Roux-en-Y gastric bypass. J Am Coll Surg, 2005. 201(3): p. 366-74.

48. Schouten, R., F.M. van Dielen, and J.W. Greve, Re-operation after laparoscopic adjustable gastric banding leads to a further decrease in BMI and obesity-related co-morbidities: results in 33 patients. Obes Surg, 2006. 16(7): p. 821-8.

49. O'Brien, P.E., et al., A prospective randomized trial of placement of the laparoscopic adjustable gastric band: comparison of the perigastric and pars flaccida pathways. Obes Surg, 2005. 15(6): p. 820-6.

50. Christou, N. and E. Efthimiou, Five-year outcomes of laparoscopic adjustable gastric banding and laparoscopic Roux-en-Y gastric bypass in a comprehensive bariatric surgery program in Canada. Can J Surg, 2009. 52(6): p. E249-58.

51. Cottam, D.R., et al., A case-controlled matched-pair cohort study of laparoscopic Roux-en-Y gastric bypass and Lap-Band patients in a single US center with three-year follow-up. Obes Surg, 2006. 16(5): p. 534-40.

52. Weiss, H.G., et al., Surgical revision after failure of laparoscopic adjustable gastric banding. Br J Surg, 2004. 91(2): p. 235-41.

53. Peterli, R., et al., Re-operations following laparoscopic adjustable gastric banding. Obes Surg, 2002. 12(6): p. 851-6. 

Quality of life assessment in morbidly obese patients: preoperative, short and long term results after restrictive procedures

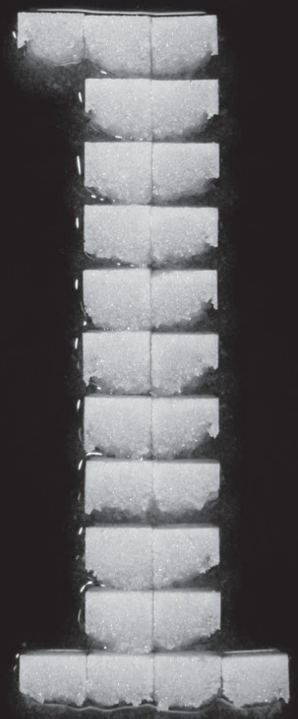

Ruben Schouten

Dorothee C.M.S. Wiryasaputra

Francois M.H. van Dielen

Wim G. van Gemert

Jan Willem M. Greve 


\section{Abstract}

Background: morbid obesity interferes unfavorably with general well-being and the psychological status of the patient. Bariatric surgery is known to improve quality of life but results after long term follow up have not been described frequently. A prospective quality of life assessment before, one year and 7 years after laparoscopic adjustable gastric banding (LAGB) and vertical banded gastroplasty (VBG) was performed.

Methods: 100 patients were included in the study. Fifty patients underwent VBG and 50 LAGB. Patients completed the quality of life questionnaires prior to surgery and 2 times during follow up. Health-related quality of life (HRQoL) questionnaires included the Nottingham Heath Profile I and II (NHP-I and II) and the Sickness Impact Profile 68 (SIP-68).

Results: follow up was $84 \%$ with a mean duration of 84 months (7 years). During follow up, $65 \%$ of VBG patients underwent conversion to roux-en-y gastric bypass (RYGB) while $44 \%$ of LAGB patients underwent a re-operation or conversion. One year after the procedure nearly all quality of life parameters significantly improved. After 7 years, the NHP-I domain "physical ability", the NHP-II and the SIP-68 domains "mobility control", "social behavior" and "mobility range" were still significantly improved in both groups. The domains "emotional reaction", "social isolation" (NHP-I) and "emotional stability" (SIP-68) remained significantly improved in the VBG group while this was true for the domain "energy level" (NHP-I) in the LAGB group. Both the type of procedure and reoperations during follow up were not of significant influence on the HRQL results. Weight loss and decrease in comorbidities were the only significant factors influencing quality of life.

Conclusion: restrictive bariatric surgery improves quality of life. Although results are most impressive one year after surgery the improvement remains significant after long term follow up. Postoperative quality of life is only dependent on weight loss and decrease in comorbidities and not on the type of procedure or surgical complications. 


\section{Introduction}

Over the past three decades, quality of life has become an increasingly important aspect of clinical investigation and patient care. The World Health Organization (WHO) defines quality of life as "a state of complete physical, mental, and social well-being and not merely the absence of disease or infirmity". For most patients, quality of life is more important than the traditional outcome measures in medical care [1]. Morbid obesity is a lifelong, progressive disease of fat storage manifested by medical, physical, psychological, social and economic comorbidities and increases the risk of developing life threatening diseases [2]. The presentation of these problems in obese persons is related to the amount of excess weight [3-5]. It is important to state that morbid obesity interferes unfavorably with general well-being and the psyche of the patient. Results of quality of life assessments of morbidly obese patients show that quality of life is better after surgically induced weight loss and seems not to be related to the type of surgical procedure or to surgical complications [6,7]. Even though the positive effects of bariatric surgery on the quality of life have been demonstrated in earlier studies, prospective studies comparing preoperative, short term and long term results are scarce [8-11]. In our institution a randomized prospective study comparing LAGB with open VBG was initiated in 1998 and 2-year clinical results are published elsewhere [12]. However, this study also included pre- and postoperative quality of life assessment. The objective of the present study was to investigate the quality of life more than 5 years after restrictive procedures and the possible influence of the type of surgery and complications.

\section{Patients and methods}

Patients and study design

One hundred morbidly obese patients, defined as a BMI above $40 \mathrm{~kg} / \mathrm{m}^{2}$ or above 35 $\mathrm{kg} / \mathrm{m}^{2}$ with obesity-related comorbidities, were selected to undergo either LAGB or open VBG. All patients were aged between 18 and 60 years and had not succeeded in losing weight through several dietary programs. Patients with severe psychiatric disorders or who had prior bariatric and / or gastric surgery were excluded from the study. After obtaining written informed consent patients were randomly assigned to the different operations by a computer generated randomization list. The initial study and long term follow up study were approved by the medical ethical committee of the Maastricht University Medical Centre, the Netherlands. Before admission for surgery all patients 
were asked to complete quality of life questionnaires. After discharge, all patients were evaluated in the outpatient clinic after 1 and 6 weeks and 3, 6, 12 and 24 months. After this period patients were evaluated at least once a year. However, patients were asked to complete quality of life questionnaire only preoperatively, after 6 weeks and 12 months. In 2007, all patients were more than 5 years past their initial surgery and were approached to complete the same quality of life questionnaires. Since baseline visit four patients had died. Therefore, 96 of the initial 100 patients were encountered to participate.

\section{Quality of life analysis}

Patients' HRQoL was investigated by using three validated methods. The Nottingham Health Profile part I (NHP-I) and part II (NHP-II) were used to provide an indication of the patient's perceived emotional, social and physical health problems [13]. In part I, 38 questions are distributed over 6 subareas with each question assigned a weighted value; the sum of all weighted values in a given subarea adds up to a score between 0 (best score) and 100 (worst score). The 6 specific domains of life are: mobility, pain, energy, sleep, social isolation and emotional reaction. In part II, the questionnaire relates to those areas of task performance most affected by health. It concerns seven statements that refer to the effects of health problems on occupation, ability to perform domestic tasks, hobbies, personal relationships, sex life, social life and holidays. The NHP-II is given as a single score ranging between 7 (best score) and 21 (worst score). Finally, the Sickness Impact Profile 68 (SIP-68) is known to be a valid and reliable instrument [14-16]. It is intended for measuring the outcomes of care in health surveys, program planning, in policy formation and in monitoring patients' progress. The SIP-68 beholds 68 items and every item contains a statement on behavior. The items are divided in 6 categories: somatic autonomy (17 items), mobility control (12 items), psychological autonomy and communication (11 items), social behavior (12 items), emotional stability (6 items) and mobility range (10 items). In every category the score is calculated in the same manner: 0 is the lowest and best possible score while the number of items (respectively 17, 12, 11, 12, 6 and 10) is identical to the highest and worst score [14]. The relation between preoperative and postoperative HRQoL one year and 7 years after LAGB and VBG was investigated using these questionnaires. Furthermore, a subgroup analysis was performed in both groups in order to investigate if re-operations and conversions after restrictive procedures had any influence on HRQoL. 


\section{Statistical analysis}

Statistical analyses were performed using the SPSS 15.0.0 statistical package (SPSS Inc., Chicago, IL, USA). Statistical analyses have been performed non-parametrically and two-sided. The Student's t-test was used to calculate differences between the groups. In case of a skewed distribution the Mann Whitney $U$ test was used for comparison between the groups and the Wilcoxon signed-ranks test for comparison in one group throughout time. To determine if certain factors were of significant influence on the HRQoL results Pearson's correlation coefficient was used and Kendall's tau in case of ranked data distribution. Data are given as mean and standard deviation. A $p$-value of $p<0.05$ or $p<0.01$ (where applicable) was denoted as statistically significant.

\section{Results}

\section{Group characteristics}

Four patients died during the follow up period; two patients as a result of postoperative complications (both VBG), one in the course of ovarian cancer (4 years after LAGB) and one as a result of a gynecological infection (5 years after VBG). Data from the last two deceased patients are included in the analysis until the moment of death. Seven patients could not be traced and were lost to follow up and 5 patients were not willing to fill out the questionnaires or did not manage to return them completely despite repeated attempts to contact these patients. The long term HRQoL study eventually included 84 patients with a mean follow up period of 84 months (7 years). The study population consisted of 68 women and 16 men. From this group, 40 patients initially underwent VBG and 44 patients LAGB. Patients in the VBG and LAGB group were comparable regarding age, preoperative weight and body mass index (BMI) (table 1).

\section{Weight loss}

Long term weight loss was significant in VBG patients (BMI decrease from 46 to $32 \mathrm{~kg} /$ $\mathrm{m}^{2}$ ) and LAGB patients (BMI decrease from 47 to $35 \mathrm{~kg} / \mathrm{m}^{2}$ ). However, weight loss after 7 years was significantly higher after VBG than after LAGB with a BMI of 32 versus 35 $\mathrm{kg} / \mathrm{m} 2(p<0.01)$ and $E W L$ of $69 \%$ versus $54 \%(p<0.05)$. 


\begin{tabular}{lccc}
\hline & $\begin{array}{c}\text { VBG } \\
(\mathrm{n}=40)\end{array}$ & $\begin{array}{c}\text { LAGB } \\
(\mathrm{n}=44)\end{array}$ & P-value * \\
\hline male : female & $6: 34$ & $10: 34$ & \\
age (years) & $37 \pm 10$ & $39 \pm 9$ & 0.32 \\
preoperative weight $(\mathrm{kg})$ & $131 \pm 24$ & $133 \pm 21$ & 0.87 \\
preoperative BMl $\left(\mathrm{kg} / \mathrm{m}^{2}\right)$ & $46 \pm 6$ & $47 \pm 6$ & 0.82 \\
final BMI $\left(\mathrm{kg} / \mathrm{m}^{2}\right)$ & $32 \pm 5$ & $35 \pm 7$ & $<0.01$ \\
final EWL $(\%)$ & $69 \pm 23$ & $54 \pm 25$ & $<0.05$ \\
\hline
\end{tabular}

Table 1: group characteristics and final weight loss

* Student T-test

\section{Re-operations}

After 7 years, 14 patients (35\%) still had VBG while 26 patients (65\%) were converted to RYGB because of staple line dehiscence (22 patients) or recurrent outlet stenosis (4 patients) (table 2). However, this had no effect on the long term weight loss results (EWL of $69 \%$ and $68 \%$, respectively). In the LAGB group, 25 patients $(57 \%)$ did not have a re-operation. Fourteen patients (32\%) underwent a refixation or replacement of the band (14 patients) because of band slippage. Conversion to RYGB and biliopancreatic diversion (BPD) was necessary in 3 and 2 patients (11\%), respectively, because of severe pouch dilatation and band erosion. Comparing the weight loss results of LAGB patients and re-operated (non-converted) LAGB patients also did not show a significant difference (EWL 54\% and 57\%, respectively).

\begin{tabular}{lcc}
\hline & VBG & LAGB \\
$(\mathrm{n}=40)$ & $(\mathrm{n}=44)$ \\
\hline No re-operation & $14(35 \%)$ & $25(57 \%)$ \\
Re-operation & - & $14(32 \%)$ \\
Conversion & $26(65 \%)$ & $5(11 \%)$ \\
\hline
\end{tabular}

Table 2: number of patients with or without re-operation / conversion during follow up 


\section{Comorbidities}

In table 3, the total number of obesity-related comorbidities in the VBG group and the LAGB group are summarized. There are no significant differences between the groups preoperatively $(p=0.97)$. Comparing pre- and postoperative comorbidities after one and 7 years show that the comorbidities significantly decreased after surgery (both $p<$ 0.01). Furthermore, the decrease is stable during follow up; the results are comparable after one and 7 years without differences between the groups.

\begin{tabular}{lccr}
\hline & VBG & LAGB & p-value \\
\hline Total comorbidities (preoperatively) & $1.3 \pm 1.1(n=50)$ & $1.3 \pm 1.0(n=50)$ & $0.97^{*}$ \\
Total comorbidities (1y postoperatively) & $0.5 \pm 0.9(n=45)$ & $0.5 \pm 0.8(n=44)$ & $<0.01^{\wedge}$ \\
Total comorbidities (7y postoperatively) & $0.6 \pm 0.9(n=40)$ & $0.6 \pm 0.8(n=44)$ & $<0.01^{\wedge}$ \\
\hline
\end{tabular}

Table 3: obesity-related comorbidities pre- and postoperatively

* total comorbidities of the VBG group compared to the LAGB group (Mann-Whitney test)

$\wedge$ total comorbidities pre- and postoperatively compared within a group (Wilcoxon signed- ranks test)

\section{Quality of life assessment after one year}

Table 4 shows the preoperative and postoperative HRQoL results one year after surgery for VBG and LAGB patients. All domains in the NHP-I and NHP-II significantly improved postoperatively in both groups except "social isolation" in the LAGB group $(p=0.10)$. The six categories of the SIP-68 all showed significant improvement except "psychic autonomy and communication" in both groups ( $p=0.21$ in the VBG group and $p=0.14$ in the LAGB group). Also, the category "somatic autonomy" did not significantly improve in the VBG group ( $p=0.06$ ). Overall it can be stated that HRQoL significantly improved one year after surgery with minor differences between VBG and LAGB.

\section{Quality of life assessment after 7 years}

The NHP-I showed improvement in all domains 7 years after surgery (table 5) but in the VBG group this reached statistical significance in only 3 of the 6 domains ("emotional reaction" ( $p<0.01)$, "social isolation" ( $p<0.01)$ and "physical abilities" $(p<0.01)$ ). In the LAGB group only 2 of the 6 domains were significantly improved ("energy level" ( $p<$ 
$0.05)$ and "physical ability" $(p<0.01)$ ). The NHP-II improved significantly in both groups $(p<0.01)$. The categories of the SIP-68 all improved except for "psychic autonomy and communication". In the VBG group there was a significant improvement of 4 of the 6 categories ("mobility control" ( $p<0.01)$, "social behavior" $(p<0.05)$, "emotional stability" $(p<0.05)$ and "mobility range" $(p<0.05))$. In the LAGB group the same significant improvements were noted except for "emotional stability" $(p=0.78)$. Overall, HRQoL was still improved 7 years after surgery. Differences between VBG and LAGB are minimal; in both groups, about half of the values were significantly improved.

\begin{tabular}{|c|c|c|c|c|c|c|}
\hline & $\begin{array}{c}\text { VBG } \\
\text { (preop) } \\
(n=50)\end{array}$ & $\begin{array}{c}\text { VBG } \\
\text { (1y postop) } \\
(\mathrm{n}=45)\end{array}$ & p-value* & $\begin{array}{l}\text { LAGB } \\
\text { (preop) } \\
(n=50)\end{array}$ & $\begin{array}{c}\text { LAGB } \\
(1 \mathrm{y} \text { postop }) \\
(\mathrm{n}=45)\end{array}$ & $p$-value* \\
\hline \multicolumn{7}{|l|}{ NHP-I } \\
\hline Energy level & 46.3 & 13.7 & $<0.01$ & 42.8 & 11.6 & $<0.01$ \\
\hline Pain & 25.8 & 8.8 & $<0.01$ & 19.5 & 9.8 & $<0.01$ \\
\hline Emotional reaction & 21.4 & 10.4 & $<0.01$ & 15.0 & 5.0 & $<0.01$ \\
\hline Sleep & 24.7 & 10.1 & $<0.01$ & 16.1 & 6.6 & $<0.05$ \\
\hline Social isolation & 21.0 & 6.8 & $<0.01$ & 16.4 & 5.8 & 0.10 \\
\hline Physical abilities & 30.3 & 6.7 & $<0.01$ & 25.0 & 9.4 & $<0.01$ \\
\hline NHP-II & 12.7 & 7.5 & $<0.01$ & 13.0 & 7.7 & $<0.01$ \\
\hline \multicolumn{7}{|l|}{ SIP-68 } \\
\hline Somatic autonomy & 2.7 & 0.8 & 0.06 & 3.6 & 1.4 & $<0.01$ \\
\hline Mobility control & 29.3 & 7.5 & $<0.01$ & 22.3 & 7.8 & $<0.01$ \\
\hline $\begin{array}{l}\text { Psychic autonomy } \\
\text { and communication }\end{array}$ & 11.1 & 7.0 & 0.21 & 8.3 & 4.6 & 0.14 \\
\hline Social behavior & 29.8 & 12.0 & $<0.01$ & 26.7 & 9.9 & $<0.01$ \\
\hline Emotional stability & 22.0 & 12.9 & $<0.05$ & 15.5 & 5.4 & $<0.01$ \\
\hline Mobility range & 10.1 & 1.3 & $<0.01$ & 8.0 & 1.9 & $<0.01$ \\
\hline
\end{tabular}

Table 4: preoperative and postoperative HRQoL results 1 year after surgery

*Wilcoxon signed-ranks test 


\begin{tabular}{|c|c|c|c|c|c|c|}
\hline & $\begin{array}{c}\text { VBG } \\
\text { (preop) } \\
(n=50)\end{array}$ & $\begin{array}{c}\text { VBG } \\
\text { (7y postop) } \\
(\mathrm{n}=40)\end{array}$ & p-value* & $\begin{array}{l}\text { LAGB } \\
(\text { preop) } \\
(n=50)\end{array}$ & $\begin{array}{c}\text { LAGB } \\
\text { (7y postop) } \\
(n=44)\end{array}$ & p-value* \\
\hline \multicolumn{7}{|l|}{ NHP-I } \\
\hline Energy level & 46.3 & 27.3 & 0.14 & 42.8 & 27.3 & $<0.05$ \\
\hline Pain & 25.8 & 15.8 & 0.25 & 19.5 & 14.1 & 0.06 \\
\hline Emotional reaction & 21.4 & 6.9 & $<0.01$ & 15.0 & 15.1 & 0.19 \\
\hline Sleep & 24.7 & 16.4 & 0.96 & 16.1 & 16.1 & 0.94 \\
\hline Social isolation & 21.0 & 4.4 & $<0.01$ & 16.4 & 12.8 & 0.21 \\
\hline Physical abilities & 30.3 & 9.7 & $<0.01$ & 25.0 & 9.9 & $<0.01$ \\
\hline NHP-II & 12.7 & 10.7 & $<0.01$ & 13.0 & 10.2 & $<0.01$ \\
\hline \multicolumn{7}{|l|}{ SIP-68 } \\
\hline Somatic autonomy & 2.7 & 2.6 & 0.50 & 3.6 & 2.1 & 0.25 \\
\hline Mobility control & 29.3 & 12.8 & $<0.01$ & 22.3 & 14.0 & $<0.05$ \\
\hline $\begin{array}{l}\text { Psychic autonomy } \\
\text { and communication }\end{array}$ & 11.1 & 14.1 & 0.25 & 8.3 & 12.0 & 0.12 \\
\hline Social behavior & 29.8 & 14.9 & $<0.05$ & 26.7 & 17.5 & $<0.01$ \\
\hline Emotional stability & 22.0 & 11.2 & $<0.05$ & 15.5 & 14.6 & 0.78 \\
\hline Mobility range & 10.1 & 2.8 & $<0.05$ & 8.0 & 3.4 & $<0.01$ \\
\hline
\end{tabular}

Table 5: preoperative and postoperative HRQoL results 7 year after surgery

*Wilcoxon signed-ranks test

Quality of life assessment: VBG versus conversion to RYGB

As mentioned before, 26 patients in the VBG group were converted to RYGB and 19 patients underwent a re-operation or conversion after LAGB because of complications (table 2). Although this had no effect on the long term weight loss results it was hypothesized it could have an effect on the HRQoL of patients. Therefore, a subgroup analysis was performed comparing patients in the VBG and LAGB group with or without re-operation or conversion. Table 6 represents the HRQoL results 7 years post-operatively subdivided into patients with or without conversion to RYGB. Again, all values improved in both groups except the SIP-68 categories "somatic autonomy" and "psychic autonomy and communication". Because of smaller patient numbers in both groups a lower number of values reached statistical significance. More importantly, there were no differences between the non-converted and converted patient group. 
Both had a significant improvement in "social isolation", "physical abilities" (both NHP-I), the NHP-II and "mobility control" (SIP-68).

\section{Quality of life assessment: LAGB with or without re-operation}

In the LAGB group without a re-operation during follow up most values were improved after 7 years although two values worsened ("sleep" and "psychic autonomy and communication", p-values of 0.73 and 0.21 respectively) (table 7). Because of smaller patient numbers only 3 values reached statistical significance; "physical abilities" ( $p$ $<0.01)$, NHP-II $(p<0.01)$ and "mobility range" $(p<0.05)$. In patients having a reoperation after LAGB during follow up these numbers were slightly different. The reoperated patient group had more improved values that reached statistical significance (5 compared to 3 values; "physical abilities" ( $p<0.01)$, NHP-II $(p<0.01)$, "somatic autonomy" ( $p<0.05)$, "mobility control" $(p<0.05)$ and "social behavior" $(p<0.05)$ ). Overall, HRQoL results are not negatively influenced by re-operations during follow up after LAGB and appear to be even better.

\section{Quality of life assessment: what factors are of influence?}

To determine if certain factors were of significant influence on the HRQ L results Pearson's and Kendall's tau correlations were calculated. Sex, age and type of procedure (VBG or LAGB) had no significant correlation with any of the NHP-I domains, NHP-II or SIP68 categories. Also, no correlations were found between HRQoL outcome after 7 years and re-operations or conversions during follow up. The strongest correlation was found between HRQoL parameters and long term weight loss. Eight of the 13 domains were negatively correlated with weight loss after 7 years, i.e. more weight loss led to a better HRQoL score (NHP-I domains "energy level" $(P<0.01)$, "pain" $(p<0.01)$, "emotional reaction" $(p<0.05)$, "sleep" $(p<0.01)$, "social isolation $(p<0.05)$, "physical abilities" ( $p$ $<0.01)$ and SIP-68 domains "mobility control" $(p<0.01)$ and "social behaviour" $(p<$ 0.01) ). Furthermore, 11 of the $13 \mathrm{HRQoL}$ domains were positively correlated with total amount of obesity-related comorbidities, i.e. patients with more comorbidities had a higher score and thus lower quality of life. The NHP-I domains "energy level" $(p<0.01)$, "pain" ( $p<0.01)$, "sleep" ( $p<0.05)$, "social isolation" $(p<0.05)$ and "physical abilities" $(p<0.01)$, the NHP-II $(p<0.01)$ and the SIP-68 domains_"somatic autonomy" $(p<$ 0.05), "mobility control" ( $p<0.01)$, "psychic autonomy and communication" $(p<0.05)$, "social behavior" ( $p<0.01)$ and "mobility control" $(p<0.01)$ were all significantly better in patients with less comorbidities. 


\begin{tabular}{|c|c|c|c|c|c|}
\hline & $\begin{array}{c}\text { VBG } \\
\text { (preop) } \\
(n=50)\end{array}$ & $\begin{array}{c}\text { VBG } \\
\text { (non-converted) } \\
(n=14)\end{array}$ & p-value* & $\begin{array}{c}\text { VBG } \\
\text { (converted to RYGB) } \\
(\mathrm{n}=26)\end{array}$ & p-value* \\
\hline \multicolumn{6}{|l|}{ NHP-I } \\
\hline Energy level & 46.3 & 18.6 & 0.10 & 34.2 & 0.53 \\
\hline Pain & 25.8 & 18.0 & 0.94 & 14.2 & 0.10 \\
\hline Emotional reaction & 21.4 & 5.9 & 0.06 & 7.9 & 0.06 \\
\hline Sleep & 24.7 & 20.8 & 0.39 & 13.2 & 0.58 \\
\hline Social isolation & 21.0 & 4.1 & $<0.05$ & 4.7 & $<0.01$ \\
\hline Physical abilities & 30.3 & 6.2 & $<0.01$ & 12.1 & $<0.01$ \\
\hline NHP-II & 12.7 & 9.9 & $<0.01$ & 11.5 & $<0.01$ \\
\hline \multicolumn{6}{|l|}{ SIP-68 } \\
\hline Somatic autonomy & 2.7 & 2.2 & 0.86 & 3.2 & 0.28 \\
\hline Mobility control & 29.3 & 11.1 & $<0.05$ & 13.0 & $<0.05$ \\
\hline $\begin{array}{l}\text { Psychic autonomy } \\
\text { and communication }\end{array}$ & 11.1 & 6.4 & 0.74 & 19.2 & 0.20 \\
\hline Social behavior & 29.8 & 12.5 & 0.05 & 16.7 & 0.12 \\
\hline Emotional stability & 22.0 & 6.2 & 0.37 & 14.4 & 0.05 \\
\hline Mobility range & 10.1 & 1.2 & 0.07 & 4.9 & 0.12 \\
\hline
\end{tabular}

Table 6: preoperative and postoperative HRQoL results 7 year after surgery; non-converted versus converted RYGB patients

* Wilcoxon signed-ranks test 


\begin{tabular}{|c|c|c|c|c|c|}
\hline & $\begin{array}{l}\text { LAGB } \\
\text { (preop) } \\
(\mathrm{n}=50)\end{array}$ & $\begin{array}{c}\text { LAGB } \\
\text { (no re-operation) } \\
(\mathrm{n}=25)\end{array}$ & p-value* & $\begin{array}{c}\text { LAGB } \\
\text { (re-operation) } \\
(n=19)\end{array}$ & p-value* \\
\hline \multicolumn{6}{|l|}{ NHP-I } \\
\hline Energy level & 42.8 & 25.0 & 0.06 & 32.1 & 0.25 \\
\hline Pain & 19.5 & 14.2 & 0.47 & 14.0 & 0.02 \\
\hline Emotional reaction & 15.0 & 13.3 & 0.41 & 19.1 & 0.28 \\
\hline Sleep & 16.1 & 19.2 & 0.73 & 15.6 & 0.67 \\
\hline Social isolation & 16.4 & 10.8 & 0.59 & 17.1 & 0.21 \\
\hline Physical abilities & 25.0 & 9.2 & $<0.01$ & 11.5 & $<0.01$ \\
\hline NHP-II & 13.0 & 10.0 & $<0.01$ & 10.6 & $<0.01$ \\
\hline \multicolumn{6}{|l|}{ SIP-68 } \\
\hline Somatic autonomy & 3.6 & 2.2 & 0.08 & 2.0 & $<0.05$ \\
\hline Mobility control & 22.3 & 14.4 & 0.17 & 13.1 & $<0.05$ \\
\hline $\begin{array}{l}\text { Psychic autonomy } \\
\text { and communication }\end{array}$ & 8.3 & 10.9 & 0.21 & 14.3 & 0.31 \\
\hline Social behavior & 26.7 & 18.2 & 0.10 & 15.6 & $<0.05$ \\
\hline Emotional stability & 15.5 & 13.6 & 0.70 & 21.7 & 0.64 \\
\hline Mobility range & 8.0 & 2.0 & $<0.05$ & 6.5 & 0.14 \\
\hline
\end{tabular}

Table 7: preoperative and postoperative HRQoL results 7 year after surgery; LAGB patient without or with re-operation

* Wilcoxon signed-ranks test

\section{Discussion}

Morbid obesity and its related comorbidities is a worldwide epidemic. Surgery is, in contrast to conventional treatment modalities, the only treatment with a proven longlasting effect on weight and comorbidities and has a positive effect on the quality of life of patients [17, 18]. Meta-analyses have been performed and provide evidence-based data that bariatric surgery causes weight loss and a decrease in comorbidities [3, 19 , $20]$ while mortality is very low $(0.07 \%)$ in case of laparoscopic restrictive procedures [21]. Besides the physical effects, morbid obesity also influences the general well being and psyche of patients in a negative manner. Morbidly obese patients have an impaired quality of life indicated by lower values on nearly all quality of life tests compared to control groups from a normal weight population. The average mental well being of morbidly obese patients in the study by Sullivan et al. was worse compared 


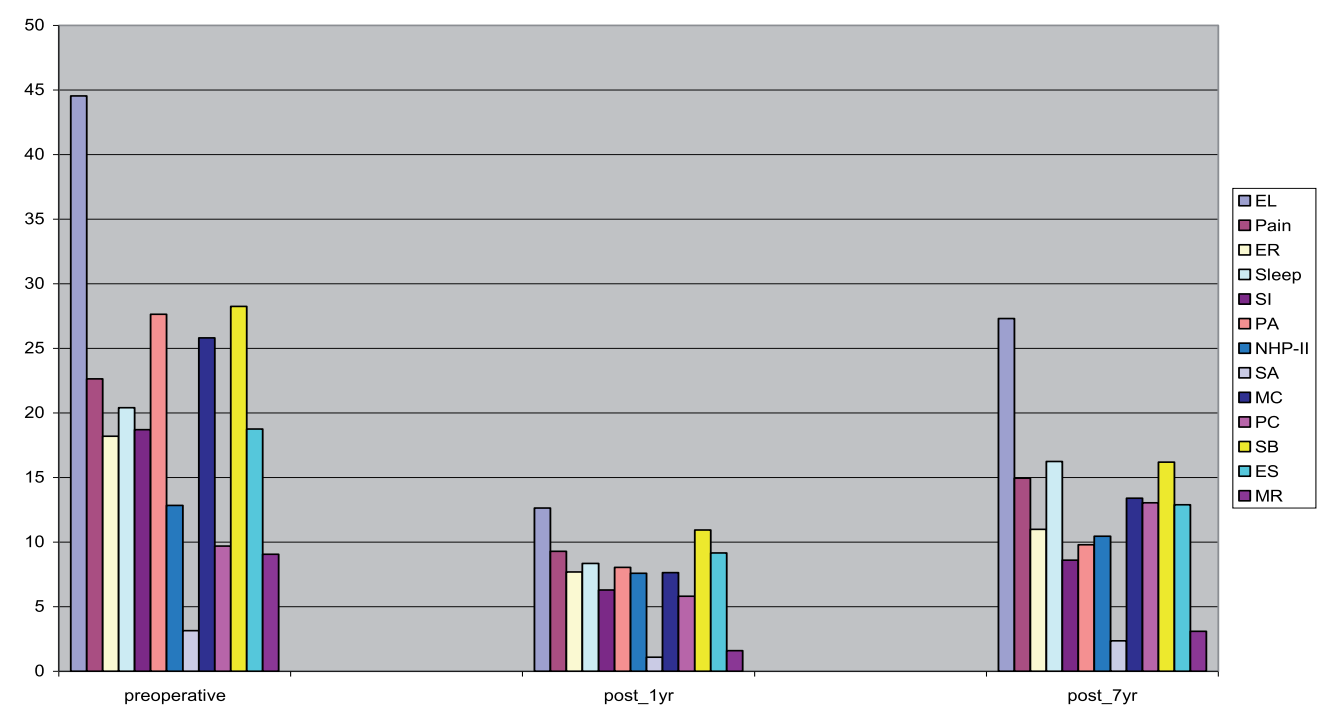

Figure 1: mean values of $\mathrm{HRQoL}$ parameters preoperatively, 1 and 7 years after restrictive procedures (VBG and LAGB, $\mathrm{n}=84$ )

$E L=$ energy level, $E R=$ emotional reaction, $\mathrm{SI}=$ social isolation, $\mathrm{PA}=$ physical abilities (all NHP-I), $\mathrm{SA}=$ somatic autonomy, $\mathrm{MC}=$ mobility control, $\mathrm{PC}=$ psychic autonomy and communication, $\mathrm{SB}=$ social behavior, $\mathrm{ES}=$ emotional stability, MR = mobility range (all SIP-68)

to chronically ill patients or cancer survivors [22]. Literature shows that surgically induced weight loss results in a better HRQoL in the short and mid term postoperative period [9, 23-26]. Studies focusing on long term HRQoL results after bariatric surgery are few. The results of the SOS study, with a follow up period of 10 years, show that improvement and deterioration of $\mathrm{HRQ}$ oL are associated with the magnitude of weight loss and weight regain, respectively [17]. The retrospective study by Mathus-Vliegen et al. showed, using the NHP-I and II questionnaires and a follow up period of 8.7 years, that quality of life was better in patients operated more than 5 years ago than patients operated less than 5 years ago. Furthermore, results were more dependent on weight loss than on time lapse [9]. De Zwaan et al. compared a group of 78 RYGB patients with 110 preoperative morbidly obese patients. Follow up period was 13.8 years and HRQoL, measured with the SF-36 (Short Form 36 Health Survey), was significantly better in the postoperative group. Especially the physical domains improved and this improvement was dependent on total weight loss [27]. The same conclusions are drawn by van Gemert et al. in their HRQoL_analysis with a follow up of 85 months [6]. Quality of 
life improvement was long lasting and solely dependent on weight loss. Similar findings are also reported by other authors [23, 24, 28-32]. On the other hand, weight loss is not the only factor influencing postoperative HRQoL. In the study by Müller et al., comparing HRQoL after LAGB and laparoscopic RYGB, other factors influenced the results (female gender, marital status and sport activities) while actual BMI and EWL were no independent factors [33]. In a study by van Hout et al., HRQoL results were also not significantly influenced by postoperative weight loss [34]. However, most reports state that improvement in HRQoL is mainly dependent on weight loss. This is confirmed in the present study; significant correlations between weight loss and improvement of 8 of the $13 \mathrm{HRQ}$ oL domains were found. The total amount of obesity-related comorbidities also had a significant correlation with $11 \mathrm{HRQ}$ oL domains, i.e. less comorbidities led to a better quality of life.

Another important phenomenon in HRQoL analysis after bariatric surgery is the peak improvement after the first postoperative year and stabilization afterwards. For example, in the SOS study, HRQoL improvement was the greatest after 1 year and stabilized after 6 to 10 years [17]. This phenomenon has been shown in other studies as well [6, 32, 34-36]. The present study shows the same trend: one year after surgery practically all values in the HRQoL analysis were significantly improved while after 7 years this was reduced to about half of the values. Therefore, although the quality of life is at its best 1 to 2 years after surgery, it remains improved after long term follow up compared to the preoperative quality of life. An illustration of this is provided in figure I. However, a major issue in comparing studies focusing on HRQoL after bariatric surgery is that a variety of questionnaires are used. This makes true comparison nearly impossible. On the other hand, all studies report improvement in HRQoL after short, mid and long term follow up compared to preoperative data independent of the used method. The method for analysis of HRQoL should however be standardized in future research to make comparison between studies possible. The Bariatric Analysis and Reporting Outcome System (BAROS) might be a good instrument because it is specifically designed to analyze HRQoL in bariatric patients and has been updated recently [37, 38].

Another aspect of bariatric surgery that is far from standardized is the operative technique. The influence of the type of surgery on HRQoL was investigated by Hell et al. They compared HRQoL at least 3 years after LAGB, VBG and RYGB. Weight loss was better after RYGB and as a consequence HRQoL using the BAROS questionnaire was also better. However, the results were positive after all procedures because LAGB and VBG patients had "very good" results and RYGB patients had "excellent" results [23]. Cross-sectional studies by van Gemert et al., comparing VBG to RYGB patients, 
showed the same results with an improvement in both quality of life parameters and psychosocial functioning in both groups $[6,8]$. A recently published randomized trial comparing laparoscopic RYGB with LAGB also showed improvement in HRQoL one year after surgery without significant differences between the procedures [39]. Finally, the study by Müller et al. compared HRQoL by use of the SF-36 and Moorhead-Ardelt II questionnaires in patients after LAGB and laparoscopic RYGB. Three years after the procedure the HRQoL indexes were similar [33]. On the other hand, a long term follow up study by Miller et al., comparing open VBG to LAGB, showed significantly better results (using the BAROS score) after a minimum follow up of 10 years in favor of the LAGB group. The explanation for this might be the higher failure rate $(12.3 \%$ versus $3.2 \%)$ and reoperation rate (40\% versus $8 \%$ ) after VBG [40]. A limitation of the latter and present study is the comparison of an open (VBG) with a laparoscopic (LAGB) approach. However, in the present study this difference in operative technique did not influence the HRQoL results, which is reported by others as well. One and 5 year follow up studies by Mathus-Vliegen et al. showed comparable HRQoL results after laparoscopic and open gastric banding $[28,29]$. In the present study the impaired quality of life preoperatively in both the VBG and LAGB group was improved overall postoperatively with minor differences in HRQoL parameters. Therefore, literature findings as well as our results indicate that the impaired quality of life in morbidly obese patients is reversed by surgically induced weight loss independent of the type and technique of the procedure. Another interesting question is whether re-operations during follow up have an influence on the HRQoL of patients. O'brien et al. reported on 25 patients who underwent a reoperation after LAGB and described a significant improvement in 7 of the 8 SF-36 scales after one year [41]. Dixon et al. described the results of more than 1000 LAGB patients. One hundred and four patients underwent revisional procedures because of band erosion and prolapse. The improvement in HRQoL, using the SF-36 questionnaire, was comparable in patients with or without re-operations during follow up visits afterwards [10]. Results from the present study also suggest that re-operations during follow up seem to be of little importance with relation to the quality of life. HRQoL parameters are comparable between patients with or without conversion to RYGB after failure of VBG. Weight loss was also comparable between these groups. Re-operated patients in the LAGB group had even more HRQoL parameters significantly improved than patients without re-operations. Weight loss was slightly better in the re-operated group (EWL $57 \%$ and $54 \%$ ). Therefore, these results only emphasize that postoperative quality of life is solely dependent on weight loss and decrease of comorbidities and not on the type of procedure or complications. 


\section{Conclusion}

Restrictive bariatric surgery improves quality of life. Although results are most impressive one year after surgery the improvement in quality of life remains significant after long term follow up. Furthermore, quality of life results are only dependent on weight loss and reduction in comorbidities and not on the type of surgery or surgical complications. 


\section{References}

1. Saxena, S. and J. Orley, Quality of life assessment: The world health organization perspective. Eur Psychiatry, 1997. 12S3: p. 263s-266s.

2. Cowan, G.S., Jr., et al., Obesity Stereotypes Among Physicians, Medical and College Students, Bariatric Surgery Patients and Families. Obes Surg, 1991. 1(2): p. 171-176.

3. Buchwald, H., et al., Bariatric surgery: a systematic review and meta-analysis. Jama, 2004. 292(14): p. 1724-37.

4. Kral, J.G., L.V. Sjostrom, and M.B. Sullivan, Assessment of quality of life before and after surgery for severe obesity. Am J Clin Nutr, 1992. 55(2 Suppl): p. 611S-614S.

5. Abiles, V., et al., Psychological Characteristics of Morbidly Obese Candidates for Bariatric Surgery. Obes Surg, 2008.

6. van Gemert, W.G., et al., Psychological functioning of morbidly obese patients after surgical treatment. Int J Obes Relat Metab Disord, 1998. 22(5): p. 393-8.

7. Steffen, R., et al., Successful multi-intervention treatment of severe obesity: a 7-year prospective study with 96\% follow-up. Obes Surg, 2009. 19(1): p. 3-12.

8. van Gemert, W.G., et al., Quality of life assessment of morbidly obese patients: effect of weight-reducing surgery. Am J Clin Nutr, 1998. 67(2): p. 197-201.

9. Mathus-Vliegen, E.M., Long-term health and psychosocial outcomes from surgically induced weight loss: results obtained in patients not attending protocolled follow-up visits. Int J Obes (Lond), 2007. 31(2): p. 299-307.

10. Dixon, J.B., M.E. Dixon, and P.E. O'Brien, Quality of life after lap-band placement: influence of time, weight loss, and comorbidities. Obes Res, 2001. 9(11): p. 713-21.

11. Nguyen, N.T., et al., Laparoscopic versus open gastric bypass: a randomized study of outcomes, quality of life, and costs. Ann Surg, 2001. 234(3): p. 279-89; discussion 289-91.

12. van Dielen, F.M., et al., Laparoscopic adjustable gastric banding versus open vertical banded gastroplasty: a prospective randomized trial. Obes Surg, 2005. 15(9): p. 1292-8.

13. Hunt, S.M., J. McEwen, and S.P. McKenna, Measuring health status: a new tool for clinicians and epidemiologists. J R Coll Gen Pract, 1985. 35(273): p. 185-8.

14. de Bruin, A.F., et al., The sickness impact profile: SIP68, a short generic version. First evaluation of the reliability and reproducibility. J Clin Epidemiol, 1994. 47(8): p. 863-71.

15. de Bruin, A.F., et al., The development of a short generic version of the Sickness Impact Profile. J Clin Epidemiol, 1994. 47(4): p. 407-18.

16. de Bruin, A.F., et al., Assessing the responsiveness of a functional status measure: the Sickness Impact Profile versus the SIP68. J Clin Epidemiol, 1997. 50(5): p. 529-40.

17. Karlsson, J., et al., Ten-year trends in health-related quality of life after surgical and conventional treatment for severe obesity: the SOS intervention study. Int J Obes (Lond), 2007. 31(8): p. 1248-61.

18. Sjostrom, L., et al., Lifestyle, diabetes, and cardiovascular risk factors 10 years after bariatric surgery. N Engl J Med, 2004. 351(26): p. 2683-93.

19. Maggard, M.A., et al., Meta-analysis: surgical treatment of obesity. Ann Intern Med, 2005. 142(7): p. 547-59.

20. O'Brien, P.E., et al., Systematic review of medium-term weight loss after bariatric operations. Obes Surg, 2006. 16(8): p. 1032-40.

21. Buchwald, H., et al., Trends in mortality in bariatric surgery: a systematic review and metaanalysis. Surgery, 2007. 142(4): p. 621-32; discussion 632-5.

22. Sullivan, M., et al., Swedish obese subjects (SOS)--an intervention study of obesity. Baseline evaluation of health and psychosocial functioning in the first 1743 subjects examined. Int J Obes Relat Metab Disord, 1993. 17(9): p. 503-12. 
23. Hell, E., et al., Evaluation of health status and quality of life after bariatric surgery: comparison of standard Roux-en-Y gastric bypass, vertical banded gastroplasty and laparoscopic adjustable silicone gastric banding. Obes Surg, 2000. 10(3): p. 214-9.

24. Kinzl, J.F., et al., Quality of life in morbidly obese patients after surgical weight loss. Obes Surg, 2007. 17(2): p. 229-35.

25. Champault, A., et al., Quality of life after laparoscopic gastric banding: Prospective study (152 cases) with a follow-up of 2 years. Surg Laparosc Endosc Percutan Tech, 2006. 16(3): p. 131-6.

26. Dziurowicz-Kozlowska, A., et al., Health-related quality of life after the surgical treatment of obesity. J Physiol Pharmacol, 2005. 56 Suppl 6: p. 127-34.

27. de Zwaan, M., et al., Health-related quality of life in morbidly obese patients: effect of gastric bypass surgery. Obes Surg, 2002. 12(6): p. 773-80.

28. Mathus-Vliegen, E.M. and L.T. de Wit, Health-related quality of life after gastric banding. $\mathrm{Br}$ J Surg, 2007. 94(4): p. 457-65.

29. Mathus-Vliegen, E.M., S. de Weerd, and L.T. de Wit, Health-related quality-of-life in patients with morbid obesity after gastric banding for surgically induced weight loss. Surgery, 2004. 135(5): p. 489-97.

30. Waaddegaard, P., T. Clemmesen, and P. Jess, Vertical gastric banding for morbid obesity: a long-term follow-up study. Eur J Surg, 2002. 168(4): p. 220-2.

31. Sanchez-Santos, R., et al., Long-term health-related quality of life following gastric bypass: influence of depression. Obes Surg, 2006. 16(5): p. 580-5.

32. Folope, V., et al., Weight loss and quality of life after bariatric surgery: a study of 200 patients after vertical gastroplasty or adjustable gastric banding. Eur J Clin Nutr, 2008. 62(8): p. 1022-30.

33. Muller, M.K., et al., Quality of life after bariatric surgery--a comparative study of laparoscopic banding vs. bypass. Obes Surg, 2008. 18(12): p. 1551-7.

34. van Hout, G.C., et al., Health-related quality of life following vertical banded gastroplasty. Surg Endosc, 2009. 23(3): p. 550-6.

35. Larsen, J.K., et al., Psychosocial functioning before and after laparoscopic adjustable gastric banding: a cross-sectional study. Obes Surg, 2003. 13(4): p. 629-36.

36. Waters, G.S., et al., Long-term studies of mental health after the Greenville gastric bypass operation for morbid obesity. Am J Surg, 1991. 161(1): p. 154-7; discussion 157-8.

37. Oria, H.E. and M.K. Moorehead, Bariatric analysis and reporting outcome system (BAROS). Obes Surg, 1998. 8(5): p. 487-99.

38. Oria, H.E. and M.K. Moorehead, Updated Bariatric Analysis and Reporting Outcome System (BAROS). Surg Obes Relat Dis, 2009. 5(1): p. 60-6.

39. Nguyen, N.T., et al., A Prospective Randomized Trial of Laparoscopic Gastric Bypass Versus Laparoscopic Adjustable Gastric Banding for the Treatment of Morbid Obesity: Outcomes, Quality of Life, and Costs. Ann Surg, 2009.

40. Miller, K., A. Pump, and E. Hell, Vertical banded gastroplasty versus adjustable gastric banding: prospective long-term follow-up study. Surg Obes Relat Dis, 2007. 3(1): p. 84-90.

41. O'Brien, P., W. Brown, and J. Dixon, Revisional surgery for morbid obesity--conversion to the Lap-Band system. Obes Surg, 2000. 10(6): p. 557-63. 

CHAPTER 3

Re-operations after restrictive procedures

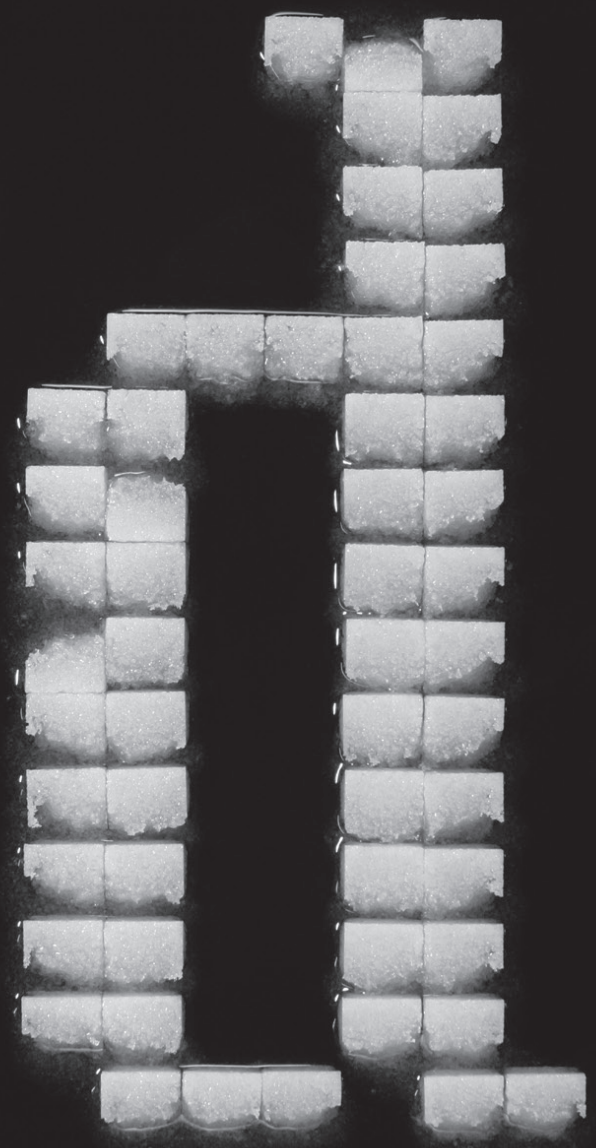


Conversion of vertical banded gastroplasty to Roux-en-Y gastric bypass results in restoration of the positive effect on weight loss and comorbidities.

Evaluation of 101 patients

Ruben Schouten

Francois M.H. van Dielen

Wim G. van Gemert

Jan Willem M Greve

Obesity Surgery 2007; May, 17(5): 622-30 


\section{Abstract}

Background: vertical banded gastroplasty (VBG) is a widely used restrictive procedure in bariatric surgery. However, the re-operation rate after this procedure is high. In case of VBG failure a conversion to Roux-en-Y gastric bypass (RYGB) is one of the possibilities. This study was performed in order to evaluate the results of the conversion from VBG to RYGB.

Methods: 101 patients had a conversion from VBG to RYGB. Patients were separated into three groups based on the indication for conversion: weight regain (group 1), excessive weight loss (group 2) and severe eating difficulties (group 3). Data for the study were collected by retrospective analysis of prospectively recorded data.

Results: weight regain (group 1) was the reason for conversion in $73.3 \%$ of patients. Stapler line disruption was the most important cause for the weight regain $(74.3 \%)$. Excessive weight loss (group 2) affected $14 \%$ of patients and was caused by outlet stenosis in $78.6 \%$ of patients. The remaining $13 \%$ had severe eating difficulties as a result of outlet stenosis (46.1\%), pouch dilatation (30.8\%) and pouch diverticula $(23.1 \%)$. Mean BMI before conversion to RYGB was 40.5, 22.3 and $29.8 \mathrm{~kg} / \mathrm{m}^{2}$ in group 1, 2 and 3 , respectively. Minor or major direct postoperative complications were observed in $2.0 \%$ to $7.0 \%$. Long-term complications were more frequent and consisted mainly of anastomotic stenosis $(22.7 \%)$ and incisional hernia $(16.8 \%)$.

Follow-up after conversion was achieved in all patients (100\%) with a mean period of 38 \pm 29 months. BMI decreased from 40.5 to $30.1 \mathrm{~kg} / \mathrm{m}^{2}$, increased from 22.3 to $25.3 \mathrm{~kg} /$ $\mathrm{m}^{2}$. and decreased slightly from 29.8 to $29.0 \mathrm{~kg} / \mathrm{m}^{2}$ in group 1,2 and 3, respectively. All patients in group 3 noticed an improvement in eating difficulties.

Conclusion: complications after conversion from failed VBG to RYGB are substantial and need to be considered. However, the conversion itself is a successful operation in terms of effect on body weight and treating eating difficulties after VBG. 


\section{Introduction}

Morbid obesity is a rapidly growing problem in western society. In the United States, $2 \%$ of men and $6 \%$ of women are morbidly obese and have a mortality rate up to 12 times greater compared to normal weight individuals [1-4]. In the Netherlands the prevalence is less disturbing but the incidence of obesity and especially morbid obesity, defined as a Body Mass Index (BMI) of $>40 \mathrm{~kg} / \mathrm{m}^{2}$ or $>35 \mathrm{~kg} / \mathrm{m}^{2}$ with obesity-related comorbidities [4] is rising progressively to $1.5 \%$ of the total population in 2004 [3].

At this moment surgical therapy is the only treatment option for these patients that results in sufficient long-term weight loss [5]. Non-surgical approaches, like low energy diets and behavior modification, are not successful in the long-term with respect to maintaining weight loss and decreasing obesity-related comorbidity [6].

Gastric restrictive surgery was introduced in the mid-1970s in the form of transverse gastroplasty and has been developed and improved since [7]. This procedure evolved to vertical banded gastroplasty (VBG) as described by Mason and others and has been performed on thousands of patients worldwide [8-11]. However, revisional surgery is often necessary after VBG with reported percentages in the literature of $10 \%$ to $41 \%$, mainly because of stoma stenosis, pouch enlargement and stapler line disruption [1217].

In case of VBG failure, conversion to another bariatric procedure is a possibility. According to the available literature, conversion to Roux-en-Y gastric bypass (RYGB) seems to have good results [16, 18-21]. The present study was conducted in order to evaluate the mid-term results of the conversion from VBG to RYGB.

\section{Patients and methods}

\section{Patients}

Between April 1988 and January 2002 a total of 288 patients underwent VBG in our clinic. All patients were between 18 and 60 years at the time of operation and had failed previous non-surgical attempts to lose weight. Patients were considered eligible if the BMI was above $40 \mathrm{~kg} / \mathrm{m}^{2}$ or above $35 \mathrm{~kg} / \mathrm{m}^{2}$ with obesity-related comorbidities. All patients treated by VBG were followed postoperatively. Between December 1996 and November 2005, a total of 101 patients had a conversion from VBG to RYGB because of weight regain, excessive weight loss or severe eating difficulties. Thirteen patients from this group (12.9\%) were referred from other hospitals. Failure rate after VBG in 
patients from our clinic was $30.6 \%$ (88 patients). Patient characteristics are listed in table 1. The patient group consisted of 15 males and 86 females with a mean age of $40.0 \pm 8.4$ years. Mean weight and BMI before VBG was $137.0 \pm 27.5 \mathrm{~kg}$ and $48.4 \pm$ $7.7 \mathrm{~kg} / \mathrm{m}^{2}$.

\section{Surgical technique}

The surgical technique of the vertical banded gastroplasty has previously been described in detail $[10,11,16]$.

Roux-en-Y gastric bypass was performed through the old upper midline incision. The operative field was freed by sharp and blunt dissection and the band was removed. In case of stapler line disruption the pouch was created with a diameter of one centimeter $(\mathrm{cm})$ and a length of five to six $\mathrm{cm}$. In other cases the existing stapler line was transected after which the pouch was trimmed by resection of excess gastric tissue with a stapler device (GIA-60; Autosuture, Zeist, the Netherlands). The latter to prevent formation of an excluded segment of stomach which can result in a mucocele. In all cases the gastric pouch was completely disconnected from the excluded stomach. Next, the jejunum was

\begin{tabular}{ll}
\hline Variables & Before VBG \\
\hline Patients $(\mathrm{N})$ & 101 \\
$\mathrm{M}: \mathrm{F}$ & $15: 86$ \\
Age $($ years $)$ & $40.0(26-64) \pm 8.4$ \\
Weight $(\mathrm{kg})$ & $137.0(90.0-229.5) \pm 27.5$ \\
BMl $\left(\mathrm{kg} / \mathrm{m}^{2}\right)$ & $48.4(35.9-74.0) \pm 7.7$ \\
\hline
\end{tabular}

Table 1: patients characteristics

transected 40 to $60 \mathrm{~cm}$ after the ligament of Treitz. The stapler line of the long limb was reinforced with a running suture and brought retrocolic and retrogastric to the gastric pouch. Through a small opening on the antimesenteric side an end-to-side gastrojejunal anastomosis was created. The Roux-en-Y reconstruction was completed with an end-toside jejunojejunal anastomosis 60 to $120 \mathrm{~cm}$ distally from the gastrojejunal anastomosis. To prevent herniation all mesenteric defects were closed with a nonabsorbable suture. The abdominal wall was closed with a running nonabsorbable suture and the skin with staplers. Due to a high anastomotic stenosis rate in patients operated before 2004 the 
operation technique was adapted in this year, where instead of a small anastomosis, calibrated with a charriere 14 nasogastric tube, a wider anastomosis was calibrated with a charriere 32 tube. This widening of the anastomosis was performed in association with placement of a silastic ring of 6 to $6.5 \mathrm{~cm}$ in diameter one $\mathrm{cm}$ proximal to the gastrojejunostomy, as described by Fobi et al $[22,23]$. The last 13 patients $(12.9 \%)$ are operated according to this technique. Patients received intravenous prophylactic antibiotics and subcutaneous heparin. Vitamin A, B, D and iron supplementation was prescribed postoperatively.

\section{Data collection}

Patients were seen on a regular basis at the outpatient clinic by the surgeon, nurse practitioner, dietician and psychologist. Necessary data for this study were collected by retrospective analysis of prospectively recorded data. In order to accomplish a complete database, questionnaires were sent to the patients to collect up-to-date information on body weight, comorbidities, complications and symptoms. Presence and resolution of obesity-related comorbodities were quantified by the use and discontinuation postoperatively of medication in case of diabetes, hypertension and hypercholesterolemia. Joint problems, asthma, GERD and depression were quantified by both history taking and medication. The presence of preoperative sleep apnea syndrome was quantified by sleep studies in all patients, the resolution postoperatively by subjective improvement of sleep and daily drowsiness and the discontinuation of the use of CPAP masks.

Patients were categorized into three groups for analysis based on the indication for conversion; Group 1: weight regain after initially successful weight loss, group 2: excessive weight los (leading to a BMI $<25$ with malnutrition (low albumin and total protein levels)) and group 3: severe eating difficulties (daily nausea, vomiting or pyrosis), gastric pain (pain in the epigastric area) or dysphagia while eating and not pre-operatively existing, continuous epigastric pain postoperatively not caused by other demonstrable problems except the operation or daily passage problems with solid food. Despite these eating difficulties, patients from group 3 had an acceptable weight loss postoperatively.

The effect of the conversion on weight loss and comorbidities was the main interest of the study. Furthermore, data were collected on the time between the operations, operation time, hospital stay, perioperative and long-term complications and reoperations performed during follow-up.

All data are reported as the mean value \pm the standard deviation. 


\section{Results}

Indications for conversion

Patients were categorized into three groups based on the indication for conversion (table 2).

\section{Group 1: weight regain}

This group consists of 74 patients $(73.3 \%)$ with initially successful weight loss after VBG but weight regain during follow-up. Causes of this weight regain were mainly stapler line disruption (74.3\%) and pouch dilatation (9.4\%), defined as increased pouch size on upper gastrointestinal series compared to the first postoperative series but without anastomotic stenosis. The size of the pouch was measured in relation to the vertebrae. Furthermore, four patients $(5.4 \%)$ were sweets eaters. Infrequent causes were outlet stenosis $(1.4 \%)$, complicated by pouch diverticula and resulting in intake of high caloric liquids, persistent retrosternal pain (1.4\%) caused by anastomotic stenosis and solid food intolerance leading to change of eating habits (high caloric liquids) and a wide outlet of the pouch $(1.4 \%)$ while in $6.7 \%$ of patients the cause remained unknown. All causes are summarized in table 3-1.

\section{Group 2: excessive weight loss}

Fourteen patients $(13.9 \%)$ had excessive weight loss after VBG for which conversion to RYGB was necessary in order to stabilize weight. The main cause for the excessive weight loss was outlet stenosis $(78.6 \%)$. One patient $(7.1 \%)$ had a pouch dilatation while in two patients (14.3\%) the cause was not established (table 3-2).

\section{Group 3: severe eating difficulties}

Thirteen patients $(12.8 \%)$ developed severe eating difficulties during follow-up after VBG. The most frequent difficulties were passage problems of solid foods (100\%), daily vomiting (92.3\%) and pyrosis (76.9\%). All eating difficulties are summarized in table 8. Weight loss was successful after VBG in this group and conversion to RYGB was performed in order to treat the symptoms. Causes of these severe eating difficulties were outlet stenosis (46.1\%), pouch dilatation (30.8\%) and pouch diverticula $(23.1 \%)$ (table 3-3). 


\begin{tabular}{ll}
\hline Indication & Patients (\%) \\
\hline Group 1: weight gain & $74(73.3 \%)$ \\
Group 2: excessive weight loss & $14(13.9 \%)$ \\
Group 3 severe eating / passage difficulties & $13(12.8 \%)$ \\
\hline
\end{tabular}

Table 2: indications for conversion from VBG to GB

\begin{tabular}{llll}
\hline Cause & Patients (N) & $\begin{array}{l}\text { Percentage } \\
\text { (of group) }\end{array}$ & $\begin{array}{l}\text { Percentage } \\
\text { (of total) }\end{array}$ \\
\hline Stapler line disruption & 55 & $74.3 \%$ & $54.5 \%$ \\
Pouch dilatation & 7 & $9.4 \%$ & $6.9 \%$ \\
Sweets eater & 4 & $5.4 \%$ & $4.0 \%$ \\
Wide outlet & 1 & $1.4 \%$ & $1.0 \%$ \\
Pouch diverticula & 1 & $1.4 \%$ & $1.0 \%$ \\
Pain & 1 & $1.4 \%$ & $1.0 \%$ \\
Unknown & 5 & $6.7 \%$ & $5.0 \%$ \\
\hline
\end{tabular}

Table 3-1: causes of VBG failure group 1: weight regain $(\mathrm{N}=74)$

\begin{tabular}{llll}
\hline Cause & Patients (N) & $\begin{array}{l}\text { Percentage } \\
\text { (of group) }\end{array}$ & $\begin{array}{l}\text { Percentage } \\
\text { (of total) }\end{array}$ \\
\hline Outlet stenosis & 11 & $78.6 \%$ & $10.9 \%$ \\
Pouch formation & 1 & $7.1 \%$ & $1.0 \%$ \\
Unknown & 2 & $14.3 \%$ & $2.0 \%$ \\
\hline
\end{tabular}

Table 3-2: causes of VBG failure group 2: excessive weight loss ( $\mathrm{N}=14$ )

\begin{tabular}{llll}
\hline Cause & Patients (N) & $\begin{array}{l}\text { Percentage } \\
\text { (of group) }\end{array}$ & $\begin{array}{l}\text { Percentage } \\
\text { (of total) }\end{array}$ \\
\hline Outlet stenosis & 6 & $46.1 \%$ & $6.0 \%$ \\
Pouch formation & 4 & $30.8 \%$ & $4.0 \%$ \\
Pouch diverticula & 3 & $23.1 \%$ & $3.0 \%$ \\
\hline
\end{tabular}

Table 3-3: causes of VBG failure group 3: severe eating problems $(N=13)$ 


\section{Operation and hospitalization details}

Mean time between VBG and conversion to RYGB was $62 \pm 50$ months for the total group (range five to 309 months). There were notable differences between the groups (table 4). Mean time between the operations was shorter in group 2 with $30 \pm 23$ months in comparison with group 1 (65 \pm 51 months) and group 3 (76 \pm 50 months).

Mean operation time was $3.7 \pm 0.9$ hours with a range from 1.9 to 6.8 hours. There were no significant differences between the groups. Cholecystectomy was performed in six patients $(5.9 \%)$ during the same operative session. In another 15 patients (14.9\%) cholecystectomy was performed during follow-up after RYGB, all because of symptomatic gallbladder stones.

Mean hospital stay after RYGB was 12 days with a wide range of three to 84 days. Patients from group 2 were relatively malnourished before the conversion to RYGB because of the excessive weight loss and five patients (36\%) received total parental nutrition for a mean ten days prior to surgery. Other patients had already started a high protein diet with vitamin and mineral supplements at home. As a result, the mean hospitalization was significantly longer in group 2 (24 days) compared to group 1 (ten days) and group 3 (eight days). Patients from group $2(\mathrm{~N}=14)$ had varying dietary deficiencies preoperatively: albumin (10), iron (10), total protein (8), magnesium (6), vitamin B1 (4), B6 (3), folic acid (3), zinc (3), copper (1) and vitamin B12 (1). The conversion was performed as soon as these deficiencies were corrected.

\begin{tabular}{lcccc}
\hline & Group 1 & Group 2 & Group 3 & Total group \\
\hline Time VBG - GB (months) & $65 \pm 51$ & $30 \pm 23$ & $76 \pm 50$ & $62(5-309) \pm 50$ \\
$\begin{array}{l}\text { Operation time } \\
\text { (hours) }\end{array}$ & $3.7 \pm 0.9$ & $3.6 \pm 0.7$ & $3.4 \pm 1.0$ & $3.7(1.9-6.8) \pm 0.9$ \\
$\begin{array}{l}\text { Cholecystectomy during } \\
\text { RYGB (N) }\end{array}$ & 3 & 1 & 2 & $6(5.9 \%)$ \\
$\begin{array}{l}\text { Cholecystectomy during } \\
\text { follow up (N) } \\
\text { Hospital stay (days) }\end{array}$ & 12 & 3 & 0 & $15(14.9 \%)$ \\
\hline
\end{tabular}

Table 4: RYGB operation details 


\section{Complications}

Forty-five patients (44.6\%) did not have any complications. Either direct postoperative and / or long-term complications occurred in 56 patients (55.4\%). Nineteen patients $(18.8 \%)$ had more than one complication.

Mortality. Two patients died after conversion from VBG to RYGB (2.0\%). These two patients had weight regain after initially successful weight loss; a cause was not found. Both developed a severe sepsis postoperatively; one due to leakage at the gastrojejunostomy and one due to a small bowel laceration probably brought on by release of adhesions.

Major direct postoperative complications. Anastomotic leakages, treated conservatively or operatively depending on the clinical condition of the patient, occurred in respectively $2.0 \%$ and $4.0 \%$ of the patients (table 5 ). Intraabdominal abscess formation and internal herniation also occurred in $2.0 \%$ and $4.0 \%$, respectively. Intraabdominal abscesses were treated by $(\mathrm{CT})$ guided percutaneous punction and drainage. Internal herniation was treated during re-laparotomy by closure of mesenterial defects.

\begin{tabular}{|c|c|c|c|c|}
\hline Complication & Group $1(\mathrm{~N}=74)$ & Group $2(\mathrm{~N}=14)$ & Group $3(N=13)$ & Total $(\mathrm{N}=101)$ \\
\hline Anastomotic stenosis & $10(13.5 \%)$ & $9(64.3 \%)$ & $4(30.8 \%)$ & $23(22.7 \%)$ \\
\hline $\begin{array}{l}\text { Anastomotic leakage } \\
\text { (operative) }\end{array}$ & $2(2.7 \%)$ & $2(14.3 \%)$ & 0 & $4(4.0 \%)$ \\
\hline $\begin{array}{l}\text { Anastomotic leakage } \\
\text { (conservative) }\end{array}$ & $2(2.7 \%)$ & 0 & 0 & $2(2.0 \%)$ \\
\hline Intraabdominal abscess & 1 (1.4\%) & $1(7.1 \%)$ & 0 & $2(2.0 \%)$ \\
\hline Wound abscess & $6 \quad(8.1 \%)$ & $1(7.1 \%)$ & 0 & $7 \quad(7.0 \%)$ \\
\hline Wound infection & $1(1.4 \%)$ & 0 & $1(7.7 \%)$ & $2(2.0 \%)$ \\
\hline Urine tract infection & $3(4.1 \%)$ & $1(7.1 \%)$ & $2(15.4 \%)$ & $6 \quad(6.0 \%)$ \\
\hline Pneumonia & $2(2.7 \%)$ & 0 & 0 & $2(2.0 \%)$ \\
\hline Incisional hernia & $14(18.9 \%)$ & $1(7.1 \%)$ & $2(15.4 \%)$ & $17(16.8 \%)$ \\
\hline Internal herniation & $1(1.4 \%)$ & $2(14.3 \%)$ & $1(7.7 \%)$ & $4(4.0 \%)$ \\
\hline Death & $2(2.7 \%)$ & 0 & 0 & $2(2.0 \%)$ \\
\hline
\end{tabular}

Table 5: complications after RYGB 
Minor direct postoperative complications. Wound abscess (7.0\%), urinary tract infection $(6.0 \%)$, pneumonia $(2.0 \%)$ and wound infection $(2.0 \%)$ were all treated without reoperation by antibiotics and wound / abscess drainage on the surgical ward.

Long-term complications. During the follow-up 23 patients $(22.7 \%)$ developed an anastomotic stenosis. In group 2, 64.3\% of the patients had an anastomotic stenosis compared to $13.5 \%$ in group 1 and $30.8 \%$ in group 3 . Since the introduction of the larger anastomosis with a silastic ring around the pouch (Fobi-Pouch), a technique used in the last 13 patients, no more anastomotic stenosis have been observed. All stenosis were treated by endoscopic dilatation. The mean number of endoscopic dilatations was $2 \pm 1$ sessions with a range of one to four sessions.

Seventeen patients (16.8\%) developed an incisional hernia during follow-up. Patients from group 1 had more incisional hernias (18.9\%) compared to patients from group 2 $(7.1 \%)$ and $3(15.4 \%)$. All were treated by surgical correction using mesh repair.

\section{Effect on body weight}

Follow-up after conversion was achieved in all patients (100\%) with a mean period of 38 \pm 29 months. In group 2 the follow-up period was longer with $48 \pm 34$ months compared to $39 \pm 29$ and $24 \pm 20$ months for group 1 and 3 .

Group 1 had a mean weight and BMI before VBG of $139 \pm 28 \mathrm{~kg}$ and $49.6 \pm 8.0 \mathrm{~kg} / \mathrm{m}^{2}$, respectively (table 6). These patients initially had successful weight loss after VBG. The lowest mean weight and BMl during follow-up was $84 \pm 19 \mathrm{~kg}$ and $30.4 \pm 6.5 \mathrm{~kg} / \mathrm{m}^{2}$. Patients had weight regain leading to a mean weight and BMI of $113 \pm 23 \mathrm{~kg}$ and 40.5 $\pm 7.1 \mathrm{~kg} / \mathrm{m}^{2}$ before the conversion. RYGB led to a successful weight loss with a mean weight and $\mathrm{BMI}$ of $83 \pm 23 \mathrm{~kg}$ and $30.1 \pm 8.4 \mathrm{~kg} / \mathrm{m}^{2}$, comparable to the maximum weight loss after VBG.

Group 2 had a mean weight and BMI before VBG of $134 \pm 27 \mathrm{~kg}$ and $45.1 \pm 5.1 \mathrm{~kg} / \mathrm{m}^{2}$, respectively. This group lost significant weight in a relatively short period. In order to prevent further weight loss and serious malnutrition, conversion to RYGB was performed when weight and BMI were $69 \pm 15 \mathrm{~kg}$ and $22.3 \pm 4.8 \mathrm{~kg} / \mathrm{m}^{2}$. After a mean follow-up period of 48 months, weight and BMI were increased and stabilized at $75 \pm 15 \mathrm{~kg}$ and $25.3 \pm 5.2 \mathrm{~kg} / \mathrm{m}^{2}$.

Group 3 had a mean weight and BMI before VBG of $127 \pm 24 \mathrm{~kg}$ and $44.7 \pm 6.8 \mathrm{~kg} /$ $\mathrm{m}^{2}$, respectively. RYGB was performed in order to treat symptoms while weight loss was satisfactory after VBG (mean BMI of $29.8 \pm 7.9 \mathrm{~kg} / \mathrm{m}^{2}$ ). After conversion to RYGB, weight and BMI remained stable at $82 \pm 17 \mathrm{~kg}$ and $29.0 \pm 5.0 \mathrm{~kg} / \mathrm{m}^{2}$. 


\section{Effect on comorbidities}

After VBG and before the conversion to RYGB, comorbidities were already decreased because of the overall weight loss (table 7). For example, diabetes already dissolved in 4 of the 5 patients and hypertension in 10 of the 22 patients. Parallel to the weight loss after conversion to RYGB, obesity-related comorbidities decreased further in group 1. There was a continuous decrease in comorbidities after the conversion but numbers are small because of the already substantial decrease after VBG. Diabetes and sleep apnea syndrome completely dissolved after RYGB while hypertension, hypercholesterolemia, joint problems, asthmatic complaints, GERD and depression all improved further.

\begin{tabular}{lcccc}
\hline & Group 1 $(\mathbf{N}=\mathbf{7 4})$ & Group 2 $(\mathbf{N}=\mathbf{1 4})$ & Group 3 (N=13) & Total \\
\hline $\begin{array}{l}\text { Follow up after RYGB } \\
\text { (months) }\end{array}$ & $39 \pm 29$ & $48+34$ & $24 \pm 20$ & $38 \pm 29$ \\
$\begin{array}{l}\text { Weight before VBG } \\
(\mathrm{kg})\end{array}$ & $139 \pm 28$ & $134 \pm 27$ & $127 \pm 24$ & $137 \pm 27.5$ \\
$\begin{array}{l}\text { BMl before VBG } \\
\left(\mathrm{kg} / \mathrm{m}^{2}\right)\end{array}$ & $49.6 \pm 8.0$ & $45.1 \pm 5.1$ & $44.7 \pm 6.8$ & $48.4 \pm 7.7$ \\
$\begin{array}{l}\text { Weight before RYGB } \\
(\mathrm{kg})\end{array}$ & $113 \pm 23$ & $69 \pm 19.5$ & $83 \pm 24$ & \\
$\begin{array}{l}\text { BMl before RYGB } \\
\left(\mathrm{kg} / \mathrm{m}^{2}\right)\end{array}$ & $40.5 \pm 7.1$ & $22.3 \pm 4.8$ & $29.8 \pm 7.9$ & \\
$\begin{array}{l}\text { Final weight } \\
(\mathrm{kg})\end{array}$ & $83 \pm 23$ & $75 \pm 15$ & $82 \pm 17$ & - \\
$\begin{array}{l}\text { Final BMI } \\
\left(\mathrm{kg} / \mathrm{m}^{2}\right)\end{array}$ & $30.1 \pm 8.4$ & $25.3 \pm 5.2$ & $29.0 \pm 5.0$ & - \\
\hline
\end{tabular}

Table 6: body weight before VBG, before and after RYGB

\begin{tabular}{|c|c|c|c|}
\hline Comorbidity & Before VBG & Before RYGB & After RYGB \\
\hline Diabetes & $5(6.8 \%)$ & $1(1.4 \%)$ & $0 \quad(0 \%)$ \\
\hline Hypertension & $22(29.7 \%)$ & $12(16.2 \%)$ & $2(2.7 \%)$ \\
\hline Hypercholesterolemia & $5(6.8 \%)$ & $2(2.7 \%)$ & 1 (1.4\%) \\
\hline Sleep apnea syndrome & $7(9.5 \%)$ & $2(2.7 \%)$ & $0 \quad(0 \%)$ \\
\hline Joint problems & $41(55.4 \%)$ & $30(40.5 \%)$ & $13(17.6 \%)$ \\
\hline Asthmatic complaints & $12(16.2 \%)$ & $7(9.5 \%)$ & $1(1.4 \%)$ \\
\hline GERD & $13(17.6 \%)$ & $15(20.3 \%)$ & $8(10.8 \%)$ \\
\hline Depression & $22(29.7 \%)$ & $20(27.0 \%)$ & $11(14.9 \%)$ \\
\hline
\end{tabular}

Table 7: obesity-related comorbidities before VBG, before and after RYGB ( group $1 ; \mathrm{N}=74$ ) 


\section{Effect on patients' symptoms}

Patients from group 3 were specifically operated in order to treat symptoms caused by complications of the VBG while weight loss was already satisfactory. All symptoms consisted of upper abdominal complaints: nausea, vomiting, pyrosis, gastric and eating pain, dysphagia and eating difficulties. The presence of symptoms before and after conversion to RYGB is described in table 8. All were significantly improved after the conversion.

\begin{tabular}{lcc}
\hline Symptoms & Before RYGB & After RYGB \\
\hline Nausea & $6(46.2 \%)$ & $1(7.7 \%)$ \\
Vomiting & $12(92.3 \%)$ & $1(7.7 \%)$ \\
Pyrosis & $10(76.9 \%)$ & $2(15.4 \%)$ \\
Gastric pain & $7(53.8 \%)$ & $2(15.4 \%)$ \\
Dysphagia & $3(23.1 \%)$ & $1(7.7 \%)$ \\
Pain (while eating) & $7(53.8 \%)$ & $2(15.4 \%)$ \\
Passage problem & $13(100 \%)$ & $2(15.4 \%)$ \\
\hline
\end{tabular}

Table 8: patients' symptoms before and after RYGB (group 3; $\mathrm{N}=13$ )

\section{Revisional surgery after conversion to RYGB}

Seven patients $(6.9 \%)$ needed revisional surgery after conversion from VBG to RYGB after a mean period of 32 months. All patients were from group 1. Five patients again developed a significant weight regain after initially successful weight loss. In four patients, three with initially stapler line disruption and one a sweets eater as the indication for conversion, the RYGB was converted to a distal RYGB with a common channel of one to 1.5 meters. In one patient with spinal cord injury and permanent immobility an adjustable gastric band was placed around the gastric pouch in order to initialize more weight loss but minimize the chance on diarrhea. Furthermore, one patients developed late internal herniation. During elective re-operation $20 \mathrm{~cm}$ of jejunum was resected and a new gastrojejunostomy was created. The seventh patient complained of severe eating difficulties caused by anastomotic stenosis. After 3 endoscopic dilatations the symptoms remained unchanged. During elective re-operation a thorough adhesiolysis was performed and the anastomosis was disconnected and transected. A new and wider gastrojejunostomy was created. In the last three patients the initial indication for 
conversion from VBG to RYGB was pouch dilatation and two patients with stapler line disruption, respectively.

\section{Discussion}

After the introduction of vertical banded gastroplasty [24] thousands of morbidly obese patients have been treated with this restrictive procedure. Long-term follow-up studies of VBG report a variable success rate in terms of maintenance of weight loss. Balsiger et al. found a maintenance of at least $50 \%$ excess weight loss ( $\% \mathrm{EWL})$ ten years after VBG in only $26 \%$ of the patients while Sugerman et al. reported an \%EWL three years after VBG of only $38 \%[25,26]$. The patient group of van Dielen et al. had a better $\%$ EWL of $70 \%$ after one year but the mean weight slightly increased again after two years [27]. This observation of weight regain after initial successful weight loss is also described by Nilsell et al [28]. There are however reports that show much better results of VBG with weight control in $80 \%$ of patients without revisional surgery [29].

Besides the variable success on weight loss in the long-term, a number of patients develop symptoms or complications after VBG that require revisional surgery. Wellknown postoperative problems are frequent vomiting, GERD, maladaptive eating pattern leading to weight regain ("sweets eaters") and food intolerance caused by the restriction $[13,19,23]$. A report from Balsiger et al. showed GERD to rise from 15\% preoperatively to $38 \%$ postoperatively. Furthermore, after a follow-up period of at least ten years, $30 \%$ of patients had a maladaptive eating pattern while $22 \%$ had more than one vomiting episode per week [25, 30].

As a result of unsatisfactory weight loss and / or unacceptable side effects and complications, revisional surgery after VBG is common. The reported incidence is $10 \%$ to $41 \%$ but strongly dependent on the duration and completeness of follow-up [12-17]. In case of revisional surgery after VBG several options are possible. A restoration of VBG (re-VBG) is the first option. However, literature has shown that this restoration is not always successful. Van Gemert et al. reported that after re-VBG, using a Kaplan-Meyer analysis, $68 \%$ of the patients needed further revisional surgery because of complications or unsatisfactory weight loss [16]. Other authors have reported similar poor results of reVBG [18, 20, 31-34]. Another option is conversion to adjustable gastric banding (AGB). Taskin et al. reported seven patients who underwent this conversion and achieved satisfactory results, comparable with results after primary AGB [35]. However, because of the same restrictive nature of the procedure, complications like gastro- esophageal 
reflux and maladaptive eating patterns will prevail after the conversion. Additional data about the results of the conversion from VBG to AGB are not yet available. Results of the conversion from VBG to RYGB are described more frequently. Sugerman et al. reported on 53 patients where \%EWL increased from $36 \%$ to $67 \%$ after the conversion. Results were even better in "sweets eaters"; \%EWL increased from $20 \%$ to $70 \%$ in this patient group [18]. The patient group of Cordera et al. showed a decrease in BMI of $46 \mathrm{~kg} / \mathrm{m}^{2}$ before conversion to $35 \mathrm{~kg} / \mathrm{m}^{2}$ afterwards. Also, comorbidities diminished and subjective patient satisfaction was $90 \%$ [19]. Kfoury et al. performed a distal RYGB in 45 patients after failed VBG. Results after a follow-up period of at least two years were available for 29 patients and \%EWL was $74 \%$ in this group [20]. The conversion led to a decrease in BMI from $40 \mathrm{~kg} / \mathrm{m}^{2}$ to $32 \mathrm{~kg} / \mathrm{m}^{2}$ at 16 months postoperatively in the group described by Gonzalez et al. [21]. Based on these literature findings conversion to RYGB seems to be the most successful treatment option in case of failed VBG, at least in terms of postoperative weight loss. However, our data show that the effect on weight is strongly dependent on the indication for the conversion. In patients with weight regain after initially successful VBG the mean BMI decreased from $40.5 \pm 7.1 \mathrm{~kg} / \mathrm{m}^{2}$ to $30.1 \pm 8.4$ $\mathrm{kg} / \mathrm{m}^{2}$. In contrast, patients who experienced excessive weight loss after VBG showed a slight increase in BMI while in patients with acceptable weight loss but severe eating difficulties BMI remained stable. The latter group underwent the conversion specifically in order to treat symptoms caused by failed VBG. In the study by Sugerman et al. the conversion led to a relief of symptoms in 23 patients with intractable vomiting or GERD [18]. In the study by Kfoury et al. ten patients were included with symptoms of GERD. Conversion led to a reduction of symptoms in all patients [20]. Balsiger et al. performed 25 conversions on patients with severe GERD after VBG. At follow-up after 37 months all patients were free of symptoms [30]. Results from the present study support these literature findings; In group 3, all patients had severe eating difficulties after VBG along with a range of gastrointestinal complaints. All symptoms significantly decreased after the conversion.

Other important aspects of revisional bariatric surgery are early and long term morbidity and mortality, which tend to be higher than after primary bariatric surgery. Reported postoperative mortality after revisional bariatric surgery is $0-2 \%[20,31-34,36,37]$. The overall morbidity rate is $12 \%$ to $41 \%$ and strongly dependent on the completeness and duration of follow-up [20, 31-34, 36, 37]. In the present study follow-up was $100 \%$ with a mean duration of 38 months. A low rate of perioperative complications was found ( $2 \%$ to $7 \%$ ) but long-term complications, such as anastomotic stenosis and incisional 
hernia occurred in $22.7 \%$ and $16.8 \%$, respectively. This high incidence of long-term complications is however within the range of literature findings where anastomotic stenosis is observed in $4 \%$ to $38 \%$ and incisional hernia in $2 \%$ to $20 \%[12,16,18,19$, $21,30]$. The number of hernias could decrease if the conversion from VBG to RYGB is performed by laparoscopy. Gagner et al. have performed 24 laparoscopic gastric bypasses as a revisional procedure after failed bariatric surgery; 12 patients in this group had failed VBG. Results show longer operation time but shorter hospital stay and a morbidity rate of $22 \%$. Secondary revisional surgery was necessary in $14.8 \%$ [38]. Reports by McCormick et al. and de Csepel et al. support these findings although their patient groups were small $(\mathrm{N}=5$ and $\mathrm{N}=7)[39,40]$. Future studies will have to prove whether laparoscopic revisional surgery after failed VBG is comparable with open revisional procedures in terms of results, safety and feasibility.

\section{Conclusion}

Revisional bariatric surgery has a high risk of (long term) complications and this has to be considered by the surgical team before this kind of procedure is performed. Taking this into account, conversion from failed VBG to RYGB is a successful operation. Results are strongly dependent on the indication for conversion but the desired effect on weight and patients' symptoms is achieved. 


\section{References}

1. Drenick, E.J., Definition and health consequences of morbid obesity. Surg Clin North Am, 1979. 59(6): p. 963-76.

2. Martin, L.F., et al., Severe obesity: expensive to society, frustrating to treat, but important to confront. South Med J, 1995. 88(9): p. 895-902.

3. Kemper, H.C., M. Stasse-Wolthuis, and W. Bosman, The prevention and treatment of overweight and obesity. Summary of the advisory report by the Health Council of The Netherlands. Neth J Med, 2004. 62(1): p. 10-7.

4. Obesity: preventing and managing the global epidemic. Report of a WHO consultation. World Health Organ Tech Rep Ser, 2000. 894: p. i-xii, 1-253.

5. Fisher, B.L. and P. Schauer, Medical and surgical options in the treatment of severe obesity. Am J Surg, 2002. 184(6B): p. 9S-16S.

6. Bjorntorp, P., Results of conservative therapy of obesity: correlation with adipose tissue morphology. Am J Clin Nutr, 1980. 33(2 Suppl): p. 370-5.

7. Printen, K.J. and E.E. Mason, Gastric surgery for relief of morbid obesity. Arch Surg, 1973. 106(4): p. 428-31.

8. Gomez, C.A., Gastroplasty in the surgical treatment of morbid obesity. Am J Clin Nutr, 1980. 33(2 Suppl): p. 406-15.

9. Deitel, M. and S.A. Shikora, The development of the surgical treatment of morbid obesity. J Am Coll Nutr, 2002. 21(5): p. 365-71.

10. Eckhout, G.V., O.L. Willbanks, and J.T. Moore, Vertical ring gastroplasty for morbid obesity. Five year experience with 1,463 patients. Am J Surg, 1986. 152(6): p. 713-6.

11. Mason, E.E., et al., Vertical gastroplasty: evolution of vertical banded gastroplasty. World J Surg, 1998. 22(9): p. 919-24.

12. MacLean, L.D., B.M. Rhode, and R.A. Forse, Late results of vertical banded gastroplasty for morbid and super obesity. Surgery, 1990. 107(1): p. 20-7.

13. Nightengale, M.L., et al., Prospective evaluation of vertical banded gastroplasty as the primary operation for morbid obesity. Mayo Clin Proc, 1991. 66(8): p. 773-82.

14. Naslund, E., et al., Seven year results of vertical banded gastroplasty for morbid obesity. Eur J Surg, 1997. 163(4): p. 281-6.

15. Hall, J.C., et al., Gastric surgery for morbid obesity. The Adelaide Study. Ann Surg, 1990. 211(4): p. 419-27.

16. van Gemert, W.G., et al., Revisional surgery after failed vertical banded gastroplasty: restoration of vertical banded gastroplasty or conversion to gastric bypass. Obes Surg, 1998. 8(1): p. 21-8.

17. van Gemert, W.G., J.W. Greve, and P.B. Soeters, Long-term results of vertical banded gastroplasty: Marlex versus Dacron banding. Obes Surg, 1997. 7(2): p. 128-35.

18. Sugerman, H.J., et al., Conversion of failed or complicated vertical banded gastroplasty to gastric bypass in morbid obesity. Am J Surg, 1996. 171(2): p. 263-9.

19. Cordera, F., et al., Unsatisfactory weight loss after vertical banded gastroplasty: is conversion to Roux-en-Y gastric bypass successful? Surgery, 2004. 136(4): p. 731-7.

20. Kfoury, E. and A. Vanguri, Distal Roux-en-Y Gastric Bypass Conversion Operation for Failed Vertical Banded Gastroplasty. Obes Surg, 1993. 3(1): p. 41-43.

21. Gonzalez, R., et al., Operative technique for converting a failed vertical banded gastroplasty to Roux-en-Y gastric bypass. J Am Coll Surg, 2005. 201(3): p. 366-74.

22. Fobi, M.A., Placement of the GaBP ring system in the banded gastric bypass operation. Obes Surg, 2005. 15(8): p. 1196-201. 
23. Fobi, M.A. and H. Lee, The surgical technique of the Fobi-Pouch operation for obesity (the transected silastic vertical gastric bypass). Obes Surg, 1998. 8(3): p. 283-8.

24. Mason, E.E., Vertical banded gastroplasty for obesity. Arch Surg, 1982. 117(5): p. 701-6.

25. Balsiger, B.M., et al., Ten and more years after vertical banded gastroplasty as primary operation for morbid obesity. J Gastrointest Surg, 2000. 4(6): p. 598-605.

26. Sugerman, H.J., J.V. Starkey, and R. Birkenhauer, A randomized prospective trial of gastric bypass versus vertical banded gastroplasty for morbid obesity and their effects on sweets versus non-sweets eaters. Ann Surg, 1987. 205(6): p. 613-24.

27. van Dielen, F.M., et al., Laparoscopic adjustable gastric banding versus open vertical banded gastroplasty: a prospective randomized trial. Obes Surg, 2005. 15(9): p. 1292-8.

28. Nilsell, K., et al., Prospective randomised comparison of adjustable gastric banding and vertical banded gastroplasty for morbid obesity. Eur J Surg, 2001. 167(7): p. 504-9.

29. Mason, E.E., Gastric surgery for morbid obesity. Surg Clin North Am, 1992. 72(2): p. 50113.

30. Balsiger, B.M., et al., Gastroesophageal reflux after intact vertical banded gastroplasty: correction by conversion to Roux-en-Y gastric bypass. J Gastrointest Surg, 2000. 4(3): p. 27681.

31. Sugerman, H.J. and J.L. Wolper, Failed gastroplasty for morbid obesity. Revised gastroplasty versus Roux-Y gastric bypass. Am J Surg, 1984. 148(3): p. 331-6.

32. Benotti, P.N. and R.A. Forse, Safety and long-term efficacy of revisional surgery in severe obesity. Am J Surg, 1996. 172(3): p. 232-5.

33. Linner, J.H. and R.L. Drew, Reoperative surgery--indications, efficacy, and long-term followup. Am J Clin Nutr, 1992. 55(2 Suppl): p. 606S-610S.

34. Behrns, K.E., et al., Reoperative bariatric surgery. Lessons learned to improve patient selection and results. Ann Surg, 1993. 218(5): p. 646-53.

35. Taskin, M., et al., Conversion of failed vertical banded gastroplasty to open adjustable gastric banding. Obes Surg, 2001. 11(6): p. 731-4.

36. Cates, J.A., et al., Reoperative surgery for the morbidly obese. A university experience. Arch Surg, 1990. 125(10): p. 1400-3; discussion 1403-4.

37. Yale, C.E., Conversion surgery for morbid obesity: complications and long-term weight control. Surgery, 1989. 106(3): p. 474-80.

38. Gagner, M., et al., Laparoscopic reoperative bariatric surgery: experience from 27 consecutive patients. Obes Surg, 2002. 12(2): p. 254-60.

39. McCormick, J.T., et al., Laparoscopic revision of failed open bariatric procedures. Surg Endosc, 2003. 17(3): p. 413-5.

40. de Csepel, J., R. Nahouraii, and M. Gagner, Laparoscopic gastric bypass as a reoperative bariatric surgery for failed open restrictive procedures. Surg Endosc, 2001. 15(4): p. 393-7. 

Re-operation after laparoscopic adjustable gastric banding leads to a further decrease in BMI and obesity-related comorbidities:

long-term results of $\mathbf{3 3}$ patients

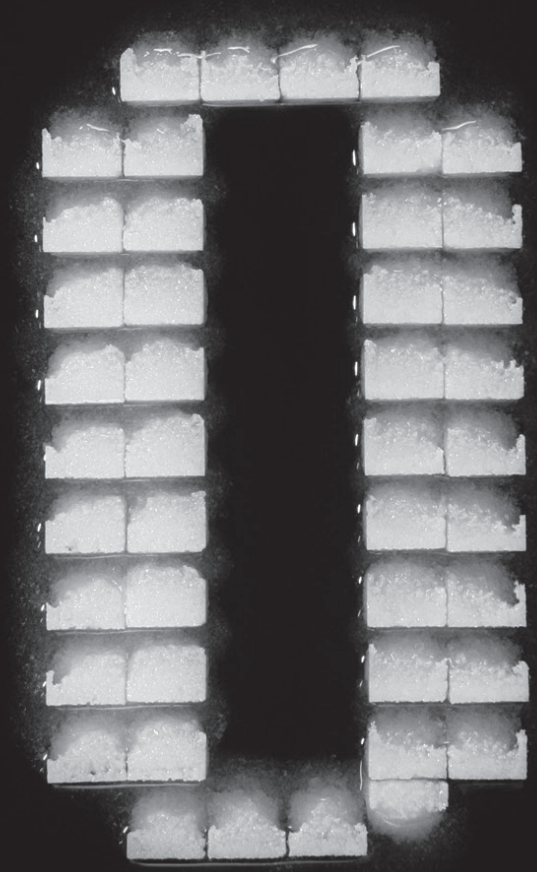

Ruben Schouten

Francois M.H. van Dielen

Jan Willem M. Greve

Obesity Surgery 2006; July, 16: 821-28 


\begin{abstract}
Introduction: laparoscopic adjustable gastric banding (LAGB) is a safe technique with few direct postoperative complications. However, long-term complications such as slippage and pouch dilatation are a well-known problem and re-operations are necessary in a substantial number of patients. In this study, the results of laparoscopic re-operations after LAGB are evaluated.
\end{abstract}

Methods: thirty-three patients had a re-operation because of failed LAGB. Twentynine patients had major re-operation and 4 patients minor re-operation under local anesthesia. The charts of these patients were retrospectively studied.

Results: mean time between the first band placement and re-operation was $28.1 \pm 17.6$ months. The cause of band dysfunction was anterior slippage $(n=17)$, band erosion $(n=5)$, band intolerance $(n=3)$, posterior slippage $(n=2)$ and band leakage $(n=2)$. Symptoms of band dysfunction were vomiting $(n=16)$, pyrosis $(n=13)$, nausea $(n=8)$, retrosternal pain $(n=11)$ and regurgitation $(n=5)$. Laparoscopic refixation of the band was performed in 19 patients. The band was replaced in 4 patients while in one patient the band was removed. In 3 patients the laparoscopic procedure was converted to open surgery. Five patients underwent conversion to a bypass procedure (biliopancreatic diversion in 3 patients and gastric bypass in 2 patients). There were no direct postoperative complications except for wound infections $(n=2)$. Postoperative follow-up was $100 \%$ with a mean period of $34 \pm 19$ months. BMI decreased further from $37.5 \pm 6.4 \mathrm{~kg} / \mathrm{m}^{2}$ before re-operation to 33 $\pm 7 \mathrm{~kg} / \mathrm{m}^{2}$. Obesity-related comorbidity also decreased further or completely dissolved. Three patients (9\%) again developed anterior slippage and a second laparoscopic reoperation was necessary.

Conclusion: a laparoscopic re-operation in case of band-related complications after LAGB is safe and feasible. In case of band slippage, a laparoscopic refixation was possible in $89 \%$. Re-operation leads to further decrease in BMI and obesity - related comorbidities. 


\section{Introduction}

Morbid obesity is a major problem in western society. The comorbidities associated with obesity are responsible for a reduced life expectancy and include type 2 diabetes mellitus, hypertension, hyperlipidemia, heart disease, stroke, asthma, several forms of cancer and joint degenerative diseases [1-4]. In the morbidly obese patient, diet therapy and other supportive lifestyle adjustments are not effective to sustain an acceptable body weight in a long-term manner [1,5].

At this moment, surgical therapy like gastric restrictive surgery or intestinal malabsorptive procedures is the only treatment option for these patients [5].

Atype of gastric restrictive surgery which gained interest the last few years is laparoscopic adjustable gastric banding (LAGB) [6, 7].

According to a meta-analysis by Buchwald et al. this procedure causes a significant decrease of BMI with an average of $10.4 \mathrm{~kg} / \mathrm{m}^{2}$ after 2 years, resulting in a significant reduction in obesity-related comorbidity [1]. LAGB is considered to be a safe technique with a low incidence of perioperative complications. However, in comparison with other bariatric procedures, the necessity of a re-operation after LABG is relatively high, mainly due to slippage or pouch dilatation $[5,8,9]$. Other complications like band erosion, band leakage and access port problems are also reported [10-12].

Little is known about the outcome of re-operations after LAGB. In this study, re-operations after LAGB due to band- or port-related problems were evaluated. Our main interest was to study whether re-operations after LAGB led to a further decrease of BMI and improvement of obesity-related comorbidity. Furthermore, early and late complications after these re-operations were assessed.

\section{Patients and methods}

\section{Patients}

In the period from December 1996 to December 2004, a total of 177 patients were operated for morbid obesity with LAGB. All patients were between 18 and 60 years and had failed previous non-surgical attempts to lose weight. Patients were considered eligible if BMI was above $40 \mathrm{~kg} / \mathrm{m}^{2}$ or above $35 \mathrm{~kg} / \mathrm{m}^{2}$ with comorbidities.

During follow up, 33 patients underwent a re-operation. Twenty-nine patients had band-related problems and 4 patients specific port-related problems. Consequently, 29 patients had major re-operation and 4 patients had minor re-operation under local 
anesthesia, all performed by one surgeon (JG). Causes of failure were variable and will be discussed in the paragraph "follow up period after initial operation".

\section{Surgical technique: initial operation}

Laparoscopic gastric banding (Lap-Band, INAMED Health, Santa Barbara, CA) was performed through five abdominal trocars. Intraabdominal pressure was maintained at $14 \mathrm{mmHg}$. The band was placed around the uppermost part of the stomach and fixed with three or four sutures at the ventral aspect of the greater curvature of the stomach. Between January 1997 and March 2001 a total of 57 patients were operated according to the classical perigastric procedure [13]. From March 2001 to December 2004, 120 patients were operated using the pars flaccida technique [14].

At 6 weeks postoperatively the band was insufflated for the first time when weight loss was insufficient (<0.5 kilogram per week). All band adjustments were performed after radiological imaging of the band with the use of contrast agent in order to inspect the pouch.

\section{Surgical technique: re-operations}

During the re-operations the operative setting was the same as during the initial laparoscopic band placement. Depending on the cause of dysfunction, a laparoscopic refixation of the band, replacement of the band or a conversion to a bypass procedure (biliopancreatic diversion (BPD) or gastric bypass (GB)) was performed.

After adhesiolysis of the band, repositioning of the slipped fundus to the correct position was performed followed by refixation with 4 non-absorbable sutures. In case of band replacement, the band was first fully mobilized before removal. All bands were replaced according to the pars flaccida technique.

All specific port problems were treated in an outpatient setting under local anesthesia. The techniques of open BPD and open GB are described elsewhere [15, 16]. Recently, we started to perform these procedures also laparoscopically.

\section{Data collection}

The charts of the patients were retrospectively studied and data about age, gender, BMI and comorbidities was assessed. All data was separated into 3 different time categories: before the initial operation, before the re-operation and after the re-operation. Furthermore, data about the period between the initial operation and the re-operation, 
causes and symptoms of dysfunctional LAGB as well as early and late results after laparoscopic re-operation were evaluated.

All data are reported as mean and standard deviation.

\section{Results}

Initial parameters

From 1997 to 2004 a total of 177 patients were operated of whom 26 patients $(14.7 \%)$ had a major re-operation and 4 patients $(2.3 \%)$ a minor re-operation during follow up. In addition, 3 patients were referred from other hospitals with complications necessitating major re-operation. The total group of 33 re-operated patients consisted of 30 women and 3 men. Before the initial operation, mean age was $37 \pm 9$ years with a range of 21 to 59 years. The initial preoperative BMI was $44.6 \pm 5.8 \mathrm{~kg} / \mathrm{m}^{2}$ with a range of 37.0 to $55.6 \mathrm{~kg} / \mathrm{m}^{2}$. As shown in table 1 , hypertension $(\mathrm{N}=12)$, diabetes mellitus $(\mathrm{N}=5)$ and joint problems $(\mathrm{N}=20)$ were the main preoperative comorbidities.

\section{Initial operation}

In the 33 patients from the re-operated group the initial band placement was according to the perigastric technique in $70 \%$, the pars flaccida technique was used in $30 \%$. In 31 patients a $9.75 \mathrm{~cm}$ silicone band was placed; in the remaining 2 patients an $11.0 \mathrm{~cm}$ band. There were no direct postoperative complications and hospital stay was $3 \pm 1$ days.

During initial band placement, one laparoscopic (perigastric) procedure was converted to an open procedure because of uncontrollable bleeding. In this patient an open band placement was performed during the same session. No further complications occurred with the band but this patient had a port dislocation 42 months after the operation. A port refixation was performed under local anesthesia.

\section{Follow-up}

Mean time between the initial operation and the re-operation was $28 \pm 17$ months. Mean BMI just before the re-operation was $37.5 \pm 6.4 \mathrm{~kg} / \mathrm{m}^{2}$. Comorbidities, especially diabetes and joint problems, were already significantly reduced. However, hypertension was still present in 8 patients. 


\begin{tabular}{ll}
\hline Variables & Before initial operation \\
\hline Patients $(\mathrm{N})$ & 33 \\
$\mathrm{M}: \mathrm{F}$ & $3: 30$ \\
Age $($ years $)$ & $37 \pm 9(21-59)$ \\
BMI $\left(\mathrm{kg} / \mathrm{m}^{2}\right)$ & $44.6 \pm 5.8(37.0-55.6)$ \\
Hospital stay (days) & $3 \pm 1(2-6)$ \\
Hypertension & 12 \\
Diabetes mellitus & 5 \\
Hyperlipidemia & 2 \\
Joint problems & 20 \\
GERD & 2 \\
Depression & 2 \\
Asthma & 4 \\
Sleep apnea syndrome & 1 \\
\hline
\end{tabular}

Table 1: patient characteristics

\section{Causes of failure}

Causes of failure for which re-operation was necessary are shown in table 2.

A total of 29 patients developed band-related problems. Nineteen of these 29 patients had band slippage of which 17 were anteriorly and 2 posteriorly. The other 10 patients with band-related problems had band erosion $(\mathrm{N}=5)$, band intolerance $(\mathrm{N}=3)$ and band leakage $(\mathrm{N}=2)$. Two patients with band erosion were referred from other hospitals. In all patients with band erosion, the perigastric technique was used during the initial band placement.

Four patients developed specific port-related problems. Three patients had a port dislocation and in one patient the port eroded through the skin after a complicated "tummy tuck" (abdominoplasty). 


\begin{tabular}{lrrrrrrrc}
\hline Causes & Patients & Vomiting & Pain & Pyrosis & Nausea & $\begin{array}{c}\text { Regurgi- } \\
\text { tation }\end{array}$ & $\begin{array}{c}\text { Pain } \\
\text { port site }\end{array}$ & $\begin{array}{c}\text { Insufflation } \\
\text { problem }\end{array}$ \\
\hline Anterior slippage & 17 & 12 & 8 & 8 & 7 & 4 & - & - \\
Posterior slippage & 2 & 1 & 0 & 2 & 1 & 0 & - & - \\
Band erosion & 5 & 0 & 3 & 1 & 0 & 0 & - & - \\
Band leakage & 2 & 0 & 0 & 0 & 0 & 0 & - & - \\
Band intolerance & 3 & 3 & 0 & 2 & 0 & 1 & - & - \\
Port dislocation & 3 & - & - & - & - & - & 3 & 3 \\
Port erosion & 1 & - & - & - & - & - & 1 & 1 \\
Total & $\mathbf{3 3}$ & $\mathbf{1 6}$ & $\mathbf{1 1}$ & $\mathbf{1 3}$ & $\mathbf{8}$ & $\mathbf{5}$ & $\mathbf{4}$ & $\mathbf{4}$ \\
\hline
\end{tabular}

Table 2: symptoms of complications after LAGB

\section{Symptoms of failure}

As shown in table 2, the band and port problems led to a variety of symptoms. Most patients with band-related problems experienced gastro-intestinal symptoms like nausea and vomiting, retrosternal pain, pyrosis and regurgitation. Patients usually had a combination of these symptoms. Patients with band leakage did not have any gastrointestinal symptoms but instead an obvious weight regain and inability to insufflate the band.

All patients with port-related problems complained of local pain at the site of the port. Next to this, insufflating the band was either difficult or even impossible.

The re-operation

The re-operations were performed in the period from November 1997 to September 2005 by one surgeon (JG). During re-operation different interventions were performed depending on the cause of failure. In table 3 performed re-operations are summarized. Nineteen patients had a band slippage. During laparoscopic re-operation, a refixation of the band was directly performed in 18 patients. One patient had an acute herniation with incarceration of the stomach. The band was opened during an emergency procedure and left open. After two days the band was repositioned and closed during a second laparoscopy.

Five patients had band erosion of which two were referred from other hospitals. In all 5 patients, the perigastric technique was used during the initial band placement. Only two of these patients had effective weight loss $\left(42.2\right.$ to $27.4 \mathrm{~kg} / \mathrm{m}^{2}$ and 50.0 to $38.0 \mathrm{~kg} /$ $\mathrm{m}^{2}$ ) prior to the band erosion. In these patients, continuation of treatment with LAGB 
was preferred. During laparoscopic re-operation, band replacement was possible in one patient during the same operative session. In the other patient the band was removed and during a second stage laparoscopic re-operation a new band was placed.

The other 3 patients with band erosion had initial poor weight loss. During an open procedure, the bands were removed and a biliopancreatic diversion according to Scopinaro was performed. In 2 patients this was performed as a one-step procedure and in one patient as a two-step procedure.

\begin{tabular}{lccccc}
\hline Causes & Refixation & Replacement & Removal $^{*}$ & GB & BPD \\
\hline Anterior slippage & 17 & 0 & 0 & 0 & 0 \\
Posterior slippage & 2 & 0 & 0 & 0 & 0 \\
Band erosion & 0 & 1 & 1 & 0 & 3 \\
Band leakage & 0 & 2 & 0 & 0 & 0 \\
Band intolerance & 0 & 1 & 0 & 2 & 0 \\
Port dislocation & 2 & 1 & 0 & 0 & 0 \\
Port erosion & 0 & 1 & 0 & 0 & 0 \\
\hline
\end{tabular}

Table 3: performed re-operations

${ }^{*}$ new band placement during a second laparoscopic re-operation

Furthermore, two patients with band leakage and one patient with band intolerance due to a small outlet with subsequently severe vomiting without nausea $(8,12$ and 1 month after the first operation, respectively) had a band replacement during laparoscopic reoperation.

Two patients had severe band intolerance that was only released by complete desufflation of the band. An insufflation of $0.25 \mathrm{cc}$ was already enough to cause serious eating difficulties due to severe vomiting without nausea. In these two patients, with initially effective weight loss (BMI of 40.3 to $29.2 \mathrm{~kg} / \mathrm{m}^{2}$ and 40.0 to $30.5 \mathrm{~kg} / \mathrm{m}^{2}$ ), the band was removed and an open conversion to a gastric bypass was performed.

All re-operations, except the bypass procedures in the initial experience, were performed by laparoscopy. Three procedures were converted to open procedures. In two patients with anterior slippage conversion was necessary due to extensive intra-abdominal adhesions and in one patient the procedure was converted because of advanced band erosion.

Mean hospital stay after re-operation was $4 \pm 3$ days. 
Apart from the band-related problems where major re-operation was necessary, four patients had specific port-related problems. These patients were successfully treated under local anesthesia in a day care setting. Port refixation was performed in 2 patients with port dislocation and port replacement in the one patient with port erosion and in one patient with port dislocation.

\section{Complications after re-operation}

Postoperative complications were observed in 4 patients $(12 \%)$. Two patients developed a superficial wound infection (6\%); one patient after laparoscopic band refixation and one patient after band removal by laparotomy for band erosion. Both were treated with conservative measures. Two patients had specific operation-related complications after BPD (6\%). One patient had severe diarrhea (10-15 times daily), which improved spontaneously. One patient was re-admitted with malnutrition (albumin $17 \mathrm{~g} / \mathrm{L}$ ) 10 months after re-operation. This patient was treated with total parental nutrition for 1 week. No postoperative complications were observed in the patient group with specific port-related problems.

\section{Follow-up after re-operation}

Follow-up after re-operation was $100 \%$ with a mean period of $34 \pm 19$ months. Before the re-operation, BMl had decreased from $44.6 \pm 5.8 \mathrm{~kg} / \mathrm{m}^{2}$ to $37.5 \pm 6.4 \mathrm{~kg} / \mathrm{m}^{2}$. After the re-operation BMI decreased further to a mean $33.4 \pm 6.8 \mathrm{~kg} / \mathrm{m}^{2}$. Differences existed between the patient groups: in the group of patients with band refixation or replacement, BMI decreased from $37.2 \pm 6.2$ to $34.4 \pm 5.6 \mathrm{~kg} / \mathrm{m}^{2}$. Patients who had a conversion to $B P D$ had a decrease in BMI from $38.3 \pm 8.2$ to $29.4 \pm 10.5 \mathrm{~kg} / \mathrm{m}^{2}$ while this was in patients converted to GB (only 2 patients) from 29.9 to $27.6 \mathrm{~kg} / \mathrm{m}^{2}$. In line with this, comorbidities were further reduced after the re-operation (table 4). The number of patients with hypertension and joint problems strongly decreased and diabetes, hyperlipidemia, asthma as well as depression completely dissolved. Hypertension disappeared in 7 patients; 6 patients in the band refixation / replacement group (6/24) and one patient in the BPD group (1/3). Other comorbidities were already improved before re-operation. In addition, gastro-intestinal symptoms caused by the dysfunctional band, present before the re-operation, were strongly reduced. As shown in table 4, only two patients still experienced nausea and vomiting and one patient had pyrosis and regurgitation. 


\section{Band problems after re-operation}

During follow-up, 3 patients $(10 \%)$ of the total of 29 patients where major re-operation was performed, again developed anterior slippage after 11, 26 and 47 months. The initial band-related problems in these 3 patients were anterior slippage, posterior slippage and band leakage. During a second laparoscopic re-operation, two band refixations and one band replacement were performed, respectively. Mean follow-up period after these second re-operations was 45 months; no further complications were observed.

\section{Port problems after re-operation}

One patient, with initially a port dislocation, was again diagnosed with a dislocation during follow-up. Placement of a new port was performed under local anesthesia. After this second port replacement no further complications were observed.

\begin{tabular}{lccc}
\hline Variables & $\begin{array}{c}\text { Before } \\
\text { initial operation }\end{array}$ & $\begin{array}{c}\text { Before } \\
\text { re-operation * }\end{array}$ & $\begin{array}{c}\text { After } \\
\text { re-operation * }\end{array}$ \\
\hline BMI & $44.6 \pm 5.8$ & $37.5 \pm 6.4$ & $33.4 \pm 6.8$ \\
Hypertension & 12 & 8 & 1 \\
Diabetes mellitus & 5 & 1 & 0 \\
Hyperlipidemia & 2 & 2 & 0 \\
Joint problems & 20 & 3 & 1 \\
GERD & 2 & 0 & 0 \\
Depression & 2 & 1 & 0 \\
Asthma & 4 & 2 & 0 \\
Sleep apnea syndrome & 1 & 0 & 0 \\
Vomiting & - & 16 & 2 \\
Pyrosis & - & 13 & 1 \\
Nausea & - & 8 & 2 \\
Retrosternal pain & - & 11 & 0 \\
Regurgitation & - & 5 & 1 \\
\hline
\end{tabular}

Table 4: BMI, comorbidities and symptoms during follow-up

* $23 \pm 15$ months after the initial operation

\# $34 \pm 19$ months after re-operation 


\section{Discussion}

Different operative techniques are used to induce weight loss in morbidly obese patients. LAGB has proven its worth in effectively reducing excess body weight and improving obesity - related comorbidities. Furthermore, it is demonstrated to be safe and reversible [5, 8, 9, 17-19]. However, compared to other bariatric procedures, it has a higher rate of re-operations, especially due to slippage or pouch dilatation. In this report we evaluated the re-operations, performed in patients with a failed LAGB. Follow up after re-operation was $100 \%$ with a mean duration of 34 months.

In a total group of 177 patients treated for morbid obesity with LAGB, $14.7 \%(26 / 177)$ needed major re-operation during follow-up because of band-related problems. In addition, 3 patients were referred from other hospitals with band-related problems. Slippage was the most important reason for re-operation (66\%; 19/29). Specific portrelated problems for which a minor re-operation under local anesthesia was necessary were observed in $2 \%(4 / 177)$ of patients. In the literature, the re-operation rate after adjustable gastric banding ranges from $2 \%$ to $80 \%$ [10, 12, 20-27]. In line with our data, Spivak et al. demonstrated that slippage and pouch dilatation are the most important reasons to perform a re-operation after LAGB with percentages in literature ranging from $2 \%$ to $24 \%$ [28].

An explanation for the wide range in re-operation rate might be the used operation technique. In the 1990s, the band was usually placed according to the perigastric technique. Since introducing the pars flaccida technique, which includes minimal dissection around the gastric wall and a higher position of the band, slippage rates tend to decrease $[6,7,14]$. As a consequence, re-operation rate decreased by using this technique. Belachew et al. reported a decrease from $13 \%$ to $0 \%$, while Dargent et al. found a reduction of the cumulative rate of slippage from $12 \%$ to $5 \%$. In a series of 250 patients, Rubin et al. found a slippage rate of only $1.6 \%$ using the pars flaccida technique $[6,14,20,29]$. In our clinic, the re-operation rate also decreased significantly after introduction of the pars flaccida technique. From 1997 to 2001 all patients were operated according to the perigastric technique and the re-operation rate from patients operated in this period was $42 \%$. Since the introduction of the pars flaccida technique in 2001 , the re-operation rate has dropped to $8 \%$. This is mainly due to a decrease in slippage and pouch dilatation; in the perigastric group this occurred in 14 of 49 patients $(29 \%)$ while in the pars flaccida group this occurred in 5 of 119 patients (4\%). However, the follow-up period after these two operation techniques is not comparable: 96 and 48 months, respectively. The number of necessary re-operations in a patient group 
will probably increase in time because slippage and pouch formation develop slowly postoperatively. However, in the present study, slippage was diagnosed after a mean 28 months after operation with a range of 7 months to 61 months. Therefore, the decrease in re-operation rate is encouraging, but a longer and complete follow up of the patient group in which the pars flaccida technique was used, is necessary.

In the present study, all patients remained in follow-up and the mean follow-up period after re-operation was 34 months. In the group of 29 patients where major re-operation was performed because of band-related problems, three patients $(10 \%)$ again developed band problems for which a second re-operation was necessary. The remaining 26 patients $(90 \%)$ from the re-operated group did not develop any complications during follow-up.

Our main interest was to study to which extent a re-operation after LAGB led to a further decrease and improvement of BMI and obesity-related comorbidity. BMI decreased from $37.5 \pm 6.4 \mathrm{~kg} / \mathrm{m}^{2}$ before the re-operation to $33.4 \pm 6.8 \mathrm{~kg} / \mathrm{m}^{2}$ after the re-operation. Comorbidities were also further reduced or dissolved after the re-operation.

There are only few studies reporting on results after re-operation in case of failed LAGB. Biertho et al. operated 824 morbidly obese patients and observed 131 band-related problems for which 121 major re-operations (14.7\%) were performed. According to a re-operation algorithm, a band replacement or removal was performed [30]. Conversion to gastric bypass or BPD was chosen if the patient had insufficient weight loss prior to the failure of the LAGB. This decision-making is consistent with our findings and has been described by other authors as well [31, 32]. However, laparoscopic band refixations and the effect of the re-operation on $\mathrm{BMI}$ and comorbidities, the main topics of the present study, are not described in these studies. Petreli et al. performed 250 operations in a period of 6 years and re-operated 39 patients $(16 \%)$ because of failed LAGB. In line with our data, $70 \%$ of the patients in this group had slippage or pouch dilatation. After re-operation $5.3 \%$ of patients developed a second failure of the band but re-slippages were not observed [11]. The report of Suter et al. was less positive: in patients where re-banding was performed after band slippage the success rate was only $33 \%$. They suggest gastric bypass as a better option in these patients. However, the patient population was small $(\mathrm{N}=9)$ [31]. Weiss et al. reported on 382 patients of whom 73 patients $(19.1 \%)$ had a surgical revision after LAGB. Only 19 patients of this re-operated group (26\%) had pouch dilatation; a refixation was performed in 4 patients. After a follow-up period of 42 months BMI decreased from $37.8 \mathrm{~kg} / \mathrm{m}^{2}$ to $29.5 \mathrm{~kg} / \mathrm{m}^{2}$, in contrast with a patient group in which the band was only removed; in this group, BMI increased from $32.6 \mathrm{~kg} / \mathrm{m}^{2}$ to $37.4 \mathrm{~kg} / \mathrm{m}^{2}$ [33]. These reports, as well as the present 
study, indicate that a re-operation after LAGB is worthwhile. The choice of re-operation (refixation, replacement or conversion) depends on the (band-related) problem of the patient and the initial weight loss after the first band placement. The proposed reoperation algorithm (figure 1) serves as a summary of these considerations.

In our opinion, in case of slippage or pouch dilatation after initially successful weight loss, laparoscopic refixation is the first option. In case of a band defect, such as leakage, laparoscopic replacement is the treatment of choice. In patients with band erosion and initially successful weight loss, maintenance of treatment with LAGB is preferred and achieved by band replacement. If this is technically not possible due to proximal gastric damage, conversion to BPD is the operation of choice because in this procedure the initial operation area of the stomach is not involved. In patients with initially poor weight loss and /or a band-related problem and / or non-compliance, a conversion to another bariatric procedure has to be considered. In case of band erosion, a conversion to BPD is the first option. In non-compliance or band intolerance, a conversion to BPD or GB is possible. Because of the malabsorptive effect of the BPD, it is considered to be the first choice. However, our results of conversion to GB are favourable with good results on weight and symptoms. This is supported by other authors although it is merely a restrictive procedure [34-36].

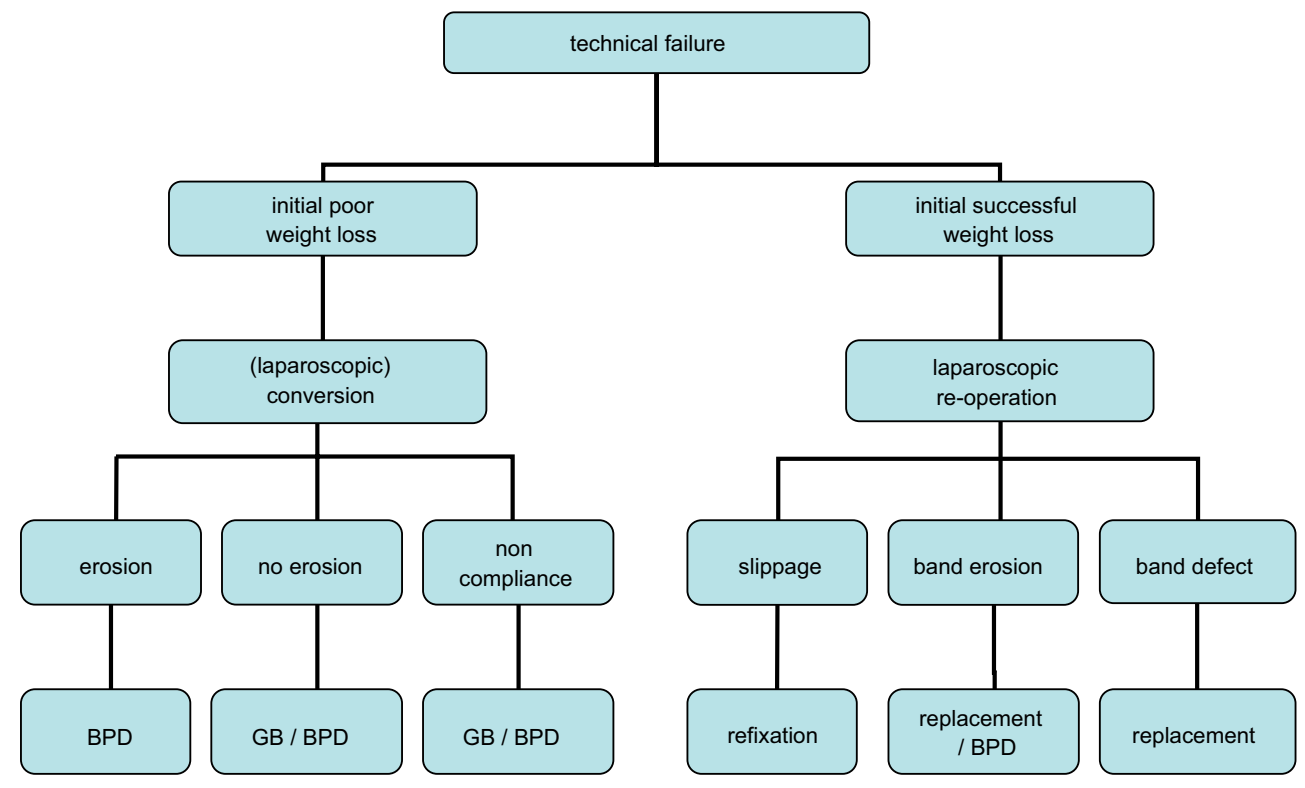

Figure 1: re-operation algorithm 


\section{Conclusion}

In this report we demonstrate that a laparoscopic re-operation in case of band-related complications after LAGB is safe and feasible. A laparoscopic refixation of the band, without replacement or removal, is possible in up to $89 \%$. The re-operation leads to a further decrease in BMI and obesity-related comorbidities. 


\section{References}

1. Buchwald, H., et al., Bariatric surgery: a systematic review and meta-analysis. Jama, 2004. 292(14): p. 1724-37.

2. Anonymous, World Health Organisation: obesity prevalence 2006, https://apps.who.int/infobase/report.aspx.

3. Must, A., et al., The disease burden associated with overweight and obesity. Jama, 1999. 282(16): p. 1523-9.

4. Overweight, obesity, and health risk. National Task Force on the Prevention and Treatment of Obesity. Arch Intern Med, 2000. 160(7): p. 898-904.

5. Fisher, B.L. and P. Schauer, Medical and surgical options in the treatment of severe obesity. Am J Surg, 2002. 184(6B): p. 9S-16S.

6. Belachew, M. and J.M. Zimmermann, Evolution of a paradigm for laparoscopic adjustable gastric banding. Am J Surg, 2002. 184(6B): p. 21S-25S.

7. Fielding, G.A. and J.W. Allen, A step-by-step guide to placement of the LAP-BAND adjustable gastric banding system. Am J Surg, 2002. 184(6B): p. 26S-30S.

8. O'Brien, P.E. and J.B. Dixon, Lap-band: outcomes and results. J Laparoendosc Adv Surg Tech A, 2003. 13(4): p. 265-70.

9. O'Brien, P.E. and J.B. Dixon, Weight loss and early and late complications--the international experience. Am J Surg, 2002. 184(6B): p. 42S-45S.

10. Doherty, C., J.W. Maher, and D.S. Heitshusen, Long-term data indicate a progressive loss in efficacy of adjustable silicone gastric banding for the surgical treatment of morbid obesity. Surgery, 2002. 132(4): p. 724-7; discussion 727-8.

11. Peterli, R., et al., Re-operations following laparoscopic adjustable gastric banding. Obes Surg, 2002. 12(6): p. 851-6.

12. Westling, A., et al., Silicone-adjustable gastric banding: disappointing results. Obes Surg, 1998. 8(4): p. 467-74.

13. Belachew, M., et al., Laparoscopic adjustable gastric banding. World J Surg, 1998. 22(9): p. 955-63.

14. Dargent, J., Pouch dilatation and slippage after adjustable gastric banding: is it still an issue? Obes Surg, 2003. 13(1): p. 111-5.

15. Scopinaro, N., et al., Biliopancreatic diversion. World J Surg, 1998. 22(9): p. 936-46.

16. Talieh, J., D. Kirgan, and B.L. Fisher, Gastric bypass for morbid obesity: a standard surgical technique by consensus. Obes Surg, 1997. 7(3): p. 198-202.

17. de Jong, J.R., et al., The influence of laparoscopic adjustable gastric banding on gastroesophageal reflux. Obes Surg, 2004. 14(3): p. 399-406.

18. Schok, M., et al., Quality of life after laparoscopic adjustable gastric banding for severe obesity: postoperative and retrospective preoperative evaluations. Obes Surg, 2000. 10(6): p. 502-8.

19. Larsen, J.K., et al., Psychosocial functioning before and after laparoscopic adjustable gastric banding: a cross-sectional study. Obes Surg, 2003. 13(4): p. 629-36.

20. Dargent, J., Surgical treatment of morbid obesity by adjustable gastric band: the case for a conservative strategy in the case of failure - a 9-year series. Obes Surg, 2004. 14(7): p. 986-90.

21. Martikainen, T., et al., Long-term results, late complications and quality of life in a series of adjustable gastric banding. Obes Surg, 2004. 14(5): p. 648-54.

22. Belachew, M., P.H. Belva, and C. Desaive, Long-term results of laparoscopic adjustable gastric banding for the treatment of morbid obesity. Obes Surg, 2002. 12(4): p. 564-8. 
23. Vertruyen, M., Experience with Lap-band System up to 7 years. Obes Surg, 2002. 12(4): p. 569-72.

24. Angrisani, L., et al., Lap Band adjustable gastric banding system: the Italian experience with 1863 patients operated on 6 years. Surg Endosc, 2003. 17(3): p. 409-12.

25. Zinzindohoue, F., et al., Laparoscopic gastric banding: a minimally invasive surgical treatment for morbid obesity: prospective study of 500 consecutive patients. Ann Surg, 2003. 237(1): p. 1-9.

26. Ceelen, W., et al., Surgical treatment of severe obesity with a low-pressure adjustable gastric band: experimental data and clinical results in 625 patients. Ann Surg, 2003. 237(1): p. 10-6.

27. van Dielen, F.M., et al., Laparoscopic adjustable gastric banding versus open vertical banded gastroplasty: a prospective randomized trial. Obes Surg, 2005. 15(9): p. 1292-8.

28. Spivak, H. and F. Favretti, Avoiding postoperative complications with the LAP-BAND system. Am J Surg, 2002. 184(6B): p. 31S-37S.

29. Rubin, M. and H. Spivak, Prospective study of 250 patients undergoing laparoscopic gastric banding using the two-step technique: a technique to prevent postoperative slippage. Surg Endosc, 2003. 17(6): p. 857-60.

30. Biertho, L., et al., Management of failed adjustable gastric banding. Surgery, 2005. 137(1): p. 33-41.

31. Suter, M., Laparoscopic band repositioning for pouch dilatation/slippage after gastric banding: disappointing results. Obes Surg, 2001. 11(4): p. 507-12.

32. Niville, E., et al., Results of lap rebanding procedures after Lap-Band removal for band erosion -- a mid-term evaluation. Obes Surg, 2005. 15(5): p. 630-3.

33. Weiss, H.G., et al., Surgical revision after failure of laparoscopic adjustable gastric banding. Br J Surg, 2004. 91(2): p. 235-41.

34. Westling, A., M. Ohrvall, and S. Gustavsson, Roux-en-Y gastric bypass after previous unsuccessful gastric restrictive surgery. J Gastrointest Surg, 2002. 6(2): p. 206-11.

35. Calmes, J.M., V. Giusti, and M. Suter, Reoperative laparoscopic Roux-en-Y gastric bypass: an experience with 49 cases. Obes Surg, 2005. 15(3): p. 316-22.

36. Suter, M., et al., Band erosion after laparoscopic gastric banding: occurrence and results after conversion to Roux-en-Y gastric bypass. Obes Surg, 2004. 14(3): p. 381-6. 


\section{A systematic literature review of re-operations after gastric banding. Is a stepwise approach justified?}

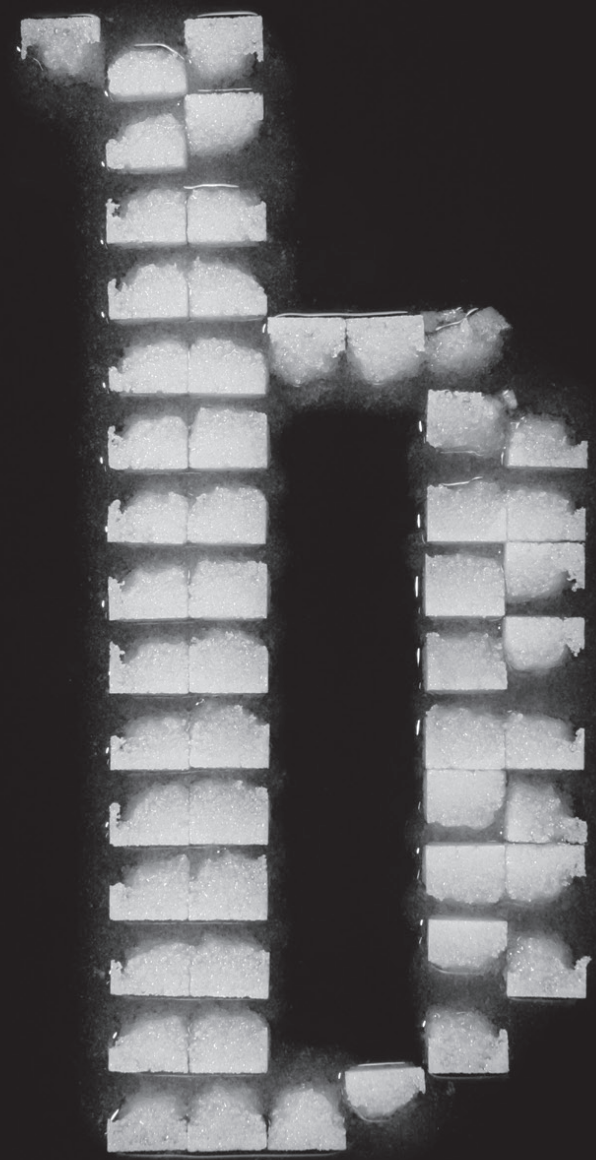

Ruben Schouten

Dennis Japink

Berry Meesters

Patty J. Nelemans

Jan Willem M. Greve 


\begin{abstract}
Background: because of the low perioperative morbidity and the long term success of LAGB this procedure is a logical first step in bariatric surgery. However, the safety and efficacy of LAGB is overshadowed by a significant number of re-operations necessary during follow up. This systematic literature review describes the results of re-operations after LAGB.
\end{abstract}

Methods: a systematic literature search was conducted. The selection of search terms was divided into groups resembling the primary intervention (LAGB) and the secondary intervention (re-operation). MeSH terms, non-MesH terms and all possible combinations between the terms and synonyms were used.

Results: a total of 33 articles were included in the review. Eleven studies focused on rebanding / replacement of the band, 12 studies focused on results of the conversion to roux-en-y gastric bypass (RYGB), 5 studies on the conversion to biliopancreatic diversion / duodenal switch (BPD / DS) and 5 studies on the conversion to gastric sleeve resection (GSR). Rebanding and conversion to RYGB are the most frequently described re-operations with comparable results although the conversion to RYGB has less long term complications and better weight loss. Conversion to BPD / DS is more complicated while weight loss is not better. The conversion to GSR has been described but results are limited.

Conclusion: in case of band failure due to purely technical band problems a refixation or replacement of the band is a feasible option. In case of poor weight loss and noncompliance conversion to laparoscopic RYGB is the preferred option with comparable early and late complications but lower rates of re-operations and a better weight loss. These re-operations are proven to be effective and safe. Because of the low perioperative morbidity and good long term results LAGB is justified as a first-step procedure. 


\section{Introduction}

Morbid obesity, defined as a body mass index (BMI) of $>40 \mathrm{~kg} / \mathrm{m}^{2}$ or $>35 \mathrm{~kg} / \mathrm{m}^{2}$ with obesity-related comorbidities, is a worldwide epidemic. For patients with morbid obesity surgical therapy is the only treatment option that results in sufficient and long term weight loss. Non-surgical approaches, like low energy diets and behavior modification, are not successful in the long term with respect to maintaining weight loss and decreasing obesity-related comorbidities [1, 2]. Results of bariatric surgery are however variable with weight loss ranging from an excess weight loss (\%EWL; amount of kilograms lost since baseline $\times 100$ / excess weight) of $47.5 \%$ after laparoscopic adjustable gastric banding (LAGB) to $70.1 \%$ after biliopancreatic diversion (BPD) [3]. Decrease in obesityrelated comorbidities tends to be in proportion to weight loss. Although weight loss and decrease in comorbidities are significantly lower after LAGB compared to more malabsorptive procedures like BPD and duodenal switch [4] is it nowadays a very popular procedure due to the low mortality and perioperative morbidity [5]. Furthermore, this laparoscopic procedure is technically easy and it can be performed as an outpatient procedure. Weight loss after LAGB tends to be slower and more gradual but lasts for a more prolonged period. The systematic review by O'Brien et al. shows that 5 years after gastric banding weight loss is comparable with other popular procedures like rouxen-y gastric bypass (RYGB). EWL 5 years after LAGB was $55.2 \%$ (range: $48 \%-57 \%$ ) compared to $58.2 \%$ after RYGB (range: $43 \%$ - $77 \%$ ) [6]. Because of the low perioperative morbidity and the long term success of LAGB this procedure is a logical first step in bariatric surgery. However, the safety and efficacy of LAGB is overshadowed by the fact that frequently re-operations are necessary during follow up. The main reasons for these re-operations are complications like pouch dilatation, anterior or posterior slippage, band erosion, band leakage and port-related problems. The percentage of re-operations varies enormously in literature from $2 \%$ to $80 \%$ [7-10]. This is caused by three important factors. First, results vary according to the used surgical technique, either perigastric or pars flaccida. The latter might have better results especially due to a decrease in band slippages although long term results have to be awaited [11, 12]. Second, the type of band is important when discussing the re-operation rate. Newer bands with a high-volume low-pressure mechanism might have fewer complications than the older low-volume high pressure bands, especially as a result of less band slippages [13, 14]. However, third and most important, a long and complete follow up is necessary for a reliable estimation of the re-operation rate because complications necessitating a re-operation occur after a mean period of 2 to 3 years $[7,15]$. These 
factors explain the variety in reported re-operation rates after LAGB. In case of failure of LAGB there are several possibilities: refixation of the band, replacement of the band, removal of the band with conversion to RYGB, BPD, DS or a gastric sleeve resection (GSR). In this systematic literature review we describe the results of re-operations after LAGB. All surgical revisional possibilities are discussed in an attempt to provide the bariatric surgeon with the information needed in case of a failure after LAGB.

\section{Methods}

\section{Search strategy}

A systemic search was conducted using the databases of Medline, Current Contents, PubMed and the Cochrane Library. The selection of search terms was divided into groups resembling the primary intervention (LAGB) and the secondary intervention (reoperation). Criteria for article inclusion on abstract basis were publication date between 1st of January 1990 and 1st of may 2010, written in the English language and patient age between 18 and 65 years old. A summary of the search results is provided in figure 1.

\section{Primary intervention}

A MeSH-term search provided no MeSH hits on "laparoscopic adjustable gastric banding" [1A], "gastric banding" [1B], "LAGB" [1C], "lap-band" [1D] and "gastric band" [1E]. These search terms were then used in a non-MeSH article search and provided 1086, 1666, 396, 193 and 2000 hits respectively.

\section{Secondary intervention}

The MeSH-database contained the terms "conversion" [2C] and "reoperation" [2D] providing 627 and 2 hits, respectively. The variations and synonyms "reoperations" [2A], "re-operations" [2B], "reintervention" [2E] and "laparoscopic reintervention" [2F] were included in the MESH-term search but provided no hits. These non-MeSH search terms resulted in 3271, 417, 1767 and 147 article hits, respectively.

Finally, a combination of all primary (1A through 1E) and secondary intervention (2A through $2 \mathrm{~F}$ ) searches was performed resulting in a total number of potentially useful articles of 706 . 


\section{Selection on abstract basis}

Two independent reviewers (R.S. and D.J) assessed all 706 articles and selected 427 based on title. After reading the selected 427 articles a total of 350 papers were excluded. These papers did not describe results of re-operations but merely operative technique or the prevalence of certain re-operations. This left 77 papers on which the following inclusion criteria were applied. Case reports and small series describing 10 patients or less were excluded $(n=31)$. Also, articles reporting mixed results of a certain re-operation after various bariatric restrictive procedures (usually a mix of LAGB and vertical banded gastroplasty (VBG)) were excluded if results were not clearly separated $(n=13)$. Finally, 33 articles were agreed on to be suitable for inclusion.

\section{Categorization of papers}

The 33 included papers were further subdivided based on the focus of the study. Eleven studies focused on rebanding / replacement of the band, 12 studies focused on results of the conversion to (laparoscopic) RYGB, 5 studies on the conversion to (laparoscopic) BPD / DS and 5 studies on the conversion to laparoscopic GSR.

\section{Rationale of data}

All studies were assigned a level of evidence based on the categories developed by the Centre for Evidence-based Medicine in Oxford, UK [16]. The different categories are outlined in table 1 . Results are reported according to the aforementioned subdivision. The nature of the published data was mainly retrospective and case series. Also, the reported results were heterogeneous including a wide range of patients in follow up as well as follow up period. Furthermore, important aspects like standard error of the mean and survival analysis were mostly not performed and / or not reported. As a consequence, a meta-analysis of pooled data was not possible and therefore the present study represents a systematic literature review. Ten of the 33 included studies did not report weight loss results. However, this is the most important outcome parameter of bariatric surgery. These studies are included in the review but because of the importance of weight loss data this is discussed separately in each paragraph. 


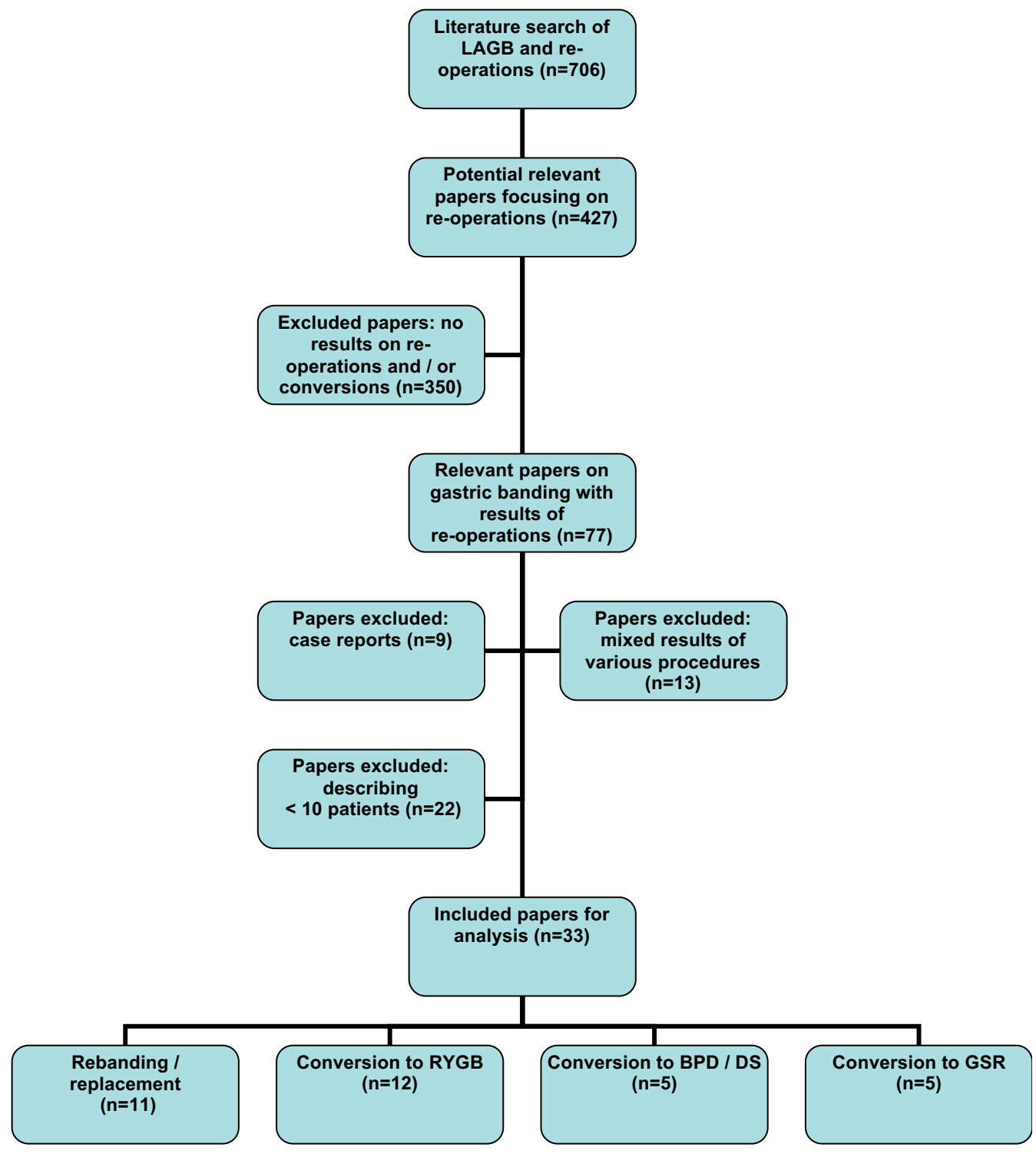

Figure 1: summary of literature search and included studies 


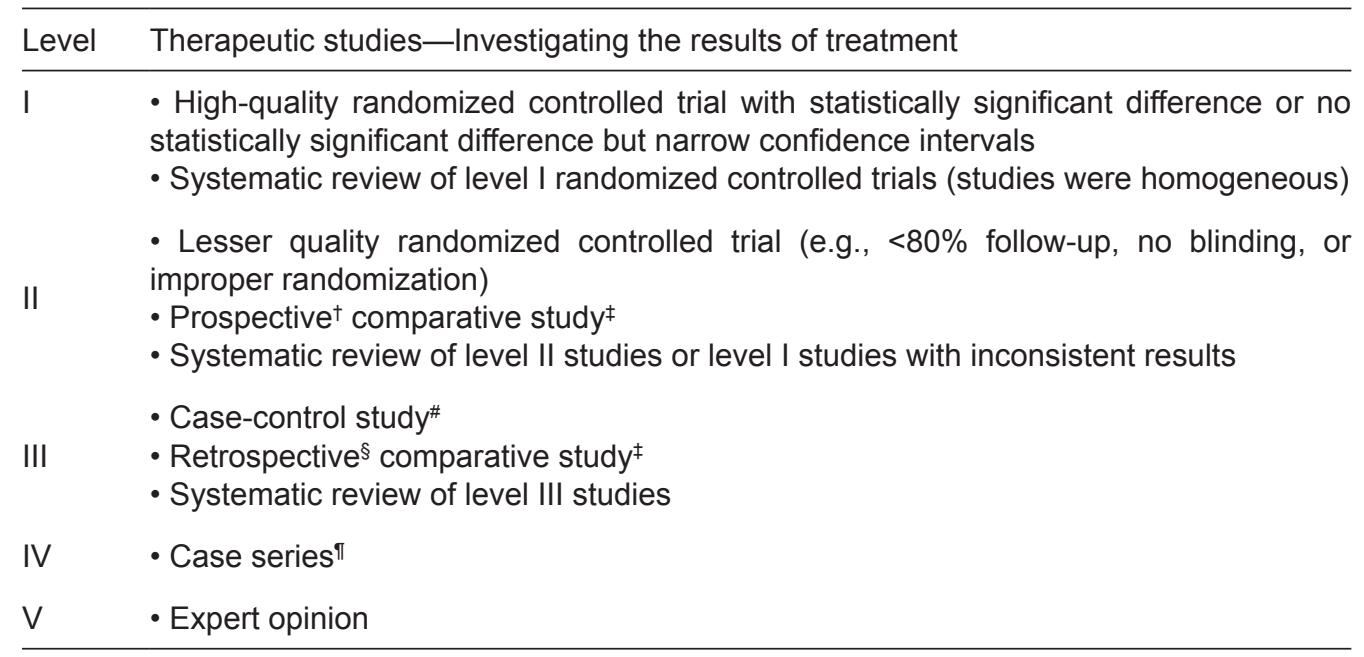

Table 1: Levels of evidence for primary research question

This chart was partly adapted from material published by the Centre for Evidence-Based Medicine, Oxford, UK. For more information, please see www.cebm.net.

+ Study was started before the first patient enrolled.

* Patients treated 1 way compared with patients treated another way at the same institution.

$\S$ Study was started after the first patient enrolled.

\# Patients identified for the study on the basis of their outcome are compared with those who did not have the outcome.

$\pi$ Patients treated 1 way with no comparison group of patients treated another way.

\section{Results}

Refixation / replacement - complications \& re-operations

The first laparoscopic repositioning of the band because of pouch dilatation was described by Niville et al. in 1999 [17]. Afterwards, many reports have been published describing the results of band refixation / replacement in case of band-related complications. Results are summarized in table 2.1. Keidar et al. retrospectively described a case series of 125 patients who had a removal, refixation, replacement or delayed replacement of the band because of posterior (103 patients) and anterior (22 patients) slippage. In 70 patients the band was only removed while 40 patients had direct refixation and 15 patients underwent replacement of the band. Overall complication rate after re-operation was $12 \%$ with an average hospital stay of 1.5 days. Late re-operation rate was $11 \%$ [18]. Abu-Abeid et al. treated 16 patients with band 
erosion by removal and direct replacement of the band along with repair of the stomach wall where necessary. Re-operation rate was $0 \%$ during a follow up period of 28 months [19]. Sixteen patients with pouch dilatation were treated by refixation in 5 cases and replacement in 11 cases by Lanthaler et al [20]. The re-operation rate was $6 \%$ including one patient with band infection. Peterli et al. performed 27 band replacements because of posterior slippage (16), lateral slippage (10) and pouch dilatation (1). Postoperative complications occurred in $7.4 \%$ while re-operation rate (after a follow up period of 24 months) was $7.4 \%$ [21]. The prospective study of Niville et al. describes 10 patients with band erosion. All bands were removed and delayed replacement (within a few weeks) was performed. Hospital stay was 1 day and the late complication rate $20 \%$ after a mean follow up period of 48 months [22]. Another study by Niville describes 16 pouch dilatations treated by band refixation. There were no postoperative or late complications but follow up was short with a mean of 11 months [23]. The retrospective analysis from Schouten et al. described 24 patients who underwent refixation or replacement of the band mainly because of slippage (19 patients). Postoperative complications occurred in $6 \%$ while late complication and re-operation rate was $10 \%$ after 34 months of follow up [7]. Muller et al. performed 44 rebanding procedures because of band slippage, pouch dilatation, erosion or leakage. Follow up after the revisional procedure was 36 months. Postoperative and late complications are not clearly stated but late re-operation rate after re-banding was $45 \%$, mostly because of band-related problems [24]. Folleto et al. reported on 29 patients with band slippage. All underwent laparoscopic re-banding. No postoperative complications occurred but re-operation rate was $17.2 \%$ after 26.9 months [25]. The study by Brown et al. describes 19 patients with pouch dilatation all treated with refixation. Perioperative complication rate was $11 \%$. Late complications requiring a re-operation occurred in only one patient but follow up period was only 8 months [26]. Finally, Bueter et al. described 25 patients who underwent replacement (18) or refixation (7) of the band depending on the cause of failure. The postoperative course was uneventful in all patients. Follow up was 56 months. During this period, 7 patients $(28 \%)$ needed revisional surgery [27].

In summary, results of refixation or replacement of the band after failed LAGB are available for 281 patients (range: $10-55$ ) with a follow up period of 8 to 58 months. Early and late complication rate ranged from $0 \%$ to $11 \%$ and from $0 \%$ to $41 \%$, respectively. In all studies mortality was $0 \%$. The re-operation rate after refixation / replacement was $0 \%$ to $45 \%$. 
Rebanding / replacement - weight loss results

Only 6 of the 11 studies focusing on rebanding procedures reported postoperative weight loss after the revision. Results are summarized in table 2.2. Weight loss results varied from a weight gain of 2.4 BMI points to a weight loss of 5.8 BMI points. However, these results are time dependent as follow up period ranged from 8 to 48 months [7, 22-26].

\section{Conversion to RYGB - complications \& re-operations}

All studies focusing on conversion to (laparoscopic) RYGB after failed LAGB reported a mortality of $0 \%$. Results are summarized in table 3.1. Langer et al. published a report on 25 patients who underwent conversion from LAGB to RYGB because of weight regain (15) and inadequate weight loss (10). Mean hospital stay was 5 days; postoperative complications were not reported. Four patients had late complications (16\%) which were all treated with conservative measures. Follow up was 12 months [28]. A retrospective study of 70 patients who underwent RYGB after failed LAGB was reported by Mognol et al. Reasons for band failure were various but mainly pouch dilatation (49\%) and inadequate weight loss (25\%). In $33 \%$ of cases the band was only removed and during a second procedure the RYGB was performed. Mean hospital stay after RYGB was 7.2 days. Early complication rate was $14.3 \%$, late complication rate $8.6 \%$ and re-operation rate $5.7 \%$. However, only 10 patients (14\%) remained in follow up after a period of 18 months [29]. Moore et al. described 26 conversions to RYGB. Reasons for band removal were various but mainly band intolerance (9) and poor weight loss (7). Average length of hospital stay was 3 days. Postoperative complication rate was $12 \%$ and one patient needed a re-operation (4\%) during a mean follow up period of 12 months [30]. The study by te Riele et al. compared 81 primary open RYGB to a group of 55 secondary open RYGB after failed LAGB. Most patients from the latter group had insufficient weight loss (78.6\%). Early complications occurred in $14.8 \%$ of patients. Follow up period was 13.4 months and late complications occurred in $16.4 \%$ while re-operation rate was $9.1 \%$ [31]. Suter et al. performed 11 conversions to open RYGB because of band erosions. Direct postoperative complications occurred in 4 patients (36\%). Follow up period and long term complications are not described [32]. Topart et al. performed 32 conversions from LAGB to RYGB. Early complication rate was $12.5 \%$ while mean hospital stay was 7 days. Re-operation rate was $9.4 \%$ after a mean follow up period of 18 months [33]. Another study by Topart reported on 58 patients converted from failed LAGB to RYGB. Postoperative complications occurred in $8.6 \%$ of patients. Length of hospital stay was 


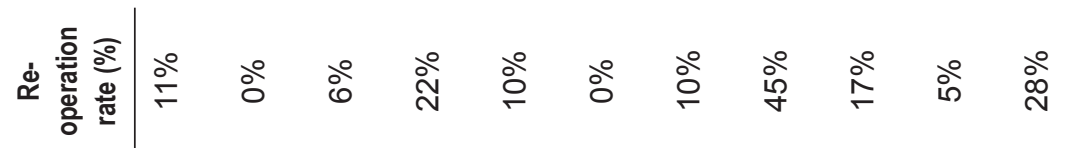

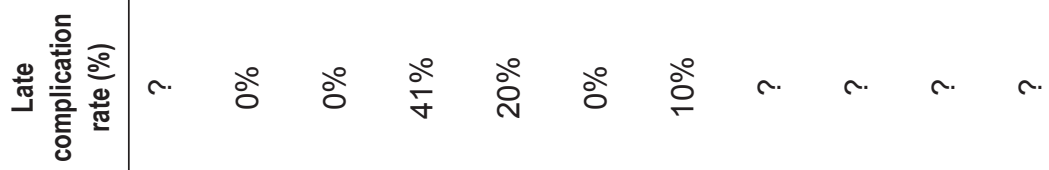

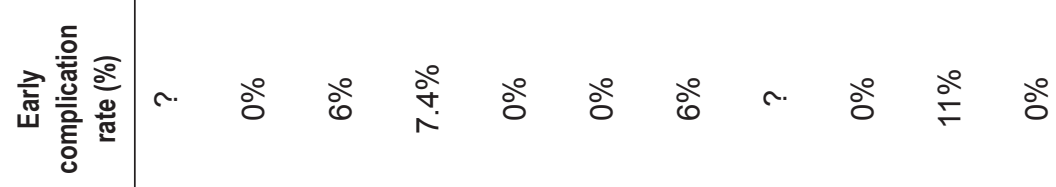

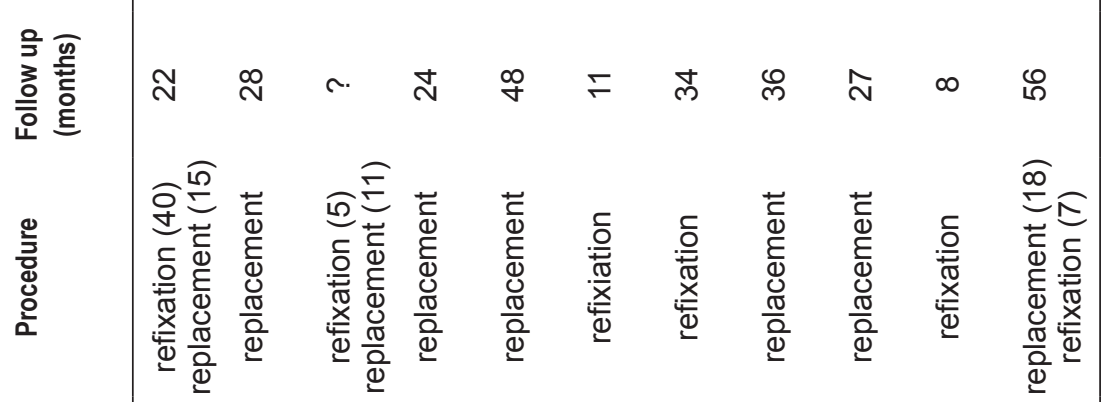

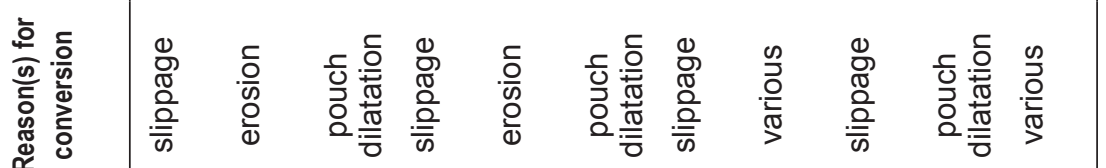

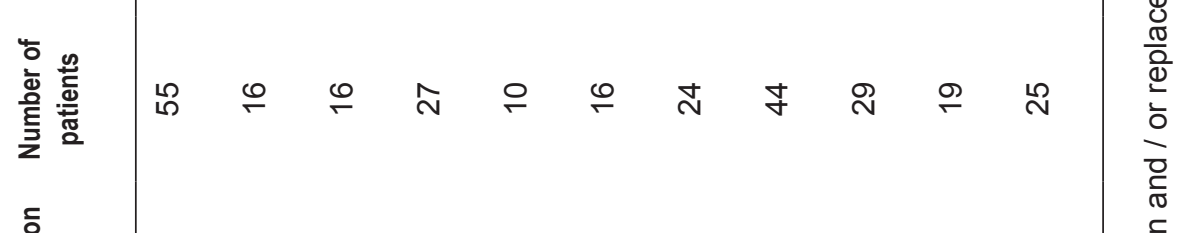

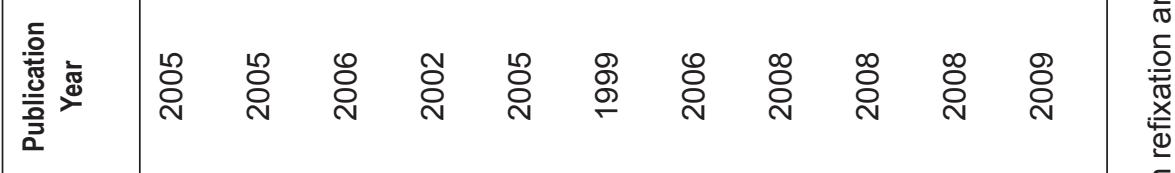

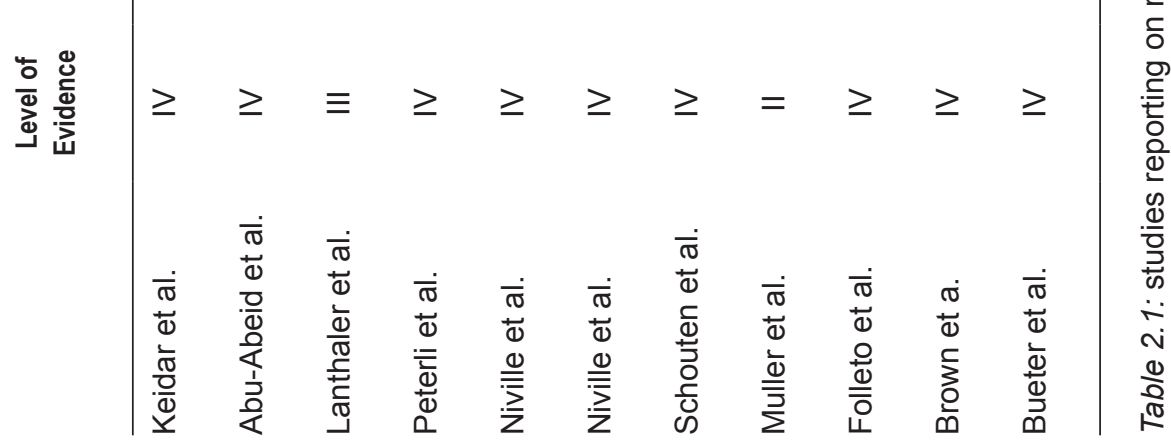




\begin{tabular}{lcc}
\hline & Follow up (months) & Weight loss (BMI) \\
\hline Niville et al. & 48 & -5.8 \\
Niville et al. & 11 & -2.2 \\
Schouten et al. & 34 & -2.8 \\
Muller et al. & 36 & +1.5 \\
Folleto et al. & 27 & -0.8 \\
Brown et al. & 8 & +2.4 \\
\hline
\end{tabular}

Table 2.2: weight loss results after rebanding procedures

7.7 days. Long term complications are not reported although it is mentioned that the reoperation rate is higher in this group compared to a patient group after primary RYGB [34]. Van Wageningen et al. described a case series of 47 conversions from failed LAGB to open (21) and laparoscopic (26) RYGB. Reasons for the conversion were again various but mostly insufficient weight loss $(62 \%)$ and band intolerance $(11 \%)$. Postoperative complications occurred in $17 \%$ and late complications in one patient (2\%). Re-operation rate was $0 \%$ although the follow up period was only 12 months [4]. Cohen et al. published a report on 38 conversions from LAGB to RYGB. Band erosion $(38 \%)$ and inadequate weight loss $(36 \%)$ were the main reasons for the conversion. This retrospective study reported $0 \%$ postoperative complications. Hospital stay was 3.2 days [35]. Muller et al. prospectively studied 30 patients that underwent conversion from LAGB to laparoscopic RYGB. Reasons for conversion were not clearly stated as well as early and late complications. However, re-operation rate after conversion was $20 \%$ [24]. Spivak. et al. described their experience with laparoscopic conversion from failed LAGB to RYGB in 33 patients with mainly a combination of insufficient weight loss (76\%) and pouch dilatation (64\%). Postoperative complications occurred $3 \%$ of patients as well as late complications and re-operations (both $3 \%$ ). Follow up with a mean period of 15.7 months was available for only 18 patients [36] . Finally, Kothari et al. performed 13 conversions from failed LAGB to open (8) and laparoscopic (5) RYGB. Early and late complications occurred in $15 \%$ and $23 \%$, respectively. Re-operations are not reported but follow up period was only 8.3 months [37].

In summary, results of the conversion to RYGB after failed LAGB are available for 438 patients (range: $11-70$ ) with a follow up period of 8 to 36 months. Of interest is that $14 \%$ to $25 \%$ of patients already underwent a revisional procedure before the conversion to RYGB because of band failure although this was only mentioned in 4 of 11 studies $[28,29,33,34]$. Early and late complication rate ranged from $0 \%$ to $17 \%$ and from 
$2 \%$ to $23 \%$, respectively. In all studies mortality was $0 \%$. The re-operation rate after conversion to RYGB was $0 \%$ to $20 \%$.

Conversion to RYGB - weight loss results

Eleven of the 12 studies focusing on the conversion from failed LAGB to RYGB reported postoperative weight loss after the conversion. Results are summarized in table 3.2. Weight loss varied from a decrease in BMI from 6.1 to $13.2 \mathrm{~kg} / \mathrm{m}^{2}$. Again, these results are time dependent as follow up period ranged from 8 to 36 months [4, 24, 28-31, 3337].

Conversion to BPD / DS - complications \& re-operations

Results of studies focusing on the conversion of failed LAGB to (laparoscopic) BPD / DS are summarized in table 4.1. A prospective study by Peterli et al. described 12 patients in whom failed LAGB was converted to open BPD. Reasons for conversion were insufficient weight loss and band intolerance. Mortality was zero and postoperative complications occurred in one patient (8\%). Two patients had to be re-operated $(16 \%)$ after a mean follow up period of 38 months [21]. Dolan et al. described 79 patients who had LAGB failure due to a variety of reasons. Conversion from LAGB to BPD was performed in 54 patients (16 open and 38 laparoscopic) and to DS in 25 patients (4 open and 21 laparoscopic). Hospital stay was 9 days. Mortality was $0 \%$ but postoperative complications, all leading to repeat laparotomies, occurred in $6.3 \%$ of patients. During a follow up period of 21 months $14 \%$ of patients needed revisional surgery. Late complications, e.g. vitamin insufficiencies, are not reported [38]. In another report by Peterli et al. 68 patients were treated by conversion from LAGB to open DS in case of band intolerance (60\%) and motility disorders (34\%). Early complication rate was $13 \%$ but no deaths occurred. However, long term complications after DS are reported in $23.5 \%$ of cases after a mean period of 4.1 years. Of note is that a wide range of vitamin and mineral deficiencies requiring hospitalization and parenteral supplementation occurred in a non-specified number of cases and was not included in the long term complications. No re-operations were performed [39]. Dapri et al. described 31 patients converted to laparoscopic DS after failed LAGB, all because of insufficient weight loss. Mortality was $3.2 \%$ (one patient) while hospital stay was 5.5 days. Early complications occurred in $13 \%$. Late complications, all leading to a re-operation, occurred in $20.6 \%$ of patients [40]. Topart en al. described their experience with the conversion of failed LAGB to open and laparoscopic DS in 21 patients. Early complication rate was $62 \%$ 
including $24 \%$ early re-operations because of leaks and abscess formation. Late reoperation rate was $9.5 \%$ after a follow up period of 18 months [33]. In summary, results of the conversion to BPD / DS after failed LAGB are available for 211 patients (range: $12-79$ ) with a follow up period of 12 to 38 months. Of interest is that $21 \%$ to $50 \%$ of patients already underwent a revisional procedure before the conversion to BPD / DS because of band failure although this was only mentioned in 2 of 5 studies. Early and late complication rate ranged from $6 \%$ to $62 \%$ and from $20.6 \%$ to $23.5 \%$, respectively. Mortality ranged from $0 \%$ to $3.2 \%$ but the latter represents only one patient. The reoperation rate after conversion to BPD / DS was $0 \%$ to $20.6 \%$.

\section{Conversion to BPD / DS - weight loss results}

Three of the 5 studies focusing on the conversion from failed LAGB to BPD / DS reported postoperative weight loss after the conversion. Results are summarized in table 4.2. Weight loss varied from an EWL of $44 \%$ to $71.1 \%$ depending on the follow up period which ranged from 12 to 28 months [33, 38, 40].

\section{Conversion to GSR - complications \& re-operations}

Studies focusing on the laparoscopic conversion from a failed LAGB to GSR are summarized in table 5. Dapri et al. describes 27 patients with inadequate weight loss after LAGB. The band was removed and a laparoscopic GSR performed. Postoperative complications occurred in one patient (3.7\%). Mean hospital stay was 3.2 days. Long term complications and re-operations are not mentioned [41]. Tucker et al. performed 10 conversions to laparoscopic GSR. Postoperative complications occurred in one patient (10\%). Long term complications and re-operations did not occur but unfortunately, both follow up period and weight loss are not mentioned [42]. Uglioni et al. reported on 29 patients undergoing a laparoscopic GSR after failed LAGB and compared these with primary GSR. Reasons for failure were various but mainly band intolerance (34\%) and slippage (31\%). Early complication rate was $13.8 \%$. Follow up was 24 months and in this period, complications occurred in $10.3 \%$ all requiring re-operations. Also, another 3 patients $(10.3 \%)$ needed second stage surgery because of insufficient weight loss. There were no significant differences between primary GSR and secondary GSR [43]. Another 10 patients underwent conversion to GSR and were described by Frezza et al. All patients had insufficient weight loss after LAGB. No deaths, short or long term complications occurred. Follow up was 19.1 months [44]. Finally, Acholonu et al. described a series of 15 patients with insufficient weight loss or weight regain (9 patients) and band slippage 


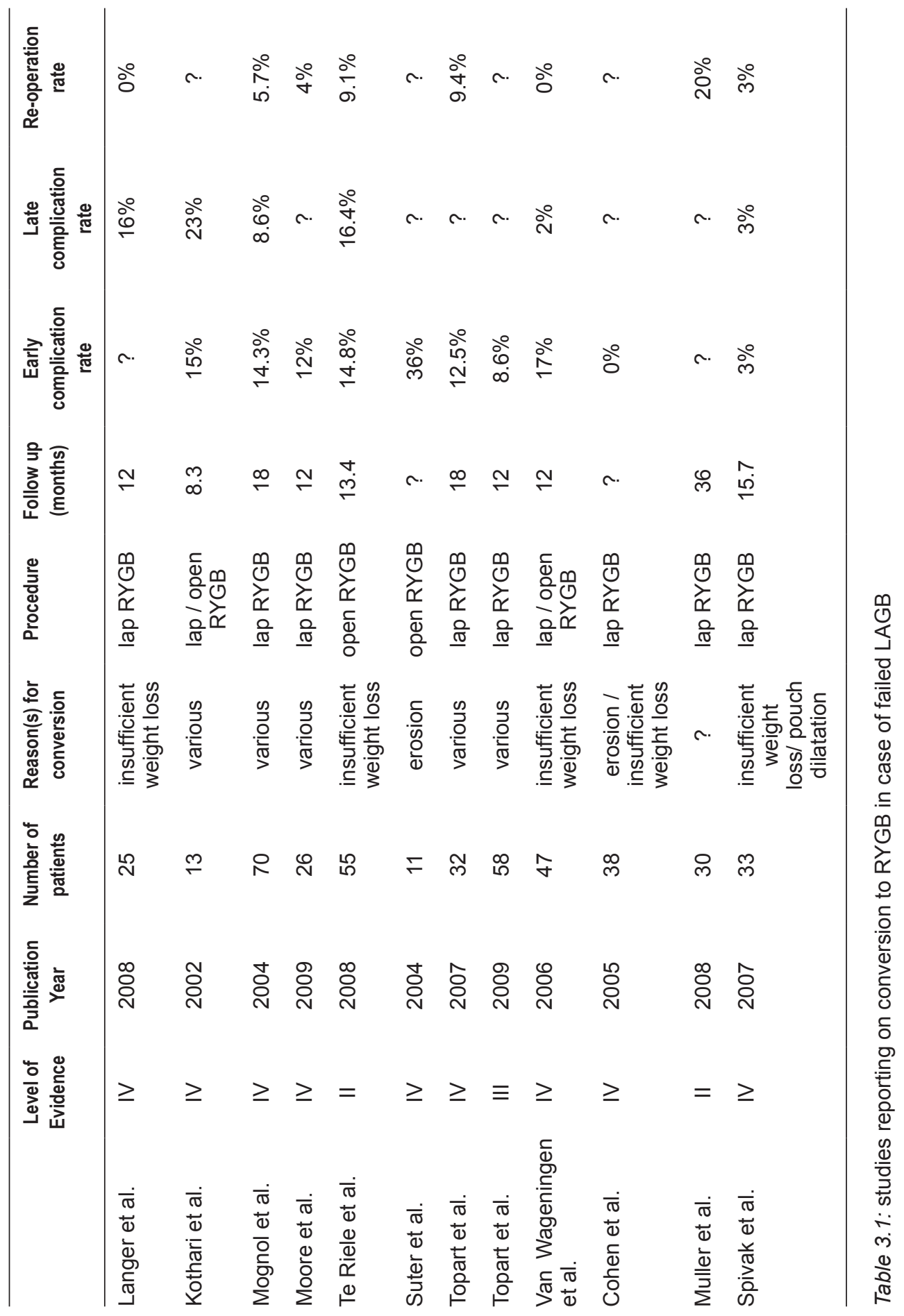




\begin{tabular}{lcc}
\hline & Follow up (months) & Weight loss (BMI / \%EWL) \\
\hline Langer et al. & 12 & -12.2 \\
Kothari et al. & 8.3 & $43 \%$ \\
Mognol et al. & 18 & -12.7 \\
Moore et al. & 12 & $33 \%$ \\
Te Riele et al. & 13.4 & -12.1 \\
Topart et al. & 18 & -11.7 \\
Topart et al. & 12 & -10.7 \\
Van Wageningen et al. & 12 & -8.1 \\
Cohen et al. & $?$ & -13.2 \\
Muller et al. & 36 & -6.1 \\
Spivak et al. & 15.7 & -11.7 \\
\hline
\end{tabular}

Table 3.2: weight loss results after conversion to RYGB

(4 patients) after LAGB. Mean hospital stay was 5 days. Early complication rate was $13 \%$, late complications and re-operations are not mentioned [45].

In summary, results of the conversion to laparoscopic GSR after failed LAGB are available for 91 patients (range: 10 - 29) with a follow up period of 12 to 24 months. No patients underwent revisional procedures before the conversion. Mortality was zero in all studies. Early and late complication rate ranged from $0 \%$ to $13.8 \%$ and from $0 \%$ to $10.3 \%$, respectively. The re-operation rate after conversion to GSR was $0 \%$ to $10.3 \%$.

Conversion to GSR - weight loss results

Only 3 of the 5 studies focusing on the conversion from failed LAGB to GSR reported postoperative weight loss after the conversion. The range of weight loss cannot be described because different outcome parameters were used (EWL, \%EBMI loss and BMI loss) [41, 44]. 


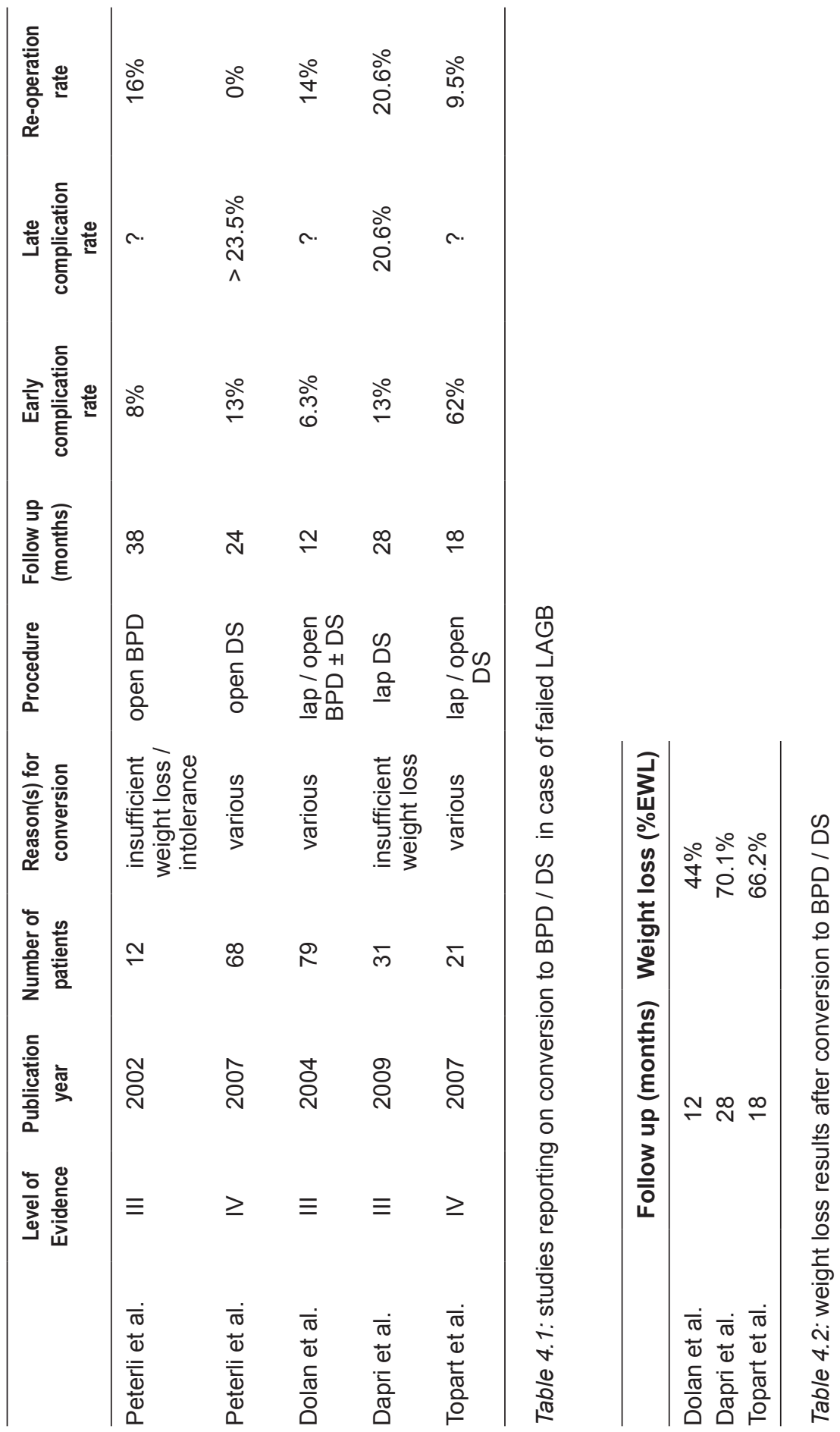




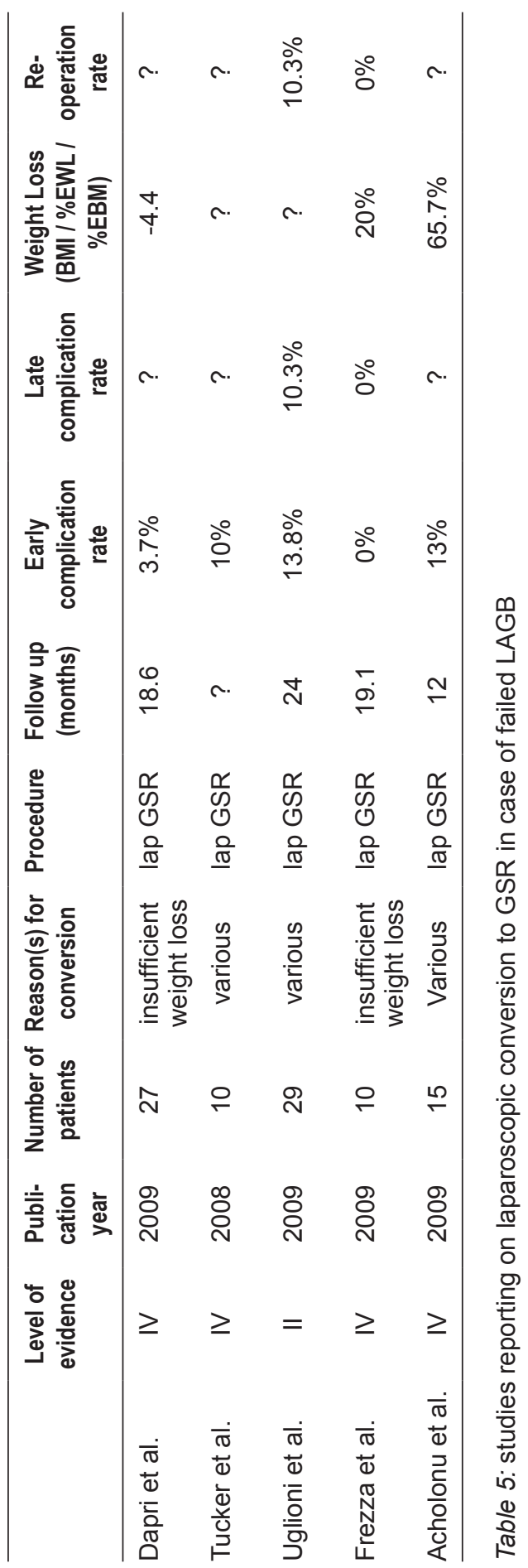




\section{Discussion}

LAGB is nowadays one of the most performed bariatric procedures. The lap-band system alone has been implanted in more than 500,000 patients worldwide and the placement of LAGB in general increased with nearly 150,000 implantations in 2008 according to a survey by Buchwald et al $[46,47]$. Results of LAGB are generally satisfactory with an EWL of $47.5 \%$ (range: $32.0 \%-70.0 \%$ ) although weight loss and decrease of obesityrelated comorbidities are better after more malabsorptive procedures [3]. However, in most studies follow up period is less than 2 years while weight loss after LAGB tends to be more slowly and gradually. The systematic review by O'Brien et al. shows that 10 years after gastric banding weight loss is comparable with other procedures like roux-en-y gastric bypass (RYGB) (59\% and 52\% EWL, respectively) [6]. However, long term results after LAGB are scarce and difficult to interpret. Many re-operations are necessary during follow up including conversions to other bariatric procedures and this obviously has influence on, for example, weight loss results. The main reasons for these re-operations are complications like pouch dilatation, anterior or posterior slippage, band erosion, band leakage and port-related problems. Fortunately, these complications are decreasing because of the development of new techniques and new bands. After the introduction of the pars flaccida technique the percentage of band slippages has dropped dramatically, as reported in several studies: from $16 \%$ to $4 \%$ [12] and from $44 \%$ to $8 \%$ [7]. Many technical improvements have been made to the band itself like low pressure - high volume bands instead of high pressure- low volume bands resulting in a decrease in re-operation rate because of less slippages and possibly erosions [13, 14, 48, 49]. However, it must be kept in mind that the follow up period is very important in discussing the re-operation rate after LAGB. Most publications report only short term results after LAGB which explains re-operation rates as low as $2 \%$. A follow up of a reasonably sized patient population of 3 years and preferably 5 years is necessary for a reliable estimation of the re-operation rate. Because of the increasing patient population worldwide with a gastric band the number of necessary re-operations will increase in the future. This literature review summarizes the possibilities in case of band failure or complications and provides where possible evidence for the different reoperations and conversions.

The most simple and straightforward method to deal with band-related problems like slippage and dilatation is to refixate or replace the band. Eleven reports have been published describing this method [7, 17-22, 24-27]. The total patient group included 281 patients with a range of 10 to 55 patients per study. All procedures were performed by 
laparoscopy and the conversion rate to laparotomy was mentioned in 8 studies: $12.5 \%$ [7], 10\% [22], 1.8\% [18] and $0 \%$ in 5 studies [17, 19-21, 24]. Postoperative mortality was $0 \%$ in all studies while the early complication rate was also $0 \%$ in 5 studies. The studies that had early postoperative complications reported a range from $6 \%$ to $11 \%$ but these were all minor complications (wound infection or hematoma, transient dysphagia). The late complication and re-operation rate are interwoven in these studies because re-operations are usually a result of a long term complication like slippage or pouch dilatation. The follow up period after the initial re-operation was 8 to 58 months with a mean of 29.4 months. Because of the late occurrence of complications after LAGB it is expected that after the re-operation a follow up period of more than 3 years is also necessary in order to give a reliable percentage of re-operations. In that case, only 3 studies are available which have re-operation rates of $10 \%, 28 \%$ and $45 \%$ [22, 24 , 27]. On the other hand, the re-operations are usually performed using new techniques (pars flaccida) and newer bands (low pressure - high volume) and are therefore not comparable with the initial LAGB. The authors all come to the same conclusion: when considering rebanding, patient selection is crucial. Patients who have had good weight loss after LAGB and have a purely technical failure do benefit from rebanding. Patients with poor weight loss or noncompliance might be better off with a conversion to another bariatric procedure because the re-failure rate is high with re-operation rates up to $45 \%$. This important conclusion has been drawn by the authors with the longest follow up period and is therefore, based on the available literature, justified [7, 24, 27].

The second possibility to deal with a band failure is conversion to the most common bariatric procedure, RYGB. This has been described in 12 reports with a total population group of 425 patients [4, 24, 28-36]. Reasons for LAGB failure were various but included pouch dilatation, slippage, band intolerance and insufficient weight loss. Also, several studies reported on the conversion to RYGB in case of band erosion [4, 32, 34, 35]. In 3 studies the procedure was performed by laparotomy [4, 31, 32]. In the remaining 8 studies it was performed by laparoscopy with a conversion to laparotomy of $4.3 \%$ [29], 3.4\% [34] and $0 \%$ in 6 studies [24, 28, 30, 33, 35, 36]. The early postoperative complication rate was $0 \%$ to $17 \%$ and therefore comparable with complications after rebanding (6\% to $11 \%)$. Early complications are usually more severe than after rebanding procedures, e.g. staple line leakage, intra-abdominal abscess formation and bowel perforations. However, mortality rate was $0 \%$ in all studies. Late complications were not described in 6 of the 12 studies and results are therefore not reliable. The re-operation rate after conversion to RYGB was $0 \%$ to $20 \%$ compared to $0 \%$ to $45 \%$ 
after rebanding. The follow up period was however not comparable with a mean of 29.4 months after rebanding and only 16.6 months after conversion to RYGB. The only study with a follow up of 3 years or more was by Muller et al. The other studies had a follow up between 12 and 18 months. The re-operation rate in all studies was between $0 \%$ and $9.4 \%$ while it was $20 \%$ in the study of Muller et al. Reasons for re-operation in the latter were insufficient weight loss, small bowel obstruction and pouch diverticula [24]. Summarizing these findings, early complications are more severe but the total amount of complications and re-operations are not higher after conversion to RYGB compared to rebanding procedures. On the other hand, weight loss is far better after conversion to RYGB with a decrease in BMI of 6.1 to $13.2 \mathrm{~kg} / \mathrm{m}^{2}$. After rebanding the decrease in BMI is at the very most $5.8 \mathrm{~kg} / \mathrm{m}^{2}$ [22].

A more technically challenging and less described possibility in case of band failure is conversion to BPD / DS. Early complication rate was comparable (6\% to $13 \%$ ) but again more severe than after rebanding procedures because of complications like staple line leakages [38-40] and pulmonary embolism [21, 39]. Mortality ranged from $0 \%$ to $3.2 \%$ but the latter represents only one patient [40]. The study by Peterli et al. described a late complication rate of $23.5 \%$. This percentage is excluding an unknown number of patients with a variety of vitamin and mineral deficiencies requiring hospitalization and parental supplementation. The study by Dolan et al. described late complications in $20.6 \%$ of patients, mainly internal hernias requiring a re-operation. Despite of all these serious problems weight loss after the conversion from LAGB to BPD / DS is very good with an EWL of $44 \%$ to $71.1 \%$. A recently added possibility in case of failure after LAGB is conversion to laparoscopic GSR. Late complications, re-operations and weight loss are poorly described in most of the studies and therefore reliable percentages and comparisons with the other revisional procedures are not possible. It seems the experience is too limited to compare the results with more extensively described procedures as rebanding or conversion to RYGB. Moreover, GSR after gastric banding is not a logic choice because the band causes adhesions and fibrosis in the fragile area of the sleeve resection.

Of interest is the low mortality rate. In all studies reporting on rebanding procedures, conversions to RYGB and conversions to GSR the mortality was $0 \%$. In one study describing conversion to BPD / DS the mortality was 3.2\%. In contrast, the meta-analysis of Buchwald et al. describing mortality rates after bariatric surgery reported a mean of $1.65 \%$ after revisional procedures and re-operations [5]. Unfortunately, this percentage is not further subdivided into categories. It might be possible that re-operations after more complex surgery like BPD / DS leads to higher mortality than re-operations after a 
"simple" LAGB. However, based on the available literature this is only speculative. The fact remains that the mortality of re-operations after LAGB in repeated series is very low with 1 out of 987 patients $(0.1 \%)$.

\section{Conclusion}

In conclusion, because of the evolution in operative techniques and the bands itself the incidence of re-operations after LAGB is decreasing. In combination with the low perioperative morbidity and satisfactory long term results LAGB will maintain its position as the first step in bariatric surgery. However, because of the large number of procedures and the late occurrence of complications many re-operations can be anticipated in the near future. It is important to decide what kind of re-operation is suitable for the patient. Summarizing the present literature review an evidence-based decision making algorithm is presented (figure 2). In case of band failure due to purely technical band problems a refixation or replacement of the band is a feasible option in patients with good weight loss and good compliance. In case of poor weight loss and non-compliance as well as severe pouch dilatation or erosion, conversion to laparoscopic RYGB is the preferred option with comparable early and late complications but lower rates of re-operations and a better weight loss. The conversion to BPD / DS is, based on the scarcely available literature, not more beneficial but late complications are more apparent especially procedure-specific nutritional problems. The described initial experience with laparoscopic conversion to GSR does not provide evidence to choose this option above the conversion to laparoscopic RYGB. Randomized trials comparing the different possibilities in case of failure after LAGB are not yet available. Future research focusing on this important topic might optimize the decision making process for bariatric surgeons. Until then, based on the available literature, it seems wise to either perform a laparoscopic rebanding or a laparoscopic conversion to RYGB in case of band failure. As these re-operations are proven to be safe and effective a stepwise approach to the bariatric patient seems warranted. The simple and safe LAGB first, followed if needed by a conversion to a different procedure of which RYGB is the best proven choice. 


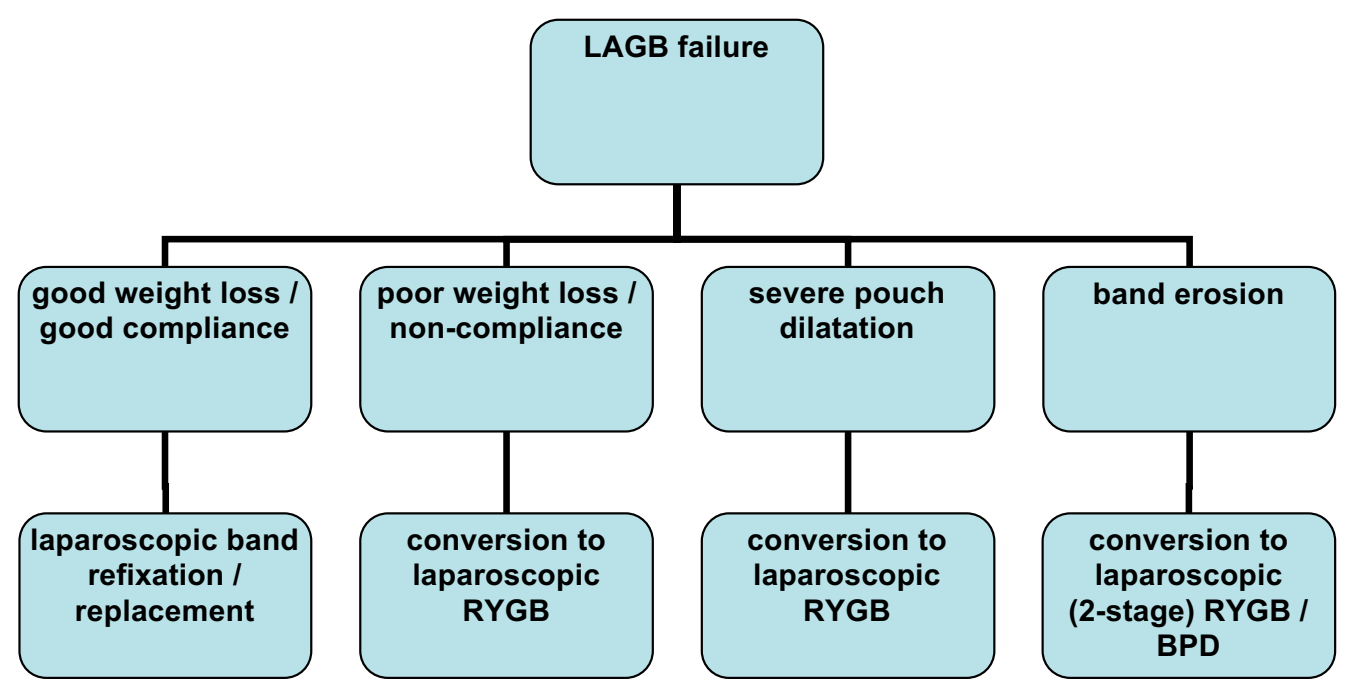

Figure 2: decision making algorithm in case of failure after LAGB 


\section{References}

1. Fisher, B.L. and P. Schauer, Medical and surgical options in the treatment of severe obesity. Am J Surg, 2002. 184(6B): p. 9S-16S.

2. Bjorntorp, P., Results of conservative therapy of obesity: correlation with adipose tissue morphology. Am J Clin Nutr, 1980. 33(2 Suppl): p. 370-5.

3. Buchwald, H., et al., Bariatric surgery: a systematic review and meta-analysis. Jama, 2004. 292(14): p. 1724-37.

4. van Wageningen, B., et al., Revision of failed laparoscopic adjustable gastric banding to Roux-en-Y gastric bypass. Obes Surg, 2006. 16(2): p. 137-41.

5. Buchwald, H., et al., Trends in mortality in bariatric surgery: a systematic review and metaanalysis. Surgery, 2007. 142(4): p. 621-32; discussion 632-5.

6. O'Brien, P.E., et al., Systematic review of medium-term weight loss after bariatric operations. Obes Surg, 2006. 16(8): p. 1032-40.

7. Schouten, R., F.M. van Dielen, and J.W. Greve, Re-operation after laparoscopic adjustable gastric banding leads to a further decrease in BMI and obesity-related co-morbidities: results in 33 patients. Obes Surg, 2006. 16(7): p. 821-8.

8. Schouten, R., et al., Conversion of vertical banded gastroplasty to Roux-en-Y gastric bypass results in restoration of the positive effect on weight loss and co-morbidities: evaluation of 101 patients. Obes Surg, 2007. 17(5): p. 622-30.

9. van Gemert, W.G., et al., Revisional surgery after failed vertical banded gastroplasty: restoration of vertical banded gastroplasty or conversion to gastric bypass. Obes Surg, 1998. 8(1): p. 21-8.

10. Chapman, A.E., et al., Laparoscopic adjustable gastric banding in the treatment of obesity: a systematic literature review. Surgery, 2004. 135(3): p. 326-51.

11. Weiner, R., et al., A prospective randomized trial of different laparoscopic gastric banding techniques for morbid obesity. Surg Endosc, 2001. 15(1): p. 63-8.

12. O'Brien, P.E., et al., A prospective randomized trial of placement of the laparoscopic adjustable gastric band: comparison of the perigastric and pars flaccida pathways. Obes Surg, 2005. 15(6): p. 820-6.

13. Fried, M., The current science of gastric banding: an overview of pressure-volume theory in band adjustments. Surg Obes Relat Dis, 2008. 4(3 Suppl): p. S14-21.

14. Fried, M., W. Lechner, and K. Kormanova, Physical principles of available adjustable gastric bands: how they work. Obes Surg, 2004. 14(8): p. 1118-22.

15. Miller, K., A. Pump, and E. Hell, Vertical banded gastroplasty versus adjustable gastric banding: prospective long-term follow-up study. Surg Obes Relat Dis, 2007. 3(1): p. 84-90.

16. Anonymous, Centre for Evidence-based Medicine, Oxford, UK

17. Niville, E., A. Dams, and T. Anne, Laparoscopic repositioning of an adjustable silicone gastric band for pouch dilatation and stoma obstruction. Surg Endosc, 1999. 13(1): p. 65-7.

18. Keidar, A., et al., Band slippage after laparoscopic adjustable gastric banding: etiology and treatment. Surg Endosc, 2005. 19(2): p. 262-7.

19. Abu-Abeid, S., et al., Treatment of intra-gastric band migration following laparoscopic banding: safety and feasibility of simultaneous laparoscopic band removal and replacement. Obes Surg, 2005. 15(6): p. 849-52.

20. Lanthaler, M., et al., Laparoscopic gastric re-banding versus laparoscopic gastric bypass as a rescue operation for patients with pouch dilatation. Obes Surg, 2006. 16(4): p. 484-7.

21. Peterli, R., et al., Re-operations following laparoscopic adjustable gastric banding. Obes Surg, 2002. 12(6): p. 851-6. 
22. Niville, E., et al., Results of lap rebanding procedures after Lap-Band removal for band erosion -- a mid-term evaluation. Obes Surg, 2005. 15(5): p. 630-3.

23. Niville, E. and A. Dams, Late pouch dilation after laparoscopic adjustable gastric and esophagogastric banding: incidence, treatment, and outcome. Obes Surg, 1999. 9(4): p. 381-4.

24. Muller, M.K., et al., High secondary failure rate of rebanding after failed gastric banding. Surg Endosc, 2008. 22(2): p. 448-53.

25. Foletto, M., et al., Laparoscopic gastric rebanding for slippage with pouch dilation: results on 29 consecutive patients. Obes Surg, 2008. 18(9): p. 1099-103.

26. Brown, W.A., et al., Symmetrical pouch dilatation after laparoscopic adjustable gastric banding: incidence and management. Obes Surg, 2008. 18(9): p. 1104-8.

27. Bueter, M., et al., Reoperations after gastric banding: replacement or alternative procedures? Surg Endosc, 2009. 23(2): p. 334-40.

28. Langer, F.B., et al., Inadequate weight loss vs secondary weight regain: laparoscopic conversion from gastric banding to Roux-en-Y gastric bypass. Obes Surg, 2008. 18(11): $p$. 1381-6.

29. Mognol, P., D. Chosidow, and J.P. Marmuse, Laparoscopic conversion of laparoscopic gastric banding to Roux-en-Y gastric bypass: a review of 70 patients. Obes Surg, 2004. 14(10): p. 1349-53.

30. Moore, R., et al., Early results of conversion of laparoscopic adjustable gastric band to Roux-en-Y gastric bypass. Surg Obes Relat Dis, 2009. 5(4): p. 439-43.

31. te Riele, W.W., et al., Conversion of failed laparoscopic gastric banding to gastric bypass as safe and effective as primary gastric bypass in morbidly obese patients. Surg Obes Relat Dis, 2008. 4(6): p. 735-9.

32. Suter, M., et al., Band erosion after laparoscopic gastric banding: occurrence and results after conversion to Roux-en-Y gastric bypass. Obes Surg, 2004. 14(3): p. 381-6.

33. Topart, P., G. Becouarn, and P. Ritz, Biliopancreatic diversion with duodenal switch or gastric bypass for failed gastric banding: retrospective study from two institutions with preliminary results. Surg Obes Relat Dis, 2007. 3(5): p. 521-5.

34. Topart, P., G. Becouarn, and P. Ritz, One-year weight loss after primary or revisional Rouxen-Y gastric bypass for failed adjustable gastric banding. Surg Obes Relat Dis, 2009. 5(4): p. 459-62.

35. Cohen, R., et al., Laparoscopic revisional bariatric surgery: myths and facts. Surg Endosc, 2005. 19(6): p. 822-5.

36. Spivak, H., et al., Laparoscopic revision from LAP-BAND to gastric bypass. Surg Endosc, 2007. 21(8): p. 1388-92.

37. Kothari, S.N., et al., Lap-band failures: conversion to gastric bypass and their preliminary outcomes. Surgery, 2002. 131(6): p. 625-9.

38. Dolan, K. and G. Fielding, Bilio pancreatic diversion following failure of laparoscopic adjustable gastric banding. Surg Endosc, 2004. 18(1): p. 60-3.

39. Peterli, R., et al., Prospective study of a two-stage operative concept in the treatment of morbid obesity: primary lap-band followed if needed by sleeve gastrectomy with duodenal switch. Obes Surg, 2007. 17(3): p. 334-40.

40. Dapri, G., G.B. Cadiere, and J. Himpens, Laparoscopic conversion of adjustable gastric banding and vertical banded gastroplasty to duodenal switch. Surg Obes Relat Dis, 2009. 5(6): p. 678-83.

41. Dapri, G., G.B. Cadiere, and J. Himpens, Feasibility and technique of laparoscopic conversion of adjustable gastric banding to sleeve gastrectomy. Surg Obes Relat Dis, 2009. 5(1): p. 72-6. 
42. Tucker, O., et al., Revisional surgery after failed laparoscopic adjustable gastric banding. Surg Obes Relat Dis, 2008. 4(6): p. 740-7.

43. Uglioni, B., et al., Midterm results of primary vs. secondary laparoscopic sleeve gastrectomy (LSG) as an isolated operation. Obes Surg, 2009. 19(4): p. 401-6.

44. Frezza, E.E., et al., Laparoscopic sleeve gastrectomy after gastric banding removal: a feasibility study. Surg Innov, 2009. 16(1): p. 68-72.

45. Acholonu, E., et al., Safety and short-term outcomes of laparoscopic sleeve gastrectomy as a revisional approach for failed laparoscopic adjustable gastric banding in the treatment of morbid obesity. Obes Surg, 2009. 19(12): p. 1612-6.

46. Buchwald, H. and D.M. Oien, Metabolic/bariatric surgery Worldwide 2008. Obes Surg, 2009. 19(12): p. 1605-11.

47. Anonymous, lap-band surgery quick facts. www.lap-band.us 2010.

48. Fried, M., K. Miller, and K. Kormanova, Literature review of comparative studies of complications with Swedish band and Lap-Band. Obes Surg, 2004. 14(2): p. 256-60.

49. Ceelen, W.P., A. Cardon, and P. Pattyn, Gastric banding for clinically severe obesity: results with the Swedish band. Surg Technol Int, 2004. 12: p. 103-9. 
CHAPTER 4

The endoscopic treatment of morbid obesity

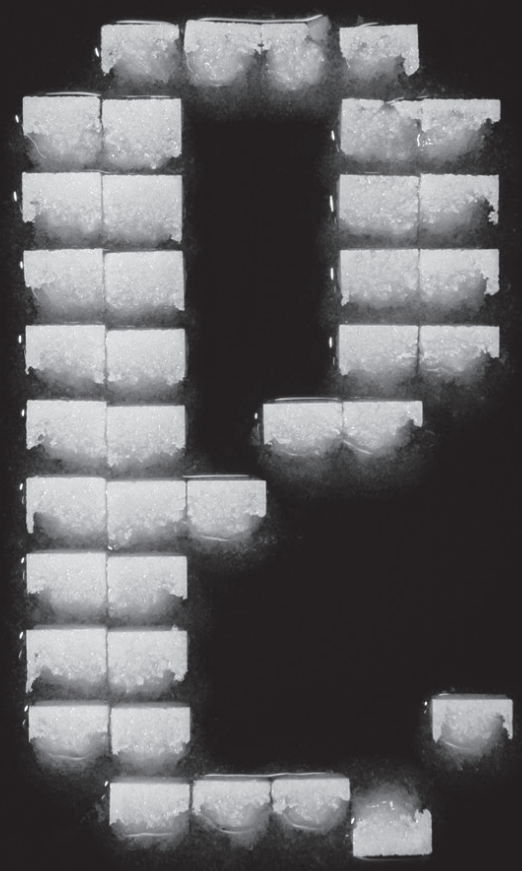




\section{Endoscopic duodenal - jenunal bypass sleeve in the treatment of morbid obesity}

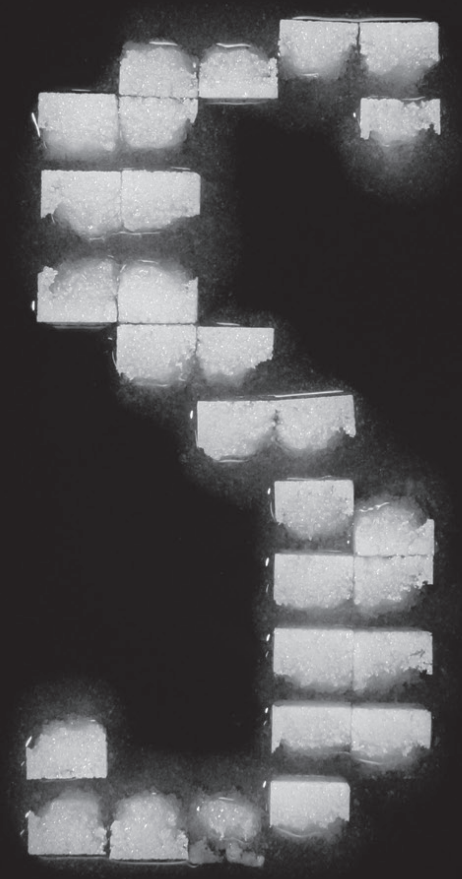

Ruben Schouten

Jan Willem M. Greve

Handbook of Obesity Surgery 2010

Editor: M. Deitel, FD-communications Inc., Toronto, Canada ISBN 978-0-9684426-5-4 


\section{Introduction}

Bariatric surgery is an important option in the treatment of morbid obesity. Several studies have shown that conservative measures (e.g. diet, exercise and lifestyle modification) are not successful in a long term manner. Bariatric operations on the other hand induce long term weight loss, a reduction or even cessation of obesity-related comorbidities (in particular diabetes, cardiovascular disease and obstructive sleep apnea syndrome) and have a positive influence on the quality of life in these chronically ill patients. However, the success of bariatric surgery also has a drawback. The direct postoperative complications after these procedures are an important issue, with a mortality rate ranging from $0.1 \%$ for purely restrictive procedures to $1.1 \%$ for malabsorptive procedures like biliopancreatic diversion (BPD). Moreover, the number of long term complications and re-operations is high, specifically after restrictive procedures like vertical banded gastroplasty (10-41\%) and laparoscopic adjustable gastric banding (2-80\%, depending on used technique and duration of follow-up). Known risk factors for mortality and for developing complications are male patients, superobesity and one or more comorbidities.

\section{Pre-operative weight loss}

Studies on preoperative weight loss prior to bariatric surgery in order to decrease the risk of developing perioperative and late complications have been performed. The only prospective randomized trial in this matter is by Alami et al. and showed a significant reduction in operation time and in short-term excess weight loss (\%EWL). Complication and conversion rate, as well as long-term weight loss, were not affected by preoperative weight loss. In a prospective study by Still et al., $48 \%$ of patients lost more than $10 \%$ of their excess body weight prior to surgery by means of a diet. Postoperatively, these patients had a shorter hospital stay and better short-term weight loss. Alvadaro et al. performed a retrospective analysis and also found shorter hospital stay and operation time after a preoperative weight loss of more than $5 \%$ body weight. Other authors have reported more possible advantages of preoperative weight loss, e.g. less blood loss during surgery and a reduction in liver size which makes the operation technically easier. Even more interesting is the effect of preoperative weight loss on the long-term results of bariatric surgery. Alger-Mayer et al. showed in 95 patients that even 4 years after the operation preoperative weight loss was still positively correlated with \%EWL. Although these studies have reported various outcome parameters the overall message is that preoperative weight loss is a valuable preparation for the morbidly obese patient. 
However, many patients fail to lose weight before the operation, even in a studycontrolled environment, because it is usually by means of a diet.

\section{DJBS: design}

The DJBS, also known as the EndoBarrier Gastrointestinal Liner (GI Dynamics, Inc, Lexington, Massachusetts, USA) is a minimally invasive tool designed to help patients lose weight preoperatively. It is a single use minimally invasive device mimicking a duodenal-jejunal bypass (figure 1). The device is comprised of a nitinol anchor, which is used to reversibly affix the device to the wall of the duodenum (duodenal bulb) and an impermeable fluoropolymer sleeve extending $60 \mathrm{~cm}$ into the small bowel (figure 2). The device is open at both ends to allow food to pass. The anchor is located in the duodenal bulb and the sleeve stretches out into the duodenum and partially into the jejunum. As a result, pancreatic and bile juices will mix with the food only after the sleeve which may induce malabsorption and creates a bypass of the proximal intestinal tract.

\section{DJBS: working mechanism}

The bypass effect of the device is relatively small because only the duodenum and part of the jejunum are excluded. In comparison with malabsorptive procedures like BPD this is negligible. There is also no restriction in the gastrointestinal tract although the presence of a foreign body in the duodenum causes early satiety. This was reported by patients from our clinic in up to $80 \%$. Recently, a number of studies have investigated the role of foregut exclusion in the treatment of obesity and specifically in combination with type 2 diabetes mellitus (T2DM). Bypassing the duodenum could be the main working mechanism of the DJBS. This will be addressed more thoroughly in the paragraph on diabetes. 


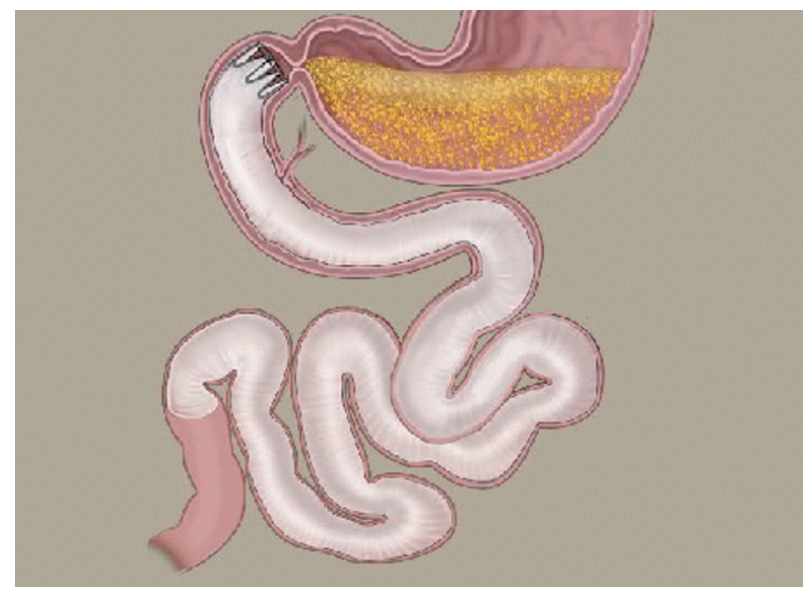

Figure 1: the DJBS mimics a duodenal-jejunal bypass

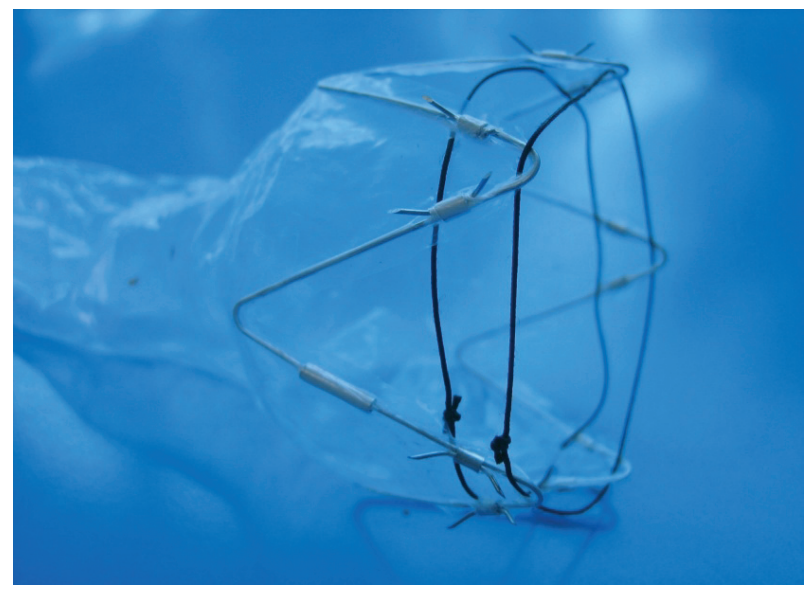

Figure 2: the device is comprised of a nitinol anchor and an impermeable fluoropolymer sleeve

\section{DJBS: procedure}

Initial access to the stomach and duodenum is achieved by a standard gastroscope through which a guide wire is advanced into the duodenum. The encapsulated device on a custom catheter is tracked over the guide wire into the duodenum. The capsule at the distal end holds the sleeve and anchor (figure 3). The catheter has an atraumatic ball end which is advanced through the intestine deploying the sleeve behind itself. After full extension of the sleeve the anchor is deployed in the duodenal bulb $0.5 \mathrm{~cm}$ distally from the pylorus. The procedure is performed under fluoroscopic control. 
Removal of the DJBS is achieved with a custom grasper that grasps the polypropylene tether on the anchor. A foreign body retrieval hood at the tip of the endoscope is used to incorporate the device in order to avoid any damage of the stomach or esophagus on the way out of the patient's body.

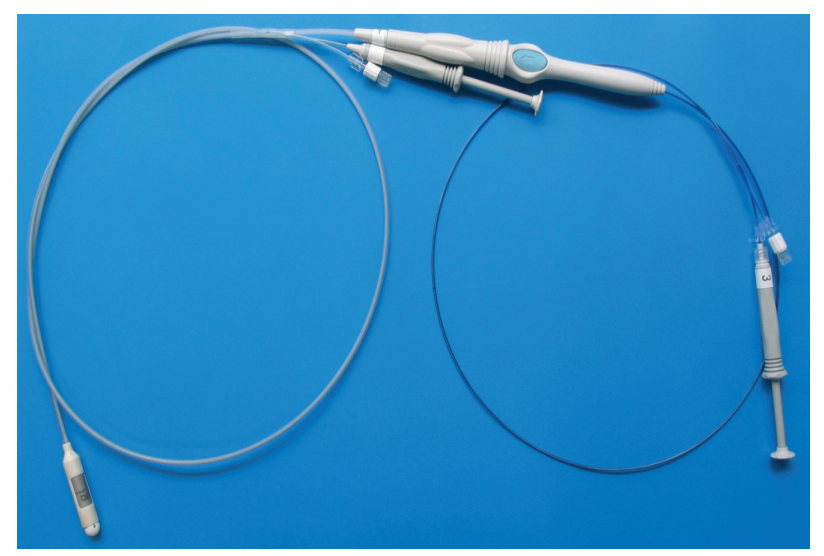

Figure 3: the implant device with capsule

\section{Results}

Tarnhof et al. reported the first experience with the device in an animal (porcine) model. Six animals underwent implantation and the device was left in situ for 90 to 120 days. Technical feasibility and patency of the device were good while tissue response was minimal. The first implantation in a human patient was reported by Gersin et al. Untill now, 3 studies have been performed describing consecutive treated patients with the DJBS. The results of these first 3 clinical studies are summarized in table 1.

The first series of 12 patients was described by Rodriquez-Grunert et al. In this nonrandomized prospective study the mean preoperative BMl was $43.0 \mathrm{~kg} / \mathrm{m}^{2}$. Mean weight loss was $23.6 \%$ EWL after 3 months while all patients lost more than $10 \%$ of their excess weight. Implant time was 33 minutes and explant time 43 minutes. No severe adverse events (AE) occurred. Post-implant nausea and abdominal pain were the most frequently reported mild AE's along with temporarly explant or post-explant site inflammation. 
A prospective randomized trial was reported by Tarnoff et al. describing 25 device patients compared to 14 control patients. Both groups followed a strict low fat diet. Twenty patients $(80 \%)$ kept the device for a total of 12 weeks. Five patients had to undergo early explantation due to upper gastrointestinal bleeding (3), anchor migration (1) and sleeve obstruction (1). Apart from these complications the acceptance of the device by the patients was high. Weight loss after 12 weeks was $22 \%$ EWL in the device group and $5 \%$ in the control group.

Unpublished data from another prospective randomized trial from our clinic shows comparable results. Thirty device patients were included and compared to 11 control patients. Four devices could not be placed because of techical problems. No severe AE's occurred. Also in this study, post-implant nausea and abdominal pain were the most frequently reported AE's, mainly in the first 2 weeks after implantation. Four devices had to be removed early because of sleeve obstruction (1), migration (2) and unexplained abdominal pain (1). Weight loss after 12 weeks was respectively $19.0 \%$ and $6.9 \%$ for the device group and control group while $88 \%$ of patients lost more than $10 \%$ of their excess weight. Implant and explant times were shorter in this study; 26 and 17 minutes, respectively.

Rodriguez et al.

Tarnoff et al.

Schouten et al.

\begin{tabular}{lcccccc}
\hline & Device & Control & Device & Control & Device & control \\
\hline Patients $(\mathrm{n})$ & 12 & - & 25 & 14 & 30 & 11 \\
BMI $\left(\mathrm{kg} / \mathrm{m}^{2}\right)$ & 43 & - & 42 & 40 & 49 & 49 \\
Implant time $(\mathrm{min})$ & 27 & - & 39 & - & 26 & - \\
Explant time $(\mathrm{min})$ & 43 & - & 21 & - & 17 & - \\
Severe AE's(n) & none & - & 5 & none & none & none \\
Mild AE's $(\mathrm{n})$ & 71 & - & 56 & none & 80 & 3 \\
Early explants $(\mathrm{n})$ & 2 & - & 5 & - & 4 & - \\
Weight loss $(\% \mathrm{EWL})$ & 23.6 & - & 22 & 5 & 19.0 & 6.9 \\
\hline
\end{tabular}

Table 1: results of the DJBS in clinical trials

\section{Diabetes}

Because of the theoretical impact on diabetes mellitus caused by the foregut exclusion (duodenum bypass), the DJBS has gained interest not only for its potential role in weight loss but also in the treatment of T2DM. Recently, a number of studies have investigated 
the role of foregut exclusion in the treatment of obesity and specifically in combination with T2DM. Observational studies of roux-en-y gastric bypass patients have shown an early improvement of T2DM after the operation when weight loss was not yet achieved. Studies by Rubino et al. prove that bypassing a short segment of proximal intestine causes a rapid improvement of glucose homeostasis in diabetic rats, independently of food intake, body weight, malabsorption or nutrient delivery to the more distal bowel. The mechanism behind this phenomenon lies in the intestinal hormones produced in the duodenum and the proximal jejunum (foregut exclusion theory). Involved hormones are glucose-dependent insulinotropic polypetide (GIP), which has a positive effect on insulin production and sensitivity and cholecystokinin (CCK), which influences satiety as well as insulin production. Another theory is that the delivery of undigested nutrients to the more distal bowel could also cause an improvement in T2DM patients (hindgut theory) caused by elevation of the intestinal hormones produced in the ileum. These hormones, glucagon like peptide-1 (GLP-1) and peptide YY (PYY), cause improvement of diabetes and obesity by stimulating the growth of beta cell mass and inducing satiety. The design and position of the DJBS, with a small but specific part of excluded intestine, suggests that bypassing the duodenum is more important than the delivery of undigested nutrients to the ileum. The 3 clinical studies mentioned in the "results" parapgraph all describe the effect of the DJBS on T2DM although the number of patients with diabetes were small. Results are summarized in table 2. Four patients had diabetes in the study by Rodriquez-Grunert and it resolved in 3 cases. In the study by Tarnoff, 3 patients were diabetic. Improvement was observed in 2 patients while in 1 patient resolution occurred. In our study 8 patients had diabetes in the device group. Improvement was observed in 6 patients and resolution in 1 patient. These 7 patients were able to significantly lower insulin dosages and oral medication. Mean fasting glucose levels before the device placement and after 12 weeks were respectively $11.1 \mathrm{mmol} / \mathrm{L}$ and $9.3 \mathrm{mmol} / \mathrm{L}$. HbA1c levels decreased in the same period from $8.8 \%$ to $7.7 \%$.

In our opinion this is the most interesting feature of the DJBS. Because of the epidemic of T2DM, also in the non-obese population, treating therapy-resistent or severe T2DM patients with bariatric procedures is now being discussed. If the DJBS is capable of successfully treating and curing T2DM it would be preferable to a more invasive procedure. However, more research has to be performed focusing on diabetes and long term results. 
Rodriguez et al.

Tarnoff et al.

Schouten et al.

\begin{tabular}{lcccccc}
\hline & Device & Control & Device & Control & Device & control \\
\hline Patients $(n)$ & 4 & - & 3 & 1 & 8 & 2 \\
T2DM resolved $(n)$ & 3 & & 1 & 0 & 1 & 0 \\
T2DM improved $(n)$ & 0 & & 2 & 1 & 7 & 0 \\
T2DM no change $(n)$ & 1 & & 0 & 0 & 0 & 2 \\
\hline
\end{tabular}

Table 2: the effect of the DJBS on T2DM

\section{Conclusion}

The duodenal-jejunal bypass sleeve is safe and feasible for the treatment of morbid obesity. It is a totally endoscopic non-invasive device with good short-term weight loss. Furthermore, the device has a significant positive effect on glucose homeostasis in diabetic patients possibly due to bypassing the duodenum. More studies focusing on the working mechanism of the device have to be performed with the possibility of discovering important new aspects about the pathofysiology and treatment of obesity and diabetes. 


\section{Literature}

1. M. Tarnoff, S. Shikora and A. Lembo. Acute technical feasibility of an endoscopic duodenaljejunal bypass sleeve in a porcine model: a potentially novel treatment for obesity and type 2 diabetes. Surg Endosc, 2008. 22(3): p. 772-6.

2. L. Rodriguez-Grunert, M. Galvao Neto, M. Alamo et al. First human experience with endoscopically delivered and retrieved duodenal-jejunal bypass sleeve. Surg Obes Relat Dis, 2008. 4(1): p. 55-9.

3. M. Tarnoff, S. Shikora, A. Lembo et al. Chronic in-vivo experience with an endoscopically delivered and retrieved duodenal-jejunal bypass sleeve in a porcine model. Surg Endosc, 2008. 22(4): p. 1023-8.

4. K. Gersin, J. Keller, D. Stefanidis et al., Duodenal- jejunal bypass sleeve: a totally endoscopic device for the treatment of morbid obesity. Surg Innov, 2007. 14(4): p. 275-8.

5. M. Tarnoff, L. Rodriguez, A. Escalona et al. Open label, prospective, randomized controlled trial of an endoscopic duodenal-jejunal bypass sleeve versus low calorie diet for preoperative weight loss in bariatric surgery. Surg Endosc, 2008. 23(3): p. 650-6 



\section{A multi-center, randomized efficacy study of the EndoBarrier ${ }^{\mathrm{TM}}$ Gastrointestinal Liner for pre-surgical weight loss prior to bariatric surgery}

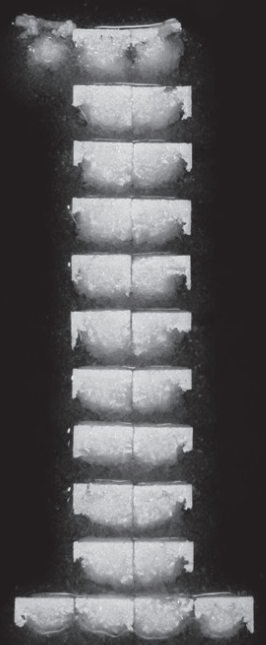

Ruben Schouten

Carianne S. Rijs

Nicole D. Bouvy

Wim Hameeteman

Ger H. Koek

Ignace M.C. Janssen

Jan-Willem M. Greve

Annals of Surgery 2010 Feb, 251(2): 236-43. 


\begin{abstract}
Background: the endoscopically placed duodenal-jejunal bypass sleeve (DJBS) or EndoBarrier ${ }^{\mathrm{TM}}$ Gastrointestinal Liner has been designed to achieve weight loss in morbidly obese patients. We report on the first European experience with this device.
\end{abstract}

Methods: a multi-center, randomized clinical trial was performed. Forty-one patients were included and 30 underwent sleeve implantation. Eleven patients served as a diet control group. All patients followed the same low-calorie diet during the study period. The purpose of the study was to determine the safety and efficacy of the device.

Results: 26 devices were successfully implanted. In 4 patients, implantation could not be achieved. Four devices were explanted prior to the initial protocol endpoint because of migration (1), dislocation of the anchor (1), sleeve obstruction (1) and continuous epigastric pain (1). The remaining patients all completed the study. Mean procedure time was 35 minutes (range: 12 - 102 minutes) for a successful implantation and 17 minutes (range: 5 - 99 minutes) for explantation. There were no procedure related adverse events. During the study period the 26 DJBS patients $(100 \%)$ had at least one adverse event, mainly abdominal pain and nausea during the first week after implantation. Initial mean body mass index (BMI, $\mathrm{kg} / \mathrm{m}^{2}$ ) was 48.9 and $47.4 \mathrm{~kg} / \mathrm{m}^{2}$ for the device and control patients, respectively. Mean excess weight loss (EWL) after 3 months was $19.0 \%$ for device patients versus $6.9 \%$ for control patients $(p<0.002)$. Absolute change in $\mathrm{BMI}$ at 3 months was 5.5 and $1.9 \mathrm{~kg} / \mathrm{m}^{2}$, respectively. Type 2 Diabetes mellitus was present at baseline in 8 patients of the device group and improved in 7 patients during the study period (lower glucose levels, $\mathrm{HbA} 1 \mathrm{c}$ and medication requirements).

Conclusion: the EndoBarrier Gastrointestinal Liner is a feasible and safe noninvasive device with excellent short-term weight loss results. The device also has a significant positive effect on Type 2 diabetes mellitus. Long term randomized and sham studies for weight loss and treatment of diabetes are necessary to determine the role of the device in the treatment of morbid obesity. 


\section{Introduction}

Morbid obesity, defined as a body mass index (BMI) of $>40 \mathrm{~kg} / \mathrm{m}^{2}$ or $>35 \mathrm{~kg} / \mathrm{m}^{2}$ with obesity related comorbidities, is a rapidly growing problem in western society. Worldwide the incidence of morbid obesity has doubled and about 300 million are now obese [1, 2]. At this moment surgical therapy is the only treatment option for these patients that results in sufficient long-term weight loss. Non-surgical approaches, like low energy diets and behavior modification, are not successful in the long-term with respect to maintaining weight loss and decreasing obesity-related comorbidities [2, 3]. Results of surgery are, however, variable with weight loss ranging from an EWL of $47.5 \%$ after gastric banding to $70.1 \%$ after biliopancreatic diversion (BPD) [4]. Also, the number of re-operations, especially in the long term, varies enormously in literature ranging from $2 \%$ to $80 \%$ for gastric banding, $10 \%$ to $41 \%$ for gastroplasty and $12 \%$ to $33 \%$ for gastric bypass [5-8]. Many causes for this high number of re-operations have been proposed. As a consequence, many technical adaptations and perioperative strategies have been put forward. One of the strategies to improve outcomes after bariatric surgery is preoperative weight loss. It is suggested in literature that this strategy leads to better results, for example shorter length of hospital stay, operation time and better short term postoperative weight loss [9-14]. Moreover, Alger-Mayer et al. showed in 95 patients that even 4 years after the operation preoperative weight loss was still positively correlated with \%EWL [14]. These studies show that preoperative weight loss is a valuable additional preparation in the morbidly obese patient. However, many patients fail to lose weight before the operation, even in a study-controlled environment, because it is usually by means of a very low energy diet (VLED). For example, in the study by Still et al. only $48 \%$ of the patient population lost more than $10 \%$ excess body weight prior to surgery [15]. In the study by Alger-Mayer et al. this was only 43\% [14]. Because of the high failure rate of VLED in this patient population a wide range of minimally invasive treatments have been developed that might help in achieving (preoperative) weight loss [16].

A new form of minimally invasive totally endoscopic treatment for morbid obesity is the duodenal-jejunal bypass sleeve (DJBS), also known as the EndoBarrier Gastrointestinal Liner (GI Dynamics, Inc, Lexington, Massachusetts, USA). Feasibility studies in animals and humans have been published. Recently, two animal-based (porcine) studies did show a good patency of the device and acceptable tissue response while weight loss was better in treated animals compared to sham-treated animals [17]. The first 2 human studies described a safe delivery and subsequent removal of the device. Weight loss in the first prospective, nonrandomized series of 12 patients was $23.6 \%$ EWL after 
12 weeks while all patients achieved at least $10 \%$ excess weight loss $[16,18]$. This study included 4 patients with type 2 diabetes mellitus (T2DM). It was observed during the study period that T2DM resolved in 3 of these patients while weight loss was not greater compared to patients without T2DM. In the present study we describe the first European experience with the device as well as the first randomized efficacy study of the EndoBarrier Gastrointestinal Liner for weight loss prior to bariatric surgery. Because of the observed effects of the device on T2DM in earlier studies this was included in the present study as a secondary study parameter.

\section{Study purpose}

The purpose of the study was to evaluate the safety and initial efficacy of the EndoBarrier Gastrointestinal Liner device in patients who require bariatric surgery. The primary endpoint was assessment of the difference in weight loss between the device group and a non-device, medically supervised diet group. Secondary endpoints were the effect of the device on Type 2 diabetes mellitus and the safety expressed as perioperative complications, technical difficulties and device related adverse events during follow-up.

\section{Patients and Methods}

\section{Technique}

The EndoBarrier Gastrointestinal Liner is a single use endoscopic implant mimicking a duodenal-jejunal bypass (figure 1). The device is comprised of a nitinol anchor, which is used to reversibly affix the device to the wall of the duodenum, and an impermeable fluoropolymer sleeve extending $60 \mathrm{~cm}$ into the small bowel (figure 2). The device is open at both ends to allow food to pass. The anchor is located in the duodenal bulb and the sleeve stretches out into the duodenum and partially into the jejunum. As a result, pancreatic and bile juices will mix with the food only after the sleeve which may induce malabsorption and creates a bypass of the proximal intestinal tract. Because of the limited experience with the device in humans, the procedure was performed under general anesthesia with endotracheal intubation and the patient in lateral decubitus. All patients received a double dose of low molecular weight heparin preoperatively; antibiotics were not given. Initial access to the stomach and duodenum is achieved by a standard gastroscope through which a guide wire is advanced into the duodenum. The encapsulated device on a custom catheter is tracked over the guide wire into the 
duodenum. The capsule at the distal end holds the sleeve and anchor (figure 3). The catheter has an atraumatic ball end which is advanced through the intestine deploying the sleeve behind itself. After full extension of the sleeve the anchor is deployed in the duodenal bulb $0.5 \mathrm{~cm}$ distally from the pylorus. After the first 8 implantations the technique of the delivery of the capsule to the duodenum was changed from delivery under direct endoscopic control to delivery under fluoroscopic control. We observed that with the endoscope in the stomach it was more difficult to manouver the capsule.

Removal of the EndoBarrier Gastrointestinal Liner is achieved with a custom grasper that grasps the polypropylene tether on the anchor. A foreign body retrieval hood at the tip of the endoscope is used to incorporate the device in order to avoid any damage of the stomach or esophagus on the way out of the patient's body.

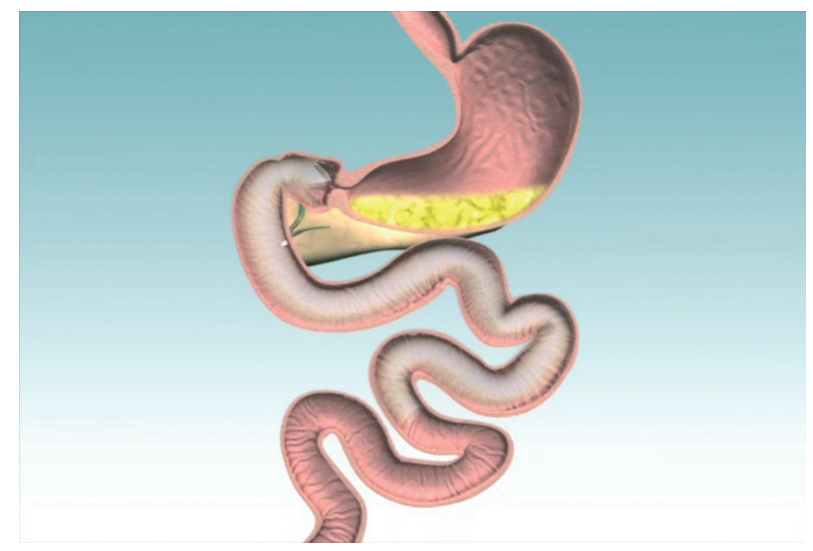

Figure 1: illustration of the EndoBarrier Gastrointestinal Liner. The device is endoscopically placed in the duodenum in order to form a barrier between chyme and the intestinal wall, creating a duodenal-jejunal bypass effect 


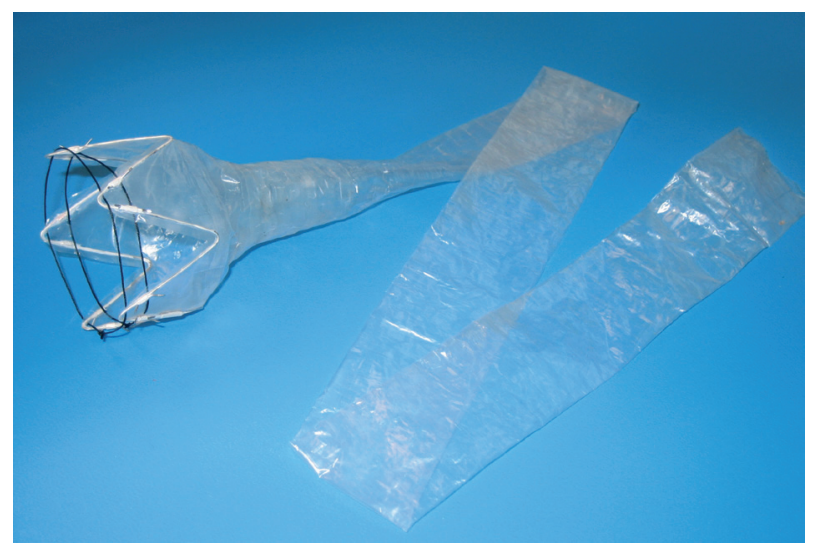

Figure 2: the device is comprised of a nitinol anchor with barbs and an impermeable fluoropolymer sleeve of $60 \mathrm{~cm}$. The polypropylene drawstring is necessary for removal of the device

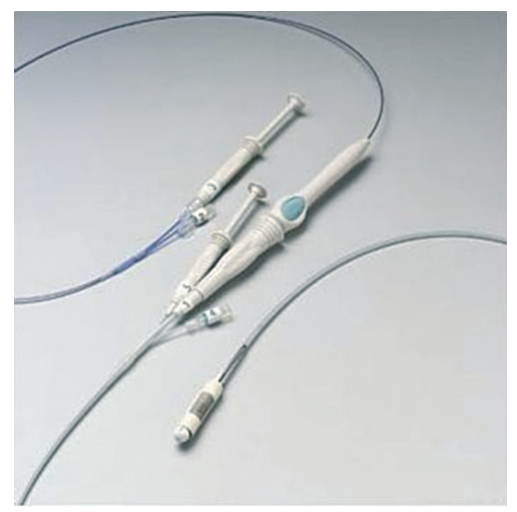

Figure 3: the implant device with guide wire, deployment device and encapsulated sleeve

The study was approved by the medical ethical committee of both participating hospitals (Maastricht University Medical Centre and Rijnstate Hospital Arnhem). Patients were included after informed consent was obtained and signed by both patient and surgeon.

\section{Patients}

Patients were considered eligible for the study if they were aged between 18 and 55 years and BMI was between 40 and $60 \mathrm{~kg} / \mathrm{m}^{2}$ or above $35 \mathrm{~kg} / \mathrm{m}^{2}$ with obesity-related comorbidities. All patients enrolled in the study were already thoroughly screened by a dietician and a psychologist and on the waiting-list for a laparoscopic gastric bypass. Main exclusion criteria were: anticoagulation use, inflammatory bowel disease, known 
bacterial infection at time of implant, severe coagulopathy, anomalies or previous surgery of the gastrointestinal tract and patients with severe reflux disease.

\section{Methods}

Two centers participated in the study. The Maastricht University Medical Centre included 30 patients (22 device patients and 8 diet control patients) and the Rijnstate Hospital Arnhem included 11 patients (8 device patients and 3 diet control patients). Patients were assigned to 1 of 2 treatment groups (diet control or device) based on a computer generated randomization schedule after informed consent was obtained and signed by both patient and surgeon. Because of the design of the study (efficacy) randomization was employed in a 3:1 fashion favouring the device by using randomly permuted blocks stratified by centre. Furthermore, because of this specific study design, intention-totreat was defined as subjects who were successfully implanted. At the beginning of the study, baseline demographics, physical examination and medical history were collected. This included weight, BMI and waist / hip ratio. An EKG, chest X-ray and abdominal ultrasound were also obtained in the device patients in order to rule out the presence of any serious cardiovascular disease, kidney- or gallstones. A range of laboratory parameters were obtained before the study period and at regular intervals during the study (total bilirubin, gamma GT, SGOT, SGPT, LDH, ALK phospatase, total cholesterol, $\mathrm{HDL}$, LDL, triglycerides, glucose, amylase, lipase, HbA1C and insulin level). Patients were admitted to the hospital the evening before the implantation and discharged the day after, if they were able to tolerate a liquid diet and the postoperative abdominal X-ray showed a normal position of the anchor. Patients received a prescription for proton pump inhibitors and multivitamin supplements for the entire study period. After the implantation the patients were seen at the outpatient department at 1, 4, 8 and 12 weeks.

At each visit the following items were evaluated: weight, BMI, hip / waist ratio, adverse events, abdominal X-ray (position of the anchor) and laboratory parameters. According to the study protocol, in the absence of any serious adverse events the last 10 patients of the device group would keep the device in situ for 24 weeks in order to investigate the safety and efficacy of the device for a longer period. Follow-up after these implantations was the same with additional visits at 16, 20 and 24 weeks. Removal of the device was performed as an outpatient procedure under general anaesthesia after 12 and 24 weeks, respectively. Two weeks after explant of the device an upper endoscopy was performed in order to rule out any gastrointestinal mucosal damage inflicted by the device or its removal. The control diet group had the same follow-up schedule with the same evaluation items at 1, 4, 8 and 12 weeks. The control group exited the study at the 12 week visit. 
Device and control diet patients had to follow a low calorie diet under strict supervision of a dietician who also screened the patients preoperatively and evaluated their dietary habits at 1, 4, 8 and 12 weeks. In between visits, patients were contacted by telephone in order to verify if they were able to keep to the prescribed diet. In the first study week, i.e. after placement of the device or in case of a control patient in the first week of diet, patients were prescribed a liquid diet with a maximum of 600 kilocalories (kcal) per day plus 1500 millilitres $(\mathrm{ml})$ of clear fluids, for example tea, (mineral) water and bouillon. From the second week on until the end of the study (12 weeks or 24 weeks) patients were allowed a normal diet with a maximum of $1200 \mathrm{kcal}$ (female subjects) or $1500 \mathrm{kcal}$ (male subjects) plus $1500 \mathrm{ml}$ of clear fluids. An example of a meal according to the diet prescribed in week 1 and afterwards is provided in appendix 1.

\section{Statistical analysis}

Analyses of data were performed using $S A S \circledR$ Version 9.1. Efficacy data are presented by variable, via proportions or as means with standard deviations (SD) or confidence intervals, as appropriate. The Two - Sample T-test was used for comparison between groups and a p-value of $<0.05$ was denoted as statistically significant. Adverse events are classified according to a standardized coding dictionary specifically designed for this study and categorized as mild, moderate or severe (figure 4). Calculation of ideal weight was according to the Metropolitan Life Tables and loss of body weight is expressed as $\%$ excess weight loss (amount of kilograms lost since baseline x 100 / excess weight).

1 = Mild: Any event which:

A) results in minimal transient impairment of a body function or damage to a body structure; or

B) does not require any intervention other than monitoring or OTC medication.

2 = Moderate: Any event which:

A) results in moderate transient impairment of a body function or transient damage to a body structure; or

B) requires intervention, such as the administration of medication or cardioversion to prevent permanent impairment of a body function or damage to a body structure.

3 = Severe: Any event which:

A) is life threatening;

B) results in permanent impairment of a body function or permanent damage to a body structure; death or

C) necessitates significant intervention, such as major surgery, to prevent permanent impairment of a body function or permanent damage to a body structure.

Figure 4: classification of adverse events 


\section{Results}

\section{Patient demographics}

A total of 41 patients were included in the study; 30 patients in the device group and 11 patients in the diet control group. One extra patient was included because one patient in the device group did not want to continue after randomization and withdrew from the study. In order to maintain the randomization process, stratified by centre, one more patient in the diet control group was necessary. Mean pre-operative age, weight and $\mathrm{BMI}$ are listed in table 1. There were no significant differences between the groups. Preoperative obesity-related comorbidities are shown in table 2. Hypertension and Type 2 diabetes mellitus had a high prevalence in the combined patient group with 20 and 10 patients at the beginning of the study, respectively. A total of 32 other comorbidities were present at baseline, mainly obesity-related joint problems.

\begin{tabular}{lcc}
\hline & Device group & Control group \\
\hline Age $(\mathrm{yrs})$ & $40.9(20-59)$ & $41.2(19-57)$ \\
M : F & $8: 22$ & $2: 9$ \\
Weight $(\mathrm{kg})$ & $142.5(114-189)$ & $137.5(86-160)$ \\
BMI $\left(\mathrm{kg} / \mathrm{m}^{2}\right)$ & $48.9(39-60)$ & $49.2(37-60)$ \\
\hline
\end{tabular}

Table 1: patient demographics

\begin{tabular}{lccr}
\hline & $\begin{array}{c}\text { Device group } \\
(\mathrm{N}=30)\end{array}$ & $\begin{array}{c}\text { Control group } \\
(\mathrm{N}=11)\end{array}$ & Total \\
\hline Hypertension & $15(50 \%)$ & $5(45 \%)$ & 20 \\
Diabetes & $8(27 \%)$ & $2(18 \%)$ & 10 \\
Hyperlipidemia & $6(20 \%)$ & $0(0 \%)$ & 6 \\
Other & 24 & 8 & 32 \\
\hline
\end{tabular}

Table 2: obesity-related comorbidities $(\mathrm{N})$

\section{Procedures}

Thirty procedures were performed of which 26 were successful. Implantation could not be accomplished in 4 patients. These 4 procedures took place in the primary centre at 
the beginning of the study period (patients 4, 5, 6 and 8). Difficulties in device placement were mainly related to anatomical problems; for example, a sharp curve between pylorus and duodenal bulb. There were no procedure-related adverse events during the implant or explant procedures. Four of the 26 successfully implanted devices had to be removed prior to the 12 or 24 weeks study period. One patient developed severe nausea and vomiting 1 week after the procedure caused by a sleeve obstruction. One patient had epigastric pain 3 months after implantation caused by a dislocation of one of the anchor crowns with subsequent rotation of the anchor. In another patient with epigastric pain it was decided to remove the device also after 3 months. However, during the explant procedure no abnormalities were found. Finally, one patient did not have any complaints but the abdominal X-ray at 4 months showed a $30 \mathrm{~cm}$ migration of the device. The device was removed with the help of a colonoscope. No complications occurred during this procedure. After this migration at 4 months post-implantation it was decided for safety reasons to remove the devices in the remaining 4 patients who still had the device in situ. These patients were all randomized to the 24 week device group. As a result only 3 patients kept the device for the full period of 24 weeks. Eighteen out of the 26 device patients completed the study. Procedure and fluoroscopy times can be found in table 3 . Mean implantation time in the patient group with a successful procedure was 35 minutes with an explant time of 17 minutes. As a result of the learning curve, it took less time as the investigators gained experience with the procedure.

This is clearly shown in figures 4 and 5 .

\begin{tabular}{lcc}
\hline & Implant procedure & Explant procedure \\
\hline Procedure time $(\min )$ & $35(12-102)$ & $17(5-99)$ \\
Fluoroscopy time $(\min )$ & $10(5-36)$ & $2(1-6)$ \\
\hline
\end{tabular}

Table 3: procedure times, $\mathrm{n}=26$ 


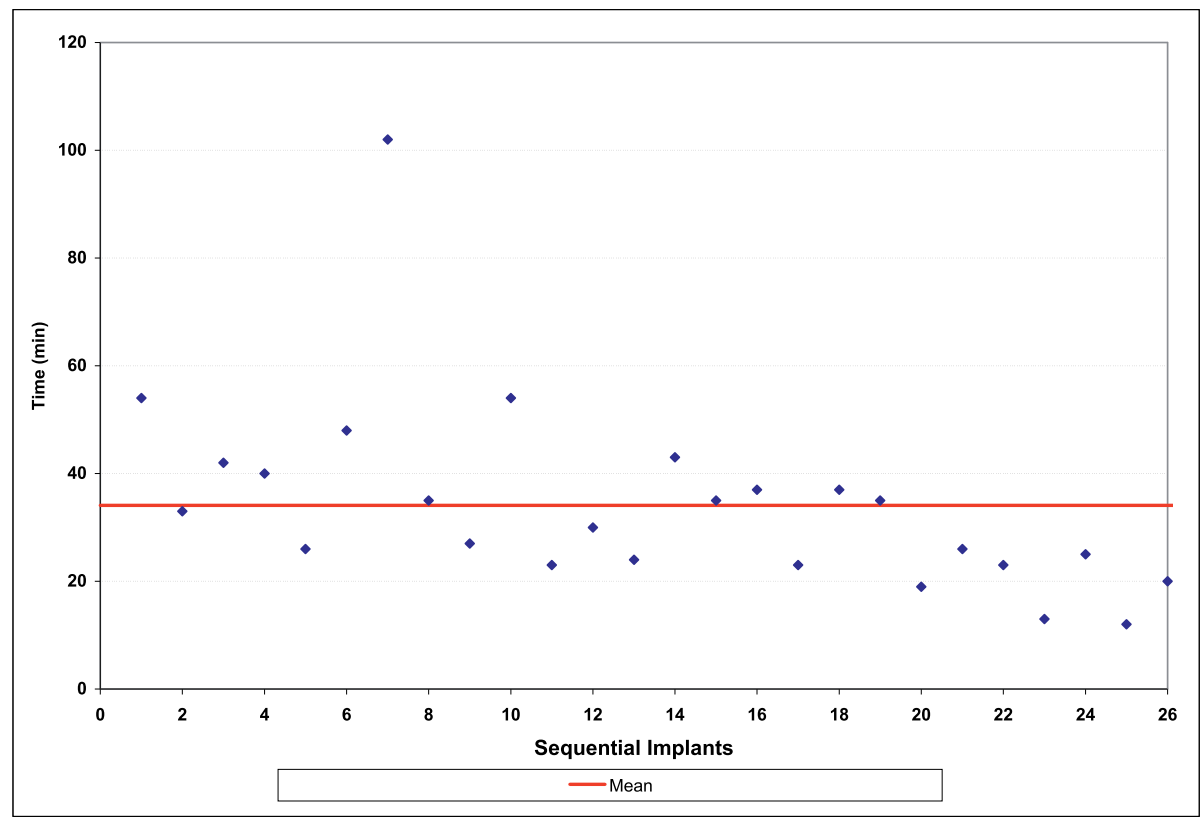

Figure 4: sequential implantation procedure times (min) (Successful implantations only)

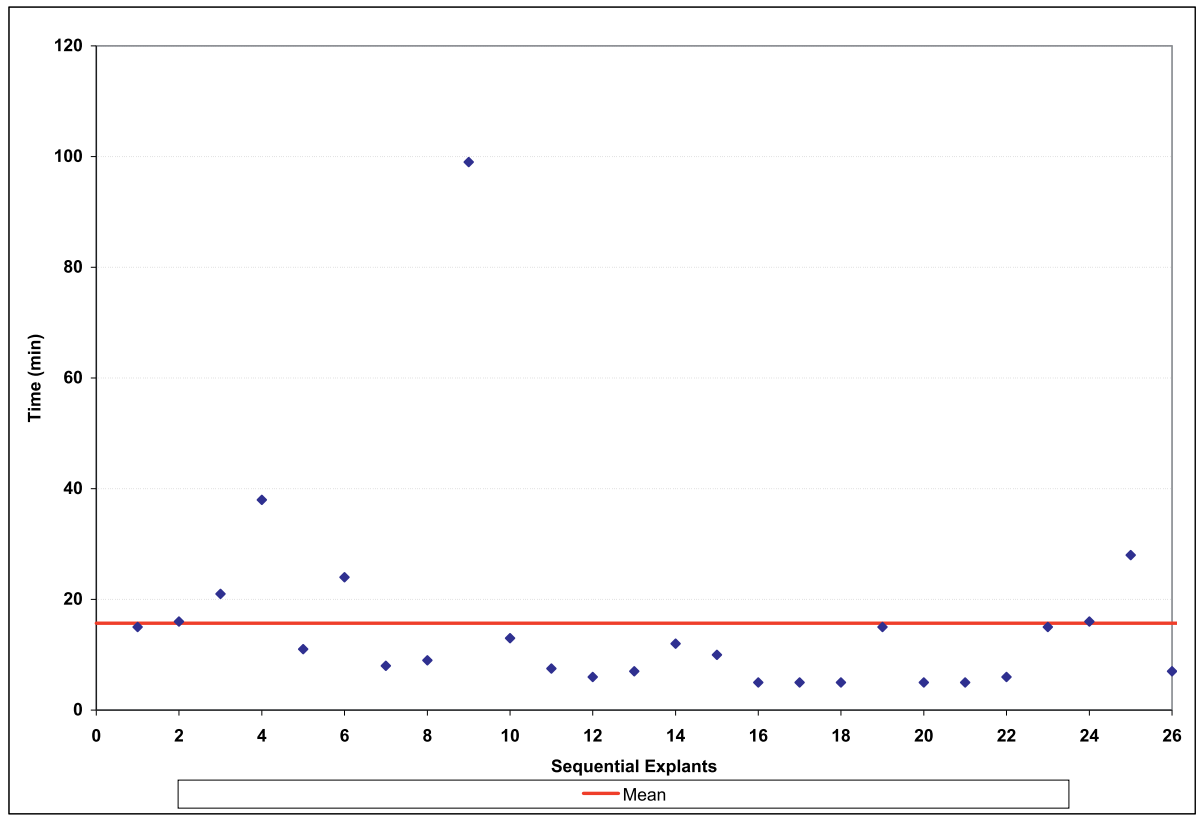

Figure 5: sequential explantation procedure times (min) 


\section{Adverse events}

Twenty-six patients (100\%) in the device group had at least one adverse event (AE) during follow-up compared to 3 patients $(27.3 \%)$ in the diet control group (table 4$)$. None of the adverse events were classified as "severe", $61.3 \%$ of the AE's were considered "mild" and $38.7 \%$ as "moderate". Observed AE's with the highest frequency in the device group were nausea $(76.9 \%)$ and upper abdominal pain $(50 \%)$, both mainly during the first week after the procedure. Pseudopolyp formation and implant site inflammation seen during the explant procedure or during the follow-up endoscopy were observed in $50.0 \%$ and $38.5 \%$ of the patients, respectively There were many other minor AE's $(73.1 \%)$, e.g. transient pyrosis, perioperative hypoxia or chest pain. All minor AE's resolved either spontaneously or after temporary medication with no further sequelae.

\begin{tabular}{lcc}
\hline & $\begin{array}{c}\text { Device group } \\
(\mathrm{N}=26)\end{array}$ & $\begin{array}{c}\text { Control group } \\
(\mathrm{N}=11)\end{array}$ \\
\hline Patients with $\geq 1 \mathrm{AE}$ & $26(100 \%)$ & $3(27.3 \%)$ \\
Nausea (first week) & $20(76.9 \%)$ & $1(9.1 \%)$ \\
Upper abdominal pain (first week) & $13(50.0 \%)$ & - \\
Pseudopolyp formation (explant) & $13(50.0 \%)$ & - \\
Implant site inflammation (explant) & $10(38.5 \%)$ & - \\
Vomiting (first week) & $6(23.0 \%)$ & - \\
Adverse drug reaction & $2(7.7 \%)$ & 1 \\
HbA1c increase & - & $(9.1 \%)$ \\
Hypercholesterolemia & - & 1 \\
Other & $19(73.1 \%)$ & $(9.1 \%)$ \\
\hline
\end{tabular}

Table 4: adverse events

\section{Weight loss}

In table 5, weight loss after 1, 12 and 24 weeks is listed, although the latter was only available for 3 patients. At the first week, weight loss was not significantly different between the device and the diet control group (7.5\% and $5.3 \%$, respectively). At 12 weeks the difference was significant with a EWL of $19.0 \%$ in the device group versus $6.9 \%$ in the diet control group ( $p<0.002$ ). Change in BMI at 12 weeks was -5.5 and $-1.9 \mathrm{~kg} / \mathrm{m}^{2}$, respectively. In 3 patients who kept the device for 24 weeks the EWL was $24.3 \%$. No comparison was possible with the diet control group because this group only 
remained in follow-up for 12 weeks per the protocol. The percentage of patients who had more than $10 \%$ excess weight loss at 12 weeks was $88.0 \%$ in the device group and $27.3 \%$ in the control diet group $(p<0.05)$.

\begin{tabular}{lcrccc}
\hline & Subjects & Device group & Subjects & Control group & P value $^{*}$ \\
\hline Preoperative BMI & 30 & $48.9 \pm 6.2$ & 11 & $49.2 \pm 7.1$ & 0.68 \\
BMI (1 week) & 25 & $46.3 \pm 6.6$ & 11 & $48.1 \pm 6.4$ & 0.51 \\
$\%$ EWL (1 week) & 25 & $7.5 \pm 5.1$ & 11 & $5.3 \pm 1.8$ & 0.08 \\
BMI (12 weeks) & 24 & $43.4 \pm 6.7$ & 11 & $47.3 \pm 6.7$ & 0.23 \\
$\% E W L(12$ weeks) & 24 & $19.0 \pm 10.9$ & 11 & $6.9 \pm 6.1$ & 0.00 \\
BMI (24 weeks) & 3 & $44.1 \pm 5.2$ & - & - & N/A \\
$\% E W L(24$ weeks) & 3 & $24.3 \pm 5.8$ & - & - & N/A \\
\hline
\end{tabular}

Table 5: weight loss after 1 and 12 weeks

* Two-sample T-test

\section{Diabetes}

There was a difference in the number of patients with diabetes: 8 of 26 patients in the device group (30.8\%) versus 2 of 11 patients in the diet control group (18.2\%). However, this difference was not statistically significant $(p=0.45)$. At the beginning of the study patients had T2DM for a mean period of 3.6 years (range: 1 - 10 years). Four patients used a combination of insulin and oral antidiabetic medication, 4 patients used only oral antidiabetic medication and 2 patients did not use any medication. Fasting plasma glucose (mmol / L) and $\mathrm{HbA} 1 \mathrm{c}$ preoperatively and after 12 weeks can be found in table 6. HbA1c was significantly lower preoperatively in the control group $(p=0.04)$. At 12 weeks the total change in fasting plasma glucose was -1.8 and $-0.9 \mathrm{mmol} / \mathrm{L}$ for the device group and diet control group, respectively. Changes in $\mathrm{HbA} 1 \mathrm{c}$ were $-1.1 \%$ and $-0.4 \%$ for the device and control group. However, these differences did not reach statistical significance. Noteworthy is that 6 of 8 patients in the device group decreased insulin dosages and / or oral antidiabetic medication after 1 week. At 12 weeks, there was still an ongoing improvement in 5 patients (continuous lowering of medication requirements) while 1 patient was able to completely stop medication. One patient was not able to decrease any medication during the 12 week study period. 


\section{Laboratory results}

During follow-up, there were no significant differences between the groups in their laboratory parameters (total bilirubin, gamma GT, SGOT, SGPT, LDH, ALK phospatase, total cholesterol, HDL, LDL, triglycerides, amylase, lipase and insulin level). No parameters were out of the normal range. In particular, there were no signs of liver failure or pancreatic dysfunction in the device group.

\begin{tabular}{lccc}
\hline & $\begin{array}{c}\text { Device group } \\
(\mathrm{N}=8)\end{array}$ & $\begin{array}{c}\text { Control group } \\
(\mathrm{N}=2)\end{array}$ & P-value* $^{*}$ \\
\hline Preoperative fasting glc (mmol/L) & $11.1 \pm 4.3$ & $7.6 \pm 2.4$ & 0.23 \\
Preoperative HbA1c (\%) & $8.8 \pm 1.7$ & $7.3 \pm 0.1$ & 0.04 \\
Fasting glc (12 wks) & $9.3 \pm 3.8$ & $6.7 \pm 1.1$ & 0.13 \\
HbA1c (12 wks) & $7.7 \pm 1.8$ & $6.9 \pm 0.6$ & 0.32 \\
\hline
\end{tabular}

Table 6: pre- and postoperative glucose and $\mathrm{HbA} 1 \mathrm{c}$ values in Type 2 diabetic patients

* Two-sample T-test

\section{Discussion}

Morbid obesity and its related comorbidities is a worldwide problem and surgery is the only treatment option with a proven long term effect $[19,20]$. The range and availability of bariatric operations are increasing although results are variable. Bariatric surgeons are still looking for the "perfect" operation which should be minimally invasive with a zero mortality, low morbidity and excellent long-lasting weight loss. In order to reduce the surgical risk, certain measures can be taken, for example preoperative weight loss [16]. However, many patients fail to lose weight before the operation, even in a studycontrolled environment $[14,15,21]$. There is a need for a minimally invasive tool to help patients lose weight preoperatively. Several preliminary reports on the feasibility of the DJBS (EndoBarrier Gastrointestinal Liner) have been published. Tarnoff et al. reported their experience with the device in pigs [17, 22].

The first implantation in a human patient was reported by Gersin et al. while the first series was described by Rodriquez-Grunert et al. [16, 18]. In this 12-patient nonrandomized prospective study mean pre-operative BMI was lower than in the present study (43.0 and $48.9 \mathrm{~kg} / \mathrm{m}^{2}$, respectively). Implant time was comparable (26 and 35 minutes) but explant time was shorter is the present study (43 and 17 minutes). Mean 
excess weight loss in the Rodriquez-Grunert study was $23.6 \%$ after 3 months while all patients lost more than $10 \%$ of their excess weight. In the present study mean excess weight loss after 3 months was $19.0 \%$, while $88 \%$ of patients lost more than $10 \%$ excess weight. In both studies all patients experienced one or more adverse events. No severe AE's occurred and in both studies postimplant nausea and abdominal pain were most frequently observed along with explant or post-explant site inflammation. The learning curve for placing the device is apparent as no problems were observed after the 8th implant attempt. However, the implantation technique may also have contributed to the initial problems with the delivery. During the first procedures the delivery capsule was advanced into the duodenum under direct vision of the endoscope. After changing to delivery of the capsule under fluoroscopic control, no further problems were observed and implantation times decreased (figure 5). Although the device has been placed under general anaesthesia, it is a totally endoscopic procedure of approximately 30 minutes. In the future it should be possible to perform the procedure under conscious sedation. In comparison with the DJBS several minimal invasive tools have been designed to treat morbid obesity either to induce preoperative weight loss or as a treatment modality on its own. Recently, the results of 21 patients treated with transoral gastroplasty were published by Deviere et al. Excess weight loss after this procedure was $22.6 \%$ and $24.4 \%$ after 3 and 6 months, respectively. However, 11 out of 21 patients developed a stapler line failure during follow-up. The most frequently reported adverse events were comparable with DJBS: nausea, vomiting and pain [23]. Endoscopic botulinum toxin injection in the gastric antrum and fundus is another possibility and has been investigated by Foschi et al in a randomized, double-blind study. Weight loss was again comparable with the DJBS with a decrease in BMI of $4 \mathrm{~kg} / \mathrm{m}^{2}$ although the follow-up period was only 8 weeks. No complications occurred during the procedure and no adverse events were reported. Because of the known temporary effect of botulinum a longer follow-up study is necessary [24]. Another minimally invasive option is laparoscopic implantable gastric stimulation (gastric pacing) and several reports have been published with favourable results. Excess weight loss after 1 year was $23.8 \%$ to $26.6 \%$ in the studies by Favretti et al. and Bohdjalian et al. No severe postoperative complications were reported but only 13 and 9 patients were included, respectively [25, 26]. A larger patient group is described by Miller et al. The latter reported on 91 patients with a follow-up period of 2 years. Mean excess weight loss was $25 \%$ after 1 year and $20 \%$ after 2 years [27]. Finally, results of the "oldest" minimally invasive tool to treat obesity, the intragastric balloon, were recently described in a review by Mathus - Vliegen et al. In randomized trials, weight loss of 16 to $21 \mathrm{~kg}$ was obtained after 6 months. Failure rate after balloon 
placement, described as no or insufficient weight loss, was $15.3 \%$ while intolerance of the balloon with removal as a consequence was reported in $6.7 \%$ [28]. In comparison, the failure rate after DJBS in our study was $12 \%$ (less than $10 \%$ excess weight loss after 3 months) with similar intolerance to the balloon as 4 of 26 devices (15.4\%) were removed because of complaints or migration. Although the percentages of failure and intolerance seem comparable the experience with the balloon is much greater than with the DJBS. The failure rate of the DJBS will probably decrease in the future as the experience with the procedure grows.

Although weight loss, perioperative complications and adverse events are all quite comparable in these minimally invasive devices the effect of the DJBS on Type 2 diabetes is interesting. Four patients had diabetes in the study by Rodriquez-Grunert et al. and it resolved in 3 cases [16]. In the present study 8 patients had diabetes in the device group. Improvement was observed in 6 patients and resolution in 1 patient. The bypass effect of the duodenum and a small portion of the jejunum are probably causing this improvement in glucose control. Studies by Rubino et al. show that by bypassing a short segment of proximal intestine, glucose homeostasis in diabetic rats directly improves, independently of food intake, body weight, malabsorption or nutrient delivery to the more distal bowel. The positive effect of delivery of undigested nutrients to the more distal bowel in Type 2 diabetes is another theory proven in several studies [2931]. In combination with the above theories, studies on patients after roux-en-y gastric bypass have shown increased levels of the satiety inducing agents GLP-1 and PYY. This gastric bypass effect is mimicked by the DJBS [32, 33]. Because of the small but specific part of excluded intestine with DJBS the bypass effect of the duodenum seems more important than the delivery of undigested nutrients to the more distal bowel. The weight loss and especially the improvement of diabetes after placement of the device is probably multi-causative and of great interest for surgeons, gastro-enterologists and endocrinologists. More studies focusing on the working mechanism of the device have to be performed with the possibility of discovering important new aspects about the pathophysiology and treatment of obesity and diabetes. 


\section{Conclusion}

The duodenal-jejunal bypass sleeve is safe and feasible for the treatment of morbid obesity. It is an endoscopically placed non-surgical device with excellent short-term weight loss. Furthermore, the device has a positive effect on glucose homeostasis in Type 2 diabetic patients possibly due to the bypassing of the duodenum. Long term randomized and sham controlled studies are necessary to determine the role of the device in the treatment of morbid obesity and diabetes.

\section{Acknowledgments}

This study was supported by GI Dynamics, Inc (Lexington, Massachusetts, USA). All data were collected under the supervision of MedPass (MedPass International, Paris, France). The authors thank Rob Boetzkes, Willemien Kuijper and Yanti Slaats for their help with data collection. 


\section{References}

1. Mitka, M., Surgery for obesity: demand soars amid scientific, ethical questions. Jama, 2003. 289(14): p. 1761-2.

2. Tessier, D.J. and J.C. Eagon, Surgical management of morbid obesity. Curr Probl Surg, 2008. 45(2): p. 68-137.

3. Bjorntorp, P., Results of conservative therapy of obesity: correlation with adipose tissue morphology. Am J Clin Nutr, 1980. 33(2 Suppl): p. 370-5.

4. Buchwald, H., Y. Avidor, E. Braunwald et al., Bariatric surgery: a systematic review and meta-analysis. Jama, 2004. 292(14): p. 1724-37.

5. Schouten, R., F.M. van Dielen, and J.W. Greve, Re-operation after laparoscopic adjustable gastric banding leads to a further decrease in $\mathrm{BMI}$ and obesity-related comorbidities: results in 33 patients. Obes Surg, 2006. 16(7): p. 821-8.

6. Schouten, R., F.M.H van Dielen, J.W.M. Greve, Conversion of vertical banded gastroplasty to Roux-en-Y gastric bypass results in restoration of the positive effect on weight loss and co-morbidities: evaluation of 101 patients. Obes Surg, 2007. 17(5): p. 622-30.

7. van Gemert, W.G., M.M. van Wersch, J.W.M Greve et al, Revisional surgery after failed vertical banded gastroplasty: restoration of vertical banded gastroplasty or conversion to gastric bypass. Obes Surg, 1998. 8(1): p. 21-8.

8. Chapman, A.E., G. Kiroff, P. Game et al., Laparoscopic adjustable gastric banding in the treatment of obesity: a systematic literature review. Surgery, 2004. 135(3): p. 326-51.

9. van de Weijgert, E.J., C.H. Ruseler, and J.W. Elte, Long-term follow-up after gastric surgery for morbid obesity: preoperative weight loss improves the long-term control of morbid obesity after vertical banded gastroplasty. Obes Surg, 1999. 9(5): p. 426-32.

10. Mathus-Vliegen, E.M., Long-term health and psychosocial outcomes from surgically induced weight loss: results obtained in patients not attending protocolled follow-up visits. Int J Obes (Lond), 2007. 31(2): p. 299-307.

11. Alvarado, R., R.S. Alami, G. Hsu et al., The impact of preoperative weight loss in patients undergoing laparoscopic Roux-en-Y gastric bypass. Obes Surg, 2005. 15(9): p. 1282-6.

12. Liu, R.C., A.A. Sabnis, C. Forsyth et al., The effects of acute preoperative weight loss on laparoscopic Roux-en-Y gastric bypass. Obes Surg, 2005. 15(10): p. 1396-402.

13. Huerta, S., S. Dredar, E. Hayden et al., Preoperative Weight Loss Decreases the Operative Time of Gastric Bypass at a Veterans Administration Hospital. Obes Surg, 2008.

14. Alger-Mayer, S., J.M. Polimeni, and M. Malone, Preoperative Weight Loss as a Predictor of Long-term Success Following Roux-en-Y Gastric Bypass. Obes Surg, 2008. 18(7): p. 7725 .

15. Still, C.D., P. Benotti, G.C. Wood et al., Outcomes of preoperative weight loss in highrisk patients undergoing gastric bypass surgery. Arch Surg, 2007. 142(10): p. 994-8; discussion 999.

16. Rodriguez-Grunert, L., M.P. Galvao Neto, M. Alamo et al., First human experience with endoscopically delivered and retrieved duodenal-jejunal bypass sleeve. Surg Obes Relat Dis, 2008. 4(1): p. 55-9.

17. Tarnoff, M., S. Shikora, A. Lembo et al., Chronic in-vivo experience with an endoscopically delivered and retrieved duodenal-jejunal bypass sleeve in a porcine model. Surg Endosc, 2008. 22(4): p. 1023-8.

18. Gersin, K.S., J.E. Keller, D. Stefanidis et al., Duodenal- jejunal bypass sleeve: a totally endoscopic device for the treatment of morbid obesity. Surg Innov, 2007. 14(4): p. 275-8. 19 
19. Karlsson, J., C. Taft, A. Ryden et al., Ten-year trends in health-related quality of life after surgical and conventional treatment for severe obesity: the SOS intervention study. Int $J$ Obes (Lond), 2007. 31(8): p. 1248-61.

20. Sjostrom, L., A.K. Lindroos, M. Peltonen et al., Lifestyle, diabetes, and cardiovascular risk factors 10 years after bariatric surgery. N Engl J Med, 2004. 351(26): p. 2683-93.

21. Alami, R.S., J.M. Morton, R. Schuster et al., Is there a benefit to preoperative weight loss in gastric bypass patients? A prospective randomized trial. Surg Obes Relat Dis, 2007. 3(2): p. 141-5; discussion 145-6.

22. Tarnoff, M., S. Shikora, and A. Lembo, Acute technical feasibility of an endoscopic duodenal-jejunal bypass sleeve in a porcine model: a potentially novel treatment for obesity and type 2 diabetes. Surg Endosc, 2008. 22(3): p. 772-6.

23. Deviere, J., G. Ojeda Valdes, L. Cuevas Herrera et al., Safety, feasibility and weight loss after transoral gastroplasty: First human multicenter study. Surg Endosc, 2008. 22(3): p. 589-98.

24. Foschi, D., F. Corsi, M. Lazzorini et al., Treatment of morbid obesity by intraparietogastric administration of botulinum toxin: a randomized, double-blind, controlled study. Int J Obes (Lond), 2007. 31(4): p. 707-12.

25. Bohdjalian, A., G. Prager, R. Aviv et al., One-year experience with Tantalus: a new surgical approach to treat morbid obesity. Obes Surg, 2006. 16(5): p. 627-34.

26. Favretti, F., M. De Luca, G. Segato et al., Treatment of morbid obesity with the Transcend Implantable Gastric Stimulator (IGS): a prospective survey. Obes Surg, 2004. 14(5): p. 66670.

27. Miller, K., E. Hoeller, and F. Aigner, The Implantable Gastric Stimulator for Obesity : An Update of the European Experience in the LOSS (Laparoscopic Obesity Stimulation Survey) Study. Treat Endocrinol, 2006. 5(1): p. 53-8.

28. Mathus-Vliegen, E.M., Intragastric balloon treatment for obesity: what does it really offer? Dig Dis, 2008. 26(1): p. 40-4.

29. Patriti, A., M.C. Aisa, C. Annetti et al., How the hindgut can cure type 2 diabetes. Ileal transposition improves glucose metabolism and beta-cell function in Goto-kakizaki rats through an enhanced Proglucagon gene expression and L-cell number. Surgery, 2007. 142(1): p. 74-85.

30. Patriti, A., E. Facchiano, C. Annetti et al., Early improvement of glucose tolerance after ileal transposition in a non-obese type 2 diabetes rat model. Obes Surg, 2005. 15(9): p. 1258-64.

31. de Paula, A.L., A.L. Macedo, A.S. Prudente et al., Laparoscopic sleeve gastrectomy with ileal interposition ("neuroendocrine brake")--pilot study of a new operation. Surg Obes Relat Dis, 2006. 2(4): p. 464-7.

32. Morinigo, R., V. Moize, M. Musri et al., Glucagon-like peptide-1, peptide YY, hunger, and satiety after gastric bypass surgery in morbidly obese subjects. J Clin Endocrinol Metab, 2006. 91(5): p. 1735-40.

33. Morinigo, R., J. Vidal, A.M. Lacy et al., Circulating peptide YY, weight loss, and glucose homeostasis after gastric bypass surgery in morbidly obese subjects. Ann Surg, 2008. 247(2): p. 270-5. 


\section{Appendix 1}

\section{First week}

(liquid diet, $600 \mathrm{kcal}$ )

\begin{tabular}{ll}
\hline & Example diet \\
\hline Breakfast & 1 glass milk \\
& 1 bowl of cornflakes \\
Lunch & 1 glass juice \\
& 2 pieces fruit \\
Diner & 1 bowl soup \\
& 1 cup curds \\
\hline
\end{tabular}

Second week - female

(normal diet, $1200 \mathrm{kcal}$ )

\begin{tabular}{ll}
\hline & Example diet \\
\hline Breakfast & 2 slices brown bread* \\
& 1 glass of milk \\
& 1 piece of fruit \\
In between & 2 slices brown bread \\
Lunch & 1 glass of milk \\
& 4 tablespoons of vegetables \\
Diner & 3 potatoes / 3 tablespoons \\
& 1 pasta \\
& 1 diary product \\
In between & 1 piece of fruit \\
\hline
\end{tabular}

* male patients were allowed $1500 \mathrm{kcal}$ a day, for example 2 slices of brown bread extra. 

CHAPTER 5

General discussion and summary

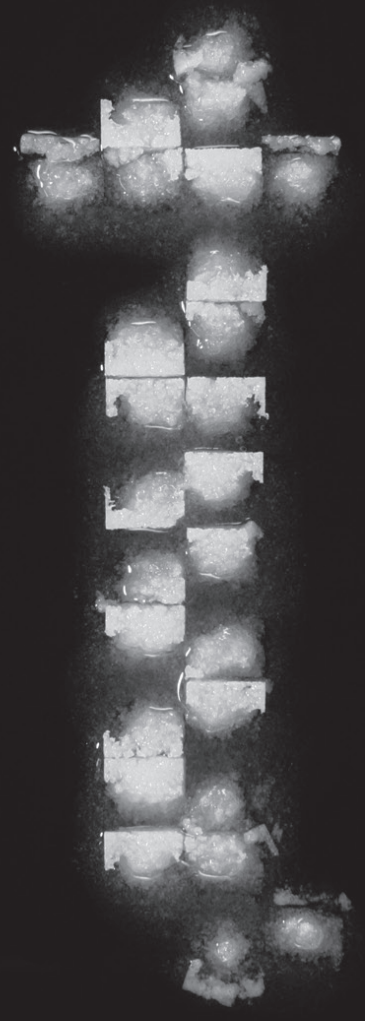




\section{Bariatric surgery}

The main purpose of this thesis was to describe the clinical results of bariatric surgery. Traditionally, bariatric operations have been subdivided into restrictive and malabsorptive procedures. The history of bariatric surgery began with a range of malabsorptive procedures which have been either abandoned because of severe side effects or have been considerably modified [1]. Restrictive procedures have less severe side effects because the gastrointestinal tract remains intact and the digestive functionality unchanged. As a result, vitamin and mineral deficiencies are rare [2-5]. Although a wide range of procedures is available nowadays there are certainly a number of standard bariatric procedures. Laparoscopic adjustable gastric banding (LAGB) and (laparoscopic) vertical banded gastroplasty (VBG) are purely restrictive in nature while biliopancreatic diversion (BPD) and duodenal switch (DS) result in some restriction but their effect is largely based on malabsorption. The roux-en-y gastric bypass (RYGB) procedure combines a slight malabsorption with restriction while the recently popularized gastric sleeve resection (GSR) is merely a restrictive procedure. These standard bariatric procedures all have their own specific effect on the gastrointestinal tract, intestinal hormone levels and vitamin and mineral status. For example, the effect of RYGB is partially caused by the duodenal bypass effect. Excluding the duodenum from nutrients improves glucose homeostasis by itself [6]. The positive effect on weight loss by the delivery of undigested nutrients to the more distal bowel in Type 2 diabetes is another theory proven in several studies [7-9]. The gastric fundus resection in GSR plays an important role in the postoperative weight loss because of the decrease in ghrelin production [10]. Although in recent years much knowledge has been gained through intensive research, the exact working mechanisms of bariatric procedures are not yet fully understood. There is however extensive evidence that bariatric surgery does what it is designed to do. Independent of the type of procedure it results in sufficient and long term weight loss and a decrease in obesity-related comorbidities [11-13]. According to the meta-analysis of Buchwald et al., weight loss varies from a mean excess weight loss (\%EWL) of $47.5 \%$ after LAGB to $70.1 \%$ after BPD and DS. Decrease in obesityrelated comorbidities is in proportion with weight loss [13]. However, differences in weight loss decline in the postoperative years. After 3 years, weight loss after LAGB is $49.4 \%$ EWL compared to $62.2 \%$ EWL after RYGB, according to a meta-analysis of Garb et al. [14]. Long term results described by O'Brien et al. indicate that LAGB and RYGB have comparable results after 10 years with an EWL of $59 \%$ and $52 \%$, respectively [15]. The same accounts for the postoperative quality of life. Improvement in quality of life 
after bariatric surgery is comparable after LAGB, VBG and RYGB [16-18]. Quality of life improvement is long lasting and solely dependent on weight loss as reported by many authors [16, 17, 19-26]. This is described and confirmed in paragraph 2.2; significant correlations between weight loss and improvement of 8 of the $13 \mathrm{HRQ}$ L domains were found independent of the type of procedure. Because results of weight loss, decrease in comorbidities and improvement in quality of life are comparable after the different procedures the focus in bariatric surgery should not be exclusively on these parameters. More attention should be given on the distinguishing features of the different types of operations. Important aspects are the long term complications and re-operations which are specifically addressed in the present thesis.

\section{Results of LAGB}

In chapter 2.1, the long term results of LAGB are described. An EWL of 55\% after 2 years and $54 \%$ after 7 years was found with an accompanying significant decrease in obesity-related comorbidities. This is consistent with the literature findings of $56 \%$ to $62 \%$ EWL after a follow up period of at least 5 years [27-29]. However, this success is overshadowed by frequent long term complications usually leading to revisional surgery. After LAGB, 44\% of patients underwent a re-operation during follow up due to band-related complications. Frequently encountered problems were pouch dilatation $(21 \%)$, slippage $(17 \%)$, band erosion $(4 \%)$ and leakage $(2 \%)$. Although the percentages of complications appear to be high they are consistent with the literature. Band erosion occurs in $0 \%$ to $14 \%$ [29-33], pouch dilatation in $8 \%$ to $24 \%$ [30, 33-35], slippage in $2 \%$ to $24 \%$ [30, 33-35] and band leakage or related tubing problems in $1 \%$ to $38 \%$ [33-35]. Because of these complications frequent re-operations are necessary after LAGB with a range in the literature of $2 \%$ to $80 \%$ [34, 36-43]. In chapter 2.1 a re-operation rate of $44 \%$ after 7 years is described. Mean time between the primary operation and the reoperation because of complications was 3 years. However, the number of re-operations is declining over the last years. Several mechanisms are responsible for the decrease in complications and re-operations. First, the surgical technique of placing the band has changed from perigastric to pars flaccida. Band slippages and pouch dilatation have decreased significantly from $29 \%$ to $4 \%$ after introduction of the pars flaccida technique in our clinic. In two randomized studies from Weiner et al. and O'Brien et al. the pars flaccida technique was demonstrated to be a safer technique with less complications, especially due to a decrease in (posterior) slippages from $16 \%$ to $4 \%$ and from $4 \%$ to $0 \%$ 
$[44,45]$. Second, many technical improvements have been made to the band itself like low pressure - high volume bands instead of high pressure- low volume bands resulting in a decrease in re-operation rate because of less slippages and possibly less erosions [46-49]. With use of the former, slippage rates as low as $2 \%$ have been reported after a follow up period of 2 years [50]. However, these encouraging numbers have to be brought into perspective because the third and most important reason for the reported differences in complications and re-operations after LAGB is the completeness and duration of follow up. In the literature, follow up period is highly variable with subsequent differences in re-operation rate, e.g. 3.3\% after 2 years and $58 \%$ after 7 years [30, 51]. Apart from the duration the completeness of follow up is also very important. The reoperation rate in a retrospective study by Christou et al. was $16.1 \%$ after 3 years but only one third of patients were available for follow up [52]. In a case-controlled study by Cottam et al. the re-operation rate was $53 \%$ in the first year decreasing to $0 \%$ in the third year. However, follow up after 3 years was only 25\% [53]. In chapter 2.1, mean time between the primary operation and the re-operation because of complications was 3 years. These results emphasize that a follow up of a reasonable patient population of 3 years and preferably 5 years is necessary for a reliable estimation of the re-operation rate.

In case of a failure after LAGB the first option is to preserve the band by performing a refixation or replacement. In the present thesis this option is described in chapter 3.2. Weight loss after laparoscopic refixation of the band was a decrease in BMI of $4.5 \mathrm{~kg} /$ $\mathrm{m}^{2}$ after a mean follow up period of 34 months. The late re-operation rate because of complications was $5 \%$. Results of a refixation or replacement of the band have been variable in the literature. The re-operation rate is $0 \%$ to $45 \%$ while weight results varied from a weight gain of $2.4 \mathrm{BMI}$ points to a weight loss of $5.8 \mathrm{BMI}$ points [54-65]. In order to compare refixation or replacement of the band with other revisional options a literature review is described in chapter 3.3. In the literature, results after conversion to RYGB in case of $L A G B$ failure seem to be better. The re-operation rate after conversion to RYGB was $0 \%$ to $20 \%$. Weight loss varied with a decrease in BMI between 6.1 to $13.2 \mathrm{~kg} / \mathrm{m}^{2}[55,66-75]$. The conversion to BPD or DS leads to more complications, especially procedure-specific nutritional problems, while weight loss is not significantly better [76-79]. Only in case of band erosion the conversion to BPD might be a feasible option because the procedure can be performed away from the eroded proximal gastric tissue. The preliminary results of conversion to GSR are encouraging [80-84] but longer follow up is necessary before this option can be considered as a feasible alternative. 
In conclusion, patients with satisfying weight loss after LAGB suffering from a pure technical failure benefit from refixation or replacement of the band. For patients with poor weight loss or non-compliance a conversion to RYGB is the best option.

\section{Results of VBG}

In chapter 2.1 the long term results of VBG are described. This restrictive procedure results in an EWL of $69 \%$ after a mean follow up of 7 years. Weight loss more than 5 years after VBG varies in the literature from $30 \%$ to $59 \%$ EWL $[27,28,85]$. However, this apparent success of VBG is overshadowed by a high percentage of failures. Frequent complications necessitating a re-operation are stapler line dehiscence $(51 \%)$ and anastomotic stenosis (9\%). This ranges in literature from $29 \%$ to $50 \%$ [86-89] and from $14 \%$ to $40 \%$ [86-88], respectively. Because of several other long term complications like pouch dilatation and weight loss failure the percentage of re-operations after VBG is even higher. Re-operation percentages in the literature range from $10 \%$ to $79 \%$ [ 85 , $86,89-92$ ] and the present thesis confirms this high failure rate $(65 \%)$ after a follow up period of 7 years. Based on the literature findings and the present thesis it can be stated that VBG is a successful operation in terms of weight loss, also in a long term manner, but the failure rate is too high.

In case of failure after VBG several revisional procedures are possible. Although not investigated in the present thesis it has been indisputably proven in literature that re-doing the procedure (re-VBG) leads to poor results and a re-re-operation rate of up to $68 \%$ [86, $87,93-96]$. Therefore, a conversion to another bariatric procedure is always necessary in the case of VBG failure. Results of the conversion from VBG to LAGB have been described infrequently $[97,98]$ because both are purely restrictive procedures and prone to the same complications. The conversion from VBG to BPD is difficult because of the presence of a vertical stapler line but has been described in literature recently [99]. Conversion form VBG to DS also has been described in a single report [79]. Furthermore, the laparoscopic conversion from failed VBG to GSR has been reported but with poor results including a complication rate of $17 \%$ and $84 \%$ and a reoperation rate of $5 \%$ and $33 \%[100,101]$. In chapter 3.1 , results of the conversion from VBG to RYGB are described. Follow up was $100 \%$ with a mean duration of 38 months. A low rate of perioperative complications was found (2\%) but long term complications occurred in $22.7 \%$, mainly anastomotic stenosis which could be treated by endoscopic dilatation. However, re-operations were necessary in $6.9 \%$ of cases because of renewed 
weight gain. Weight loss was successful with a decrease in BMI of $10.4 \mathrm{~kg} / \mathrm{m}^{2}$ which is consistent with the literature (decrease in BMI of 8 to $11 \mathrm{~kg} / \mathrm{m}^{2}$ ) [87, 88, 102-106]. The conversion to RYGB was also successful in patients with specific upper abdominal complaints which all decreased afterwards.

In conclusion, VBG is a successful operation in terms of weight loss but the failure rate is too high and it should not be performed anymore. The only evidence-based option in case of failure is conversion to RYGB which has good results on weight loss, patients' symptoms and has a low re-operation rate.

\section{Endoscopic treatment}

As a reaction to the high failure rate of restrictive procedures, the necessity of reoperations and the procedure-specific complications of malabsorptive bariatric operations many new techniques and devices are being developed. The ultimate goal is a minimally invasive technique with a low morbidity rate, no long term complications and a good and durable effect on weight and comorbidities. Apart from new laparoscopic techniques a whole variety of endoscopic procedures is now available which are described in chapter 4.1. Transoral gastroplasty is a technique where endoscopically guided staplers are placed and used to create a stapled restrictive pouch along the lesser curve of the stomach. Recently, the results of 21 patients treated with transoral gastroplasty were published by Deviere et al. Excess weight loss after this procedure was $22.6 \%$ and $24.4 \%$ after 3 and 6 months, respectively. However, 11 of 21 patients developed a stapler line failure during follow up. The most frequently reported adverse events were nausea, vomiting and pain [107]. Especially the side-effects of this technique are comparable with VBG. Therefore, the practical and widespread use of transoral gastroplasty in the future is highly questionable. Endoscopic botulinum toxin injection in the gastric antrum and fundus is another possibility and has been investigated by Foschi et al in a randomized, double-blind study. Weight loss with a decrease in BMI of $4 \mathrm{~kg} / \mathrm{m}^{2}$ was promising although follow up period was only 8 weeks. No complications occurred during the procedure and no adverse events were reported. Because of the known temporary effect of botulinum longer follow up studies are necessary to draw any conclusions about the use of this technique [108]. Another minimally invasive option is laparoscopic implantable gastric stimulation (gastric pacing) and several reports have been published with favourable results. Excess weight loss after 1 year was $23.8 \%$ to $26.6 \%$ in the studies by Favretti et al. and Bohdjalian et al. No severe postoperative 
complications were reported. However, these studies included only 13 and 9 cases, respectively [109, 110]. A larger patient group is described by Miller et al. reporting 91 patients with a follow up period of 2 years. Mean excess weight loss was $25 \%$ after 1 year and $20 \%$ after 2 years [111]. However, recently published results of a randomized sham-controlled trial showed no benefit of gastric pacing after 12 months [112]. Finally, results of the endoscopically placed intragastric balloon were recently described in a review by Mathus - Vliegen et al. In randomized trials, weight loss of 16 to $21 \mathrm{~kg}$ was obtained after 6 months. Failure rate after balloon placement, described as no or insufficient weight loss, was $15.3 \%$ while intolerance of the balloon with removal as a consequence was reported in $6.7 \%$ [113]. In chapter 4.2 , a new minimally invasive, endoscopically placed device was investigated. The duodenal-jejunal bypass sleeve (DJBS; EndoBarrier Gastrointestinal Liner, GI Dynamics, Inc, Lexington, Massachusetts, USA) is a single use endoscopic implant mimicking a duodenal-jejunal bypass. The device is comprised of a nitinol anchor, which is used to reversibly affix the device to the wall of the duodenum, and an impermeable fluoropolymer sleeve extending $60 \mathrm{~cm}$ into the small bowel. The anchor is located in the duodenal bulb and the sleeve stretches out into the duodenum and partially into the jejunum. As a result, pancreatic and bile juices will mix with the food only after the sleeve which may induce malabsorption and creates a bypass of the proximal intestinal tract.

Feasibility studies in animals and humans have been published. Two animal-based (porcine) studies showed a good patency of the device and acceptable tissue response while weight loss was better in treated animals compared to sham-treated animals [114]. The first 2 human studies described a safe delivery and subsequent removal of the device $[115,116]$. In the present thesis the first European experience with the device is described. Thirty device patients were included and compared to 11 control patients. Four devices could not be placed because of technical problems. No severe adverse events occurred. Post-implant nausea (76.9\%) and abdominal pain (50\%) were the most frequently reported mild adverse events and occurred only in the first week after implantation. Four devices had to be removed early because of sleeve obstruction (1), migration (2) and unexplained abdominal pain (1). Weight loss after 12 weeks was respectively $19.0 \%$ and $6.9 \%$ for the device group and control group while $88 \%$ of patients in the device group lost more than $10 \%$ of their excess weight. Comparison of these results with the other minimally invasive techniques is difficult because of differences in weight loss parameters, follow up period and definition of failure. However, with an EWL of $19 \%$ and a failure rate of $15.3 \%$ compared to $20 \%-26.6 \%$ and $15.3 \%$ - $52 \%$, as described in the available literature of the other techniques, the device is 
promising. Furthermore, because of the theoretical impact on diabetes mellitus caused by the foregut exclusion (duodenum bypass), the DJBS has gained interest not only for its potential role in weight loss but also in the treatment of T2DM. Recently, a number of studies have investigated the role of foregut exclusion in the treatment of obesity and specifically in combination with T2DM. Observational studies of RYGB patients have shown an early improvement of T2DM after the operation when weight loss was not yet achieved $[117,118]$. Studies by Rubino et al. prove that bypassing a short segment of proximal intestine causes a rapid improvement of glucose homeostasis in diabetic rats, independently of food intake, body weight, malabsorption or nutrient delivery to the more distal bowel. The mechanism behind this phenomenon lies in the intestinal hormones produced in the duodenum and the proximal jejunum (foregut exclusion theory). Involved hormones are glucose-dependent insulinotropic polypeptide, which has a positive effect on insulin production and sensitivity and cholecystokinin, which influences satiety as well as insulin production [6]. Another theory is that the delivery of undigested nutrients to the more distal bowel could also cause an improvement in T2DM patients (hindgut theory) caused by elevation of the intestinal hormones produced in the ileum. These hormones, glucagon like peptide-1 and peptide YY, cause improvement of diabetes and obesity by stimulating the growth of beta cell mass and inducing satiety [7-9]. The design and position of the DJBS, with a small but specific part of excluded intestine, suggests that bypassing the duodenum is more important than the delivery of undigested nutrients to the ileum. In the study, described in chapter 4.2, 8 patients had diabetes in the device group. Improvement was observed in 6 patients and resolution in one patient. These 7 patients were able to significantly lower insulin dosages and oral medication. Mean fasting glucose levels before the device placement and after 12 weeks were, respectively, $11.1 \mathrm{mmol} / \mathrm{L}$ and $9.3 \mathrm{mmol} / \mathrm{L}$. HbA1c levels decreased in the same period from $8.8 \%$ to $7.7 \%$. In our opinion this is the most interesting feature of the DJBS. Because of the epidemic of T2DM, also in the non-obese population, treating therapy-resistant or severe T2DM patients with bariatric procedures is now being discussed. If the DJBS is capable of successfully treating and curing T2DM it would be preferable to a more invasive procedure. However, more research has to be performed focusing specifically on T2DM and long term results. 


\section{Conclusion}

Good and durable results can be achieved with restrictive bariatric procedures although this success comes with a price. The percentage of failures and necessary re-operations after VBG is unacceptably high and therefore this procedure should not be performed anymore. In case of a failure the conversion to RYGB is a good option with excellent results on patients' weight loss, decrease in comorbidities and symptoms. Long term success can be achieved with the LAGB but a certain amount of revisional procedures will have to be taken into account. However, these re-operations in the form of refixation of the band or a conversion to RYGB are successful and have a low mortality and acceptable morbidity. A complete and durable follow up after all bariatric procedures and revisions is mandatory in order to achieve long term success. Because of the complications of the current bariatric procedures future research should focus on the development of minimally invasive but still successful techniques and devices. The DJBS is an example of a promising new technique which should be investigated more thoroughly especially because of the interesting effects on T2DM.

The future of bariatric surgery will be exciting and full of discoveries about morbid obesity and its related metabolic disorders. From around the world, medical professionals and their patients will follow the progress of bariatric surgery with great interest. 


\section{References}

1. Deitel, M., A synopsis of the development of bariatric operations. Obes Surg, 2007. 17(6): p. 707-10.

2. Gasteyger, C., et al., Changes in body composition, metabolic profile and nutritional status 24 months after gastric banding. Obes Surg, 2006. 16(3): p. 243-50.

3. Pournaras, D.J. and C.W. le Roux, After bariatric surgery, what vitamins should be measured and what supplements should be given? Clin Endocrinol (Oxf), 2009. 71(3): p. 322-5.

4. Coupaye, M., et al., Nutritional consequences of adjustable gastric banding and gastric bypass: a 1-year prospective study. Obes Surg, 2009. 19(1): p. 56-65.

5. Cooper, P.L., et al., Nutritional consequences of modified vertical gastroplasty in obese subjects. Int J Obes Relat Metab Disord, 1999. 23(4): p. 382-8.

6. Rubino, F., et al., The mechanism of diabetes control after gastrointestinal bypass surgery reveals a role of the proximal small intestine in the pathophysiology of type 2 diabetes. Ann Surg, 2006. 244(5): p. 741-9.

7. de Paula, A.L., et al., Laparoscopic sleeve gastrectomy with ileal interposition ("neuroendocrine brake")--pilot study of a new operation. Surg Obes Relat Dis, 2006. 2(4): p. 464-7.

8. Patriti, A., et al., How the hindgut can cure type 2 diabetes. Ileal transposition improves glucose metabolism and beta-cell function in Goto-kakizaki rats through an enhanced Proglucagon gene expression and L-cell number. Surgery, 2007. 142(1): p. 74-85.

9. Patriti, A., et al., Early improvement of glucose tolerance after ileal transposition in a nonobese type 2 diabetes rat model. Obes Surg, 2005. 15(9): p. 1258-64.

10. Langer, F.B., et al., Sleeve gastrectomy and gastric banding: effects on plasma ghrelin levels. Obes Surg, 2005. 15(7): p. 1024-9.

11. Fisher, B.L. and P. Schauer, Medical and surgical options in the treatment of severe obesity. Am J Surg, 2002. 184(6B): p. 9S-16S.

12. Bjorntorp, P., Results of conservative therapy of obesity: correlation with adipose tissue morphology. Am J Clin Nutr, 1980. 33(2 Suppl): p. 370-5.

13. Buchwald, H., et al., Bariatric surgery: a systematic review and meta-analysis. Jama, 2004. 292(14): p. 1724-37.

14. Garb, J., et al., Bariatric surgery for the treatment of morbid obesity: a meta-analysis of weight loss outcomes for laparoscopic adjustable gastric banding and laparoscopic gastric bypass. Obes Surg, 2009. 19(10): p. 1447-55.

15. O'Brien, P.E., et al., Systematic review of medium-term weight loss after bariatric operations. Obes Surg, 2006. 16(8): p. 1032-40.

16. Hell, E., et al., Evaluation of health status and quality of life after bariatric surgery: comparison of standard Roux-en-Y gastric bypass, vertical banded gastroplasty and laparoscopic adjustable silicone gastric banding. Obes Surg, 2000. 10(3): p. 214-9.

17. van Gemert, W.G., et al., Quality of life assessment of morbidly obese patients: effect of weight-reducing surgery. Am J Clin Nutr, 1998. 67(2): p. 197-201.

18. Nguyen, N.T., et al., A Prospective Randomized Trial of Laparoscopic Gastric Bypass Versus Laparoscopic Adjustable Gastric Banding for the Treatment of Morbid Obesity: Outcomes, Quality of Life, and Costs. Ann Surg, 2009.

19. Kinzl, J.F., et al., Quality of life in morbidly obese patients after surgical weight loss. Obes Surg, 2007. 17(2): p. 229-35.

20. Mathus-Vliegen, E.M. and L.T. de Wit, Health-related quality of life after gastric banding. $\mathrm{Br}$ J Surg, 2007. 94(4): p. 457-65. 
21. Mathus-Vliegen, E.M., S. de Weerd, and L.T. de Wit, Health-related quality-of-life in patients with morbid obesity after gastric banding for surgically induced weight loss. Surgery, 2004. 135(5): p. 489-97.

22. Waaddegaard, P., T. Clemmesen, and P. Jess, Vertical gastric banding for morbid obesity: a long-term follow-up study. Eur J Surg, 2002. 168(4): p. 220-2.

23. Sanchez-Santos, R., et al., Long-term health-related quality of life following gastric bypass: influence of depression. Obes Surg, 2006. 16(5): p. 580-5.

24. Folope, V., et al., Weight loss and quality of life after bariatric surgery: a study of 200 patients after vertical gastroplasty or adjustable gastric banding. Eur J Clin Nutr, 2008. 62(8): p. 1022-30.

25. Karlsson, J., et al., Psychosocial functioning in the obese before and after weight reduction: construct validity and responsiveness of the Obesity-related Problems scale. Int J Obes Relat Metab Disord, 2003. 27(5): p. 617-30.

26. Mathus-Vliegen, E.M., Long-term health and psychosocial outcomes from surgically induced weight loss: results obtained in patients not attending protocolled follow-up visits. Int J Obes (Lond), 2007. 31(2): p. 299-307.

27. Nilsell, K., et al., Prospective randomised comparison of adjustable gastric banding and vertical banded gastroplasty for morbid obesity. Eur J Surg, 2001. 167(7): p. 504-9.

28. Miller, K., A. Pump, and E. Hell, Vertical banded gastroplasty versus adjustable gastric banding: prospective long-term follow-up study. Surg Obes Relat Dis, 2007. 3(1): p. 84-90.

29. O'Brien, P.E. and J.B. Dixon, Lap-band: outcomes and results. J Laparoendosc Adv Surg Tech A, 2003. 13(4): p. 265-70.

30. Gustavsson, S. and A. Westling, Laparoscopic adjustable gastric banding: complications and side effects responsible for the poor long-term outcome. Semin Laparosc Surg, 2002. 9(2): p. 115-24.

31. Weiss, H.G., et al., Surgical revision after failure of laparoscopic adjustable gastric banding. Br J Surg, 2004. 91(2): p. 235-41.

32. Silecchia, G., et al., Laparoscopic adjustable silicone gastric banding: prospective evaluation of intragastric migration of the lap-band. Surg Laparosc Endosc Percutan Tech, 2001. 11(4): p. 229-34.

33. Spivak, H. and F. Favretti, Avoiding postoperative complications with the LAP-BAND system. Am J Surg, 2002. 184(6B): p. 31S-37S.

34. Doherty, C., J.W. Maher, and D.S. Heitshusen, Long-term data indicate a progressive loss in efficacy of adjustable silicone gastric banding for the surgical treatment of morbid obesity. Surgery, 2002. 132(4): p. 724-7; discussion 727-8.

35. Doldi, S.B., et al., Adjustable gastric banding: 5-year experience. Obes Surg, 2000. 10(2): p. 171-3.

36. Westling, A., et al., Silicone-adjustable gastric banding: disappointing results. Obes Surg, 1998. 8(4): p. 467-74.

37. Martikainen, T., et al., Long-term results, late complications and quality of life in a series of adjustable gastric banding. Obes Surg, 2004. 14(5): p. 648-54.

38. Belachew, M., P.H. Belva, and C. Desaive, Long-term results of laparoscopic adjustable gastric banding for the treatment of morbid obesity. Obes Surg, 2002. 12(4): p. 564-8.

39. Dargent, J., Surgical treatment of morbid obesity by adjustable gastric band: the case for a conservative strategy in the case of failure - a 9-year series. Obes Surg, 2004. 14(7): p. 986-90.

40. Vertruyen, M., Experience with Lap-band System up to 7 years. Obes Surg, 2002. 12(4): p. 569-72. 
41. Angrisani, L., et al., Lap Band adjustable gastric banding system: the Italian experience with 1863 patients operated on 6 years. Surg Endosc, 2003. 17(3): p. 409-12.

42. Zinzindohoue, F., et al., Laparoscopic gastric banding: a minimally invasive surgical treatment for morbid obesity: prospective study of 500 consecutive patients. Ann Surg, 2003. 237(1): p. 1-9.

43. Ceelen, W., et al., Surgical treatment of severe obesity with a low-pressure adjustable gastric band: experimental data and clinical results in 625 patients. Ann Surg, 2003. 237(1): p. $10-6$.

44. Weiner, R., et al., A prospective randomized trial of different laparoscopic gastric banding techniques for morbid obesity. Surg Endosc, 2001. 15(1): p. 63-8.

45. O'Brien, P.E., et al., A prospective randomized trial of placement of the laparoscopic adjustable gastric band: comparison of the perigastric and pars flaccida pathways. Obes Surg, 2005. 15(6): p. 820-6.

46. Fried, M., The current science of gastric banding: an overview of pressure-volume theory in band adjustments. Surg Obes Relat Dis, 2008. 4(3 Suppl): p. S14-21.

47. Fried, M., W. Lechner, and K. Kormanova, Physical principles of available adjustable gastric bands: how they work. Obes Surg, 2004. 14(8): p. 1118-22.

48. Fried, M., K. Miller, and K. Kormanova, Literature review of comparative studies of complications with Swedish band and Lap-Band. Obes Surg, 2004. 14(2): p. 256-60.

49. Ceelen, W.P., A. Cardon, and P. Pattyn, Gastric banding for clinically severe obesity: results with the Swedish band. Surg Technol Int, 2004. 12: p. 103-9.

50. Blanc, P.M., et al., Preliminary results of the laparoscopic adjustable gastric banding procedure by a new generation of silicone band: MIDBAND. Obes Surg, 2008. 18(5): p. 569-72.

51. Weiner, R., D. Wagner, and H. Bockhorn, Laparoscopic gastric banding for morbid obesity. J Laparoendosc Adv Surg Tech A, 1999. 9(1): p. 23-30.

52. Christou, N. and E. Efthimiou, Five-year outcomes of laparoscopic adjustable gastric banding and laparoscopic Roux-en-Y gastric bypass in a comprehensive bariatric surgery program in Canada. Can J Surg, 2009. 52(6): p. E249-58.

53. Cottam, D.R., et al., A case-controlled matched-pair cohort study of laparoscopic Roux-en-Y gastric bypass and Lap-Band patients in a single US center with three-year follow-up. Obes Surg, 2006. 16(5): p. 534-40.

54. Bueter, M., et al., Reoperations after gastric banding: replacement or alternative procedures? Surg Endosc, 2009. 23(2): p. 334-40.

55. Muller, M.K., et al., High secondary failure rate of rebanding after failed gastric banding. Surg Endosc, 2008. 22(2): p. 448-53.

56. Foletto, M., et al., Laparoscopic gastric rebanding for slippage with pouch dilation: results on 29 consecutive patients. Obes Surg, 2008. 18(9): p. 1099-103.

57. Brown, W.A., et al., Symmetrical pouch dilatation after laparoscopic adjustable gastric banding: incidence and management. Obes Surg, 2008. 18(9): p. 1104-8.

58. Lanthaler, M., et al., Laparoscopic gastric re-banding versus laparoscopic gastric bypass as a rescue operation for patients with pouch dilatation. Obes Surg, 2006. 16(4): p. 484-7.

59. Schouten, R., F.M. van Dielen, and J.W. Greve, Re-operation after laparoscopic adjustable gastric banding leads to a further decrease in BMI and obesity-related co-morbidities: results in 33 patients. Obes Surg, 2006. 16(7): p. 821-8.

60. Keidar, A., et al., Band slippage after laparoscopic adjustable gastric banding: etiology and treatment. Surg Endosc, 2005. 19(2): p. 262-7.

61. Abu-Abeid, S., et al., Treatment of intra-gastric band migration following laparoscopic banding: safety and feasibility of simultaneous laparoscopic band removal and replacement. Obes Surg, 2005. 15(6): p. 849-52. 
62. Niville, E., et al., Results of lap rebanding procedures after Lap-Band removal for band erosion -- a mid-term evaluation. Obes Surg, 2005. 15(5): p. 630-3.

63. Niville, E., A. Dams, and J. Vlasselaers, Lap-Band erosion: incidence and treatment. Obes Surg, 2001. 11(6): p. 744-7.

64. Niville, E., A. Dams, and T. Anne, Laparoscopic repositioning of an adjustable silicone gastric band for pouch dilatation and stoma obstruction. Surg Endosc, 1999. 13(1): p. 65-7.

65. Niville, E. and A. Dams, Late pouch dilation after laparoscopic adjustable gastric and esophagogastric banding: incidence, treatment, and outcome. Obes Surg, 1999. 9(4): p. 381-4.

66. Langer, F.B., et al., Inadequate weight loss vs secondary weight regain: laparoscopic conversion from gastric banding to Roux-en-Y gastric bypass. Obes Surg, 2008. 18(11): $p$. 1381-6.

67. Mognol, P., D. Chosidow, and J.P. Marmuse, Laparoscopic conversion of laparoscopic gastric banding to Roux-en-Y gastric bypass: a review of 70 patients. Obes Surg, 2004. 14(10): p. 1349-53.

68. Moore, R., et al., Early results of conversion of laparoscopic adjustable gastric band to Roux-en-Y gastric bypass. Surg Obes Relat Dis, 2009. 5(4): p. 439-43.

69. te Riele, W.W., et al., Conversion of failed laparoscopic gastric banding to gastric bypass as safe and effective as primary gastric bypass in morbidly obese patients. Surg Obes Relat Dis, 2008. 4(6): p. 735-9.

70. Suter, M., et al., Band erosion after laparoscopic gastric banding: occurrence and results after conversion to Roux-en-Y gastric bypass. Obes Surg, 2004. 14(3): p. 381-6.

71. Topart, P., G. Becouarn, and P. Ritz, One-year weight loss after primary or revisional Rouxen-Y gastric bypass for failed adjustable gastric banding. Surg Obes Relat Dis, 2009. 5(4): p. 459-62.

72. Topart, P., G. Becouarn, and P. Ritz, Biliopancreatic diversion with duodenal switch or gastric bypass for failed gastric banding: retrospective study from two institutions with preliminary results. Surg Obes Relat Dis, 2007. 3(5): p. 521-5.

73. van Wageningen, B., et al., Revision of failed laparoscopic adjustable gastric banding to Roux-en-Y gastric bypass. Obes Surg, 2006. 16(2): p. 137-41.

74. Cohen, R., et al., Laparoscopic revisional bariatric surgery: myths and facts. Surg Endosc, 2005. 19(6): p. 822-5.

75. Spivak, H., et al., Laparoscopic revision from LAP-BAND to gastric bypass. Surg Endosc, 2007. 21(8): p. 1388-92.

76. Peterli, R., et al., Prospective study of a two-stage operative concept in the treatment of morbid obesity: primary lap-band followed if needed by sleeve gastrectomy with duodenal switch. Obes Surg, 2007. 17(3): p. 334-40.

77. Peterli, R., et al., Re-operations following laparoscopic adjustable gastric banding. Obes Surg, 2002. 12(6): p. 851-6.

78. Dolan, K. and G. Fielding, Bilio pancreatic diversion following failure of laparoscopic adjustable gastric banding. Surg Endosc, 2004. 18(1): p. 60-3.

79. Dapri, G., G.B. Cadiere, and J. Himpens, Laparoscopic conversion of adjustable gastric banding and vertical banded gastroplasty to duodenal switch. Surg Obes Relat Dis, 2009. 5(6): p. 678-83.

80. Dapri, G., G.B. Cadiere, and J. Himpens, Feasibility and technique of laparoscopic conversion of adjustable gastric banding to sleeve gastrectomy. Surg Obes Relat Dis, 2009. 5(1): p. 72-6.

81. Tucker, O., et al., Revisional surgery after failed laparoscopic adjustable gastric banding. Surg Obes Relat Dis, 2008. 4(6): p. 740-7. 
82. Uglioni, B., et al., Midterm results of primary vs. secondary laparoscopic sleeve gastrectomy (LSG) as an isolated operation. Obes Surg, 2009. 19(4): p. 401-6.

83. Frezza, E.E., et al., Laparoscopic sleeve gastrectomy after gastric banding removal: a feasibility study. Surg Innov, 2009. 16(1): p. 68-72.

84. Acholonu, E., et al., Safety and short-term outcomes of laparoscopic sleeve gastrectomy as a revisional approach for failed laparoscopic adjustable gastric banding in the treatment of morbid obesity. Obes Surg, 2009. 19(12): p. 1612-6.

85. Balsiger, B.M., et al., Ten and more years after vertical banded gastroplasty as primary operation for morbid obesity. J Gastrointest Surg, 2000. 4(6): p. 598-605.

86. van Gemert, W.G., et al., Revisional surgery after failed vertical banded gastroplasty: restoration of vertical banded gastroplasty or conversion to gastric bypass. Obes Surg, 1998. 8(1): p. 21-8.

87. Sugerman, H.J., et al., Conversion of failed or complicated vertical banded gastroplasty to gastric bypass in morbid obesity. Am J Surg, 1996. 171(2): p. 263-9.

88. Gonzalez, R., et al., Operative technique for converting a failed vertical banded gastroplasty to Roux-en-Y gastric bypass. J Am Coll Surg, 2005. 201(3): p. 366-74.

89. MacLean, L.D., B.M. Rhode, and R.A. Forse, Late results of vertical banded gastroplasty for morbid and super obesity. Surgery, 1990. 107(1): p. 20-7.

90. Hall, J.C., et al., Gastric surgery for morbid obesity. The Adelaide Study. Ann Surg, 1990. 211(4): p. 419-27.

91. Nightengale, M.L., et al., Prospective evaluation of vertical banded gastroplasty as the primary operation for morbid obesity. Mayo Clin Proc, 1991. 66(8): p. 773-82.

92. Naslund, E., et al., Seven year results of vertical banded gastroplasty for morbid obesity. Eur J Surg, 1997. 163(4): p. 281-6.

93. Sugerman, H.J. and J.L. Wolper, Failed gastroplasty for morbid obesity. Revised gastroplasty versus Roux-Y gastric bypass. Am J Surg, 1984. 148(3): p. 331-6.

94. Kfoury, E. and A. Vanguri, Distal Roux-en-Y Gastric Bypass Conversion Operation for Failed Vertical Banded Gastroplasty. Obes Surg, 1993. 3(1): p. 41-43.

95. Behrns, K.E., et al., Reoperative bariatric surgery. Lessons learned to improve patient selection and results. Ann Surg, 1993. 218(5): p. 646-53.

96. Linner, J.H. and R.L. Drew, Reoperative surgery--indications, efficacy, and long-term followup. Am J Clin Nutr, 1992. 55(2 Suppl): p. 606S-610S.

97. Thill, V., et al., Laparoscopic gastric banding as revisional procedure to failed vertical gastroplasty. Obes Surg, 2009. 19(11): p. 1477-80.

98. Taskin, M., et al., Conversion of failed vertical banded gastroplasty to open adjustable gastric banding. Obes Surg, 2001. 11(6): p. 731-4.

99. Daskalakis, M., et al., Conversion of failed vertical banded gastroplasty to biliopancreatic diversion, a wise option. Obes Surg, 2009. 19(12): p. 1617-23.

100. Elazary, R., et al., Feasibility of sleeve gastrectomy as a revision operation for failed silastic ring vertical gastroplasty. Obes Surg, 2009. 19(5): p. 645-9.

101. Foletto, M., et al., Sleeve gastrectomy as revisional procedure for failed gastric banding or gastroplasty. Surg Obes Relat Dis. 6(2): p. 146-51.

102. Cordera, F., et al., Unsatisfactory weight loss after vertical banded gastroplasty: is conversion to Roux-en-Y gastric bypass successful? Surgery, 2004. 136(4): p. 731-7.

103. Balsiger, B.M., et al., Gastroesophageal reflux after intact vertical banded gastroplasty: correction by conversion to Roux-en-Y gastric bypass. J Gastrointest Surg, 2000. 4(3): p. 27681.

104. McCormick, J.T., et al., Laparoscopic revision of failed open bariatric procedures. Surg Endosc, 2003. 17(3): p. 413-5. 
105. Gagner, M., et al., Laparoscopic reoperative bariatric surgery: experience from 27 consecutive patients. Obes Surg, 2002. 12(2): p. 254-60.

106. de Csepel, J., R. Nahouraii, and M. Gagner, Laparoscopic gastric bypass as a reoperative bariatric surgery for failed open restrictive procedures. Surg Endosc, 2001. 15(4): p. 393-7.

107. Deviere, J., et al., Safety, feasibility and weight loss after transoral gastroplasty: First human multicenter study. Surg Endosc, 2008. 22(3): p. 589-98.

108. Foschi, D., et al., Treatment of morbid obesity by intraparietogastric administration of botulinum toxin: a randomized, double-blind, controlled study. Int J Obes (Lond), 2007. 31(4): p. 707-12.

109. Bohdjalian, A., et al., One-year experience with Tantalus: a new surgical approach to treat morbid obesity. Obes Surg, 2006. 16(5): p. 627-34.

110. Favretti, F., et al., Treatment of morbid obesity with the Transcend Implantable Gastric Stimulator (IGS): a prospective survey. Obes Surg, 2004. 14(5): p. 666-70.

111. Miller, K., E. Hoeller, and F. Aigner, The Implantable Gastric Stimulator for Obesity : An Update of the European Experience in the LOSS (Laparoscopic Obesity Stimulation Survey) Study. Treat Endocrinol, 2006. 5(1): p. 53-8.

112. Shikora, S.A., et al., Implantable gastric stimulation for the treatment of clinically severe obesity: results of the SHAPE trial. Surg Obes Relat Dis, 2009. 5(1): p. 31-7.

113. Mathus-Vliegen, E.M., Intragastric balloon treatment for obesity: what does it really offer? Dig Dis, 2008. 26(1): p. 40-4.

114. Tarnoff, M., et al., Chronic in-vivo experience with an endoscopically delivered and retrieved duodenal-jejunal bypass sleeve in a porcine model. Surg Endosc, 2008. 22(4): p. 1023-8.

115. Rodriguez-Grunert, L., et al., First human experience with endoscopically delivered and retrieved duodenal-jejunal bypass sleeve. Surg Obes Relat Dis, 2008. 4(1): p. 55-9.

116. Gersin, K.S., et al., Duodenal- jejunal bypass sleeve: a totally endoscopic device for the treatment of morbid obesity. Surg Innov, 2007. 14(4): p. 275-8.

117. Morinigo, R., et al., Circulating peptide YY, weight loss, and glucose homeostasis after gastric bypass surgery in morbidly obese subjects. Ann Surg, 2008. 247(2): p. 270-5.

118. Morinigo, R., et al., Glucagon-like peptide-1, peptide $Y Y$, hunger, and satiety after gastric bypass surgery in morbidly obese subjects. J Clin Endocrinol Metab, 2006. 91(5): p. 173540. 

Samenvatting 


\section{Bariatrische chirurgie}

Het doel van dit promotie onderzoek is het beschrijven van de klinische resultaten van bariatrische operaties. Deze operaties worden verdeeld in twee groepen, te weten restrictieve en malabsorptieve ingrepen. Voorbeelden van puur restrictieve operaties zijn de laparoscopische aanpasbare maagband (LAMB) en de verticale maagverkleining (VMV). Daar tegenover staan de grotendeels malabsorptieve ingrepen als de biliopancreatische diversie (BPD) volgens Scopinaro en de duodenal switch (DS). Hoewel de bariatrische chirurgie is begonnen met malabsorptieve ingrepen zijn de meeste hiervan verlaten door het grote aantal complicaties [1]. Restrictieve operaties zijn minder complicatie gevoelig en veroorzaken tevens minder mineralenen vitaminetekorten. De huidige meest toegepaste ingrepen zijn de LAMB en de (laparoscopische) maagomleiding (MO). De laatste techniek is een mengvorm van een restrictieve en malabsorptieve ingreep. Het werkingsmechanisme van de LAMB berust vooral op voedselrestrictie terwijl de LMO behalve restrictie ook een effect heeft op de hormoonhuishouding van het duodenum doordat dit orgaan wordt uitgeschakeld van de voedselstroom. Dit op zichzelf heeft een belangrijke en gunstige invloed op de glucoseregulatie bij patiënten met type 2 diabetes mellitus (T2DM) [2]. Hoewel er nog veel onduidelijk is over het werkingsmechanisme van bariatrische ingrepen is evident aangetoond dat de operaties significant en langdurig gewichtsverlies bewerkstelligen. Tevens veroorzaken de operaties een verbetering of zelfs genezing van met obesitas gerelateerde ziekten als T2DM, hart- en vaatziekten, slaap apneu syndroom, gewrichtsklachten en bepaalde soorten kanker [3, 4]. Ook de kwaliteit van leven verbetert aanzienlijk en langdurig na de operatie [5-7]. Dit effect wordt bevestigd in het huidige onderzoek en beschreven in hoofdstuk 2.2. Omdat deze verbeteringen optreden na alle operaties en de verschillen in de loop van de jaren verdwijnen is het niet alleen belangrijk om de operaties te beoordelen op deze parameters. Juist de onderscheidende factoren als lange termijn complicaties en re-operaties zouden meer aandacht moeten krijgen in toekomstig onderzoek. Dit promotie onderzoek is vooral gericht op de lange termijn resultaten, complicaties en re-operaties na de meest gebruikelijke operaties. Tevens wordt aandacht besteed aan nieuwe technieken welke minder invasief zijn en mogelijk minder complicaties veroorzaken. 


\section{Resultaten van de laparoscopische aanpasbare maagband}

In hoofdstuk 2.1 worden de lange termijn resultaten van de LAMB beschreven. Het gewichtsverlies na 7 jaar is goed en vergelijkbaar met de beschreven literatuur [8-10]. Uitgedrukt in \%excess weight loss (\%EWL; de mate van overgewicht wat de patiënt heeft verloren) bedraagt dit $54 \%$. Echter, dit succes gaat gepaard met vele noodzakelijke re-operaties gedurende de follow-up. Als gevolg van onder andere uitzetten van de maagpouch en "slippen" van de band moesten $44 \%$ van de patiënten opnieuw geopereerd worden na een gemiddelde periode van 3 jaar. Door een verbetering van techniek, de leercurve en betere kwaliteit van de banden daalt het aantal re-operaties de laatste jaren aanzienlijk $[11,12]$. In de literatuur worden getallen van $2 \%$ re-operaties genoemd [13]. Een aantal factoren is echter zeer belangrijk bij het analyseren van deze getallen. De follow-up moet compleet en langdurig zijn om betrouwbare gegevens op te leveren. Gezien het feit dat de gemiddelde tijd tussen de eerste en de tweede operatie in deze studie 3 jaar was is een follow-up periode van minimaal 3 jaar maar bij voorkeur 5 jaar noodzakelijk om iets te kunnen zeggen over re-operaties. In hoofdstuk 2.1 wordt een follow-up van 7 jaar beschreven van $91 \%$ van de patiënten. Deze getallen kunnen derhalve als betrouwbaar worden beschouwd.

Wanneer er een complicatie optreedt na de LAMB zijn er verschillende opties. Allereerst moet getracht worden de band te behouden door deze te refixeren of eventueel te vervangen. Deze optie wordt besproken in hoofdstuk 3.2. Een laparoscopische refixatie van de band is een succesvolle ingreep aangezien de patiënten na deze re-operatie opnieuw gewicht verloren en het aantal complicaties laag was. Er moet echter wel rekening worden gehouden met de soort complicatie van de band welke de re-operatie noodzakelijk maakt. Patiënten met puur technisch falen van de band die daarvoor met de band een bevredigend gewichtsverlies hadden bereikt kunnen goed geholpen worden met een refixatie. Is er echter sprake van therapieontrouw of een onvoldoende effect van de band, dan kan er mogelijk beter worden gekozen voor het omzetten van de LAMB naar een ander soort bariatrische operatie. Deze verschillende vormen van conversie worden beschreven in hoofdstuk 3.3. Hieruit blijkt dat een refixatie van de band of een conversie naar een $\mathrm{MO}$ de beste opties zijn in het geval van een complicatie na een LAMB. De keuze tussen deze twee opties berust op de eerder genoemde factoren. Een conversie naar meer ingewikkelde malabsorptieve ingrepen verdient niet de voorkeur omdat het gewichtsverlies niet significant beter is en er wel meer complicaties optreden. 
Concluderend is de LAMB een succesvolle operatie op de lange termijn met bevredigend gewichtsverlies. Complicaties welke een re-operatie noodzakelijk maken komen veel voor maar zijn goed te behandelen met ofwel een refixatie van de band ofwel een conversie naar een $\mathrm{MO}$.

\section{Resultaten van de verticale maagverkleining}

In hoofdstuk 2.1 worden de lange termijn resultaten van de VMV beschreven. Het gewichtsverlies na 7 jaar is goed met $69 \%$ EWL en zelfs beter dan de beschreven literatuur [8, 9, 14]. Echter, dit succes gaat gepaard met een hoog faalpercentage gedurende de follow-up [15-18]. Het opnieuw uitvoeren van een VMV na een complicatie is niet succesvol en daarom dient altijd een conversie naar bijvoorbeeld een MO te worden uitgevoerd [17]. In de huidige studie was dit noodzakelijk bij $65 \%$ van de patiënten na een gemiddelde follow-up van 7 jaar. De VMV dient dan ook niet meer uitgevoerd te worden ondanks het succesvolle gewichtsverlies op de lange termijn. Het aantal complicaties en re-operaties wordt te hoog geacht.

In het geval van een complicatie na een VMV, bijvoorbeeld het loslaten van de nietjesrij of een uitgangsstenose, kan een conversie na een andere bariatrische ingreep worden overwogen. Conversies naar LAMB, BPD en DS zijn in de literatuur weinig beschreven en over het algemeen gecompliceerd [19-22]. De conversie naar een $\mathrm{MO}$ is de meest logische keuze en wordt beschreven in hoofdstuk 3.1. Hoewel de conversie gepaard gaat met een significant aantal complicaties (22.7\%) wordt deze toch als succesvol beschouwd aangezien het gewicht verder daalt en het aantal re-operaties nadien laag is. Verder blijken de resultaten onafhankelijk te zijn van de reden van de conversie onderverdeeld in gewichtstoename, extreem gewichtsverlies of gastro-intestinale klachten.

Concluderend is de VMV op de lange termijn een succesvolle operatie qua gewichtsverlies maar dient niet meer uitgevoerd te worden omdat het aantal complicaties te hoog is. Het falen van de VMV dient bij voorkeur te worden opgelost door te converteren naar een $\mathrm{MO}$. 


\section{Endoscopische behandeling}

Als reactie op de lange termijn complicaties en re-operaties na restrictieve ingrepen en de procedurespecifieke problemen van de malabsorptieve ingrepen zijn er vele nieuwe technieken ontwikkeld. Idealiter is dit een minimaal invasieve techniek met weinig complicaties en een langdurig effect op gewicht en obesitas-gerelateerde ziekten. Behalve de ontwikkelingen in de laparoscopische chirurgie is er ook veel aandacht voor endoscopische technieken. Transorale gastroplastiek, endoscopische botuline injectie en maagstimulatie middels "pacing" zijn hier voorbeelden van [23-26]. In hoofdstuk 4.1 wordt een nieuwe endoscopische techniek beschreven. De duodenal-jejunal bypass sleeve (DJBS; EndoBarrier Gastrointestinal Liner, GI Dynamics, Inc, Lexington, Massachusetts, USA) is een gastroscopisch ingebrachte fluoropolymere sleeve welke wordt gefixeerd in de bulbus duodeni en over $60 \mathrm{~cm}$ de wand van duodenum en jejunum bedekt. Het gevolg is dat er geen contact is tussen het voedsel en de darmwand. Behalve dat dit een omleidingseffect heeft vergelijkbaar met MO is er tevens een effect op de hormoonhuishouding van het duodenum. Dit blijkt uit de snelle verbetering van T2DM na implantatie van de sleeve. In de literatuur zijn enkele dierexperimentele studies en de eerste menselijke implantaties beschreven [27-31]. In hoofdstuk 4.2 wordt de eerste Europese studie met de DJBS beschreven. Op een totaal van 30 implantaties konden er 4 niet worden uitgevoerd door technische problemen. Gedurende de followup werden er 4 devices verwijderd als gevolg van complicaties. Het gewichtsverlies was $19.0 \%$ EWL en dit was significant hoger dan in de controle groep welke alleen een dieet volgde (6.9\%). Verder werd specifiek aandacht besteed aan de patiënten met T2DM (8 in de device groep) gezien het omleidingseffect van de DJBS. Zes patiënten merkten een verbetering op; dat wil zeggen zij hoefden minder insuline te gebruiken en hun glucose en $\mathrm{HbA} 1 \mathrm{c}$ waardes verlaagden. Een patiënt gebruikte zelfs helemaal geen medicatie meer. Gezien het wereldwijd toenemende probleem van T2DM, vaak gepaard gaande met overgewicht, is dit mogelijk de belangrijkste eigenschap van de DJBS. Specifieke studies naar het werkingsmechanisme van de DJBS en het effect op T2DM zijn echter noodzakelijk. Deze studies worden op dit moment in onder andere onze kliniek uitgevoerd. 


\section{Conclusies}

Restrictieve bariatrische ingrepen zijn succesvol op de lange termijn. Echter, het aantal complicaties en re-operaties na VMV is onacceptabel hoog. Deze operatie dient niet meer uitgevoerd te worden. Patiënten met een complicatie na een VMV zijn het beste geholpen met een conversie naar een MO. Het lange termijn succes van de LAMB gaat ook gepaard met een significant aantal re-operaties. In dit geval kan vaak worden volstaan met een refixatie van de band of een conversie naar een $\mathrm{MO}$, afhankelijk van de indicatie tot re-operatie. Deze ingrepen hebben een laag complicatie percentage en zijn zeer succesvol. Derhalve is de LAMB een succesvolle bariatrische operatie en een goede eerste keuze voor morbide obese patiënten. Gezien het aantal complicaties op de lange termijn na alle ingrepen dienen alle patiënten langdurig in follow-up te blijven. Tevens zal er verder onderzoek moeten worden gedaan naar nieuwe minimaal invasieve technieken gepaard gaande met minder complicaties. De DJBS is een voorbeeld van een veelbelovende techniek met een opvallend effect op T2DM.

Bariatrische chirurgie heeft de toekomst. Als gevolg van deze operaties zal meer kennis worden vergaard over morbide obesitas en alle aan obesitas-gerelateerde ziekten. Medici en wetenschappers zullen de ontwikkelingen op dit gebied dan ook met veel interesse volgen. 


\section{Referenties}

1. Deitel, M., A synopsis of the development of bariatric operations. Obes Surg, 2007. 17(6): p. 707-10.

2. Rubino, F., et al., The mechanism of diabetes control after gastrointestinal bypass surgery reveals a role of the proximal small intestine in the pathophysiology of type 2 diabetes. Ann Surg, 2006. 244(5): p. 741-9.

3. Bjorntorp, P., Results of conservative therapy of obesity: correlation with adipose tissue morphology. Am J Clin Nutr, 1980. 33(2 Suppl): p. 370-5.

4. Fisher, B.L. and P. Schauer, Medical and surgical options in the treatment of severe obesity. Am J Surg, 2002. 184(6B): p. 9S-16S.

5. van Gemert, W.G., et al., Quality of life assessment of morbidly obese patients: effect of weight-reducing surgery. Am J Clin Nutr, 1998. 67(2): p. 197-201.

6. Nguyen, N.T., et al., Laparoscopic versus open gastric bypass: a randomized study of outcomes, quality of life, and costs. Ann Surg, 2001. 234(3): p. 279-89; discussion 289-91.

7. Hell, E., et al., Evaluation of health status and quality of life after bariatric surgery: comparison of standard Roux-en-Y gastric bypass, vertical banded gastroplasty and laparoscopic adjustable silicone gastric banding. Obes Surg, 2000. 10(3): p. 214-9.

8. Nilsell, K., et al., Prospective randomised comparison of adjustable gastric banding and vertical banded gastroplasty for morbid obesity. Eur J Surg, 2001. 167(7): p. 504-9.

9. Miller, K., A. Pump, and E. Hell, Vertical banded gastroplasty versus adjustable gastric banding: prospective long-term follow-up study. Surg Obes Relat Dis, 2007. 3(1): p. 84-90.

10. O'Brien, P.E. and J.B. Dixon, Lap-band: outcomes and results. J Laparoendosc Adv Surg Tech A, 2003. 13(4): p. 265-70.

11. O'Brien, P.E., et al., A prospective randomized trial of placement of the laparoscopic adjustable gastric band: comparison of the perigastric and pars flaccida pathways. Obes Surg, 2005. 15(6): p. 820-6.

12. Weiner, R., et al., A prospective randomized trial of different laparoscopic gastric banding techniques for morbid obesity. Surg Endosc, 2001. 15(1): p. 63-8.

13. Blanc, P.M., et al., Preliminary results of the laparoscopic adjustable gastric banding procedure by a new generation of silicone band: MIDBAND. Obes Surg, 2008. 18(5): p. 569-72.

14. Balsiger, B.M., et al., Ten and more years after vertical banded gastroplasty as primary operation for morbid obesity. J Gastrointest Surg, 2000. 4(6): p. 598-605.

15. Sugerman, H.J., et al., Conversion of failed or complicated vertical banded gastroplasty to gastric bypass in morbid obesity. Am J Surg, 1996. 171(2): p. 263-9.

16. Gonzalez, R., et al., Operative technique for converting a failed vertical banded gastroplasty to Roux-en-Y gastric bypass. J Am Coll Surg, 2005. 201(3): p. 366-74.

17. van Gemert, W.G., et al., Revisional surgery after failed vertical banded gastroplasty: restoration of vertical banded gastroplasty or conversion to gastric bypass. Obes Surg, 1998. 8(1): p. 21-8.

18. MacLean, L.D., B.M. Rhode, and R.A. Forse, Late results of vertical banded gastroplasty for morbid and super obesity. Surgery, 1990. 107(1): p. 20-7.

19. Thill, V., et al., Laparoscopic gastric banding as revisional procedure to failed vertical gastroplasty. Obes Surg, 2009. 19(11): p. 1477-80.

20. Taskin, M., et al., Conversion of failed vertical banded gastroplasty to open adjustable gastric banding. Obes Surg, 2001. 11(6): p. 731-4.

21. Daskalakis, M., et al., Conversion of failed vertical banded gastroplasty to biliopancreatic diversion, a wise option. Obes Surg, 2009. 19(12): p. 1617-23. 
22. Dapri, G., G.B. Cadiere, and J. Himpens, Laparoscopic conversion of adjustable gastric banding and vertical banded gastroplasty to duodenal switch. Surg Obes Relat Dis, 2009. 5(6): p. 678-83.

23. Deviere, J., et al., Safety, feasibility and weight loss after transoral gastroplasty: First human multicenter study. Surg Endosc, 2008. 22(3): p. 589-98.

24. Favretti, F., et al., Treatment of morbid obesity with the Transcend Implantable Gastric Stimulator (IGS): a prospective survey. Obes Surg, 2004. 14(5): p. 666-70.

25. Foschi, D., et al., Treatment of morbid obesity by intraparietogastric administration of botulinum toxin: a randomized, double-blind, controlled study. Int J Obes (Lond), 2007. 31(4): p. 707-12.

26. Bohdjalian, A., et al., One-year experience with Tantalus: a new surgical approach to treat morbid obesity. Obes Surg, 2006. 16(5): p. 627-34.

27. Tarnoff, M., S. Shikora, and A. Lembo, Acute technical feasibility of an endoscopic duodenal-jejunal bypass sleeve in a porcine model: a potentially novel treatment for obesity and type 2 diabetes. Surg Endosc, 2008. 22(3): p. 772-6.

28. Rodriguez-Grunert, L., et al., First human experience with endoscopically delivered and retrieved duodenal-jejunal bypass sleeve. Surg Obes Relat Dis, 2008. 4(1): p. 55-9.

29. Tarnoff, M., et al., Chronic in-vivo experience with an endoscopically delivered and retrieved duodenal-jejunal bypass sleeve in a porcine model. Surg Endosc, 2008. 22(4): p. 1023-8.

30. Tarnoff, M., L.M. Kaplan, and S. Shikora, An evidenced-based assessment of preoperative weight loss in bariatric surgery. Obes Surg, 2008. 18(9): p. 1059-61.

31. Gersin, K.S., et al., Duodenal- jejunal bypass sleeve: a totally endoscopic device for the treatment of morbid obesity. Surg Innov, 2007. 14(4): p. 275-8. 


\section{Dankwoord}


Hoe vaak is het mij wel niet gezegd hoe moeilijk het zou zijn om te promoveren tijdens de opleiding? Dat het niet samen gaat, de opleiding tot chirurg en het gehele promotietraject? Ik ben dan ook bijzonder verheugd met de afronding van dit proefschrift. Dat het ooit zo ver is gekomen was onmogelijk geweest zonder de hulp en steun van een groot aantal collega's en vrienden.

Mijn promotor, prof. dr J.W.M. Greve. Beste Jan Willem, wie had dat toch ooit gedacht toen ik als broekie op sollicitatiegesprek bij je op kantoor kwam? Jij waarschijnlijk wel! Vanaf het begin heb je me continu gestimuleerd om verder te gaan. Elk afgerond artikel leidde tot een nieuw idee waarmee je me goed bezig en scherp hield. Zonder jouw enthousiasme en inzet was het nooit zo ver gekomen. Tevens ben je in Maastricht mijn opleider geweest en hebben we in Heerlen ook veel samen geopereerd. Daar heb ik bijzonder veel van geleerd want je bent een begenadigd operateur. Al met al heb ik veel aan je te danken!

Mijn copromotor, dr. W.G. van Gemert. Beste Wim, ondanks alle wisselingen tussen Maastricht en Heerlen ben je altijd betrokken geweest bij mijn onderzoek. Ik heb een voorbeeld genomen aan jouw uitstekende promotie onderzoek en je hebt altijd kritisch naar mijn werk gekeken. Verder ervaar ik de samenwerking in de kliniek als zeer prettig; je bent een bijzonder kundige chirurg en de band die jij met je patiënten hebt (en met name zij met jou) is uniek en bewonderenswaardig. Ik ben trots om jou als leraar en copromotor te hebben!

Dr. F.M.H. van Dielen, beste Francois, praktisch alle fundamenten voor het onderzoek in dit proefschrift zijn door jou gelegd. Jij hebt mij in Maastricht op sleeptouw genomen en mij de beginselen van research geleerd. Verder heb ik veel van jou data gebruikt dus ik ben je bijzonder dankbaar voor alles wat je hebt gedaan.

Dorothee Wiryasaputra, mijn enige echte semi-arts. Jij hebt me enorm geholpen met het verzamelen van de data. Wat heb je de patiënten achter de broek aangezeten! En met succes want daardoor konden we twee mooie artikelen schrijven. Onze reis naar Argentinië was daar een mooie beloning voor.

Jeroen Nijhuis en Yanti Slaats, mijn bariatrische research collega's in Maastricht. Hartelijk dank voor de prettige samenwerking en de hulp die ik van jullie heb gekregen in de beginfase. 
The one and only Rob Boetzkes. Beste Rob, jij bent absoluut de bindende factor van het bariatrische team zowel in Maastricht als Heerlen. Ik vond het heuglijk nieuws toen je de overstap maakte naar Heerlen zodat we weer konden samenwerken. Hartelijk dank voor alle planning, data management en de gezelligheid!

I would like to thank all members of the reviewing committee: Prof. dr. A.A.M. Masclee, Prof. dr. L. Angrisani, Prof. dr. M.J.H.M. Jacobs, dr. B. van Ramshorst and Prof. dr. N.C. Schaper, for their evaluation of the manuscript.

Alle collega arts-assistenten chirurgie in Maastricht en Heerlen wil ik bedanken voor hun steun en begrip tijdens mijn opleidingsjaren. Ik denk dat ik tegen iedereen wel eens heb lopen klagen wanneer het onderzoek niet lekker liep of wanneer ik ietwat druk was met alles, dank voor het aanhoren! Ik heb altijd geprobeerd om tijdens werktijd niet te veel aan onderzoek te klussen en hopelijk ben ik daarin geslaagd.

De stafleden chirurgie van het Maastricht University Medical Centre dank ik voor het verzorgen van mijn eerste twee opleidingsjaren. In het bijzonder dank ik Prof. dr. C.H.C. Dejong en Dr. N.D. Bouvy. Beste Cees, ook jij hebt mij altijd flink gestimuleerd om onderzoek te doen en met succes. En verder ben je ook nog een hele gezellige vent...Beste Nicole, ik vond het heel fijn om met je samen te werken op chirurgisch en wetenschappelijk gebied. Gelukkig kom ik volgend jaar weer naar Maastricht zodat ik met jullie beide nog eens mag werken.

De maatschap chirurgie van het Atrium MC. Hartelijk dank voor het verzorgen van een prima opleiding gedurende 3 boeiende jaren. Ik hoop niet dat jullie al te veel gemerkt hebben van mijn onderzoeksbezigheden. Een aantal leden wil ik in het bijzonder bedanken. Dr. R.J.Th.J. Welten, beste Rob, je bent een prima opleider die goed zorgt voor zijn chirurgische "kindjes". Wij zijn jouw assistenten en daar moeten ze niet aankomen! Trouwens, had jij niet gezegd dat ik nooit zou promoveren tijdens de opleiding? Dat was zeker stimulerend bedoeld! Drs. B. Meesters, beste Berry, als chirurgisch Meester heb ik veel van jou geleerd. Bijzonder verheugd was ik toen jij je steeds meer ging richten op de bariatrische chirurgie. Hopelijk betekent dit dat we in de toekomst nog veel mogen samenwerken? Lijkt me gezellig! Last but not least: Dr. M.N. Sosef. Beste Meindert, dank voor alles wat je me hebt geleerd over gastro-enterologische en oncologische chirurgie. Jouw inzet voor het ziekenhuis en de patiënten is bewonderenswaardig. Ik hoop nog veel met je te mogen samenwerken in de toekomst. 
Het Rijnstate Ziekenhuis Arnhem, met in het bijzonder Drs. C.S. Rijs, Drs. I.M.C. Janssen en Willemien Kuijper, wil ik bedanken voor de prettige samenwerking tijdens de Endobarrier studie.

Door het enthousiasme van de chirurgische maatschap van het Gelderse Vallei Ziekenhuis te Ede heb ik definitief besloten om chirurg te worden. Hartelijk dank voor het "duwtje" in de juiste richting want ik heb nog nooit in mijn leven zo'n goede beslissing genomen. In het bijzonder dank ik Dr. J.H.C. Kuijpers die mij goed heeft begeleid tijdens mijn eerste onderzoeksstapjes.

Dank aan alle medewerkers van de polikliniek chirurgie van het MUMC, met in het bijzonder Bernadette, voor het verzamelen van alle patiëntendossiers.

Alle dames (en heer) van de polikliniek chirurgie van het Atrium MC te Heerlen en Brunssum. Hartelijk dank voor alle ondersteuning en de gezellige spreekuren. Met name op de maandagochtend was ik altijd bijzonder blij met de soepjes en andere lekkernijen!

Evelien Goldberg van het secretariaat chirurgie van het MUMC. Heel veel dank voor alles wat je voor me hebt geregeld, met name de agenda van Jan Willem zo plannen dat ik er altijd even bij kon.

Het secretariaat chirurgie van het Atrium MC, Jolanda, Margot, Marlies, Caroline en Nancy. Ook al zeggen jullie weinig gemerkt te hebben van mijn aanstaande promotie heb ik toch regelmatig eventjes iets gevraagd, geregeld, gefaxt of gebeld waarvoor dank.

Mijn paranymfen, Bjorn Telgenkamp en Dennis Japink. Bjorn, jij bent vanaf de eerste dag dat je binnenliep in het MUMC met je "parkstadse kapotgebokste ghetto-koppie" altijd mijn maatje geweest. Hoewel we het op de werkvloer niet altijd eens zijn (wat dan weer interessante discussies oplevert) vind ik je een prima collega en vriend. Dennis, we hebben maar heel kort samengewerkt in de kliniek maar des te meer op onderzoeksgebied. Jouw perfectionisme en precisie heb ik zeer gewaardeerd tijdens het organiseren van de winterbijscholing en tijdens het voorbereiden van het laatste artikel. Verder kunnen we buiten de werkvloer ook prima met elkaar opschieten dus een betere paranymf kon ik me niet voorstellen. 
Mijn ouders dank ik voor de onaflatende steun door alle jaren heen. Men zei dat het VWO al te hoog gegrepen was voor mij maar zie daar: met een beetje inzet en een familie die in je gelooft kom je een heel eind! Ik weet dat jullie trots op me zijn en dat is wederzijds.

De familie van Abbema dank ik voor alle gezelligheid en steun de afgelopen jaren. Vooral Jelte van Abbema wil ik in het bijzonder bedanken voor het prachtige coverwerk.

Mijn eeuwige vriendengroep: Tijmen \& Miranda, Hugo \& Julia en Sebastiaan \& Marjolein. Dankzij jullie heb ik de afgelopen jaren ook nog af en toe wat leuks gedaan en niet alleen maar gewerkt (hoewel jullie waarschijnlijk vinden dat het nog veel te veel was). Dank voor de vriendschap, friends forever!

En de belangrijkste als laatste: Doris. Je bent zowel de liefde van mijn leven als mijn beste vriendin. Al jouw hulp, steun en begrip hebben me er doorheen geholpen. Jij weet als geen ander dat het hele traject moeizaam is geweest. Nooit heb je geklaagd als ik weer eens tot diep in de nacht of in de weekenden zat te werken. Maar nu is het bijna af (hoewel je zegt dat ik wel weer iets anders verzin...) dus het wordt tijd om samen te genieten! 

Curriculum Vitae 

Ruben Schouten was born May 28th 1977 in Haarlem, the Netherlands. After graduating from the Alberdingk Thijm College in Hilversum he attended medical school at the Free University Medical Centre in Amsterdam and obtained his medical degree in September 2002. Thereafter he worked as a resident at the department of surgery of the Gelderse Vallei Ziekenhuis in Ede (Dr. R.M.H.G. Mollen, Dr. J.H.C. Kuijpers). By the end of 2004 he started working as a resident at the department of surgery of the Maastricht University Medical Centre and began his surgical training in January 2006 (Prof. dr. J.W.M. Greve, Prof. dr. C.H.C. Dejong). During this period he started working on the present thesis under the supervision of Prof. dr. J.W.M. Greve and Dr. W.G. van Gemert. His surgical training was continued at the Atrium Medical Centre Parkstad in Heerlen (Dr. R.J.Th.J. Welten, Dr. M.N. Sosef) in the year 2008 up to 2010. His last year of surgical training in 2011 will take place at the Maastricht University Medical Centre (Dr. L.P.S. Stassen, Prof. dr. C.H.C. Dejong) where he will differentiate in Gastrointestinal Surgery. He lives in Maastricht with his soon-to-be-wife Doris. 